\title{
Examining West Virginia's Economic Development: Natural Resources, Development Agencies, And Labor Force Development
}

\author{
Gaillynn Marie Bowman \\ West Virginia University, gmbowman@mix.wvu.edu
}

Follow this and additional works at: https://researchrepository.wvu.edu/etd

Part of the Agricultural Education Commons, Natural Resource Economics Commons, Natural Resources and Conservation Commons, Natural Resources Management and Policy Commons, and the Other Life Sciences Commons

\section{Recommended Citation}

Bowman, Gaillynn Marie, "Examining West Virginia's Economic Development: Natural Resources, Development Agencies, And Labor Force Development" (2021). Graduate Theses, Dissertations, and Problem Reports. 8295.

https://researchrepository.wvu.edu/etd/8295

This Dissertation is protected by copyright and/or related rights. It has been brought to you by the The Research Repository @ WVU with permission from the rights-holder(s). You are free to use this Dissertation in any way that is permitted by the copyright and related rights legislation that applies to your use. For other uses you must obtain permission from the rights-holder(s) directly, unless additional rights are indicated by a Creative Commons license in the record and/ or on the work itself. This Dissertation has been accepted for inclusion in WVU Graduate Theses, Dissertations, and Problem Reports collection by an authorized administrator of The Research Repository @ WVU.

For more information, please contact researchrepository@mail.wvu.edu. 
EXAMINING WEST VIRGINIA'S ECONOMIC DEVELOPMENT:

NATURAL RESOURCES, DEVELOPMENT AGENCIES, AND LABOR FORCE DEVELOPMENT

Gaillynn Marie Bowman 


\title{
Examining West Virginia's Economic Development: \\ Natural Resources, Development Agencies, and Labor Force Development
}

Gaillynn M. Bowman

\begin{abstract}
Dissertation submitted to the
Davis College of Agriculture, Natural Resources and Design

at West Virginia University

in partial fulfillment of the requirements

for the degree of
\end{abstract}

Doctor of Philosophy in

Human and Community Development

Peter V. Schaeffer, Ph.D., Chair

Alan R. Collins, Ph.D.

Harry N. Boone Jr., Ph.D.

Deborah A. Boone, Ph.D.

Hodjat Ghadimi, Ph.D.

Division of Resource Economics and Management

Morgantown, West Virginia

2021

Keywords: adult education, agency cooperation, career center, conservation program, cooperative program, economically disadvantaged, employment centers, employment programs, employment services, environmental regulations, federal programs, government funding, hardto-employ, job training, labor force development, one-stop job centers, program evaluation, program implementation, staff development, regional economics, rural development.

Copyright 2021 Gaillynn M. Bowman 


\begin{abstract}
Examining West Virginia's Economic Development:

Natural Resources, Development Agencies, and Labor Force Development
\end{abstract}

Gaillynn Bowman

Economic development is well-recognized as being fundamental to facilitating an overall improved quality of life for communities and their residents. Throughout West Virginia's history, the state has experienced economic hardships caused by boom and bust cycles associated with resource extraction. This dissertation consists of three essays that explore the impacts of economic development activities, including conservation programs, economic development agency initiatives, and workforce development agencies.

The first essay explores the relationship nonresident landowners have with the conservation programs within West Virginia, specifically the Natural Resources Conservation Service (NRCS) agency. Absentee ownership plays a significant role in the state's economic development, particularly in rural areas such as the Hampshire and Mineral county region where more than 153,000 acres belong to absentee landowners, out of the approximately 483,000 acres in these counties. The results suggest there is a statistically significant negative impact regarding absentee landowners adopting conservation practices. Farm size and land use designation have positive and statistically significant impacts on conservation adoption. Study limitations relate primarily to relatively small geographical area used in the analysis. Commonalities in resistance to adoption of conservation practice may be transferable to other government programs facing opposition.

The second essay addresses the issue of economic development sustainability. Based upon a survey of economic development professionals, the findings indicate that over time, West Virginia economic development agencies have invested in higher levels of business supports/incentives, while inversely, these same agencies have provided fewer activities in support of environmental, quality of life, and community-based economic development. This study found that concern for economic sustainability was the most significant reason for conducting their current economic development strategies. Alternatively, West Virginia economic development agencies have selected activities that do not reflect a focus on balancing the economy, addressing environmental issues, and/or providing an equitable quality of life, all of which research indicates will ensure sustainable development. Overall, when measured by a balanced approach, strategies focusing on business economic development activities, instead of environmental sustainability and social equity, have resulted in a lower range of economic activities and reduced sustainability.

The third essay examines labor force participation barriers and the employment service agencies that help West Virginians gain employment. This study finds that transportation limitations were the most common reported barrier to job placement by employment agency personnel. The study also found that the fields of occupation in which clients were placed into employment positions did not align with financial capital development nor did the industry sectors offer career pathways that would lead to earning a living wage, with the five most common employment positions ranging in median hourly wages from $\$ 11.43$ to $\$ 16.07$. These 
occupations included the fields of health care, customer service/retail, food operation, cleaning and maintenance, and factory workers. The five least common job placements ranged in median hourly wages from $\$ 9.99$ to $\$ 38.31$, and in the following fields: IT sector, child development, small business owner, financial operations, and the education sector. Statistical significance indicated the range of workforce placements was more positively related to the range of workforce development activities and services provided by agencies than to the range of professional certifications held by the agencies' staff members. With regards to financial, social, and human capital, this research found that increasing the range of employment activities and services leads to increases in job placements in higher wage sectors, as indicated by the increased range of job placement fields. 


\section{DEDICATION}

I would like to thank my family and friends for their encouragement and support, particularly my husband of thirty-nine years, always there, always wise. 


\section{ACKNOWLEDGMENTS}

I would like to thank my committee chair and advisor, Peter V. Schaeffer, for the support and guidance he provided throughout the doctoral process. I would also like to thank my other deeply valued committee members, Alan R. Collins, Harry N. Boone Jr., Deborah A. Boone, and Hodjat Ghadimi for the help and support they provided. I also greatly appreciate West Virginia University for the financial assistance provided during my graduate studies. 


\section{TABLE OF CONTENTS}

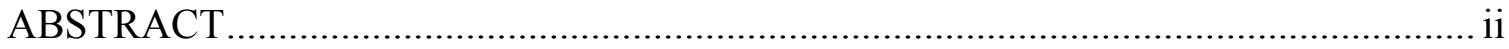

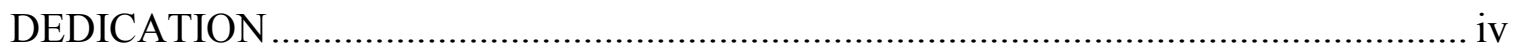

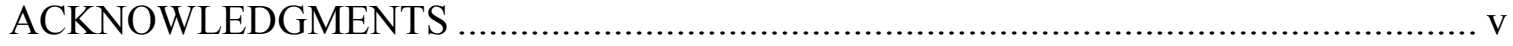

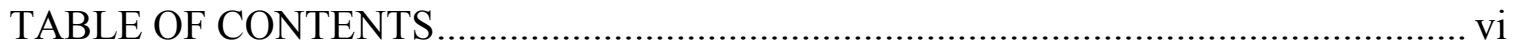

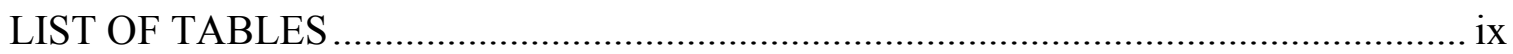

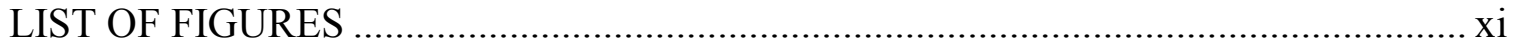

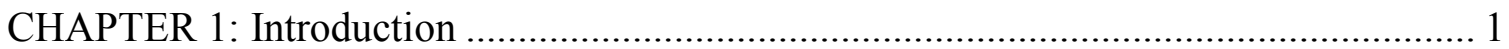

CHAPTER 2: Essay 1 -Assessment of The Distribution of NRCS Assistance Programs in West Virginia and Strategic Enhancement of Future Outreach Efforts ....................................... 5

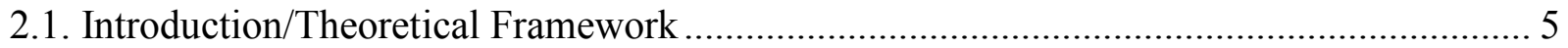

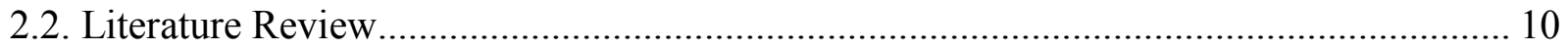

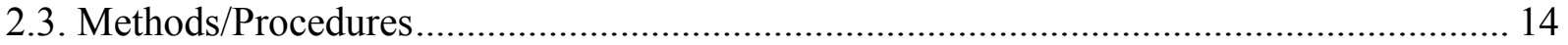

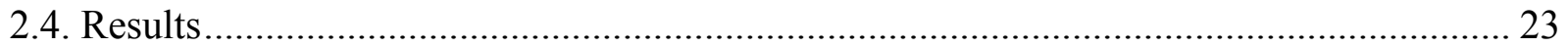

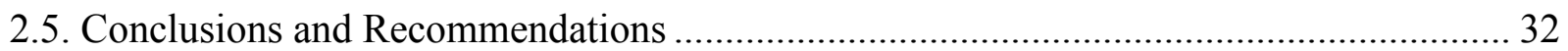

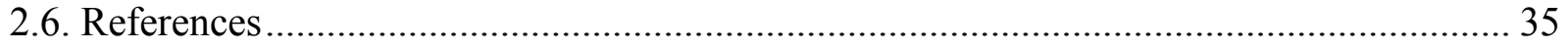

CHAPTER 3: ESSAY 2 - Analysis of West Virginia's Regional Economic Development Agencies' Utilization of Impact Strategies ...................................................................... 40

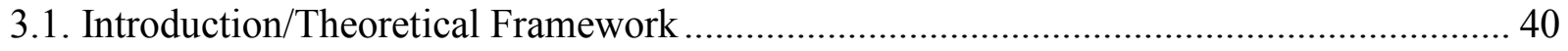

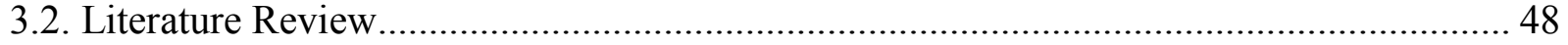

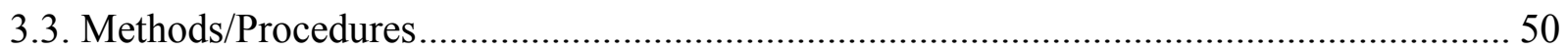

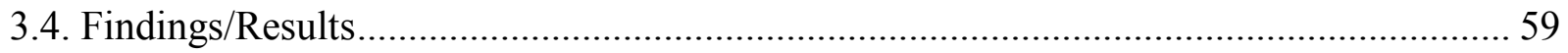




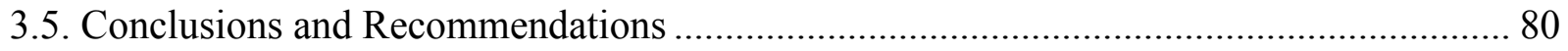

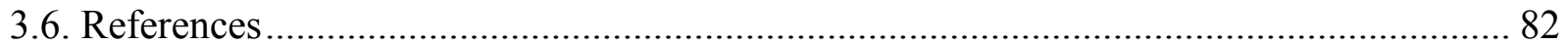

CHAPTER 4: ESSAY 3 - Labor Force Participation in West Virginia.......................... 91

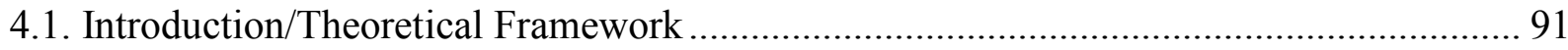

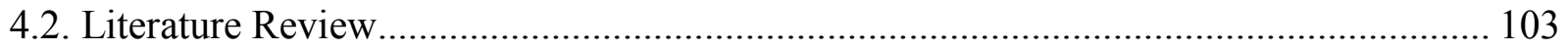

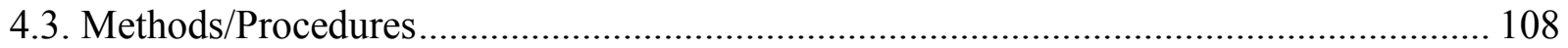

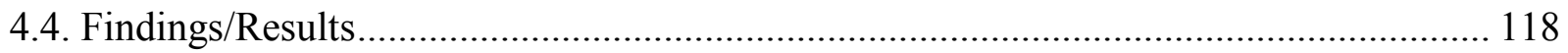

4.5. Conclusions/Limitations/Recommendations ....................................................... 179

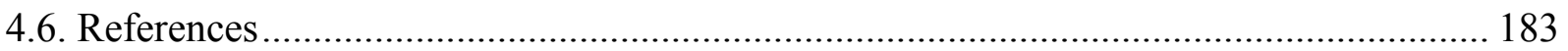

CHAPTER 5: Summary and Conclusions ................................................................ 193

5.1. Summary Results and Policy Implications .......................................................... 193

5.2. Limitations and Future Research ........................................................................... 195

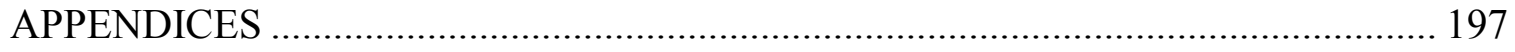

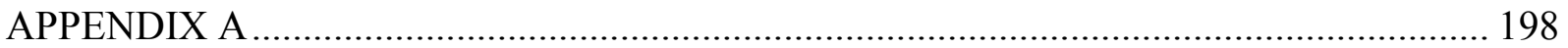

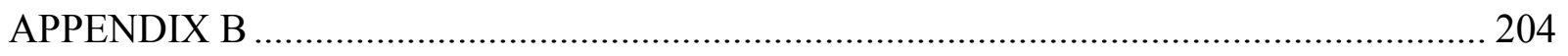

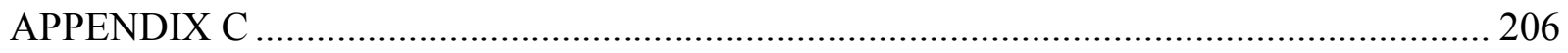

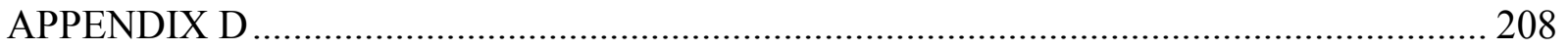

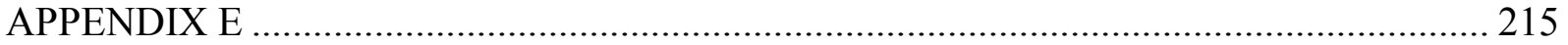

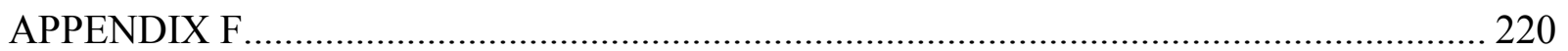

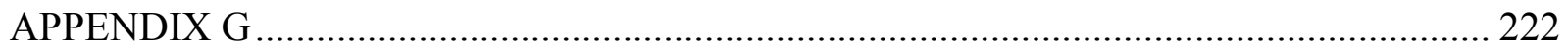




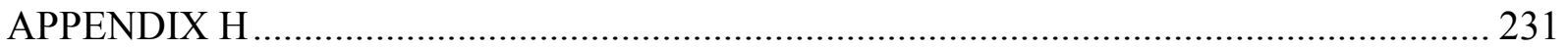

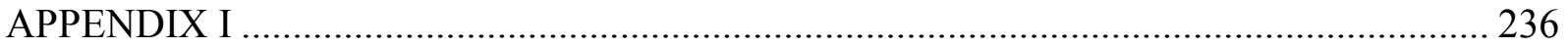

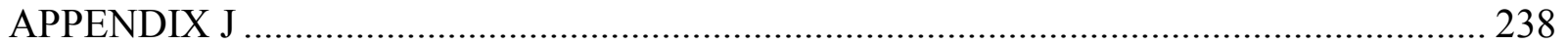




\section{LIST OF TABLES}

Table 2.1: Adoption Barrier Theories .......................................................................... 12

Table 2.2: County Assessor Land Use Codes ........................................................... 16

Table 2.3: Variables Description ......................................................................... 21

Table 2.4: Communication Methods used by NRCS DCs............................................. 25

Table 2.5: Demographics of Landowner Respondents ................................................ 27

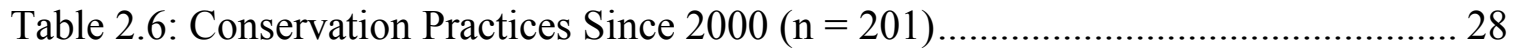

Table 2.7: Respondents' Preferred Communication Methods .......................................... 29

Table 2.8: Descriptive Statistics of Variables .............................................................. 30

Table 2.9: Estimation Results for Logit Model ............................................................. 31

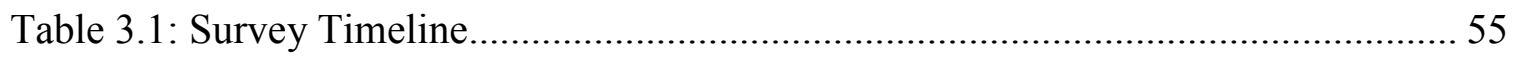

Table 3.2: Background of Economic Development Agencies........................................... 61

Table 3.3: Demographics of Economic Development Respondents ................................. 62

Table 3.4: Current Economic Development Activities...................................................... 63

Table 3.5: Issues Driving the Selection of Current Economic Development Activities .. 65

Table 3.6: Barriers to Planning and Implementing Economic Development Activities... 68

Table 3.7: Effectiveness levels of Economic Development tools...................................... 71

Table 3.8: EDOs’ Attitudes Toward Relationship Activities ............................................. 75

Table 3.9: Economic Development Certifications held by WV EDO Staff ..................... 78

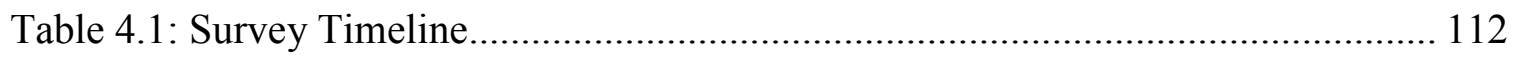

Table 4.2: Characteristics of Employment Agencies Providing Services to West Virginia119

Table 4.3: Employment Agencies' Staffing Capacity ……………………………........ 120

Table 4.4: Demographics of Employment Agencies' Respondents ............................... 122

Table 4.5: Regions Served by Employment Agency Types ............................................. 123 
Table 4.6: Annual Budgets of Employment Agencies by Region ................................. 126

Table 4.7: Employment Agencies' Funding Sources …………………………......... 128

Table 4.8: Workforce Development Activities, Educational Services .......................... 130

Table 4.9: Workforce Development Activities, Employment Services........................... 137

Table 4.10: Workforce Development Activities, Support Services............................... 138

Table 4.11: Workforce Development Activities, Services for Special Populations....... 139

Table 4.12: Effectiveness of Workforce Development Activities and Retention Strategies 144

Table 4.13: Highly Effective Workforce Development Activities and Retention Strategies 149

Table 4.14: Barriers to Employment, Ranked by Impact .............................................. 151

Table 4.15: Barriers to Employment, Ranked by High Impact, with Regional Responses155

Table 4.16: Changes in Barriers, Pre- and Peri-Pandemic, with Regional Responses ... 159

Table 4.17: Influenced by Other Agencies' Strategic or Development Plans ................ 161

Table 4.18: Employment Agencies: Partnerships, Activities, and Industry Standards .. 165

Table 4.19: Target Population Demographics, in Ranked Order.................................. 168

Table 4.20: Target Population Race/Ethnicity, in Ranked Order .................................... 169

Table 4.21: Placed in Industry Sectors, Ranked Order ................................................ 170

Table 4.22: Estimated Number Served and Competitively Employed Rate.................... 172

Table 4.23: Dropout Rate and Employed 90 Consecutive Days Rate .............................. 174

Table 4.24: Postsecondary Credential Attainment Goals .............................................. 175

Table 4.25: Workforce Development Certifications held by Agencies' Staff................. 176

Table 4.26: Correlations.................................................................................... 178 


\section{LIST OF FIGURES}

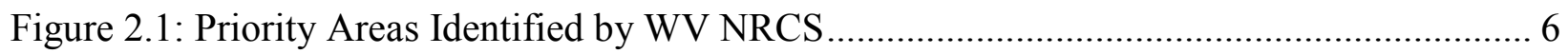

Figure 3.1: Regional Planning \& Development Councils $\mid$ Metropolitan Planning Organizations 45

Figure 3.2: West Virginia Development Office, Regional Economic Development Authorities 46

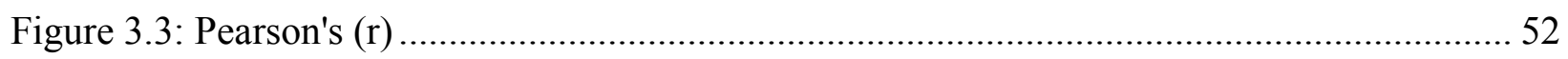

Figure 3.4: Issues Driving the Selection of Current Economic Development Initiatives.............. 65

Figure 3.5: Barriers to Planning and Implementing Economic Development Initiatives.............. 67

Figure 3.6: Range of Current Economic Development Activities................................................ 79

Figure 4.1: U.S. Civilian Labor Force Participation Rate, Seasonally Adjusted........................... 92

Figure 4.2: U.S. and West Virginia Civilian Labor Force Participation Rate, Seasonally Adjusted (2.

Figure 4.3: CPS Interview Manual, Figure C71, NLFACT, Current Status................................. 98

Figure 4.4: WorkForce West Virginia Map ................................................................................ 107 


\section{CHAPTER 1: INTRODUCTION}

Economic development is well-recognized as being fundamental to facilitating an overall improved quality of life for communities and their residents. Throughout West Virginia's history, the state has struggled to secure economic stability. To increase stability, in 1962, West Virginia was the first state to take legislative action to address its economic condition by establishing public/government corporation for economic development (Lovett, 2014, The West Virginia Economic Development Authority Act, 1962). Despite the passage of this groundbreaking legislation, the state and its residents have continued to experience economic hardships caused by boom and bust cycles associated with resource extraction. This dissertation consists of three essays that explore the impacts of economic development activities, including conservation programs, economic development agency initiatives, and the efforts of the workforce development agencies that serve the state.

The first essay explores the relationship nonresident landowners have with the conservation programs within West Virginia, specifically the Natural Resources Conservation Service (NRCS) agency. Absentee ownership plays a significant role in the state's economic development, particularly in rural areas such as the Hampshire and Mineral county region where $153,178.53$ acres belong to absentee landowners out of the $483,336.67$ acres in these counties. Surveys of the absentee landowners indicate the owners' perceived multiple barriers to adoption of NRCS conservation practices, including lack of awareness of conservation services available in the region. Additionally, a logit model was used to quantify factors influencing the adoption of conservation practices. The results suggest there is a statistically significant negative impact regarding absentee landowners adopting conservation practices. Farm size and land use designation have positive impacts on conservation adoption. Study limitations relate primarily to 
relatively small geographical area used in the analysis. Further, the limited selective sample used in this study does not allow for the results to be generalizable. Commonalities in resistance to adoption of conservation practice may be transferable to other programs facing opposition.

The second essay addresses the issue of economic sustainability. For example, over time West Virginia economic development agencies have invested in higher levels of business supports/incentives, while inversely, these same agencies have provided fewer activities in support of environmental, quality of life, and community-based economic development. The findings indicated that the main reasons for selecting and implementing specific economic development programs were driven by 1) concerns about economic sustainability, 2) changes in the local economy, 3) funding sources motivating activities, 4) increased competition, 5) changes in economic development leadership, and 6) changes in political leadership. The survey results further indicate that the five top barriers to development included 1) inadequate infrastructure, 2) lack of skilled labor, 3) land and/or buildings availability/cost, 4) lack of capital/funding, and 5) declining market due to population loss.

With regards to sustainable practices, this study found that concern for economic sustainability was the most significant reason for conducting their current economic development strategies. Still, West Virginia economic development agencies selected activities that do not reflect a focus on balancing the economy, addressing environmental issues, and/or providing an equitable quality of life. It is a combination of these activities which ensures sustainable development. Overall, when measured by a balanced approach, strategies focusing on business economic development activities, instead of environmental sustainability and social equity, have resulted in a lower range of services and reduced sustainability. 
The third essay examines labor force participation barriers and the employment service agencies that help West Virginians find employment. This study finds that transportation limitations were the most common barrier to employment, with the following completing the top five barriers to employment: lack of job skills, local labor market, low-wages outweighing the additional costs of working, e.g., childcare and transportation costs, and the lack of work experience. By comparison, agency respondents indicated the top five most effective activities/services provided were vocational training, access to technology and/or internet service, soft skills training, industry-recognized certification training, and high school equivalency assistance. Transportation was ranked seventh in effectiveness by respondents. The results also found that, during the pandemic, the majority of agencies reported their participants did not experience changes in the employment barriers faced by job seekers.

With regards to the strength of the agencies' workforce development networking and collaboration efforts, the results indicated that the majority of agencies, $64 \%$, do not have partnerships that support their strategic planning processes, while 79\% indicated their agencies do have partnerships that provide support in other areas. Further, the agencies assisted a more ethnically diverse population than the state's population, serving target populations of individuals with low incomes, community members with disabilities/health conditions, young adults, adults, and unemployed individuals, as the five most served. Conversely, the five least served populations were college students, ex-offenders, individuals in recovery and/or chemically dependent, homeless people, and specific ethnic groups.

This study also found that the fields of employment in which clients were placed into employment positions did not align with financial capital development nor did the industry sectors offer career pathways that would lead to earning a living wage, with the five most 
common employment positions ranging in median hourly wages from \$11.43 to \$16.07, and being in the fields of health care, customer service/retail, food operation, cleaning and maintenance, and factory workers, while the five least common job placements ranged in median hourly wages from $\$ 9.99$ to $\$ 38.31$, and in the following fields: IT sector, child development, small business owner, financial operations, and the education sector.

Further resonating with previous research, this evaluation found that combining employment strategies was observed to be "more promising than using either strategy alone" (Butler et al., 2015, p. 67). Statistical significance indicated the range of workforce placements was more positively related to the range of workforce development activities and services provided by agencies than to the range of professional certifications held by the agencies' staff members. With regards to financial, social, and human capitals, this research found that increasing the range of employment activities and services leads to increases in job placements in higher wage sectors, as indicated by the expanded range of job placement fields. 


\section{CHAPTER 2: ESSAY 1 -ASSESSMENT OF THE DISTRIBUTION OF NRCS ASSISTANCE PROGRAMS IN WEST VIRGINIA AND STRATEGIC ENHANCEMENT OF FUTURE OUTREACH EFFORTS}

\subsection{Introduction/Theoretical Framework}

The Natural Resources Conservation Service (NRCS) expanded its services to underserved populations in accordance with the Food, Agriculture, Conservation, and Trade (FACT) Act of 1990, also referred to as Section 2501 Program of the 1990 U.S. Farm Bill, which addresses "the unique circumstances and concerns of socially disadvantaged farmers and ranchers, as well as beginning and limited resource farmers and ranchers" (United States Department of Agriculture [USDA], 1990, para. 1), and further defined as "a farmer or rancher who has been subjected to racial or ethnic prejudices because of their identity as a member of a group without regard to their individual qualities" (USDA, 1990, para. 2).

As part of this effort to increase services to underserved landowners, NRCS requested West Virginia University (WVU) to assess the equity of conservation services across the state. Phase I of the NRCS and WVU project Spatial Distribution of Applied NRCS Conservation Practices in West Virginia examined "the spatial distribution of NRCS assistance programs throughout the state" (Zimmerman, 2016, p. 16). Utilizing the resulting data analysis, the NRCS Leadership Team identified two districts and three service areas: Southern Conservation District; West Fork Conservation District; Buckeye Service Area; Keyser Service Area; and Romney Service Area (see Figure 2.1). In these underserved regions, the 15 lowest ranking underserved census tracts represented parcels within 10 counties: Barbour, Hampshire, Jefferson, Mercer, Mineral, Pendleton, Pocahontas, Randolph, Upshur, and Webster. Six of these underserved counties are designated as persistent poverty counties (Barbour, Hampshire, Mercer, Randolph, Upshur, and Webster) under USDA's Strike Force Initiative for Rural Growth and Opportunity, 
which addresses specific economic challenges associated with rural poverty, including preserving natural resources and protecting the environment (USDA, 2016).

Figure 2.1: Priority Areas Identified by WV NRCS

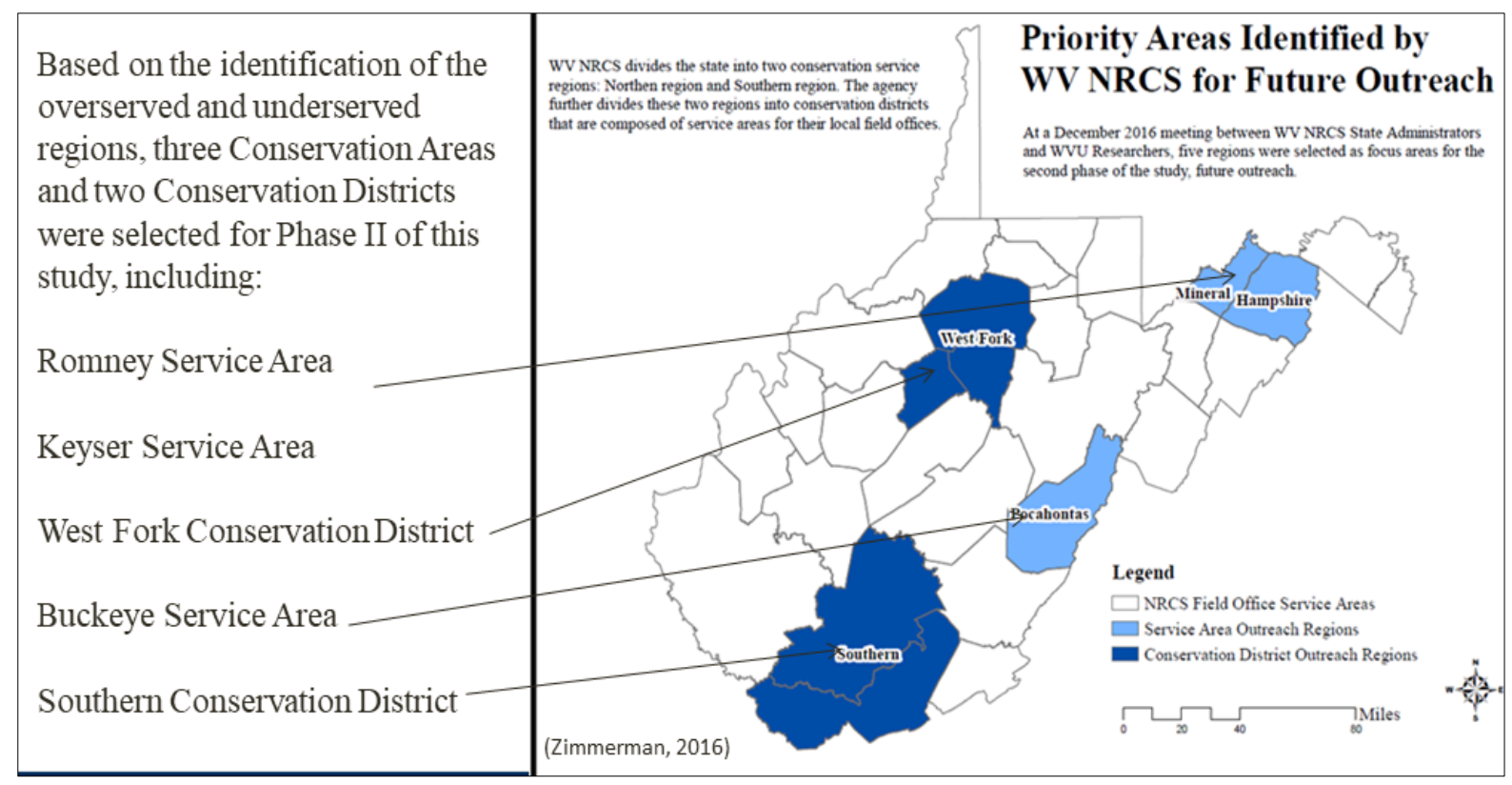

Note. From Spatial distribution of applied NRCS conservation practices in West Virginia: Phase I. West Virginia University, by Zimmerman, B., Collins, A. \& Lacombe, D. (2016). Report submitted to the Natural Resource Conservation Service, Morgantown, WV.

The aim of this study, Phase II of the Conservation Practices project, was to evaluate landowners' possible conservation adoption barriers to NRCS services in the underserved areas previously identified. In a literature review of conservation practice theories, detailed in Table 2.1, influences affecting adoption include the dynamics of social network power-positions, such as of the Economic Elite, Actor-Network and Status Seeking theories (Agrawal, 1999; Frank, 1985; Knowler \& Bradshaw, 2007). Also, the issue of Farm Stewardship Intensity may stem from a sense of moral obligation to the land and result in the adoption (or non-adoption) of 
conservation practices (Carolan, 2005; Schaible et al., 2015), which aligns with theories of Ethics and Responsibility, Norm-Activation, and Value-Belief-Norm (Agrawal, 1999; Lesch \& Wachenheim, 2014; Meleady et al., 2013). Further, prior research indicates that government agencies have used multiple adoption engagement strategies based on economic Coping Appraisal factors, as well as Risk-Based, Control-Based, and Efficacy-Based beliefs (Lesch \& Wachenheim, 2014; Wilson et al., 2014) to overcome conservation adoption barriers, with varying degrees of success (Petrzelka et al., 2020; Samanta et al., 2020). For example, previous research indicates tax credits or deductions increase the number of conservation-practice acreage engaged by absentee landowners (non-resident landowners), land tenure, or non-operating landowners (Sawadgo et al., 2021). In addition, Petrzelka and Armstrong found that land management motivations for absentee agricultural landowners "are related to information source usage" (2015, p. 312), and that the venues absentee landowners use to gather conservation information differ from residence-based landowners.

Building on previous studies, this research contributes to the understanding of absentee landowners in underserved areas and provides communication strategies and venues tailored to engage non-resident landowners in conservation practices. The overarching research question is: Is there a relationship between landowners' residency and participation in conservation practices? Utilizing multiple stages that rely on primary (non-experimental/survey data) and secondary data (cross-section data utilized in Phase I), there are five main objectives in answering this question: (1) assess stakeholder perceptions within the region regarding the relationships between landowners, communities, and the NRCS's personnel/resources, (2) identify groups/segments within the landowner population who are potentially underserved by NRCS programs, (3) develop a process to determine appropriate outreach strategies which 
addresses the barriers faced by underserved populations identified in Phase I, (4) arrange for implementation of outreach strategies to engage underserved landowner populations in NRCS programs, and (5) assess the relationship between landowners' residency and participation in conservation practices.

Based upon a review of literature and theory, the following hypothesis was evaluated regarding the relationship between conservation practices adoption and landowners. Hypothesis

$\mathrm{H}_{0}$ : There is no relationship between landowners' residency and participation in conservation practices.

$\mathrm{H}_{1}$ : There is a relationship in terms of landowners' residency and participation in conservation practices.

This report examined two representative case study counties, Hampshire and Mineral, which were selected using criteria of: low participation rates of conservation adoption, prevalence of out-of-county parcel ownership, and demographic factors. Further, this research offers recommendations to help address identified conservation barriers and includes observations and concerns supported by previous research and expressed by WVU Extension Service agents, DCs and absentee landowners survey respondents:

- Tax assessor's data should be mined for addresses to send brochures and website links, which would engage out-of-county landowners on their two most desired methods of communication.

- Increased funding or support services would also alleviate the hardship resulting from Department of Forestry layoffs, which have prevented development of Forest Stewardship plans. 
- Respondents noted they were already participating in other conservation practices, including forestry management, and conservation easements, which research indicates will increase the likelihood they will adopt NRCS conservation practices, given the opportunity.

The remainder of this essay is structured as follows: the second section provides an overview of theories relating to the adoption of conservation practices (see Table 2.1) and affords insight into some of the most common barriers, as indicated by previous research. The methods/procedures are described in section three, with the empirical results presented in section four. Finally, the conclusion and recommendations are provided in section five. 


\subsection{Literature Review}

Government agencies have used multiple strategies to overcome conservation adoption barriers, with varying degrees of success. Overall, there are approximately 10 recognized adoption barrier theories to accepting government policies and programs (see Table 2.1). The adoption theories in the table are arranged to correspond to the barriers to adoption and the related strategies to address adoption barriers. This list reflects an overview, not the specific barriers faced by potential participants in West Virginia.

Previous research offers several engagement avenues designed to overcome communication barriers for landowners living in rural or isolated regions, which are analogous to the underserved regions of the state. Further, prior studies have identified multiple barriers to the adoption conservation practices, which include power dynamics within the community where economic elites may attempt to marginalize other farmers or stakeholders to gain political dominance (Agrawal, 1999). Landowners also experience a high threat appraisal or high-risk perception and efficacy (Lesch \& Wachenheim, 2014), as well as a perception of government intrusion through excessive regulations and previous negative experiences with government (Kalcic et al., 2014). Also, research indicates that small farms experience a lack of resources available to participate in conservation practices (Molnar et al., 2001). Additionally, acreage characteristics, such as soil/water quality, have been a deterrent to landowners' conservation efforts (D’Souza et al., 1993). Further, research indicates absentee landowners that do not live on or near the property can have an impact on land management (Carolan, 2005; Ranjan et al., 2019). An additional impact on program participation identified in research is the lack of public awareness of conservation programs (McNairn \& Mitchell, 1992; Rogers, 1958). 
In related research, theories exploring barriers to adoption include the effects of the Economic Elite, who serve as leaders of a program's acceptance, and the dynamics of the ActorNetwork within the local landowner system, as well as the hazards caused by individuals who seek to increase their social position by controlling the region's conservation adoption process (Agrawal, 1999; Frank, 1985; Knowler \& Bradshaw, 2007). Further theories examine how landowners undergo internal assessments using coping appraisals, risk-based beliefs, controlbased, efficacy-based beliefs (Lesch \& Wachenheim, 2014; Wilson et al., 2014). Also indicated in the related Justice of the Procedure theory is the belief that some individuals will receive greater benefits based on social position or that the outcomes will vary depending on the individual's perceived prestige (Barrett-Howard, 1986). Addressed by Farm Stewardship Intensity theory is the issue of a landowners' commitment to the land, which is often seen as a generational obligation to the well-being of the property (Schaible et al., 2015). This sense of commitment is closely connected to the theories of Ethics \& Responsibility, Norm-Activation theory, and Value-Belief-Norm theory, which speak to landowners' belief regarding the longterm sustainability of the land (Agrawal, 1999; Lesch \& Wachenheim, 2014; Meleady et al., 2013). 
Table 2.1: Adoption Barrier Theories

\section{Adoption Theories}

Economic Elite (Agrawal, 1999)

Actor-Network: local individuals

(Knowler \& Bradshaw, 2007)

Status Seeking (Frank, 1985)

\section{Coping appraisals}

Risk-based beliefs, control-based, efficacybased beliefs (Lesch \& Wachenheim, 2014)

\begin{tabular}{lll}
\hline & $\bullet$ Government intrusion \\
Justice of the Procedure & $\bullet$ Excessive regulations \\
(Barrett-Howard, 1986) & $\bullet \begin{array}{l}\text { Previous negative experiences with } \\
\text { government }\end{array}$ & $\begin{array}{l}\text { Government programs need to provide flexibility in } \\
\text { addressing farmers' needs (Gasteyer, 2001) }\end{array}$ \\
& $\begin{array}{l}\text { Agencies hold a "one-size-fits-all”" } \\
\text { approach (Kalcic et al., 2014) }\end{array}$ & \\
\hline
\end{tabular}

Lack of resources (Molnar et al., 2001)
Economic elites may attempt to marginalize other farmers or stakeholders to gain political dominance (Agrawal, 1999)

High threat appraisal or high-risk perception and efficacy (Lesch \& Wachenheim, 2014)
Strategies to Address Adoption Barriers

Ensure diversity in community representation during program development and process (Gasteyer, 2001)
Present positive/negative impacts and economic effectiveness (Gasteyer, 2001)
Farm Stewardship Intensity (Schaible et al., 2015)

Soil/groundwater characteristics (D'Souza et al., 1993)

Absentee landownership (Rasmussen, 2014; Carolan, 2005)

Ethics \& responsibility (Lesch \& Wachenheim, 2014)

Norm-activation (Meleady et al., 2013)

Insufficient public awareness of programs (McNairn \& Mitchell, 1992)

Value-belief-norm (Agrawal, 1999)

Incentives \& technical support (Lambert et al., 2006)

Communication streams (McNairn \& Mitchell, 1992)

"Foot in the door technique" (Wilson et al., 1993, 2014). Engagement in one conservation program may lead to further adoptions (Kalcic et al., 2014) 
Integrating theories with strategies designed to address barriers provides government agencies tools to overcome landowners' adoption resistance. Previous research indicates these strategies involve ensuring there is economic and social diversity represented during program development and process of enhancing community participation in conservation services (Gasteyer, 2001). Moreover, previous negative experiences with government agencies can create program resistance. Further, researchers find that government programs need to provide flexibility in addressing farmers' needs or provide incentives and technical support and expand communication avenues to connect landowners with conservation methods and opportunities (Gasteyer, 2001; Lambert et al., 2006; McNairn \& Mitchell, 1992). The "Foot in the Door Technique" addresses the issue of getting landowners to gain confidence with government agencies and conservation practices, wherein engagement in one conservation program may lead to further adoptions (Wilson et al., 1993, 2014; Kalcic et al., 2014). Further, to address landowners' concerns for coping challenges and risk issues, particularly for small farms, research indicates program managers can provide landowners the positive/negative impacts and economic effectiveness of conservation efforts (Gasteyer, 2001; Lambert et al., 2006). For example, other landowners can "act as the main information dissemination agents" (Habron, 2004, p. 114). Previous research also indicates that expansions of conservation practices campaigns are strengthened through one-to-one personal interactions (Dampney et al., 2001; Morris, et. al., 2000). The need to identify adoption barrier strategies specific for the underserved areas identified in Phase I, which would assist landowners overcome their resistance to engaging in conservation practices, prompted this study. 


\subsection{Methods/Procedures}

\section{Research Design/Instrument Development}

\section{Objective 1) Assess stakeholder perceptions within the region regarding the relationships between landowners, communities, and the NRCS's personnel/resources.}

WVU Extension Agriculture and Natural Resources Agents Interviews

Eight West Virginia University Extension Agriculture and Natural Resources Agents, whose service areas overlapped the NRCS underserved regions, were contacted during the first stage of this work to provide qualitative data on the development of the survey instrument and assess the relationships and opinions of supporting conservation agencies in order to help interpret the milieu of the inadequately served regions and NRCS, including relationships with

other agencies and landowners. The semi-structured interviews with the WVU Extension Agents were conducted by phone and email during January 2017 and provided insight into the questions for the second phase of interviews.

\section{Objective 2) Identify groups/segments within the landowner population who are potentially underserved by NRCS programs.}

NRCS District Conservationists (DCs) Interviews

The next phase of interviews, conducted in late January through mid-February 2017, included NRCS DCs of the under- and overserved regions. In preparation for the in-person and phone interviews with the NRCS DCs, an email was sent from their respective North and South Area Assistant State Conservationists-Field Operations, at the bequest of the WV State Office, Assistant State Conservationist-Management \& Strategy, which related the purpose for the 
upcoming interviews, which was to assess the perceptions of the region including the relationship between landowners, communities, and the NRCS's personnel/resources and to develop effective outreach strategies designed to engage landowners currently not being served by NRCS.

Researchers then sent a follow-up email to the DCs to schedule the interviews and reiterate the purposes of the project. The interviews with six DCs involved 22 open-ended questions and were conducted in-person, with one interview conducted via phone and in-person. The responses further added to the development of the survey instruments for the next phase. Hampshire and Mineral counties were selected as case study counties based on the input from the previous interviews, which indicated three areas of interest: where were the potential areas, who were potential clientele, and what groups of producers/farmers could become clients who are not already being served? The respondents indicated that out-of-state landowners were a significant potential clientele and, further, the Hampshire and Mineral county region's "percentage of non-resident landowners is higher than most counties."

\section{Objective 3) Develop a process to determine appropriate outreach strategies which addresses the barriers faced by underserved populations identified in Phase I.}

Based on the interview responses and feedback from the NRCS Leadership Team, a survey instrument was developed based on a previous survey instrument used to examine riparian landowners conservation usage (Mojica-Howell \& Collins, 2012). A mixed-method approach was used with the aim of collecting qualitative and quantitative data regarding out-ofcounty landowners' characteristics and behavior toward the adoption of conservation practices, particularly with regards to NRCS financial and technical services. The survey instrument (see 
Appendix A), with both close ended and open-ended questions, queried seven factors: sole or joint landowner; management of parcel; awareness of NRCS; most effective means of communication (marketing) of services; interest in NRCS services; landowners' characteristics and demographics; and open-ended feedback. The self-administered survey instrument, with Land Use Codes (see Table 2.2) specific to the landowner's parcel typed on the upper right-hand corner, was mailed with a cover letter (see Appendix B) and postage-marked return envelope.

Table 2.2: County Assessor Land Use Codes

\begin{tabular}{ll}
\hline Code Number & Definition \\
\hline 100 & Residential Vacant \\
101 & Residential 1 Family \\
112 & Active Farm \\
113 & Inactive Farm \\
123 & Large Vacant Tract - Unknown Potential \\
\hline
\end{tabular}

\section{Parcel Data Description}

The interviews of the WVU Extension Service agents and the NRCS DCs served to inform the scope of the project. For example, the survey contact list included out-of-county landowners from Hampshire and Mineral counties, areas which were identified as underserved regions in Phase I of the NRCS and WVU project Spatial Distribution of Applied NRCS Conservation Practices in West Virginia. Hampshire and Mineral counties have 40,486 parcels, with 8,807 parcels greater than 10 acres. Of these parcels, 1,602 active farm parcels, Land Use Code \#112, in Hampshire County were greater than 10 acres, of which most of these parcels had farm use tax deduction and were not sent a survey. Further, 912 active farm parcels in Mineral 
County were greater than 10 acres and, as with Hampshire County, many of these parcels had farm use tax deduction and were also not sent a survey. Financial institutions managing parcel trusts were also omitted from the mailings. Landowners with multiple parcels were sent only one survey.

\section{Conservation Data Description}

The State Tax Assessor's office provided names, addresses and deeded acreage numbers for landowners for Hampshire and Mineral counties for tax year 2017. West Virginia University's WV GIS Technical Center provided a greater level of acreage accuracy than the county assessor's office deed acreage. Data regarding landowners in Hampshire and Mineral counties who receive a Farm Tax reduction were also obtained from the West Virginia State Tax Department through a Freedom of Information request. In addition, data were also obtained from the West Virginia Division of Forestry, which provided a list of landowners in the focus counties who were current or previous participants in the Forest Stewardship program. In conjunction with these data, the Conservation Fund also provided a list of conservation easements for Hampshire and Mineral counties.

Jacquelyn Strager, a Research Coordinator with the Natural Resources Analysis Center at West Virginia University, combined these different program participation data from the sources noted previously by summarizing the total number of NRCS points and the total number of easements for each parcel, and then exporting the table out of the GIS format into an Excel file. To obtain the count of practice points, Ms. Strager “used a 'spatial join' to label each practice point with the parcel information for the parcel in which it falls (spatially)," which she followed by summarizing the dataset and joining "the summary table back to the original parcel attribute 
table, and calculated the final column COUNT_NRCS" (Strager, 2017. P. 1). To obtain the count of easements, Ms. Strager joined the existing easement summary table to the parcel attribute table and "calculated the final column COUNT_EASM to be equal to the number of easements from the existing easement summary table," after which she "calculated all other parcels to have number of easements equal to zero" (2017, p. 1). All records for the parcels were then saved in Excel format, adding the following columns:

- $\quad$ Reformatted Parcel ID

- $\quad$ COUNT_NRCS: count of practice points in that parcel

- $\quad$ COUNT_EASM: count of easements from summary table for that parcel

\section{Population: Description of Parcel Owners}

Following analysis of the interview responses from WVU Extension Service agents and the NRCS DCs along with direction from NRCS, it was determined that the survey population would include absentee landowners from Hampshire and Mineral Counties, with specific acreage minimum limits. On February $7^{\text {th }}$ and $8^{\text {th }}$ of 2018 , the first mailing was posted. The survey population included out-of-county residents who own parcels of more than 10 acres of farmland in Hampshire and Mineral Counties parcels with no conservation services, with Land Use Codes: $\# 112, \# 113$, and \#123 (see Table 2.2). Also included in the initial mailing were parcels greater than 10 acres and designated as Residential and Residential Vacant, \#100 \& \#101, with forestry practices, but receiving no other conservation services. Reminder postcards were mailed on February 21, 2018.

On April 11, 2018, the second mailing was sent and included parcels greater than 100 acres, with Land Use Codes 100 \& 101, with no engagement in conservation practices, including forestry. Reminder postcards were mailed on April 25, 2018. 


\section{Data Collection}

The cover letter (see Appendix B) enclosed with the first survey mailing provided a link and unique code for access to an online duplicate survey using Qualtrics (22 online survey attempts, with two duplications; nine completed surveys online; 13 uncompleted online surveys, of which five completed and returned paper questionnaires). A postcard reminder (see Appendix C), with a clarified description of the online process, was sent two weeks after the mailing. The initial survey was sent to 465 out-of-county residents and the response rate was $44 \%$, with 10 envelopes returned indicating relocation of owners and two questionnaires returned blank. Reminder postcards were mailed on February 21, 2018.

The survey was also mailed to a second population group of 103 landowners of parcels in Hampshire and Mineral Counties with $100+$ acres. It included a return postage-marked envelope and cover letter, with the online link removed in response to the inadequate/incomplete submissions of the first mailing. As noted previously, reminder postcards were also mailed two weeks after the second survey mailing. From this mailing, two envelopes were returned due to relocation, and the response rate was $41 \%$. Combined, the response rates average $42.5 \%$, which is within the expected range, $40 \%$ to $75 \%$, for mailed questionnaires (Ary et al., 2010).

\section{Objective 4) Arrange for implementation of outreach strategies to engage underserved landowner populations in NRCS programs.}

With input from the NRCS DCs, the out-of-county landowners, with land use codes \#112 Active Farm, \#113 Inactive Farm, and \#123 Large Vacant Tract, who indicated they would like more information regarding NRCS conservation services received two flyers: "2018 FCA Success Report," which contained the article Improving Soil Health through Better Grazing 
Management, and "NRCS Assistance Programs," which outlined NRCS's technical and financial assistance services, including the Agricultural Management Assistance program, the Environmental Quality Incentives Program (EQIP), and the Conservation Stewardship Program (CSP). Responding landowners with forest property, land use codes \#100 Residential Vacant and \#101 Residential, received two flyers: (1) National Wild Turkey Federation's "Cerulean Warbler Forest Enhancement Program”, and (2) NRCS's “Environmental Quality Incentives Program Forest Land," with NRCS contact information included on the back page.

\section{Objective 5) Assess the relationship between landowners' residency and participation in conservation practices.}

A number of studies have associated conservation adoption and non-adoption decisions to owner or ownership characteristics using logit models to analysis participation specified binary responses. For example, logit models have been used by Bell et al. (1994), to determine the influence of cost-share incentives on participation in the Tennessee Forest Stewardship Program, Al-Karablieh et al. (2009) estimated the relationships of farmers' socioeconomic factors and their adoption decisions, and Sheikh et al. (2003) identified farmer and farm characteristics that influence adoption of 'no-tillage' technologies. A similar study, by Jamnick and Beckett (1988) identified characteristics of owners who decide to harvest or not to harvest forest products, while Napier et al. (1988) examined explanatory factors influencing the adoption of soil erosion control practices.

Although the linear probability model, logit model and probit model are commonly used to measure behavior, the linear model has a defect in that it is not constrained to 0 and 1 , unless corrected by a procedure which "produces unrealistic kinks at the truncation points" (Amemiya, 
1981, p. 1486). Additionally, Amemiya (1981) notes the probit model and the logit model are similar statistically, except in cases with an extremely large number of observations or when the data are "heavily concentrated in the tails due to the characteristics of the problem being studied" (p. 1487).

Table 2.3: Variables Description

\begin{tabular}{ll}
\hline Variable & Definition: dummy variables \\
\hline Conser_Prac & $\begin{array}{l}\text { Owners engaging in conservation practices } \\
\mathrm{y}_{\mathrm{i}}=\left(1 \text { if the } \mathrm{i}^{\text {th }} \text { owner is engaged in conservation }\right. \\
\text { practices, 0 otherwise })\end{array}$ \\
\hline Out-of-county & Owner's residency $(\mathrm{Y}=1, \mathrm{~N}=0)$ \\
Acres_c & Number of Acres (non-binary) \\
Resi_vac_100 & Residential Vacant $(\mathrm{Y}=1, \mathrm{~N}=0)$ \\
Res_1Family_101 & Residential 1 Family $(\mathrm{Y}=1, \mathrm{~N}=0)$ \\
Active_farm_112 & Active Farm $(\mathrm{Y}=1, \mathrm{~N}=0)$ \\
Inactive_farm_113 & Inactive Farm $(\mathrm{Y}=1, \mathrm{~N}=0)$ \\
Large_Vac_123 & Large Vacant Tract $(\mathrm{Y}=1, \mathrm{~N}=0)$ \\
\hline
\end{tabular}

In this study, the dependent variable, Conser_Prac, is dichotomous, with only two possible outcomes $(\mathrm{Y}=1, \mathrm{~N}=0)$, which is similar to the logit model used by Al-Karablieh et al., wherein the dependent variable, adoption/non-adoption, is treated as a binary variable, with " 1 " if adopted and " 0 " if otherwise (2009, p. 255). Further, the dependent variable in this study is coded "1" to indicate landowners have received NRCS services, Conservation Easements, and/ or WV Forestry Program services, and the coded " 0 " to indicate no conservations practices were 
used by the landowners. The logit equation is written as: $\operatorname{Prob}(Y=1 \mid x)=\frac{e^{x \prime \beta}}{1+e^{x \prime} \beta}=\Lambda\left(x^{\prime} \beta\right)$ (Greene, 2002, p. 667).

Explanatory binary variables, such as landowners' residency and Land Use Codes, were utilized to explain the relationships between absentee landownership and adoption of conservation practice (see Table 2.3). Further, STATA: Statistics/Data Analysis, 14.1, software was utilized to compute the summary statistics of the variables regarding the Hampshire and Mineral County database. 


\subsection{Results}

\section{Objective 1) Assess the perceptions of the region including the relationship between landowners, communities, and the NRCS's personnel/resources.}

WVU Extension Agriculture and Natural Resources Agents Interviews

The NRCS DCs work closely with various agricultural agencies and entities in their area, including WVU Extension Service, the West Virginia Conservation Agency, Conservation

Districts, farmers markets, and other federal agencies in accomplishing outreach to farmer and landowner clientele. During the semi-structured interviews with the eight WVU Extension Service agents the following issues were expressed:

- NRCS has ineffective advertising methods and the agency is understaffed

- Area landowners have a fear of government

- Farmers must pay up-front, and wait to be reimbursed

- The conservation process is too difficult, with varying project standards

- Fencing project regulations are too complicated, with inadequate cost-shares

- There is too much paperwork

- New applicants are often rejected

- The same people are awarded

Objective 2) Identify groups/segments within the landowner population who are potentially underserved by NRCS programs.

During the interviews with the six NRCS DCs the following concerns were expressed:

- Financially disadvantaged farmers/producers do not have the funds and are unable to even secure a loan to complete the contract while waiting for NRCS reimbursement.

- Small farmers indicated that the cost-share was insufficient

- New applicants who were not funded became discouraged and dropped-out after two or three unsuccessful attempts 
NRCS has had budget difficulties. One example of how to address this concern was in Pocahontas County where the Division of Forestry and NRCS share an employee $(25 \%$ and $75 \%$, respectively). This arrangement allows for Forest Stewardship Plans to be created with the goal that the landowner's application be transferred to the NRCS for completion. Further, several DCs noted that the high-tunnel program has expanded NRCS applicants into non-traditional clientele groups - schools, small farmers, nurseries, etc. No problems were reported among the DCs with high-tunnel program in reaching out to these groups and getting enough applications. Most DCs reported a backlog of applications for their programs - e.g. more applicants than could be funded given funding or personnel constraints. NRCS forestry programs seemed to be the most problematic as they depended upon Forest Stewardship Plans being developed; Foresters from the WV Division of Forestry were typically responsible for these plans. Word-of-mouth and neighbor or family members' experiences in working with the NRCS were also mentioned as important aspects of applicant recruitment. Some DCs were resourceful in their pursuit of outreach strategies, utilizing more than a dozen methods (see Table 2.4).

During the discussions with DCs and WVU Extension Agents, three possible groups were identified for enhanced outreach: Non-resident landowners, forest landowners, and landowners and/or farmers who have anti-government attitudes. Some concerns were expressed by DCs about low-resource farmers and their inability to cost-share expenses of NRCS programs. Financially disadvantaged farmers/producers do not have the funds and are unable to even secure a loan to complete the contract while waiting for NRCS reimbursement. Some small farmers indicated that the cost-share was insufficient. Furthermore, DCs noted that new applicants who were not funded became discouraged and dropped-out after two or three unsuccessful attempts. Interviewees also indicated that enhanced support for NRCS staff could be provided on new technologies such as engineering training for alternative water solar systems. 
Table 2.4: Communication Methods used by NRCS DCs

Communication Methods

- Contacting local Farmers' Market Association

- Field Days

- Flyers in local feed stores

- Garden Club demos with Master Gardeners

- High Tunnel exhibits

- National publications

- News releases (with little media coverage)

- Participate with other conservation agencies (newsletters, websites, and dinner meetings)

- Pasture Walks

- Setup booths at county fairs, 4-H meetings \& cattle sales

- USDA mailing list

- Visit current clients

- Word-of-mouth

Objective 3) Develop a process to determine appropriate outreach strategies which addresses the barriers faced by underserved populations identified in Phase 1.

\section{Surveys of Out-of-County Owners}

Information from the two rounds of surveys was collected and compiled separately in Microsoft Excel for analysis. Of the 243 respondents who returned the questionnaires, $89 \%$ 
identified themselves as sole or joint landowners. Of the landowners $(n=216)$ responding to the subsequent question regarding the current management of the parcel, $42 \%$ indicated that they actively manage the parcel, 22\% indicated they have limited management by themselves as a sole owner, $15 \%$ indicated limited management as a joint owner, $6 \%$ lease out with an active role, and $8 \%$ lease out with a limited role. In addition, $8 \%$ of respondents indicated other as their response, with the narrative themes including, letting the property manage itself, following a timber management plan, family members raising hay or using it for hunting, and renting pastureland.

The demographics of the respondents include the gender of the individual completing the questionnaire, with $20 \%$ female and $80 \%$ male, and the age range, between 24 years of age to 96 years old, with the average age being 65 years old. Sixty-six percent of the respondents stated their age was over 60 years old, and 33\% were between 35 and 59 years old (see Table 2.5). Regarding the landowners' income from their parcels, the majority of respondents, $61 \%$, indicated that farming and/or forestry from their parcel provided them with no income; $23 \%$ indicated that farming and/or forestry provided some income, but not much relative to other income sources; $16 \%$ indicated other, with some using the property for a retirement/hunting location, leasing or renting cabins or pastureland, and low-level timbering (see Table 2.5). In addition, crop rotation, planting covers crops, grazing management, or forestry management were some of the conservation practices used by the $22 \%$ of respondents who indicated that they had engaged in land and soil conservation. The wildlife habitat enhancements included creating food plots or cutting timber for wildlife cover, and the water quality protection included tree planting, excluding livestock from ponds and streams, or animal waste storage facilities (see Table 2.6). 
Table 2.5: Demographics of Landowner Respondents

\begin{tabular}{lccccccc}
\hline $\begin{array}{l}\text { Education } \\
(\mathrm{n}=198)\end{array}$ & $\%$ & $\begin{array}{c}\text { Income } \\
\text { from } \\
\text { Property } \\
(\mathrm{n}=186)\end{array}$ & $\%$ & $\begin{array}{c}\text { Age } \\
(\mathrm{n}=188)\end{array}$ & $\%$ & $\begin{array}{c}\text { Gender } \\
(\mathrm{n}=197)\end{array}$ & $\%$ \\
\hline College & 56 & $\begin{array}{c}\text { No } \\
\text { Income }\end{array}$ & 61 & 18 to 35 & 1 & Female & 20 \\
$\begin{array}{l}\text { Associate } \\
\text { Degree }\end{array}$ & 6 & $\begin{array}{c}\text { Some } \\
\text { Income }\end{array}$ & 23 & 36 to 59 & 33 & Male & 80 \\
$\begin{array}{l}\text { Technical } \\
\text { School }\end{array}$ & 6 & Other & 16 & $60^{+}$ & 65 & & \\
$\begin{array}{l}\text { Some College, } \\
\text { No Degree }\end{array}$ & 14 & & & & & & \\
$\begin{array}{l}\text { High School } \\
\text { Sigh }\end{array}$ & 16 & & & & & & \\
$\begin{array}{l}\text { Less than High } \\
\text { School }\end{array}$ & 2 & & & & & & \\
\hline
\end{tabular}

Note. Percentages are computed within columns.

As a means of assessing current needs, the questionnaire also inquired whether there were any problems regarding land, water, or wildlife. The majority of respondents, $69 \%$, indicated no, compared to the $8 \%$ who indicated yes, and the $23 \%$ of respondents who checked other, and provided the following issues: invasive plants and insects, erosion, over population of wildlife, aging and diseased woodlands, and poachers. Respondents also indicated they used a combination of strategies, with 13 indicating land and soil conservation, water quality protection, and wildlife habitat enhancement practices had been implemented since 2000. Among the explanations given for the selection other, respondents stated they had planted fruit trees, white pine trees and native grasses, maintained a river buffer, and sprayed for Gypsy Moth.

Further, in relation to the respondents' awareness of NRCS conservation services, two questions were asked: What was their level of awareness and how did they hear about NRCS? 
The most common response by respondents, $39 \%$, was that they were somewhat aware of the NRCS. The second highest response, 30\%, was that they had never heard of this agency before, which closely mirrors the $31 \%$ of respondents who indicated they were not aware of the NRCS prior to this survey.

Table 2.6: Conservation Practices Since $2000(n=201)$

\begin{tabular}{lc}
\hline Conservation Practices & $\%$ \\
\hline No conservation practices & 41 \\
Land and soil conservation & 22 \\
Wildlife habitat enhancements & 15 \\
Limited management role & 8 \\
Other & 8 \\
Water quality protection & 6 \\
\hline
\end{tabular}

\section{Objective 4) Arrange for implementation of outreach strategies to engage underserved landowner populations in NRCS programs.}

As part of the assessment of the best communication (marketing) strategies to connect with absentee landowners, the inquiry regarding landowners gaining more information about NRCS indicated internet and traditional mailing of brochures and fact sheets were the two most requested (see Table 2.7). Of the 139 survey respondents who requested additional NRCS information and follow-up contact, four left no contact information, but several of these individuals indicated they would contact NRCS via its website, which resonates with the preferred method of communication. In addition, NRCS flyers and fact sheets, identified 
previously, were sent to all the remaining respondents who requested information, whether by traditional mail or email, depending of the requestor's preference.

Table 2.7: Respondents' Preferred Communication Methods

\begin{tabular}{lc}
\hline Communication Methods & $\%$ \\
\hline NRCS website: https://www.nrcs.usda.gov & 36 \\
Brochures and/or information mailed to landowners & 35 \\
Periodicals or newspapers & 11 \\
Word of mouth experiences from neighbors, family, or friends & 9 \\
Presentations at local community meetings (like Rotary, Ruritan, Farm & 4 \\
Bureau, etc.) & 3 \\
Learning more at information booths during fairs or festivals & 2 \\
\hline
\end{tabular}

\section{Parcel Data Analysis}

\section{Objective 5) Assess the relationship between landowners' residency and participation in conservation practices.}

To examine the relationship between landownership and conservation practices, the analysis of the data uses a logit regression (see Table 2.8) in response to the use of binary variables, dependent and independent (Wooldridge, 2012). In an overview of parcels: nearly $30 \%$ of the properties in the two research counties had previously participated in conservation 
practices, with in-state landowners holding $64.67 \%$ of the 7,566 parcels and out-of-county landowners holding 3,200 parcels, equating to $42.29 \%$ (see Table 2.8 ).

Table 2.8: Descriptive Statistics of Variables

\begin{tabular}{|c|c|c|c|c|}
\hline Variable & \multicolumn{2}{|r|}{$\mathrm{F}$} & & $\%$ of 7,566 obs. \\
\hline Conser_Prac & \multicolumn{2}{|r|}{2,269} & & 29.99 \\
\hline Out-of-county & \multicolumn{2}{|r|}{3,200} & & 42.29 \\
\hline Resi_vac_100 & \multicolumn{2}{|r|}{2,321} & & 30.68 \\
\hline Res_1Family_101 & \multicolumn{2}{|r|}{2,026} & & 26.78 \\
\hline Active_farm_112 & \multicolumn{2}{|r|}{2,515} & & 33.24 \\
\hline Inactive_farm_113 & \multicolumn{2}{|r|}{63} & & .83 \\
\hline \multirow[t]{2}{*}{ Large_Vac_123 } & \multicolumn{2}{|r|}{12} & & .15 \\
\hline & $M$ & $S D$ & Min & Max \\
\hline Acres_c & 63.88 & 129.10 & 10.01 & 1866.52 \\
\hline
\end{tabular}

Of the 3,200 absentee landowners, nearly 7\%, representing 527 parcels, were West Virginia residents who lived outside of Hampshire and Mineral counties. Further, the top five out-of-county parcel owners' residential states were: Maryland (1,145 parcels), Virginia (948 parcels), Pennsylvania (135 parcels), Florida (51 parcels), and New Jersey (40 parcels), with international parcel ownership including Australia, Austria, England, and Mexico. 
Table 2.9: Estimation Results for Logit Model

\begin{tabular}{lcc}
\hline Variable & $\begin{array}{c}\text { Coefficient } \\
\text { Estimates }\end{array}$ & $\begin{array}{c}\text { Marginal Effects } \\
\mathrm{dy} / \mathrm{dx}\end{array}$ \\
DV: Conser_Prac & $-.133^{* *}$ & $-.026^{* *}$ \\
Out-of-county & $(.060)$ & $.001^{* * *}$ \\
& $.003^{* * *}$ & \\
Acres_c & $(.000)$ & .008 \\
& .036 & \\
Resi_vac_100 & $(.115)$ & -.034 \\
& -.172 & \\
Res_1Family_101 & $(.119)$ & $.314^{* * *}$ \\
& $1.464^{* * *}$ & \\
Active_farm_112 & $(.112)$ & .045 \\
& .217 & .277 \\
Inactive_farm & $(.315)$ & \\
& $-1.516^{* * *}$ & \\
\hline Constant & $(.108)$ & \\
\hline \# of observations & 7,566 & \\
Pseudo $R$-squared & 0.1160 & \\
\hline
\end{tabular}

Note: standard errors in parenthesis. *, **, and *** represent statistical significance at $10 \%, 5 \%$, and $1 \%$ significance level, respectively.

The results from the Logit Model Regression indicate that the variable out-of-county has a statistically significant coefficient at the $5 \%$ level (see Table 2.9 ). Therefore, the null hypothesis was rejected: there is a negative relationship in terms of landowners' residency and participation in conservation practices. The marginal effects, when estimated in isolation, for the variable out-of-county indicate that an absentee landowner is $-2.6 \%$ less likely to adopt conservation practices. Further, the variable Active_Farm_112, is also positive and significant at $1 \%$, indicating owners of parcels with this land use code designation are $31.4 \%$ more likely to 
adopt conservation practices. Additionally, the Acres_c has a positive and statistically significant coefficient at $1 \%$, indicating landowners are more likely to adopt conservation practices with each additional acre owned, holding all other variables constant.

\subsection{Conclusions and Recommendations}

\section{Conclusions}

The findings of this study are consistent with previous research, as noted in the literature review, wherein living outside of the region reduces the probability landowners will engage in conservation practices (Carolan, 2005). If landowners are already participating in other conservation or tax reduction programs, it is more likely that they will adopt NRCS conservation practices (Kalcic et al., 2014). This is particularly important for the Hampshire and Mineral county region where more than $153,178.53$ acres belong to absentee landowners of the 483,336.67 acres in these counties. Further, the interviews with NRCS DCs indicated multiple barriers to conservation engagement that resonated with conservation adoption theories, as well as additional barriers unique to their regions. Surveys of the absentee landowners indicated the owners' perceived multiple barriers to adoption of NRCS conservation practices, including lack of awareness of conservation services available in the region (McNairn \& Mitchell, 1992).

Additionally, a logit model was used to quantify factors influencing the adoption of conservation practices. The results suggest that there is a statistically significant negative impact regarding absentee landowners adopting conservation practices. Further, farm size and land use designation have positive and statistically significant impacts on conservation adoption.

Study limitations relate primarily to relatively small geographical area used in the analysis. Further, the limited selective sample used in this study does not allow for the results to 
be generalizable. Commonalities in resistance to adoption of conservation practice, however, may be transferable to other programs facing opposition.

\section{Recommendations}

The interviews of WVU Extension Service agents and the DCs, in conjunction with the 244 out-of-county landowner respondents indicate there are multiple avenues open for landowners to engage in conservation methods. Out-of-County landowners generally lack the means to connect with their local conservation services centers. To address the desired means of communication, NRCS flyers and fact sheets, as noted previously, were sent to the respondents requesting information, whether by traditional mail or email, depending on the requestor's preference. Out-of-county landowners with land use codes \#112 Active Farm and \#113 Inactive Farm received two flyers: "2018 FCA Success Report," which contained the article Improving Soil Health through Better Grazing Management, and "NRCS Assistance Programs," which outlined NRCS's technical and financial assistance services, including the Agricultural Management Assistance program, the Environmental Quality Incentives Program (EQIP), and the Conservation Stewardship Program (CSP). In addition, absentee landowners with forest property, land use codes \#123 Large Vacant Tract, \#100 Residential Vacant, and \#101 Residential, received two flyers: (1) National Wild Turkey Federation's “Cerulean Warbler Forest Enhancement Program”, and (2) NRCS's “Environmental Quality Incentives Program Forest Land."

As noted in the DCs' interviews, tax assessor's data had not been previously used by NRCS personnel to identify potential audiences for NRCS services. One possible way to connect with these landowners could be if these databases were mined for addresses to send 
brochures and website links, which would engage the landowners by their two most desired methods of communication. To obtain the tax assessor's data base, the researchers of this project submitted a FOI request to Kelly Lavender, Tax Audit Clerk Senior, under the West Virginia Freedom of Information Act, §29-B-1-1 et seq., requesting the AA170ptd Farm reports for Hampshire and Mineral counties from the West Virginia State Tax Department, 1124 Smith Street, Charleston, WV 25301.

Finally, in response to the feedback from interview respondents regarding insufficient cost-share, increased funding or support services would also alleviate the hardship resulting from personnel layoffs at the West Virginia Division of Forestry, which have prevented development of Forest Stewardship plans. Overall, these strategies, in conjunction with the ongoing public awareness campaigns, would provide a systematic process to encourage and enable landowner participation in long-term land sustainability. 


\subsection{References}

Agrawal, A., \& Gibson, C. C. (1999). Enchantment and disenchantment: The role of community in natural resource conservation. World Development, 27(4), 629-649.

https://doi.org/10.1016/s0305-750x(98)00161-2

Al-Karablieh, E. K., Al-Rimawi, A. S., \& Hunaiti, D. A. (2009). Logit models for identifying the factors that influence the adoption of barley production technologies in low rainfall areas. Jordan Journal of Agricultural Sciences, 5(3), 251-265.

Amemiya, T. (1981). Qualitative response models: A survey. Journal of economic literature, 19(4), 1483-1536.

Ary, D., Jacobs, L. C., \& Sorensen, C. (2010). Introduction to research in education. ( $8^{\text {th }}$ ed.). California: Wadsworth, Cengage Learning.

Barrett-Howard \& Tyler, T. R. (1986). Procedural justice as a criterion in allocation decisions. Journal of Personality and Social Psychology, 50(2), 296-304.

Carolan, M. S. (2005). Barriers to the adoption of sustainable agriculture on rented land: An examination of contesting social fields. Rural Sociology, 70(3), 387-413.

Collins, A., Lacombe, D., Strager, J. \& Zimmerman, B. (2016). Assessment of the distribution of NRCS assistance programs in West Virginia and strategic enhancement of future outreach efforts. West Virginia University.

Dampney, P., Jones, D., \& Winter, M. (2001). Communication methods to persuade agricultural land managers to adopt practices that will benefit environmental protection and conservation management (AgriComms). ADAS Report to Defra. 
D’Souza, G., Cyphers, D., \& Phipps, T. (Oct.1993). Factors affecting the adoption of sustainable agricultural practices. Agricultural and Resource Economics Review, 159-165.

Frank, R.H. (1985). The demand for unobservable and other nonpositional goods. American Economic Review, 75(1), 101-116.

Gasteyer, S. P. (2001). Emerging bridges over contested waters: Coalitions, participatory process, social capital, and community capacity for water quality protection. Dissertation, Iowa State University.

Greene, W. H. (2002). Econometric analysis ( ${ }^{\text {th }}$ Ed.) New York, NY: Macmillan Publishing Company.

Habron, G.B. (2004). Adoption of conservation practices by agricultural landowners in three Oregon watersheds. Journal of Soil and Water Conservation, 59(3), 109-115.

Jamnick, M. S., \& Beckett, D. R. (1988). A logit analysis of private woodlot owner's harvesting decisions in New Brunswick. Canadian Journal of Forest Research, 18(3), 330-336.

Kalcic, M., Chaubey, I., Frankenberger, J., \& Prokopy, L. (2014). An in-depth examination of farmers' perceptions of targeting conservation practices. Environmental Management, (54), 795-813.

Knowler, D. \& Bradshaw, B. (2007). Farmers' adoption of conservation agriculture: a review and synthesis of recent research. Food Policy, (32), 25-48.

Lambert, D., Sullivan, P., Claassen, R., \& Foreman, L. (2006). Conservation-compatible practices and programs. who participates? United States Department of Agriculture, Economic Research Service Report, (14). Retrieved from https://naldc.nal.usda.gov/download/18041/PDF. 
Lesch, W. C. \& Wachenheim, C. J. (2014). Factors influencing conservation practice adoption in agriculture: A review of the literature. Agribusiness \& Applied Economics Report, (722).

McNairn, H.E., \& Mitchell, B., (1992). Locus of control and farmer orientation: Effect on conservation adoption. Journal of Agricultural and Environmental Ethics, 5(1), 87-101.

Meleady, R., Hopthrow, T. \& Crisp, R. J. (2013). The group discussion effect: Integrative processes and suggestions for implementation. Personality and Social Psychology Review, The Society for Personality and Social Psychology, Inc., 17(1), 56-71.

Mojica-Howell, M. N., \& Collins, A. R. (2012). What do riparian landowners know and want? Survey results from the headwaters of the Potomac River. Environment and Natural Resources Research, 2(1), 10. doi:10.5539/enrr.v2n1p10.

Molnar, J. J., Bitto, A., \& Brant, G. (May 2001). Core conservation practices: Adoption barriers perceived by small and limited resource farmers. Alabama Agricultural Experiment Station, Auburn University, Bulletin 646.

Morris, J., Mills, J., \& Crawford I. M. (2000). Promoting farmer uptake of agri-environment schemes: The countryside stewardship arable options scheme. Land Use Policy, 17(3), 241-254.

Napier, T. L., Thraen, C. S., \& McClaskie, S. L. (1988). Adoption of soil conservation practices by farmers in erosion-prone areas of Ohio: The application of logit modeling. Society \& Natural Resources, 1(1), 109-129.

Petrzelka, P., \& Armstrong, A. (2015). Absentee landowners of agricultural land: Influences upon land management decision making and information usage. Journal of Soil and Water Conservation, 70(5), 303-312. 
Petrzelka, P., Filipiak, J., Roesch-McNally, G., \& Barnett, M. J. (2020). Understanding and activating non-operator landowners. Retrieved from https://www.farmlandinfo.org/wpcontent/uploads/sites/2/2020/09/AFT-NOLs-MultiState_9_20b-web.pdf.

Ranjan, P., Wardropper, C. B., Eanes, F. R., Reddy, S. M., Harden, S. C., Masuda, Y. J., \& Prokopy, L. S. (2019). Understanding barriers and opportunities for adoption of conservation practices on rented farmland in the US. Land Use Policy, 80, 214-223.

Rasmussen, B. (2014). Absentee landowning and exploitation in West Virginia, 1760-1920. University Press of Kentucky.

Rogers, E. M. (1958). Categorizing the adopters of agricultural practices. Rural Sociology, 23(4), 346-354.

Samanta, A., Eanes, F. R., Wickerham, B., Fales, M., Bulla, B. R., \& Prokopy, L. S. (2020). Communication, partnerships, and the role of social science: Conservation delivery in a brave new world. Society \& Natural Resources, 33(7), 914-926.

Sawadgo, W., Zhang, W., \& Plastina, A. (2021). What drives landowners' conservation decisions? Evidence from Iowa. Journal of Soil and Water Conservation, 76(3), 211-221.

Schaible, G. D., Mishra, A. K., Lambert, D. M., \& Panterov, G. (2015). Factors influencing environmental stewardship in U.S. agriculture: Conservation program participants vs. non-participants. Land Use Policy, (46), 125-141.

Sheikh, A. D., Rehman, T., \& Yates, C. M. (2003). Logit models for identifying the factors that influence the uptake of new 'no-tillage' technologies by farmers in the rice-wheat and the cotton-wheat farming systems of Pakistan's Punjab. Agricultural Systems, 75(1), 7995. 
Strager, J. (2017). Notes on Hampshire, Mineral parcel work 092117. unpublished, West Virginia University.

U.S. Department of Agriculture (2016). Limited resource farmer and rancher - socially disadvantaged farmer definition. Farm Bill 1990 and Farm Bill 2008, Retrieved from https://lrftool.sc.egov.usda.gov/SDFP_Definition.aspx

U.S. Department of Agriculture. USDA's Strike Force initiative invests \$23.5 billion in rural communities, expands to four new states. Retrieved from https:/www.usda.gov/media/press-releases/2016/01/15/usdas-strikeforce-initiativeinvests-235-billion-rural-communities

Wilson, R. S., Howard, G., \& Burnett E. A. (2014). Improving nutrient management practices in agriculture: The role of risk-based beliefs in understanding farmers' attitudes toward taking additional action, Water Resources Research, (50), 6735-6746, doi:10.1002/2013WR015200

Wooldridge, J. M. (2012). Introductory Econometrics: A Modern Approach. 5th edition, SouthWestern.

Zimmerman, B., Collins, A. \& Lacombe, D. (2016). Spatial distribution of applied NRCS conservation practices in West Virginia: Phase I. West Virginia University, Report submitted to the Natural Resource Conservation Service, Morgantown, WV. 


\section{CHAPTER 3: ESSAY 2 - ANALYSIS OF WEST VIRGINIA'S REGIONAL ECONOMIC DEVELOPMENT AGENCIES' UTILIZATION OF IMPACT STRATEGIES}

\subsection{Introduction/Theoretical Framework}

History records that West Virginia has endured economic challenges since well before its formation in 1865, particularly at the regional level (Fones-Wolf \& Lewis, 2004; Gebremariam et al., 2004). In recent times, the state's economic challenges intensified during the Great Recession, which began in December 2007 and continued to mid-2009 (Boettner, 2018). Many considered this economic era as the most severe recession since the Great Depression during the 1930s (Walden, 2012). West Virginia's economic upheavals during this period also included declining coal production and the loss of manufacturing jobs (Bowen et al., 2001). Overall, the state's regional economies experienced the impact of these declining sectors to differing degrees (Deskins, 2018; Gregg, 2018). Several additional factors have contributed to unbalanced regional economic recovery, including declines in employment, which increased out-migration and resulted in a state-wide population decrease of more than 72,000 between 2012 and 2020 (West Virginia Population 1900-2020 | MacroTrends). The limited education of the labor force and low job skill levels have also compelled regions to experience booms and busts. For example, mining counties have historically had "less economic diversity, lower education levels, and higher levels of inequality," while still experiencing periods of economic growth and decline (O’Leary, 2016, p. 15).

In the long run, the success or failure of economic growth often hinges on the implementation of economic development best practices, which includes the nurturing and allocation of capital resources, financial and human (Epstein, 2014; West Virginia Forward, 2017). Numerous studies have found that effective implementation of best practices can address 
regional lagging economies and increase employment opportunities (Blair, 2016; Epstein, 2014; National Research Council, 2013; Phillips, 2014). Regional Economic Development Councils face an array of shared and unique economic challenges and opportunities that require fluid strategies designed for the 21 st century.

The International Economic Development Council (IEDC) notes that no single definition for economic development can include every aspect of economic growth, and, just as there is no universal definition, there is no perfect "strategy, policy, or program for achieving successful economic development" (IEDC Economic Development Reference Guide, n.d., p. 3). The Council also acknowledges that each community has unique economic strengths, weaknesses, and challenges.

The World Bank has called for nations to strengthen their economies through diversification of their industries, which would "increase the number and quality of jobs in the face of a rapidly rising and youthful working population" (Fruman, 2017, para. 15). The theory behind economic diversification originates from Nobel Prize winner Harry Markowitz's work, "Portfolio Selection" (1952), which was first published in The Journal of Finance (Mangram, 2013). In "Portfolio Selection: Efficient Diversification" (1959), Markowitz further expounded his theory, which laid the foundation for MPT, the 'Modern Portfolio Theory' (Mangram, 2013). Simplified, MPT follows the adage which warns against putting all your eggs in one basket, while providing the theoretical addition of quantified degrees of diversification and a lack of diversification via statistical measures of covariance or correlation (Fabozzi et al., 2002; Mangram, 2013; Markowitz, 2010).

Regarding regional economic development, economists share the view that sustainability is "reflected in regional plans that seek to integrate environmental, economic and social factors 
to create urban and regional environments that enhance quality of life, meet environmental quality goals, and achieve economic growth and employment diversification" (Stimson \& Stough, 2008, p. 19). Sustainable economic development of investing in environmental, economic, and social issues is known as the triple bottom line or TBL, as coined in the 1990s by the British entrepreneur and author John Elkington (Hammer \& Pivo, 2017). Further, Hammer \& Pivo (2017) note the TBL approach, (sometimes referred to as the 3Ps: people, planet, profit), addresses the issue that "existing development patterns cannot proceed without jeopardizing the environmental systems necessary to sustain life and economies, and that significant disparity within and between generations is neither sustainable, ethical, nor in tune with development goals" (p. 1).

This study explores the interrelationship of environmental issues, social well-being, and economic growth by employing Sustainability Theory as the core concept, reflected within the MPT and TBL theories, in the analysis of West Virginia's Economic Development entities and the utilization of economic growth activities. Building on previous research, this study also examines the processes utilized by West Virginia's regional Economic Development Organizations (EDOs), such as the West Virginia Economic Development Authority and the West Virginia Economic Development Council, to foster economic growth. An important first step is to parse out what are the current economic development activities. Of added benefit is the exploration of the motivations behind the selection process to determine why EDOs select certain Economic Development activities for their regions and what are the outcomes they are predicting or seeking to achieve. An assessment of why alternative Economic Development undertakings were not pursued is also useful in determining what motivates EDO personnel during the planning process. 
Moreover, understanding the degree to which EDOs collaborate with leaders from public and private sectors, including government, nonprofits, philanthropic foundations, and educational institutions, provides insight into future trends that could produce or avert challenges to the regional economies (Ezzell et al., 2012; IEDC, 2011, 2017; National Research Council, 2013). The state of research indicates that EDOs have a wealth of tools available to enhance their decision-making processes, which benefits both residents and corporations through an integrated Community and Economic Development framework. Overall, strategically planned investments in capacity building, education for leadership and labor force, entrepreneurship, and infrastructure network expansion (broadband) are recognized as positive economic development strategies (Eades 2017). Further, infrastructure definitions include "interrelated systems, physical components and societal needs," such as roads, bridges, railways, tunnels, water/sewers systems, and electrical or telecommunication grids (Fulmer, 2009, p. 30)

Across the state, economic recovery has varied depending on regional economic growth activities and the local and regional EDOs' strengths and challenges. This research contributes to the understanding of West Virginia's economic position, the Economic Development agencies, and the activities utilized to produce sustainable increases in community well-being. Therefore, the purpose of this study is to describe the various EDO entities in West Virginia and to examine their relationships to one another, in addition to assessing the influences affecting adoption or non-adoption of economic development activities.

To assess the economic development practices, this research project survey instrument was adapted from previous surveys (Economic, 2001; ICMA, 2014; Miller \& Smith, 1983) to determine if the economic undertakings address the recognized benchmarks and metrics leading to Economic Development, defined as "activities that expand capacities to realize the potential of individuals, firms or communities who contribute to the advancement of society through the responsible production of goods and services" (Feldman et al., 2014, p. 18). 
In 1962, West Virginia was the first state to take legislative action to address its economic conditions by establishing public/government corporation for economic development (Lovett, 2014, The West Virginia Economic Development Authority Act, 1962). In the years following the Economic Development Authority Act, between 1962 and 2011, twenty-two additional states established economic development through formal participatory governance policies (Lovett, 2014). The purpose for the Economic Development Authority Act was "to provide for the formation of a public economic development authority to promote, assist, encourage and, in conjunction with such banking corporations or institutions, trust companies, savings banks, building and loan associations, insurance companies or related corporations, partnerships, foundations, nonprofit organizations or other institutions, to develop and advance the business prosperity and economic welfare of the State of West Virginia" (The West Virginia Economic Development Authority Act, 1962). Overall, the Act was designed to promote new businesses/industries and maintain economic stability. Since passing the Act, economic wellbeing across the state has varied dependent upon the economic growth activities of local and regional EDOs, as well as the areas' unique strengths and challenges (Bukenya et al., 2003; Lovett, 2014; Lyons, 2003).

Research on economic development has examined methods of accountability, aspects of growth, and sustainability. There have been relatively few studies on the interactive nature of West Virginia's local and regional agencies to attain and sustain economic growth. Addressing this gap in research contributes to the understanding of the EDOs' efforts to achieve a sustainable economic system. To that end, the target population for this study includes 70 
Economic Development entities, including Regional Planning and Development Councils (RP\&DCs), the West Virginia Development Office (WVDO) Business Retention and Expansion Managers of the West Virginia Department of Commerce, the Regional Economic Development Authorities (EDAs), an Expressway Authority, a Regional Recreation Authority, and a federally designated Empowerment Zone. Under the 1971 Regional Planning \& Development Act, the "West Virginia Code, Chapter 8, Article 25, mandated that West Virginia be divided into 11 regions to serve as 'development districts to more effectively utilize funding resources and maximize small communities' chances of attracting funds from federal, state, and local organizations to foster community and cooperation throughout the state" (Regional Planning \& Development Councils, n.d.).

Figure 3.1:Regional Planning \& Development Councils $\mid$ Metropolitan Planning Organizations

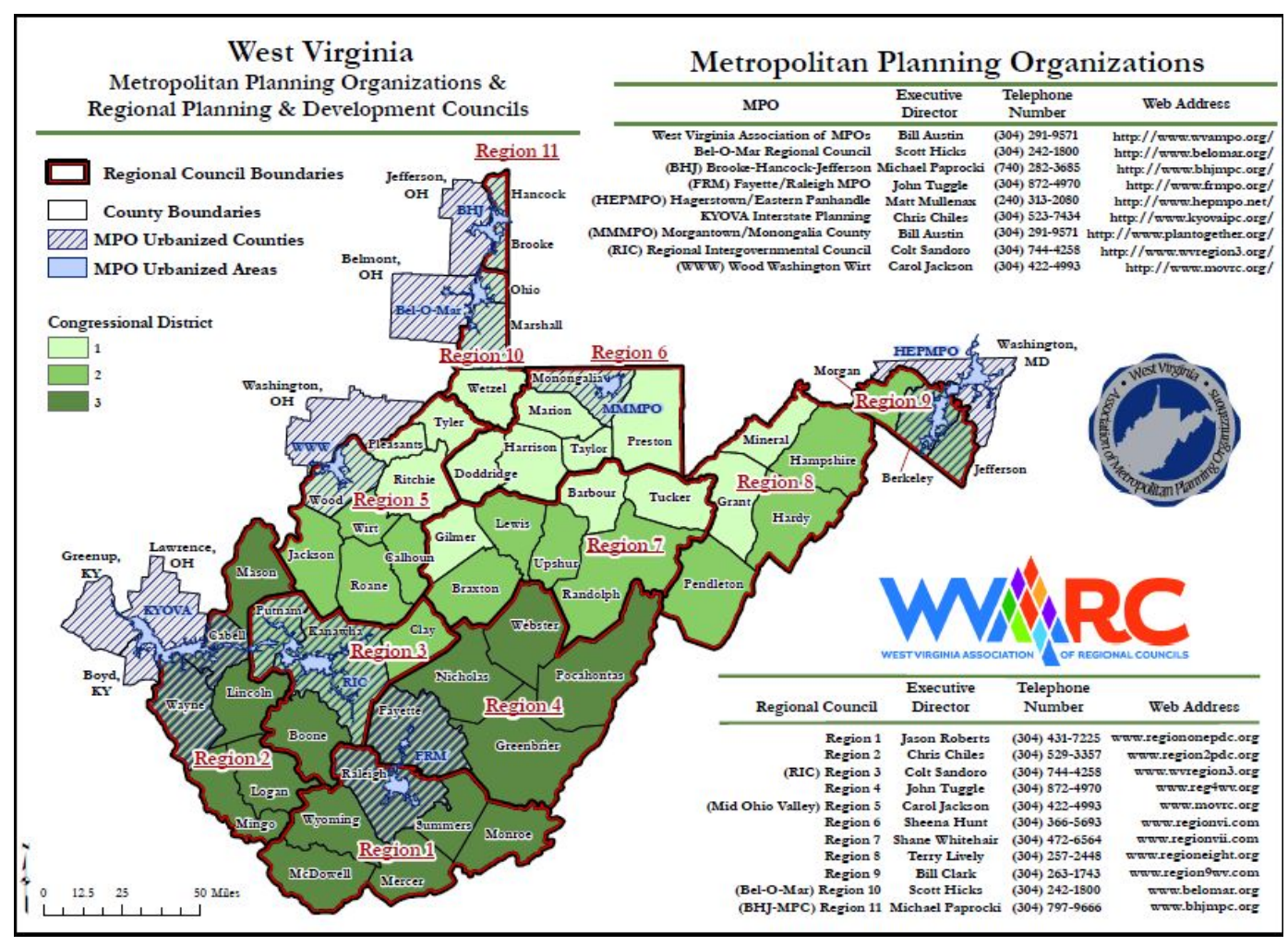

Note. From Region I Planning \& Development Council. Document Path: S: projects-one_time \regional councils lcouncils directors MPOs 072919_CE.mxd. Retrieved from https://www.wvregionalcouncils.org/. 
The U.S. Economic Administration refers to the RP\&DCs as Economic Development Districts, while the Appalachian Regional Commission (ARC) refers to these same regional councils as Local Development Districts. The RP\&DCs do not overlay the same mapped regions as the WVDO (see Figure 3.1). The counties served by WVDO's Region 2 are Berkeley, Grant, Hampshire, Hardy, Jefferson, Mineral, and Morgan, while the RP\&DC Region 2 represents Cabell, Lincoln, Logan, Mason, Mingo, and Wayne counties.

Figure 3.2: West Virginia Development Office, Regional Economic Development Authorities

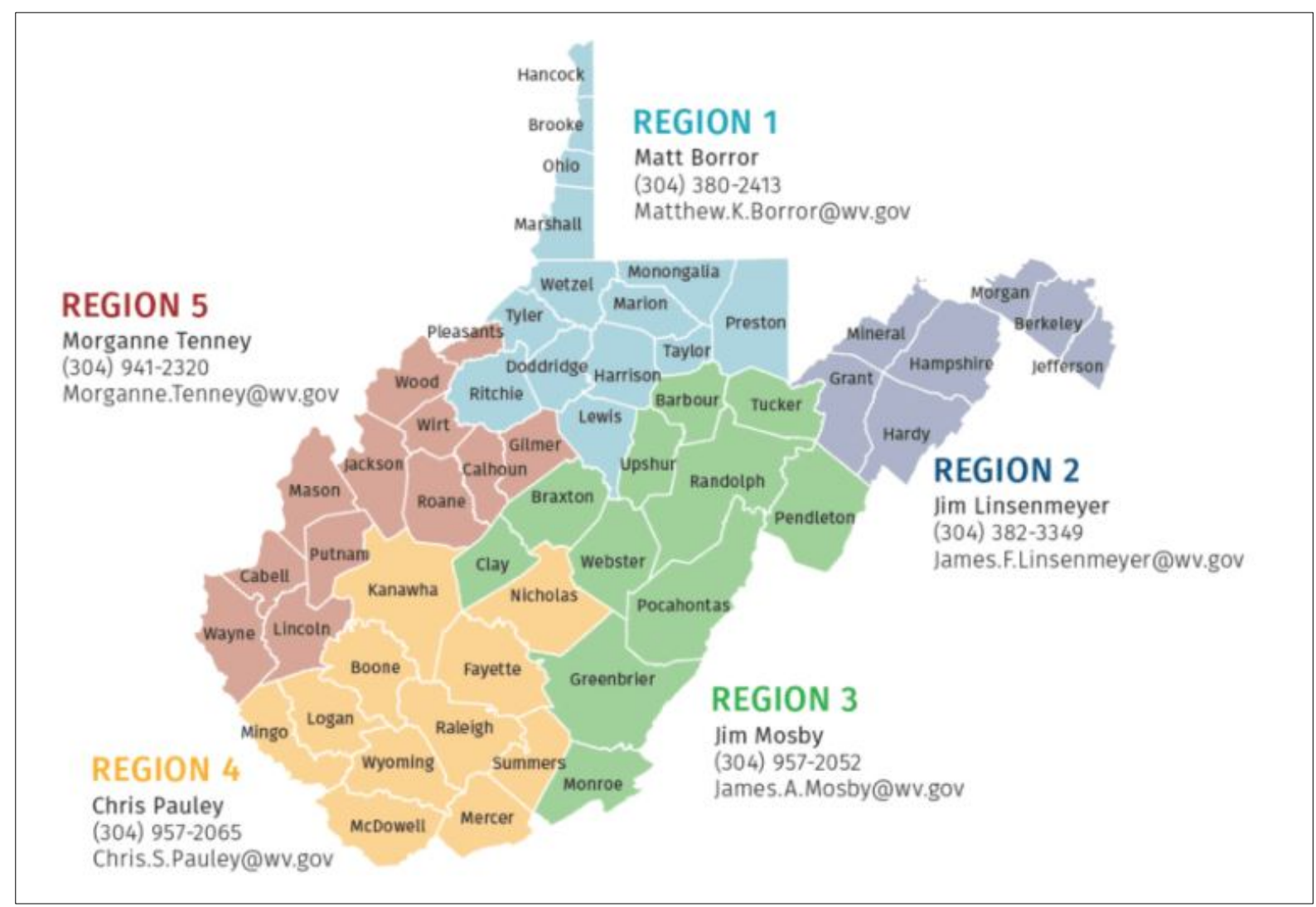

Note. From West Virginia Development Office. (n.d.). Retrieved from https://westvirginia.gov/connect-withus/local-edas/ 
By comparison, the WVDO has Business Retention and Expansion Managers which serve five regions (see Figure 3.2). The WVDO's managers work with regional and local economic development organizations to offer existing companies and new investors economic development supports such as loans and workforce training, as well as incentives including tax credits through the State Tax Department and Tax Increment Financing via the Tourism Development Act.

There are six main objectives in examining economic development practices in West Virginia: (1) Assess the EDOs' current economic development activities, (2) Determine why the current Economic Development activities were selected, (3) Determine if alternative Economic Development activities were considered, (4) Assess why the alternative Economic Development activities were not pursued, (5) Examine the relationship between West Virginia EDOs and other stakeholders in community development, such as the ARC, West Virginia Forward, and TechConnect and (6) Determine if Economic Development activities align with Sustainability Theories.

Further, based upon a review of literature and theory, the following hypothesis was evaluated regarding the relationship between economic development practices and professional Economic Development certifications.

$\mathrm{H}_{0}$ : There is no association between the range of economic development activities conducted by the EDOs and the number of professional certifications held by the agencies' staff, per capita income of the regions, or the locations (regions) of the population.

$\mathrm{H}_{1}$ : There is an association between the range of economic development activities conducted by the EDOs and the number of professional certifications held by the agencies' staff, per capita income of the regions, or the locations (regions) of the population. 
The remainder of this essay is structured as follows: the second section provides an overview of the relevant literature, the methods/procedures used in this study are explained in section three, and the results are presented and discussed in section four. Finally, the conclusion and limitations to the study, as well as recommendations for further research are outlined in section five.

\subsection{Literature Review}

As mentioned in the introduction, economic development is defined as "activities that expand capacities to realize the potential of individuals, firms or communities who contribute to the advancement of society through the responsible production of goods and services" (Feldman et al., 2014, p. 18). Building on this definition, previous studies have noted difficulties in defining and measuring best practices, which prove particularly impactful when economic growth activities are utilized in conjunction with community development (Pittman et al., 2009; Shaffer et al., 2006).

Historically, economic development research has focused on measurable outcomes, such as number of jobs, income level increases, and improvements in corporate/business revenue lines, while community development outcomes were more subjective and individually assessed, including equal access to resources, policy changes that improve quality of life, and institutional and organizational sustainability (Shaffer et al., 2006). These converging economic drivers result in challenges to assessing measurable improvements as economic development professionals move to integrate financial stimulus activities and quality of life policies.

More recent studies have examined what generally influences regional economic development entities and the processes undertaken in determining current practices (IEDC, 2011, 
2017; National Research Council, 2013). These studies offer EDOs a path to aligning a system of best practices, with regards to an interwoven view of community and economic development activities designed to address the distinctive challenges and strengths inherent to achieving each community’s increased well-being (Ezzell et al., 2012; IEDC, 2011, 2017; National Research Council, 2013).

Further, prior studies note economic development variables can be based on categories (Reese, 1997) regarding "ecological (pertaining to the local environment) or individual (related to the economic development professional)" (p. 291), which allow for an examination of the economic activities to indicate the scope of effectiveness with regards to the sustainability theory. Previous research has also focused on the relationship between social equity and economic development strategies used by local governments, examining the impact of activities based on business incentives or community economic development policies (Zhang et al., 2017). The researchers found that "municipalities that pay more attention to environmental sustainability and social equity use higher levels of community economic development tools and lower levels of business incentives” (Zang et al., 2017, p. 196). Moreover, Zang et al. (2017) note that social equity based economic development programs are "more likely to have written economic development plans and involve more participants in the economic development process" (p. 196). Inversely, the researchers found that "communities that use higher levels of business incentives have lower income and are more dependent on manufacturing employment" (p. 196). When considering economic development measures, Zang et al. (2017) found that alternative capacity measures did not have an impact on the range of economic development strategies utilized. 
To examine the varying capacity measures used by previous researchers, Reese (1997) notes that professional development has been used as a variable, asserting that "the level and extent of professionalism of the economic development enterprise can affect policies, programs, and even the way in which decisions are made" (p. 293). Going further, Reese (1997) states that “it can be hypothesized that increased and more recent education or training should produce greater familiarity with current evaluation and planning techniques and therefore an increase in their use" (p. 293). Following similar studies, this research uses the variables discussed previously regarding economic activities that involve "ecological (pertaining to the local environment) or individual (related to the economic development professional)" themes to determine if West Virginia economic development activities align with sustainability theories (Reese, 1997, p. 291).

\subsection{Methods/Procedures}

\section{Research Design/Instrument Development}

\section{Accessible Population}

The target population for this study included an Expressway Authority, a Regional Recreation Authority, a federally designated Empowerment Zone, 11 Regional Planning and Development Councils (RP\&DCs) and 58 Regional Economic Development Authorities (EDAs), which partner with the WV Development Office, an agency of the WV Department of Commerce. The combined number of regional and local EDOs included in this study was 68, since four Economic Development Authorities share directors, with the contact master list being 
generated from the West Virginia Development Office, in addition to online economic development contact sources. A coding system with the unique ID numbers was used in the online survey to maintain the survey results remained confidential.

\section{Instrumentation}

A descriptive research design was used for this study, which provides a means of summarizing the attitudes and characteristics of the individuals working for EDOs (Ary et al., 2010). The survey instrument was adapted from previous Economic Development Metrics surveys (see Appendix D). Information was gathered from this survey and used to measure the selection process of growth activities. Questions to be answered on a Likert scale, as well as closed- and open-ended questions, were used to assess the EDOs' perspectives and processes in selecting or not selecting economic growth activities. For the Likert-type statement, participants were asked to choose if they: strongly agree, agree, neither agree nor disagree, disagree, or strongly disagree, with an economic development activity statement, as well as a secondary question regarding the effectiveness of the activity, choosing from: not at all, low, medium, high, and not used.

Boone \& Boone (2012) indicate that Likert-type data are ordinal, resulting in a ranking, and not expressed in greater than or less than terms and analyzed using "appropriate for ordinal scale items include the chi-square measure of association, Kendall Tau B, and Kendall Tau C" (p. 4). When the Likert-type statements are converted into Likert scale composite score by calculating the sum or means, data should be analyzed at the interval measurement scale using Pearson's r, t-test, ANOVA, or regression procedures (2012). 
For this study, the Likert-type items provided ordinal data and were analyzed with descriptive and inferential statistics to assess mode or median for central tendency and frequencies for variability. In addition, the composite score of the Likert scale data were analyzed at the interval measurement scale using t-test and Pearson's (r) (see Figure 3.3). The Pearson (r) coefficient values, between +1 and -1 , measures the strength and direction of the quantitative relationships of two continuous variables, with the coefficient of +1 being a complete positive linear correlation and 0 having no linear correlation, while value -1 indicates a completely negative linear correlation (Septianingrum et al., 2020).

Figure 3.3: Pearson's (r)

$$
r=\frac{\sum x y-\frac{\left(\sum x\right)\left(\sum y\right)}{n}}{\sqrt{\left(\sum x^{2}-\frac{\left(\sum x\right)^{2}}{n}\right)\left(\sum y^{2}-\frac{\left(\sum y\right)^{2}}{n}\right)}}
$$

Note. From Economic inequality and its impact on human development: insight of Banten Province 2011-2015, by Septianingrum, R. S., Aditya, B., Wijaya, A. P., Irshabdillah, M. R., Husna, N. A., \& Putri, R. F. (2020, p. 5). In IOP Conference Series: Earth and Environmental Science (Vol. 451, No. 1, p. 012107), IOP Publishing.

The demographics section provides information about the population, including the years of expertise, number of full-time staff, and the professional certification levels of the employees serving in West Virginia's Economic Development entities. Additional data include an index of current economic development activities and related barriers to economic growth practices. Further, the instrument was submitted to West Virginia University's Institutional Review Board (IRB) for approval and the IRB has acknowledged this study (submitted 9/03/2019, exemption granted 9/12/2019). Initially using Qualtrics, followed by mailed questionnaires, the survey allowed the researcher to analysis attitudes toward Economic Development measures (Melkers \& 
Willoughby, 2005), as defined by the International Economic Development Council (IEDC, n.d.); the International City/County Management Association (2014); the Oregon Economic and Community Development Department (2001); and the ARC (Feser et al., 2014).

\section{Validity and Reliability}

Establishing validity of the instrument is essential to ensure the instrument and the results are accurate; to establish validity, the instrument must measure what it is supposed to measure (Ary et al., 2010). For this study, face and content validity were established by presenting the instrument to a panel of Economic Development experts, including West Virginia University faculty in Extension and Agricultural and Extension Education. The instrument cannot be valid without being reliable, which is the "degree of consistency with which it measures whatever it is measuring" (Ary et al., 2010, p. 236). To ensure reliability, a pilot test was conducted with EDOs in regions bordering West Virginia. The pilot test was emailed, with an anonymous link to the online survey. Phone call reminders were conducted, followed by emails with attached questionnaires and unique links to the duplicate online survey. Corrections implemented because of the pilot test included not using a secondary source for shortened URLs during the primary survey, which Qualtrics registers as responses.

Reliability was also established using data from the final survey via a Cronbach's alpha calculation. The reliability of survey section regarding Effectiveness of Economic Tools was found to be exemplary at 0.893, and the section addressing Agreement with Agency's Engagement in Economic Activities and Standards was found to be extensive at 0.723 (Robinson et al., 1991). The sample error was avoided by using a census of the population. The frame error (Ary et al., 2010), which involves developing a complete list of the intended population and 
surveying only the target population, was avoided by using the WV Department of Commerce official list, combined with additional reliable resources. A selection error was avoided by checking the final list for duplications. Measurement error was minimized by ensuring the instrument was valid and reliable.

\section{Data Collection}

Following the pilot test, pre-notification phone calls were made in advance of the primary survey to encourage participation and to verify email addresses and current contact information. The questionnaire link was emailed to 68 individuals (four Economic Development Authorities share directors, which reduced the number of questionnaires sent to 68).

Subsequently, an emailed duplicate questionnaire was sent as an attachment, with a link included in the email text. The survey was also sent via traditional mail. During the survey collection period, 10 contacts were conducted (see Table 3.1). Research indicates that surveys sent by email provide an efficient means of contacting the target population, although traditionally mailed surveys have garnered increased response rates (Ary et al., 2010). Based on Dillman's principles (Dillman et al., 1998; Dillman, 2000), the instrument design was concise and easy to complete. Because the response rate for internet surveys is less than mail surveys (Ary et al., 2010; Dillman \& Bowker, 2001), the online version was offered first and a mail survey was sent as a follow-up to increase the response rate, as noted previously. For the pilot test and the primary survey, a personalized cover letter (see Appendix E) was sent as an attachment and included a unique code for access to the online survey, followed by a mailed traditional postcard reminder, with link included (see Appendix F). The overall response rate for the primary survey was $78 \%$, with previous research indicting expected rates range from $40 \%$ to $75 \%$ for mailed questionnaires (Ary et al., 2010) and 62\% for push-to-web surveys (Dillman, 2011; McMaster et al., 2017; Millar \& Dillman, 2011). 
Table 3.1: Survey Timeline

\begin{tabular}{|c|c|c|}
\hline Date & Activity & Email Subject Headings \\
\hline September 26, 2019 & Emailed Pilot survey link & $\begin{array}{l}\text { WVU Economic } \\
\text { Development Research }\end{array}$ \\
\hline October 1, 2019 & $\begin{array}{l}\text { Pilot survey email reminder, } \\
\text { with survey attached }\end{array}$ & $\begin{array}{l}\text { WVU Economic } \\
\text { Development Research }\end{array}$ \\
\hline October 10, 2019 & Emailed WV EDOs survey link & $\begin{array}{l}\text { WVU Economic } \\
\text { Development Research }\end{array}$ \\
\hline October 15, 2019 & Email reminder with survey link & $\begin{array}{l}\text { WVU Economic } \\
\text { Development Research }\end{array}$ \\
\hline October 22, 2019 & $\begin{array}{l}\text { Second email reminder, with } \\
\text { link and attached survey }\end{array}$ & $\begin{array}{l}\text { Re: Update- WVU Economic } \\
\text { Development Research }\end{array}$ \\
\hline October 23, 2019 & $\begin{array}{l}\text { Mailed survey with return } \\
\text { envelopes to remaining non- } \\
\text { respondents }\end{array}$ & \\
\hline October 29, 2019 & Email reminder with survey link & $\begin{array}{l}\text { WVU Economic } \\
\text { Development Research }\end{array}$ \\
\hline October 30, 2019 & $\begin{array}{l}\text { Mailed traditional postcard } \\
\text { reminder, with link included }\end{array}$ & \\
\hline November 4, 2019 & Phone call reminders & \\
\hline $\begin{array}{l}\text { November 6-7, } \\
2019\end{array}$ & $\begin{array}{l}\text { Emailed reminder with link and } \\
\text { survey, combined with phone } \\
\text { reminders }\end{array}$ & $\begin{array}{l}\text { Re: Missing Data from } 33 \% \\
\text { of West Virginia's counties; } \\
\text { WVU Economic } \\
\text { Development Research }\end{array}$ \\
\hline November 19, 2019 & $\begin{array}{l}\text { Email final request, with survey } \\
\text { attached }\end{array}$ & $\begin{array}{l}\text { Re: Survey Closing on } \\
\text { 11/22/19; WVU Economic } \\
\text { Development Research }\end{array}$ \\
\hline
\end{tabular}




\section{Objective 1: Assess WV EDOs' Current Economic Development Activities}

The data were obtained using a series of multiple response closed ended questions regarding (Q3) Current Economic Development activities, with binary coding for the activities: Selected $=1$ and Not Selected $=0$.

\section{Objective 2: Determine why the Current Economic Development Activities were Selected}

The data were obtained using a multiple response closed ended question (Q4. Why were the current Economic Development activities identified in Q3 selected by your EDO?), with 11 possible responses, as well as a text response option, as indicated by selection other. Coded as binary: Selected $=1$ and Not Selected $=0$.

\section{Objective 3: Determine if Alternative Economic Development Activities were Considered}

The data were obtained via an open-ended question (Q6. Please explain any other Economic Development activities which were considered, and why they were not pursued.), with space available for text response.

\section{Objective 4: Assess why the Alternative Economic Development Activities were not Pursued}

The data were obtained using a multiple response question (Q7. What do you consider to be barriers to planning and implementing Economic Development activities?), with two possible responses: Barrier or Not a Barrier. Responses were treated as two separate variables and coded as binary: Selected $=1$ and Not Selected $=0$. A text response was also available, as indicated by selection: other, please explain. In addition, a series of Likert-type items were used to determine 
the respondents' attitude toward the (Q5) effectiveness levels of economic development tools, selecting from the scale: not used $=1 ;$ not at all $=2 ;$ low $=3$; medium $=4$; and high $=5$.

\section{Objective 5: Examine the relationship between West Virginia EDOs and Other Community Development Stakeholders.}

The data were obtained using Likert-type items to determine the respondents attitude toward their respective (Q12) agency's engagement in economic activities and standards. The question had six items with the codes ranging from 1 (strongly disagree) to 5 (strongly agree). The final item was written in reverse rating order and inverted during coding to ensure scaling remained consistent. Additional data were obtained via an open-ended question (Q2. Are your region's economic growth activities influenced by other agencies' economic development plans or strategic plans?) and coded as binary: No $=1$ and $\mathrm{Yes}=2$, with text response requested, please identify the other agencies.

\section{Objective 6: Determine if Economic Development Activities align with Sustainability Theories.}

The data were obtained by requesting the number of professional certifications held by staff members and asking the respondents to identify their respective certifications from a list of seven choices (Q10), including Community Development Council, International Economic Development Council, Neighborhood Reinvestment Corporation, National Development Council, a University-based Economic Development certification, no professional certifications and other. Further, testing the hypothesis of association, using Pearson's (r), was calculated using the variables: TotalEDActivities, TotalNumberCertifications, PerCapita, and Regions. 


\section{Early and Late Responders}

Respondents were divided into two groups based on the dates of their responses. Those who responded before the first deadline were considered early respondents, while those who responded after the deadline were defined as late respondents. The late respondents are similar to non-respondents (Miller \& Smith, 1983). The analysis for early and late respondents was conducted to provide an estimate of non-response error, with early respondents being defined as those individuals who completed/returned the questionnaire by the initial deadline.

For small-sized samples, such as in this study, Fisher's exact test runs an exact procedure, instead of the approximated chi-squared test which assumes a large sample (Kim, 2017). Therefore, a Fisher's statistical procedure was used to compare early and late responders on the survey question, (Q1. Which of the following statements best describes who has responsibility for economic development in your agency's designated area?). There was no significant difference between the two groups of respondents. In addition, a t-test was used to compare early and late respondents by the years of experience of the agency's Executive Director, as well as to Likert scale questions regarding the effectiveness of Economic Development strategies and the agency's relationships with other stakeholders. No statistically significant differences were found between the responses of early and late respondents, so the findings were generalized to the entire population in the study (Miller \& Smith, 1983).

\section{Data Analysis}

Data were analyzed utilizing SPSS 27.0 for Windows. The level of significance was set a priori at $\alpha<.05$ for all statistical tests. Descriptive statistical analyses appropriate for the respective scales of measurement were performed on the data including measures of central 
tendency (mean, median, and mode) and variability (frequencies or standard deviation). The results are represented as frequencies and percentages as well as means, median and mode in both table and narrative form.

\section{Use of Findings}

The results of this study can be shared with West Virginia's RP\&DCs, EDOs, and policymakers to provide perceptions and views of the local and regional economic development processes and the relative impact of professional development. Establishing a baseline of views on these aspects of the economic development methods provides insight for many, including legislatures, community organizations, funders, and investors, as well as better equipping profit and non-profit organizations to work with their community's economic development organization.

\subsection{Findings/Results}

As a means of examining the interrelations of the state's economic development organizations, the respondents $(n=53)$ were asked to describe the entity which has primary responsibility for economic development in their designated territories, given the options of selecting from (1) local government, (2) a nonprofit development corporation, (3) public-private partnerships, or (4) other, please explain. Twenty-five (48\%) respondents indicated the primary responsibility for economic development was conducted by the local government, 18 (34\%) respondents indicated nonprofit development corporations, and five (9\%) respondents reported public-private partnerships (see Table 3.2). In addition, five (9\%) respondents selected other, noting economic development was conducted through " a collaborative effort of state and local 
resources," as well as Economic Development Authority Boards, appointed by the County Commission. For example, one respondent explained that the County Redevelopment Authority has the primary responsibility, but it is a component unit of the County Commission.

For self-reported employment status, the respondents $(n=49)$ indicated $28(57 \%)$ served as development officers, 17 (35\%) were executive directors, two (4\%) were support staff, one $(2 \%)$ was a manager, one $(2 \%)$ a development director, and one $(2 \%)$ a planning director (see Table 3.2). Respondents $(n=51)$ were also asked to indicate the agency's staffing levels, which range from no full-time employees to 30 full-time employees $(\mathrm{M}=3.43, \mathrm{SD}=5.25)$. The majority, 18 (35\%) respondents had 2-3 full-time staff, and 15 (29\%) respondents had one fulltime employee. Additionally, six (12\%) respondents indicated no full-time staff, five (10\%) respondents had 4-5 staff members, four (8\%) respondents had 6-14 employees, and three (6\%) respondents had 15 or more staff members (see Table 3.2).

In addition, the respondents $(\mathrm{n}=50)$ were asked how many years of economic development experience their respective agency director had acquired. Of the 50 agencies reporting, two (4\%) respondents indicated their directors with less than one year of experience. Twelve (24\%) agencies had directors with 1-5 years of experience, followed by an additional 12 (24\%) agencies that indicated 6-10 years of experience. Thirteen (26\%) agencies had directors with 11-20 years of experience. Seven (14\%) agencies had directors with 21-30 years of experience and four (8\%) agencies had directors with 31-45 years of experience (see Table 3.2). 
Table 3.2: Background of Economic Development Agencies

\begin{tabular}{|c|c|c|c|c|c|c|c|c|c|c|c|}
\hline \multicolumn{3}{|c|}{$\begin{array}{l}\text { Entity which has } \\
\text { responsibility for } \\
\text { responding EDO } \\
\quad(\mathrm{n}=53)\end{array}$} & \multicolumn{3}{|c|}{$\begin{array}{l}\text { Employment Status } \\
\qquad(\mathrm{n}=49)\end{array}$} & \multicolumn{3}{|c|}{$\begin{array}{l}\text { Staffing Capacity } \\
\qquad(\mathrm{n}=51)\end{array}$} & \multicolumn{3}{|c|}{$\begin{array}{l}\text { Current Executive } \\
\text { Directors' Years of } \\
\text { Experience in } \\
\text { Economic } \\
\text { Development } \\
(\mathrm{n}=50)\end{array}$} \\
\hline Type & $\mathrm{N}$ & $(\%)$ & Title & $\mathrm{N}$ & $(\%)$ & $\begin{array}{l}\# \text { of } \\
\text { FTEs }\end{array}$ & $\mathrm{N}$ & $(\%)$ & $\begin{array}{l}\text { Length of } \\
\text { Time }\end{array}$ & $\mathrm{N}$ & $(\%)$ \\
\hline $\begin{array}{l}\text { Local } \\
\text { Gov. }\end{array}$ & 25 & (48) & $\begin{array}{l}\text { Dev. } \\
\text { Officer }\end{array}$ & 28 & $(57)$ & 0 FTE & 6 & (12) & $\begin{array}{l}\text { Less than } \\
1 \text { year }\end{array}$ & 2 & (4) \\
\hline $\begin{array}{l}\text { Non- } \\
\text { profit }\end{array}$ & 18 & (34) & $\begin{array}{l}\text { Exe. } \\
\text { Dir. }\end{array}$ & 17 & $(35)$ & $1 \mathrm{FTE}$ & 15 & (29) & $1-5$ years & 12 & (24) \\
\hline $\begin{array}{l}\text { Public- } \\
\text { Private } \\
\text { Partner }\end{array}$ & 5 & (9) & $\begin{array}{l}\text { Support } \\
\text { Staff }\end{array}$ & & (4) & $\begin{array}{c}2-3 \\
\text { FTEs }\end{array}$ & 18 & (35) & $6-10$ years & 12 & (24) \\
\hline \multirow[t]{3}{*}{ Other } & 5 & (9) & Mgr. & & (2) & $\begin{array}{l}4-5 \\
\text { FTEs }\end{array}$ & 5 & (10) & $\begin{array}{l}11-20 \\
\text { years }\end{array}$ & 13 & (26) \\
\hline & & & $\begin{array}{l}\text { Plan. } \\
\text { Dir. }\end{array}$ & & (2) & $\begin{array}{l}\text { 6-14 } \\
\text { FTEs }\end{array}$ & 4 & (8) & $\begin{array}{l}21-30 \\
\text { years }\end{array}$ & 7 & (14) \\
\hline & & & & & & $\begin{array}{c}15+ \\
\text { FTEs }\end{array}$ & 3 & (6) & $\begin{array}{l}31-45 \\
\text { years }\end{array}$ & 4 & (8) \\
\hline
\end{tabular}

Note. Percentages are computed within columns.

The demographics the respondents chose to complete included education levels, which ranged from high school or equivalency to master's degrees, with one (2\%) obtaining a high school degree, four ( $8 \%)$ with some college, one (2\%) completing technical school, seven (14\%) with associate degrees, $16(33 \%)$ respondents with bachelor degrees, $19(39 \%)$ with master degrees, and one (2\%) selecting other (see Table 3.3). Regarding the age range of the respondents $(\mathrm{n}=52)$, four $(8 \%)$ respondents were 26-35 years old, $10(19 \%)$ respondents were 36-45 years old, 10 (19\%) respondents were $46-55$ years old, 19 (37\%) respondents, the majority, were 56-65 years old, and four (8\%) were more than 66 years old. Five (9\%) 
respondents indicated they preferred not to disclose their age (see Table 3.3). The respondents (n $=51)$ indicating the following with regards to gender: $19(37 \%)$ females and $28(55 \%)$ males, with four (8\%) respondents indicating they preferred not to disclose their gender (see Table 3.3).

Table 3.3: Demographics of Economic Development Respondents

\begin{tabular}{|c|c|c|c|c|c|c|c|c|}
\hline $\begin{array}{l}\text { Education } \\
(\mathrm{n}=49)\end{array}$ & $\mathrm{N}$ & $(\%)$ & $\begin{array}{c}\text { Age } \\
(\mathrm{n}=52)\end{array}$ & $\mathrm{N}$ & $(\%)$ & $\begin{array}{l}\text { Gender } \\
(\mathrm{n}=51)\end{array}$ & $\mathrm{N}$ & $(\%)$ \\
\hline $\begin{array}{l}\text { High School or } \\
\text { equivalent }\end{array}$ & 1 & (2) & 26 to 35 & 4 & (8) & Male & 28 & (55) \\
\hline $\begin{array}{l}\text { Some college } \\
\text { but no degree }\end{array}$ & 4 & $(8)$ & 36 to 45 & 10 & (19) & Female & 19 & (37) \\
\hline $\begin{array}{l}\text { Technical } \\
\text { school }\end{array}$ & 1 & (2) & 46 to 55 & 10 & (19) & $\begin{array}{c}\text { Prefer } \\
\text { not to } \\
\text { disclose }\end{array}$ & 4 & (8) \\
\hline $\begin{array}{l}\text { College Assoc. } \\
\text { degree ( } 2-y r .)\end{array}$ & 7 & (14) & 56 to 65 & 19 & (37) & & & \\
\hline $\begin{array}{l}\text { College } \\
\text { Bachelor's } \\
\text { degree }\end{array}$ & 16 & (33) & $66+$ & 4 & (8) & & & \\
\hline $\begin{array}{l}\text { Master's } \\
\text { degree }\end{array}$ & 19 & (39) & $\begin{array}{c}\text { Prefer } \\
\text { not to } \\
\text { disclose }\end{array}$ & 5 & (9) & & & \\
\hline Other & 1 & (2) & & & & & & \\
\hline
\end{tabular}

Note. Percentages are computed within columns.

\section{Objective 1: Assess WV EDOs' current economic development activities}

Of the respondents $(\mathrm{n}=53)$ replying to the multiple-selection question (check all that apply) regarding the current economic development activities, 44 (83\%) respondents, the majority, indicated their agencies engaged in Infrastructure Development activities and 43 (81\%) 
respondents selected Business Retention and Expansion activities (see Table 3.4). Also, 36 (68\%) respondents indicated Small Business Development, 34 (64\%) selected Encouraging Entrepreneurship and 34 (64\%) selected Economic Development Marketing as utilized activities, with 30 (57\%) choosing Real Estate Redevelopment/Site Selection.

Table 3.4: Current Economic Development Activities

\begin{tabular}{lcc}
\hline Activities $(\mathrm{n}=53)$ & $\mathrm{N}$ & $(\%)$ \\
\hline Infrastructure Development & 44 & $(83)$ \\
Business Retention and Expansion & 43 & $(81)$ \\
Small Business Development & 36 & $(68)$ \\
Encouraging Entrepreneurship & 34 & $(64)$ \\
Economic Development Marketing & 34 & $(64)$ \\
Real Estate Redevelopment/Site Selection & 30 & $(57)$ \\
Brownfields Redevelopment & 24 & $(45)$ \\
Downtown Development & 21 & $(40)$ \\
Quality of Life Initiatives & 21 & $(40)$ \\
Empowerment Zone/Enterprise Community Initiatives & 7 & $(13)$ \\
Neighborhood Economic Development & 7 & $(13)$ \\
\hline
\end{tabular}

Note. Percentages are computed within columns, with multiple selections available.

In addition, 24 (45\%) of respondents indicated Brownfields Redevelopment as their response, while 21 (40\%) chose Downtown Development and Quality of Life Initiatives. The minority $(13 \%)$ of selections were tied, with seven respondents indicating Empowerment Zone/Enterprise Community Initiatives and seven respondents selecting Neighborhood Economic Development (see Table 3.4). 


\section{Objective 2: Determine why the current Economic Development activities were selected}

Of the respondents $(\mathrm{n}=51)$ replying to the multiple-selection question (check all that apply) regarding why the current Economic Development activities were chosen, the majority, $30(59 \%)$ respondents, indicated concern about economic sustainability drove the decision to engage in the previously listed activities, and 27 (53\%) indicated a change in local economy influenced their activities selection, with 15 (29\%) noting a funding source motivated the activity (see Figure 3.4). Further, 13 (26\%) respondents selected other, noting the following barriers and initiatives: lack of infrastructure, legislative codes, a need for potable water and sanitary sewer service, working to fulfill strategic economic development plans, pursuing new initiatives that focused on neighborhood and downtown revitalization due to new funding and the prevalence of BAD (Brownfield, Abandoned, Dilapidated) buildings, and pursuing initiatives that fit community needs. Additionally, $11(22 \%)$ respondents indicated a change in economic development leadership drove the activity selection. Nine (18\%) respondents noted change in population drove the selection of activities, which tied with the acknowledgement that past activities were successful, but (they) tried new development tools, nonetheless. Equally, six $(12 \%)$ respondents selected income inequality and six (12\%) respondents selected increased competition. Rated as the least significant barrier to economic development, a change in political leadership was selected by four (8\%) respondents (see Table 3.5). Overall, concern about economic sustainability (59\%) was the most frequently cited reason for current economic activities. Rounding out the top three reasons were change in local economy at 53\% and funding source motivated the activity at $29 \%$ (see Figure 3.4 ). 
Table 3.5: Issues Driving the Selection of Current Economic Development Activities

\begin{tabular}{lcc} 
Activities $(\mathrm{n}=51)$ & $\mathrm{N}$ & $(\%)$ \\
\hline Concern about economic sustainability & 30 & $(59)$ \\
Change in local economy & 27 & $(53)$ \\
Funding source motivated the activity & 15 & $(29)$ \\
Past activities were not successful and trying new development tools & 12 & $(24)$ \\
Change in economic development leadership & 11 & $(22)$ \\
Past activities were successful, but tried new development tools & 9 & $(18)$ \\
Change in population & 9 & $(18)$ \\
Increased competition & 6 & $(12)$ \\
Income inequality & 6 & $(12)$ \\
Change in political leadership & 4 & $(8)$ \\
Other & 13 & $(26)$
\end{tabular}

Note. Percentages are computed within columns, with multiple selections available.

Figure 3.4: Issues Driving the Selection of Current Economic Development Initiatives

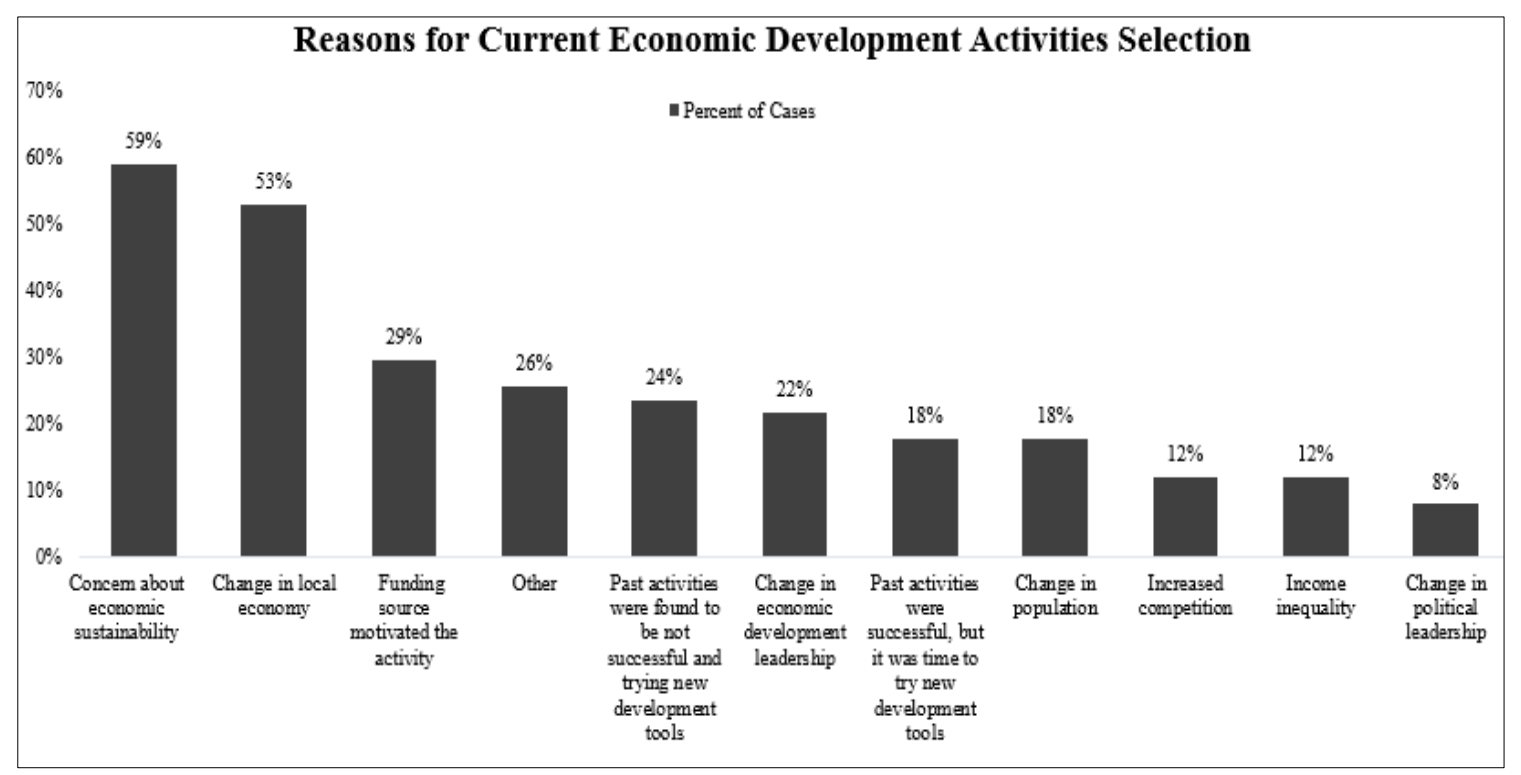




\section{Objective 3: Determine if alternative Economic Development activities were considered}

In a follow-up open ended question, the population was also asked to describe what other activities were considered and to explain why these activities were not pursued. The responses noted alternative activities included offering a Life Skills program, creating a business incubator, and establishing a USDA Intermediary Relending Program, which provides one percent lowinterest loans to improve economic conditions and create jobs in rural communities. Further, the respondents indicated that the alternative activities faced barriers such as staff shortages, capacity limitations, lack of funding, and the agency's leadership that was not interested.

\section{Objective 4: Assess why the alternative Economic Development activities were not pursued}

To examine barriers more fully, the respondents $(n=53)$ were asked to reply to the binary question (check either barrier or not a barrier) regarding issues that restrict growth activities (see Table 3.6). The majority, 49 (93\%) respondents, indicated inadequate infrastructure posed the most frequent barrier. Further, $46(87 \%)$ indicated a lack of skilled labor was the second most prevalent barrier. Additionally, 45 (85\%) indicated land and/or buildings availability/cost and 40 (76\%) respondents stated lack of capital/funding, while 38 (72\%) selected declining market due to population loss. Thirty-one (59\%) respondents indicated a limited number of major employers restricted growth. Further, 29 (55\%) respondents noted that capacity of local economic development organizations was a barrier. Twenty-three (43\%) noted inadequate public transit presented a barrier. In addition, $19(36 \%)$ respondents indicated growth restrictions involved permit process/regulations and 19 (36\%) also selected distance from major markets, followed by 17 (32\%) indicating citizen opposition presented a barrier. 
Sixteen (30\%) respondents found that quality of life barriers and $16(30 \%)$ respondents indicated lack of political support were barriers. Eight (15\%) respondents indicated the high cost of labor as a barrier to economic development activities. In addition, four (8\%) respondents selected other, noting barriers to economic development also included a lack of funding for education, with financial support being "cut at both state and local levels." Moreover, one respondent noted, "It is hard to compete with states that have access to more funds and programs."

Figure 3.5: Barriers to Planning and Implementing Economic Development Initiatives

\begin{tabular}{|c|c|}
\hline \multicolumn{2}{|c|}{$\begin{array}{l}\text { Barriers to Economic Development } \\
\qquad 0 \% 10 \% 20 \% 30 \% 40 \% 50 \% 60 \% 70 \% 80 \% 90 \% 100 \%\end{array}$} \\
\hline $\begin{array}{r}\text { Inadequate infrastructure } \\
\text { Lack of skilled labor } \\
\text { Land and/or buildings availability/cost } \\
\text { Lack of capital funding } \\
\text { Declining market due to population loss } \\
\text { Limited number of major employers } \\
\text { Capacity of local economic development organizations } \\
\text { Inadequate public transit } \\
\text { Distance from major markets } \\
\text { Permit process regulations } \\
\text { Citizen opposition } \\
\text { Quality of life barriers } \\
\text { Lack of political support } \\
\text { High cost of labor }\end{array}$ & 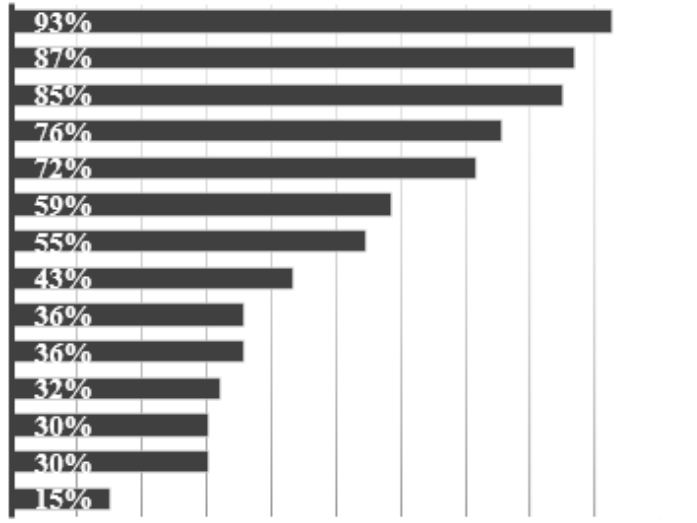 \\
\hline & - Percent of Cases \\
\hline
\end{tabular}

Further, the respondents indicated they faced a "lack of cooperation and partnerships with all economic development groups, agencies and offices," as well as "inadequate resources to adequately fund economic development marketing." As depicted in Figure 3.5, the top four barriers to economic development involve deficiencies in infrastructure, skilled labor, availability of land/buildings, and capital/funding support. Juxtaposed against these shortages 
are the four least significant barriers: citizen opposition, quality of life issues, lack of political support, and a high cost of labor. Creating economic growth with a limited number of major employers and/or facing reduced capacity levels for local EDOs are barriers for approximately half of the respondents, at 59\% and 55\%, respectively. Regarding this issue, a respondent noted, "the activities we undertake are directly related to problems and barriers identified that impede business creation and expansion."

Table 3.6: Barriers to Planning and Implementing Economic Development Activities

\begin{tabular}{lll}
\hline Responses (n=53) & $\mathrm{N}$ & $(\%)$ \\
\hline Inadequate infrastructure & 49 & $(93)$ \\
Lack of skilled labor & 46 & $(87)$ \\
Land and/or buildings availability/cost & 45 & $(85)$ \\
Lack of capital/funding & 40 & $(76)$ \\
Declining market due to population loss & 38 & $(72)$ \\
Limited number of major employers & 31 & $(59)$ \\
Capacity of local economic & 29 & $(55)$ \\
development organizations & 23 & $(43)$ \\
Inadequate public transit & 19 & $(36)$ \\
Distance from major markets & 19 & $(36)$ \\
Permit process/regulations & 17 & $(32)$ \\
Citizen opposition & 16 & $(30)$ \\
Quality of life barriers & 16 & $(30)$ \\
Lack of political support & 8 & $(15)$ \\
High cost of labor & 4 & $(8 \%)$ \\
Other
\end{tabular}

Note. Percentages are computed within columns. 
Respondents were also asked to rate the effectiveness levels of economic development tools, selecting from the scale: not used $=1 ;$ not at all $=2 ;$ low $=3 ;$ medium $=4$; and high $=5$ (see Table 3.7). Listing responses in order of most effective to least effective, Job training for low skilled workers $(\mathrm{n}=50)$ was selected the most effective, overall. Further, $20(40 \%)$ respondents selected job training as a highly effective economic development tool, with 16 (32\%) respondents selecting medium, and seven (14\%) respondents selecting low. No respondents $(0 \%)$ selected not effective and seven (14\%) respondents selected not used. In addition, a revolving loan fund $(\mathrm{n}=52)$ was considered to be a highly effective by $16(31 \%)$ respondents, with 10 (19\%) respondents selecting medium, seven (13\%) respondents selecting low, three (6\%) respondents selecting not effective, and 16 (31\%) respondents selecting not used, which is the same percentage that found the tool to be highly effective (see Table 3.7).

Additionally, marketing assistance $(\mathrm{n}=52)$ was also identified as highly effective by 16 (31\%) respondents, with $18(35 \%)$ respondents selecting medium, eight (15\%) respondents selecting low, one (2\%) respondent selecting not effective, and nine (17\%) respondents selecting not used. Operating a small business development center $(\mathrm{n}=51)$ was considered to be highly effective by $14(27 \%)$ respondents, with 19 (37\%) respondents selecting medium, 11 (22\%) respondents selecting low, two (4\%) respondents selecting not effective, and five (10\%) respondents selecting not used (see Table 3.7).

Further, matching improvement grants $(\mathrm{n}=52)$ were considered to be highly effective by $13(25 \%)$ respondents, with $21(40 \%)$ respondents selecting medium, four (8\%) respondents selecting low, two (4\%) respondents selecting not effective, and 12 (23\%) respondents selecting not used (see Table 3.7). Again, the highly effective percentage (25\%) was nearly the same as the agencies $(23 \%)$ that do not use this economic development tool. Developing business 
clusters and industrial districts $(\mathrm{n}=52)$ was considered to be highly effective by $11(21 \%)$ respondents, with 18 (35\%) respondents selecting medium, five (10\%) respondents selecting low, three (6\%) respondents selecting not effective, and $15(29 \%)$ respondents selecting not used (see Table 3.7).

This was followed by vendor/supplier matching $(\mathrm{n}=50)$, which was considered to be highly effective by nine (18\%) respondents, with eight (16\%) respondents selecting medium, 10 (20\%) respondents selecting low, three (6\%) respondents selecting not effective, and $20(40 \%)$ respondents selecting not used. Main street initiatives $(\mathrm{n}=51)$ were also considered to be highly effective by nine (18\%) respondents, with 14 (27\%) respondents selecting medium, nine (18\%) respondents selecting low, six respondents (12\%) selecting not effective, and 13 (25\%) respondents selecting not used. Technology zones $(\mathrm{n}=50)$ were also considered to be highly effective by seven (14\%) respondents, with 10 (20\%) respondents selecting medium, $10(20 \%)$ respondents selecting low, three (6\%) respondents selecting not effective, and $20(40 \%)$ respondents selecting not used. Management training $(\mathrm{n}=52)$ was considered to be highly effective by seven (13\%) respondents, with 19 (37\%) respondents selecting medium, nine (17\%) respondents selecting low, four (8\%) respondents selecting not effective, and 13 (25\%) respondents selecting not used. In addition, business improvement districts $(\mathrm{n}=52)$ were considered to be highly effective by seven (13\%) respondents, with nine (17\%) respondents selecting medium, 11 (21\%) respondents selecting low, five (10\%) respondents selecting not effective, and $20(38 \%)$ respondents selecting not used. Export development assistance $(\mathrm{n}=51)$ was considered to be highly effective by six (12\%) respondents, with $11(22 \%)$ respondents selecting medium, $10(20 \%)$ respondents selecting low, three (6\%) respondents selecting not effective, and 21 (41\%) respondents selecting not used (see Table 3.7). 
Table 3.7: Effectiveness levels of Economic Development tools

\begin{tabular}{|c|c|c|c|c|c|c|c|c|c|c|}
\hline $\begin{array}{l}\text { Economic } \\
\text { Development Tools }\end{array}$ & $\begin{array}{r}\text { Not } \\
\mathrm{N}\end{array}$ & $\begin{array}{l}\text { Used } \\
\%)\end{array}$ & Not 1 & $\begin{array}{l}\text { fffective } \\
(\%)\end{array}$ & & $\begin{array}{l}\mathrm{ow} \\
(\%)\end{array}$ & $\begin{array}{c}\mathrm{Med} \\
\mathrm{N}\end{array}$ & lum & & $\begin{array}{l}\text { ligh } \\
(\%)\end{array}$ \\
\hline $\begin{array}{l}\text { Job training for low } \\
\text { skilled workers }(n=50)\end{array}$ & 7 & (14) & 0 & $(0)$ & 7 & (14) & 16 & (32) & 20 & $(40)$ \\
\hline $\begin{array}{l}\text { Revolving loan fund } \\
(\mathrm{n}=52)\end{array}$ & 16 & (31) & 3 & (6) & 7 & (13) & 10 & (19) & 16 & (31) \\
\hline $\begin{array}{l}\text { Marketing assistance } \\
(\mathrm{n}=52)\end{array}$ & 9 & (17) & 1 & (2) & 8 & $(15)$ & 18 & (35) & 16 & (31) \\
\hline $\begin{array}{l}\text { Small business dev. } \\
\text { center }(\mathrm{n}=51)\end{array}$ & 5 & (10) & 2 & (4) & 11 & $(22)$ & 19 & (37) & 14 & (27) \\
\hline $\begin{array}{l}\text { Matching grants } \\
(\mathrm{n}=52)\end{array}$ & 12 & (23) & 2 & (4) & 4 & (8) & 21 & (40) & 13 & $(25)$ \\
\hline $\begin{array}{l}\text { Business clusters \& } \\
\text { industrial districts } \\
(\mathrm{n}=52)\end{array}$ & 15 & (29) & 3 & (6) & 5 & (10) & 18 & (35) & 11 & $(21)$ \\
\hline $\begin{array}{l}\text { Vendor/supplier } \\
\text { matching }(\mathrm{n}=50)\end{array}$ & 20 & $(40)$ & 3 & (6) & 10 & (20) & 8 & (16) & 9 & (18) \\
\hline Main street $(\mathrm{n}=51)$ & 13 & $(25)$ & 6 & (12) & 9 & (18) & 14 & (27) & 9 & (18) \\
\hline $\begin{array}{l}\text { Technology zones } \\
(\mathrm{n}=50)\end{array}$ & 20 & $(40)$ & 3 & (6) & 10 & (20) & 10 & (20) & 7 & (14) \\
\hline $\begin{array}{l}\text { Management training } \\
(\mathrm{n}=52)\end{array}$ & 13 & $(25)$ & 4 & (8) & 9 & (17) & 19 & (37) & 7 & (13) \\
\hline $\begin{array}{l}\text { Business improvement } \\
\text { districts }(\mathrm{n}=52)\end{array}$ & 20 & (38) & 5 & (10) & 11 & (21) & 9 & (17) & 7 & (13) \\
\hline $\begin{array}{l}\text { Export development } \\
\text { assistance }(\mathrm{n}=51)\end{array}$ & 21 & (41) & 3 & (6) & 10 & (20) & 11 & (22) & 6 & (12) \\
\hline $\begin{array}{l}\text { Energy efficiency } \\
\text { programs }(n=52)\end{array}$ & 17 & (33) & 3 & (6) & 16 & $(31)$ & 12 & (23) & 4 & (8) \\
\hline $\begin{array}{l}\text { Microenterprise } \\
(\mathrm{n}=51)\end{array}$ & 23 & (45) & 7 & (13) & 9 & (18) & 9 & (18) & 3 & (6) \\
\hline
\end{tabular}

Note. Percentages are computed across rows. 
Further, energy efficiency programs $(\mathrm{n}=52)$ were considered to be highly effective by four (8\%) respondents, with $12(23 \%)$ respondents selecting medium, 16 (31\%) respondents selecting low, three (6\%) respondents selecting not effective, and 17 (33\%) respondents selecting not used. Finally, microenterprise $(\mathrm{n}=51)$ was considered to be highly effective by three $(6 \%)$ respondents, with nine (18\%) respondents selecting medium, nine (18\%) respondents selecting low, seven (13\%) respondents selecting not effective, and 23 (45\%) respondents selecting not used (see Table 3.7).

Overall, the ranking order of economic tools not used by West Virginia EDOs, by percentage selected, include:

1. $45 \%$ Microenterprise $(\mathrm{n}=51)$

2. $41 \%$ Export development assistance $(n=51)$

3. $40 \%$ Vendor/supplier matching $(\mathrm{n}=50)$

4. $40 \%$ Technology zones $(\mathrm{n}=50)$

5. $38 \%$ Business improvement districts $(\mathrm{n}=52)$

6. $33 \%$ Energy efficiency programs $(n=52)$

7. $31 \%$ Revolving loan fund $(\mathrm{n}=52)$

8. $29 \%$ Business clusters \& industrial districts $(n=52)$

9. $25 \%$ Management training $(\mathrm{n}=52)$

10. $25 \%$ Main street initiatives $(n=51)$

11. $23 \%$ Matching improvement grants $(\mathrm{n}=52)$

12. $17 \%$ Marketing assistance $(\mathrm{n}=52)$

13. $14 \%$ Job training for low skilled workers $(\mathrm{n}=50)$

14. $10 \%$ Small business development centers $(n=51)$ 


\section{Objective 5: Examine the relationship between West Virginia EDOs and other stakeholders in community development, such as the ARC and West Virginia Forward.}

The population $(\mathrm{n}=52)$ was also asked if the respective agency's economic growth activities were influenced by other agencies' economic development plans or strategic plans, (check either yes or no), with a text response requested, please identify the other agencies. Thirty-one respondents (60\%) indicated their agencies did conduct economic development activities in collaboration with other agencies, while $21(40 \%)$ respondents indicated their respective agencies did not plan their economic growth activities in alignment with other agencies' development or strategic plans. In response to the influences question, (please identify the other agencies), 27 (52\%) respondents listed the following agencies and resources influenced their economic development plans: ARC, US Economic Development Administration, US \& WV Department of Housing and Urban Development, US \& WV Environmental Protection Agency, Governor's Office, WV Development Office, WV Broadband Enhancement Council, WV Regional Planning and Development Councils, WV Division of Highways, WV Hardwood Alliance Zone, Western Potomac Economic Partnership, Regional Economic Development Authorities, Planning Commissions, regional oil \& gas development projects, county comprehensive plans, city and municipal planning agencies, business development corporations, WVU Bureau of Business \& Economic Research Economic Outlook, and the West Virginia Forward report.

In addition, respondents $(n=53)$ were asked to rate their agreement with statements regarding their respective agency's engagement in economic activities and standards, selecting from the scale: strongly agree $=1$; agree $=2$; neither agree nor disagree $=3$; disagree $=4$; and strongly disagree $=5$ (see Table 3.8). Of the respondents $(\mathrm{n}=53)$, the majority, $23(43 \%)$, 
strongly agree that their respective agencies do link with agencies that can provide workforce development training, with an additional 21 (40\%) respondents selecting agree, seven (13\%) respondents selecting neither agree nor disagree, one (2\%) respondent selecting disagree, and one $(2 \%)$ respondent selecting strongly disagree. With regards to their agencies forming strong partnerships with academic institutions, the respondents $(\mathrm{n}=45)$ indicated the majority selected either strongly agree or agree, with $16(36 \%)$ respondents selecting the former and $16(36 \%)$ respondents selecting the latter. Further, 10 respondents (22\%) selected neither agree nor disagree, two (4\%) respondents selected disagree, and one (2\%) respondent selected strongly disagree (see Table 3.8).

Next, the respondents $(\mathrm{n}=53)$ indicated if their agencies do follow uniform guidelines and performance standards, with 13 (25\%) respondents selecting strongly agree, 19 (36\%) respondents selecting agree, 16 (30\%) respondents selecting neither agree nor disagree, four (7\%) respondents selecting disagree, and one respondent (2\%) selecting strongly disagree. Overall, the combined percentage rates of the positive selections of strongly agree or agree outweighed the combined neutral to negative selections of neither agree nor disagree, disagree, and strongly disagree, 61\% and 39\%, respectively (see Table 3.8).

Regarding the agencies' efforts to work closely with county Extension offices in project development, planning, and community development, the respondents $(n=53)$ were divided between the combined percentage rates of the positive selections of strongly agree or agree (49\%) and the combined neutral to negative selections of neither agree nor disagree, disagree, and strongly disagree (51\%). Further, 10 (19\%) respondents selected strongly agree, 16 (30\%) respondents selected agree, 16 (30\%) respondents selected neither agree nor disagree, eight 
(15\%) respondents selected disagree, and three (6\%) respondents selected strongly disagree (see Table 3.8).

Table 3.8: EDOs' Attitudes Toward Relationship Activities

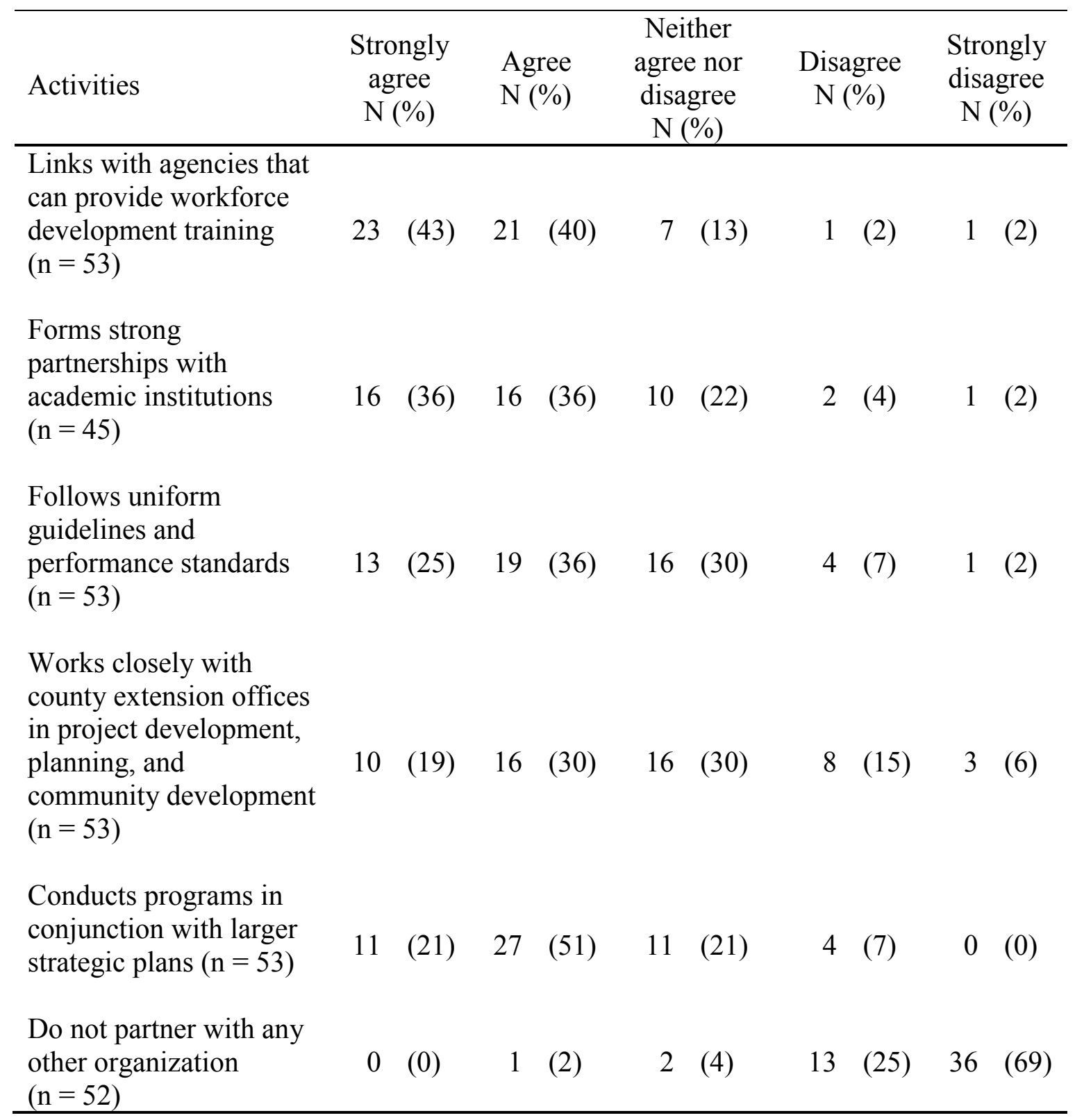

Note. Percentages are computed across rows. 
The population $(\mathrm{n}=53)$ was once again asked to confirm if their agencies were conducting programs in conjunction with larger strategic plans, using a different format than the open-ended question noted previously. Eleven (21\%) respondents selected strongly agree, 27 (51\%) respondents selected agree, 11 (21\%) respondents selected neither agree nor disagree, four $(7 \%)$ respondents selected disagree, and zero $(0 \%)$ respondents selected strongly disagree. Compared to the previous strategic plans open-ended question, the responses to the Likert-type questions resulted in differing percentages. The response rate increased by one individual between the initial open-ended question and the Likert-type question, $(\mathrm{n}=52)$ increased to $(\mathrm{n}=53)$, respectively. The percentages varied from the strategic plans open ended question with $31(60 \%)$ respondents indicating their agencies did conduct economic development activities in collaboration with other agencies to $38(72 \%)$ respondents selecting strongly agree or agree that their agencies conducted programs in conjunction with larger strategic plans. Overall, the Likert-type question resulted in a $12 \%$ increase in agencies that were conducting programs in conjunction with larger strategic plans. Relatedly, one respondent commented that an "initiative needs to take place to bring the groups and regions together and formulate a new strategy for job creation." Further, the shift from the open-ended strategic plans question to the Likert-type question moved the responses from 21 (40\%) respondents indicating their respective agencies did not plan their economic growth activities in alignment with other agencies' development or strategic plans, to 15 (28\%) respondents selecting neither agree nor disagree and disagree, with zero respondents $(0 \%)$ selecting strongly disagree.

Finally, for the Likert-type question, the respondents $(\mathrm{n}=52)$ were asked to confirm that their agencies did not partner with any other organization, with the question inversed during coding to ensure consistency. No ( $0 \%)$ respondents selected strongly agree, one (2\%) 
respondent selected agree, two (4\%) respondents selected neither agree nor disagree, 13 (25\%) respondents selected disagree, and 36 (69\%) respondents selected strongly disagree, resulting in $94 \%$ of the population indicating their agencies do partner with other organizations (see Table 3.8).

\section{Objective 6: Determine if Economic Development activities align with Sustainability Theories.}

A Pearson's (r) correlation was calculated to examine the relationships between the range of economic activities and the number of professional certifications held by the agencies' staff, per capita income of the regions, or the locations (regions) of the population. The correlation was not significant at the 0.05 level (2-tailed). The findings indicate there is not a significant linear correlation.

Hypotheses Decision: Fail to reject the null

$\mathrm{H}_{0}$ : There is no association between the range of economic development activities conducted by the EDOs and the number of professional certifications held by the agencies' staff, per capita income of the regions, or the locations (regions) of the population.

To produce the variable regarding professional certifications, as noted in the methods section, the population was asked to identify their respective professional certifications and the number of certifications (see Table 3.9). Of the respondents $(n=45), 59 \%$ indicated they did not have professional certifications, $30 \%$ indicated they did have professional certifications, and $11 \%$ selected other. The text response for other included one respondent who noted that 
educational training was difficult to complete because there was "limited time to pursue this due to only one staff member!"

Table 3.9: Economic Development Certifications held by WV EDO Staff

\begin{tabular}{|c|c|c|c|}
\hline $\begin{array}{l}\text { Certified Staff } \\
\text { Status }(n=45)\end{array}$ & $(\%)$ & Categories $(n=46)$ & $(\%)$ \\
\hline No & (59) & No professional certifications & $(50)$ \\
\hline Yes & $(30)$ & $\begin{array}{l}\text { Community Development Council: Professional } \\
\text { Community and Economic Developer (PCED) }\end{array}$ & $(15)$ \\
\hline \multirow[t]{5}{*}{ Other } & $(11)$ & $\begin{array}{l}\text { National Development Council: Economic } \\
\text { Development Finance Professional (EDFP) } \\
\text { Certification Program }^{\mathrm{TM}}\end{array}$ & (13) \\
\hline & & $\begin{array}{l}\text { International Economic Development Council } \\
\text { Certified Economic Developers (CEcD) }\end{array}$ & (9) \\
\hline & & $\begin{array}{l}\text { University-based Economic Development } \\
\text { Professional Certificate Program (e.g., Ohio } \\
\text { University, Penn State) }\end{array}$ & (9) \\
\hline & & $\begin{array}{l}\text { Neighborhood Reinvestment Corporation, dba } \\
\text { NeighborWorks }{ }^{\circledR} \text { America: Community Economic } \\
\text { Development Professional Certificate Program }\end{array}$ & $(0)$ \\
\hline & & Other & (4) \\
\hline
\end{tabular}

Note. Percentages are computed within columns.

Among the identified certifications $(n=46), 15 \%$ were certified as a Community Development Council: Professional Community and Economic Developer (PCED); 13\% were certified as a National Development Council: Economic Development Finance Professional (EDFP); 9\% were certified as International Economic Development Council Certified Economic Developers (CEcD); and 9\% held University-based Economic Development Professional Certifications, with one certified GIS Professional. No respondents selected the Neighborhood Reinvestment Corporation, dba NeighborWorks ${ }^{\circledR}$ America: Community Economic Development Professional Certificate Program and 4\% selected other. 
With regards to sustainable practices, respondents noted (see Figure 3.4) that concern for economic sustainability was the most significant reason for conducting their current economic development strategies. West Virginia EDOs selected economic development activities that do not reflect a focus on balancing the economy, addressing environmental issues, and/or providing an equitable quality of life, all of which research indicates will ensure sustainable development. For example, the top six activities selected by the population, infrastructure development, business retention and expansion, small business development, economic development marketing, encouraging entrepreneurship, and real estate site selection, are all examples of economic-based strategies (see Figure 3.6).

Figure 3.6: Range of Current Economic Development Activities

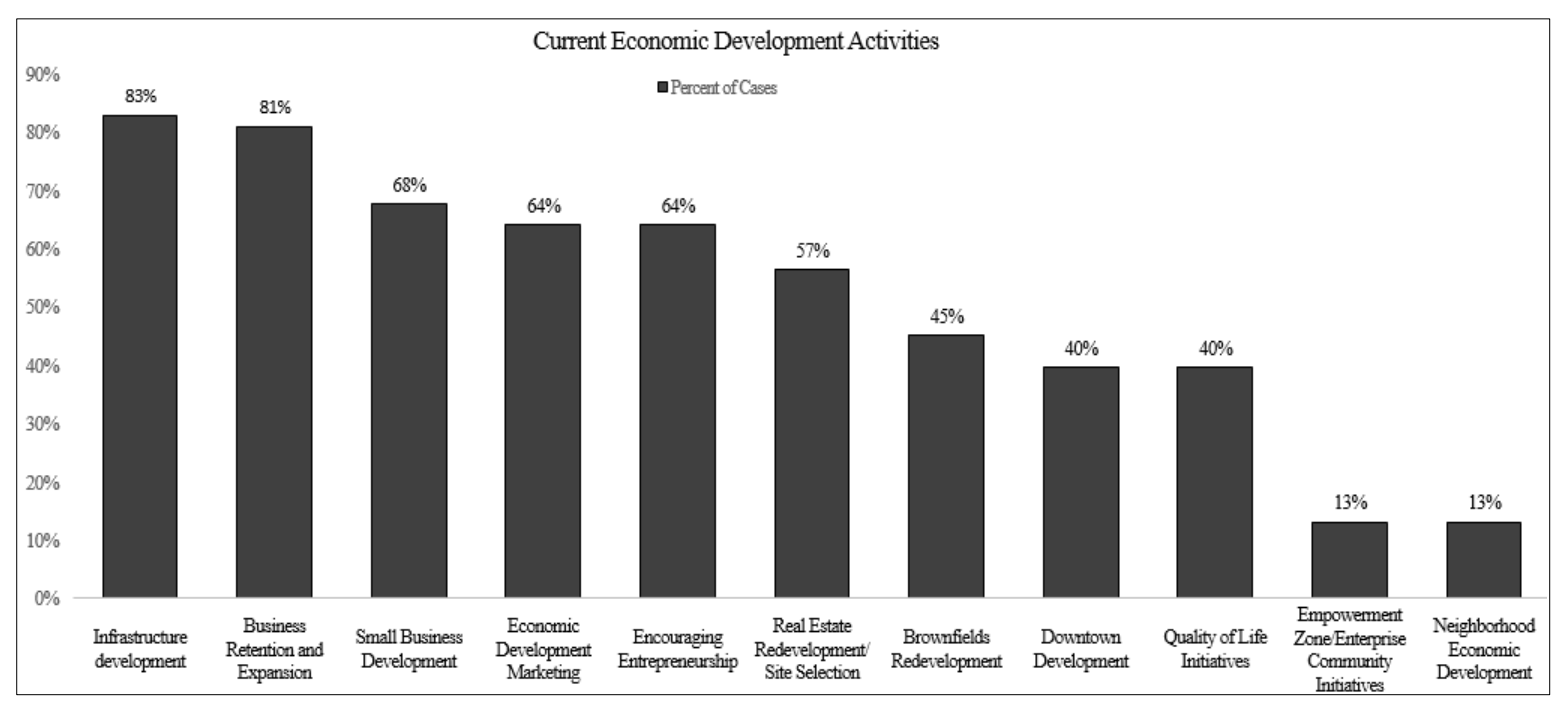

For environmental strategies, only $49 \%$ of the population selected brownfields redevelopment. Further, equity-driven strategies were the least identified activities, which include downtown development, quality of life initiatives, empowerment zone, enterprise community initiatives, and neighborhood economic development projects. 


\subsection{Conclusions and Recommendations}

\section{Conclusions}

The findings of this study are not consistent with the previous research conducted by Reese, which asserts that there should be a correlation between professional levels of certification and range of economic development activities, stating that "increased and more recent education or training should produce greater familiarity with current evaluation and planning techniques and therefore an increase in their use" (1997, p. 293). Nonetheless, this study does align with Zang et al. (2017), in that WV EDOs have invested in higher levels of business supports/incentives, while inversely, the agencies have provided fewer activities in support of environmental, quality of life, and community-based economic development. Overall, when measured by a balanced approach, strategies focusing on business economic development activities, instead of environmental sustainability and social equity, have resulted in a lower range of services and reduced sustainability.

\section{Limitations of the Study and Recommendations}

This study was limited to one Expressway Authority, one Regional Recreation Authority, 11 Regional Planning and Development Councils (RP\&DCs) and 58 Regional Economic Development Authorities (EDAs), which partner with the WV Development Office, an agency of the WV Department of Commerce. The combined number of regional and local EDOs included in this study was 68, as four Economic Development Authorities share directors. The results of 
this study can provide policymakers insight into the processes EDOs use to determine economic development activities and the relative need for continued opportunities to engage in a balanced sustainable approach, across agencies. 


\subsection{References}

Appalachian Regional Commission. (2013). Program evaluation of the Appalachian Regional Commission's infrastructure \& public works projects. Retrieved from https://www.arc.gov/assets/research_reports/ProgramEvaluationofARCInfrastructureand PublicWorksProjects-8-13.pdf

Appalachian Regional Commission. (2020). Access in Appalachia. Retrieved from https://www.arc.gov/report/transportation-access-in-appalachia/.

Ary, D., Jacobs, L. C., \& Sorensen, C. (2010). Introduction to research in education. Belmont, CA, United States: Wadesworth.

Bailey, D. \& de Propris, L. (2014). Editorial: recession, recovery and resilience?, Regional Studies, 48(11), 1757-1760, DOI: 10.1080/00343404.2014.967082

Blair, A., Michon, S., \& Conway, M. (2016). Communities that work partnership playbook. Retrieved from http://www.aspenwsi.org/wordpress/wp-content/uploads/CTWPPlaybook-Final-Nov-28-2016.pdf

Bloom, H. S., Hill, C. J., \& Riccio, J. A. (2003). Linking program implementation and effectiveness: Lessons from a pooled sample of welfare-to-work experiments. Journal of Policy Analysis and Management, 22(4), 551-575.

Boettner, T. (2018). Is West Virginia's economic 'comeback' real? West Virginia Center on Budget and Policy. Retrieved from http://www.wvpolicy.org/is_west_virginia_s_economic_comeback_real

Boone, H. N., \& Boone, D. A. (2012). Analyzing likert data. Journal of Extension, 50(2), 1-5. 
Bowen, E., Burton, M., Christiadi, Clarke D., Davis, R., Deskins, J., . . Sims, C. (2018). An economic analysis of the Appalachian coal industry ecosystem. West Virginia University and the University of Tennessee. Retrieved from https://www.arc.gov/assets/research_reports/CIESummaryAppalachianCoalIndustryEcosystemAnalysis.pdf

Bukenya, J. O., Gebremedhin, T. G., \& Schaeffer, P. V. (2003). Analysis of quality of life and rural development: Evidence from West Virginia data. Growth and Change, 34(2), 202218.

Chen, J., \& Jackson, R. (2018). Regional Industry Cluster Analysis for the Potomac Highlands in West Virginia. (No. Resource Document 2018-03).

Competitiveness, U.R., (2007). The role of regional clusters. Center for Regional Development/Center for Regional Development.

Deskins, J., Bowen E., Christiadi, Lego, B., McKenzie M., Parker J., . . Agelaraki, F. (2018). West Virginia economic outlook 2018-2022. The Bureau of Business and Economic, College of Business and Economics, West Virginia University, PO Box, 6025, 265066025.

Dillman, D. A., Tortora, R. D., \& Bowker, D. (1998, August). Principles for constructing web surveys. In Joint Meetings of the American Statistical Association.

Dillman, D. (2000). Constructing the questionnaire. Mail and internet surveys. New York.

Dillman, D. A., \& Bowker, D. K. (2001). The web questionnaire challenge to survey methodologists. Online social sciences, 53-71.

Dillman, D. A. (2011). Mail and internet surveys: The tailored design method--2007 update with new internet, visual, and mixed-mode guide. John Wiley \& Sons. 
Economic, O. (2001). Community Development Department. (2001). Community and Economic Development Readiness Assessment.

Epstein, M. J. (2014). Making sustainability work: Best practices in managing and measuring corporate social, environmental and economic impacts. Routledge.

Ezzell, T., Lambert, D., \& Ogle, E. (2012). Strategies for economic improvement in Appalachia's distressed rural counties. An analysis of ten distressed and formerly distressed Appalachian counties (Prepared for the Appalachian Regional Commission). Knoxville: The University of Tennessee Community Partnership Center.

Fabozzi, F. J., Gupta, F., \& Markowitz, H. M. (2002). The legacy of modern portfolio theory. Journal of Investing, 11(3), 7-22.

Feldman, M., Hadjimichael, T., Kemeny, T., Lanahan, L., Partridge, M., Poole, K., ... \& Wolfe, D. (2014). Economic development: A definition and model for investment.

Feser, E., Mix, T. D., White, M., \& Poole, K. (2014). ARC: Economic diversity in Appalachia: Statistics and guides for action. Center for Regional Economic Competitiveness: 2014.

Fones-Wolf, K., \& Lewis, R. L. (2004). Transnational West Virginia: Ethnic communities and economic change, 1840-1940. West Virginia University Press.

Fulmer, J. (2009). What in the world is infrastructure. PEI Infrastructure investor, 1(4), 30-32. Retrieved from https://30kwe1si3or29z2y020bgbet-wpengine.netdna-ssl.com/wpcontent/uploads/2018/03/what-in-the-world-is-infrastructure.pdf

Fruman, C. (2017). Economic diversification: A priority for action, now more than ever. Retrieved from http://blogs.worldbank.org/psd/economic-diversification-priority-actionnow-more-ever 
Gebremariam, G. H., Gebremedhin, T. G., \& Jackson, R. W. (2004). The role of small business in economic growth and poverty alleviation in West Virginia: An empirical analysis. In The paper at the American Agricultural Economics Association Annual Meeting, Denver, Colorado, August (Vol. 1, No. 4).

Ghosh, S., \& Chen, J. (2014). Making it count: Metrics for high performing EDOs. Washington, DC: International Economic Development Council.

Gregg, P., (2018). West Virginia's economic future: State’s 'uneven recovery’ sees robust growth in some areas, no development and population losses in others. Retrieved from https://wvutoday.wvu.edu/stories/2018/10/03/west-virginia-s-economic-future-state-suneven-recovery-sees-robust-growth-in-some-areas-no-development-and-populationlosses-in-others

Hammer, J., \& Pivo, G. (2017). The triple bottom line and sustainable economic development theory and practice. Economic Development Quarterly, 31(1), 25-36.

Hustedde, R. J. (2009). Seven theories for seven community developers. An introduction to community development, 20-37.

ICMA. (2014). Economic development 2014 survey results. International City/County Management Association.

IEDC. (2011). Managing economic development organizations. Retrieved from http://users.allconet.org/MISC/IEDC\%20Manuals/IEDC\%20\%20Managing\%20Economic\%20Development\%20Organizations.pdf IEDC. (2017). Organizing for success: regional economic development. Retrieved from http:/files.constantcontact.com/52f3d7d4401/6cb2abc0-d81a-4991-9444e92f62daa434.pdf 
IEDC. (n.d.). The International Economic Development Council's economic development reference guide. Retrieved from https://www.iedconline.org/clientuploads/Downloads/IEDC_ED_Reference_Guide.pdf

Jackson, R., Kahsai, M., Schaeffer, P., Middleton, M., \& Yu, J. (2015). A framework for measuring county economic resilience (No. Working Paper 2015-03).

Kemeny, T., \& Storper, M. (2015). Is specialization good for regional economic development?. Regional Studies, 49(6), 1003-1018.

Kim H. Y. (2017). Statistical notes for clinical researchers: Chi-squared test and Fisher's exact test. Restorative dentistry \& endodontics, 42(2), 152-155. https://doi.org/10.5395/rde.2017.42.2.152

Lovett, K. K. (2014). The diffusion of governance in state economic development (Doctoral dissertation, Tennessee State University)

Lyons, T. S. (2003). Policies for creating an entrepreneurial region. Main streets of tomorrow: Growing and financing rural entrepreneurs, 97-106.

Mangram, M. (2013). A simplified perspective of the Markowitz Portfolio Theory. Global Journal of Business Research, 7(1), 59-70.

Markowitz, H. (1952). Portfolio selection. The Journal of Finance, 7(1), 77-91.

Markowitz, H. M. (1959). Portfolio selection: Efficient diversification of investment. New Haven, Connecticut: Yale University Press.

Markowitz, H. M. (2010). Portfolio theory: as I still see it. Annual Review of Financial Economics, 2(1), 1-23.

McGahey, R. M. (2008). Regional economic development in theory and practice. Retooling for growth: Building a 21st century economy in America's older industrial areas, 3-32. 
McMaster, H. S., LeardMann, C. A., Speigle, S., \& Dillman, D. A. (2017). An experimental comparison of web-push vs. paper-only survey procedures for conducting an in-depth health survey of military spouses. BMC Medical Research Methodology, 17(1), 1-9.

Melkers, J., \& Willoughby, K. (2005). Models of performance-measurement use in local governments: Understanding budgeting, communication, and lasting effects. Public Administration Review, 65(2), 180-190.

Millar, M. M., \& Dillman, D. A. (2011). Improving response to web and mixed-mode surveys. Public opinion quarterly, 75(2), 249-269.

Miller, L. E. (1998). Appropriate analysis. Journal of agricultural education, 39(2), 1-10.

Miller, L. E., \& Smith, K. L. (1983). Handling nonresponse issues. Journal of Extension, 21(45$50)$.

National Research Council. (2013). Best practices in state and regional innovation initiatives: competing in the 21st century. National Academies Press.

Nourick, S. (2012). New realities for economic development organization. International Economic Development Council, Washington DC.

O’Leary, S., Boettner, T., Wilhelm, S., \& Wilson, R. (2016). The state of working West Virginia: why is West Virginia so poor? Retrieved from http://www.wvpolicy.org/state_of_working_west_virginia_2016

Osgood Jr, J. L., Opp, S. M., \& Bernotsky, R. L. (2012). Yesterday’s gains versus today’s realties: Lessons from 10 years of economic development practice. Economic Development Quarterly, 26(4), 334-350.

Pennsylvania Workforce Development Association. (2019). The history of workforce development. 
Performance Measurement in Economic Development: Development of performance measurement systems for local and regional economic development organizations. (2011). Retrieved from http://edac.ca/wp-content/uploads/2014/03/Final-Report-Oct-20Performance-Measurement-in-Economic-Development-EDAC-Project-Septversion_Addition_May7_2013.pdf

Phillips, R., \& Pittman, R. (Eds.). (2014). An introduction to community development. Routledge.

Pittman, R., Pittman, E., Phillips, R., \& Cangelosi, J. (2009). The community and economic development chain: Validating the links between processes and outcomes. Community Development, 40(1), 80-93.

Regional Planning \& Development Councils|Metropolitan Planning Organizations. (n.d.). [map] Retrieved from http://www.wvregionalcouncils.org/

Reese, L. A. (1997). The use of planning methodologies in local economic development decisionmaking. Environment and Planning C: Government and Policy, 15(3), 285-303.

Septianingrum, R. S., Aditya, B., Wijaya, A. P., Irshabdillah, M. R., Husna, N. A., \& Putri, R. F. (2020, March). Economic inequality and its impact on human development: insight of Banten Province 2011-2015. In IOP Conference Series: Earth and Environmental Science (Vol. 451, No. 1, p. 012107). IOP Publishing.

Shaffer, R., Deller, S., \& Marcouiller, D. (2006). Rethinking community economic development. Economic Development Quarterly, 20(1), 59-74.

Southwick, S. M., Bonanno, G. A., Masten, A. S., Panter-Brick, C., \& Yehuda, R. (2014). Resilience definitions, theory, and challenges: interdisciplinary perspectives. European Journal of Psychotraumatology, 5(1), 25338. http://doi.org/10.3402/ejpt.v5.25338 
Stimson, R. J., \& Stough, R. R. (2008). Changing approaches to regional economic development: Focusing on endogenous factors, financial development and regional economics. Regional Science Association International and Banco Central de la Republic Argentina.

Swan, D. (2017). West Virginia's economy ranked \#5 | 2008 Great Recession. Economy of States. Retrieved from https://economyofstates.com/west-virginias-economy-2008-greatrecession/

The West Virginia Economic Development Authority Act, §31-15-1, West Virginia Legislature, Pub. L. No. §31-15-1 § 31, §31-15-1 Stat. 1-31 (West Virginia Legislature, 1962).

Thiede, B. C., \& Monnat, S. M. (2016). The great recession and America's geography of unemployment. Demographic Research, 35, 891-928. http://doi.org/10.4054/DemRes.2016.35.30

Tunley, R. (1960). The strange case of West Virginia. Saturday Evening Post, 6.

Walden, M. (2012). Explaining differences in state unemployment rates during the Great Recession. Journal of Regional Analysis \& Policy, 42(3), 251-257.

West Virginia Development Office. (n.d.). [map] Retrieved from https://westvirginia.gov/connect-with-us/local-edas/

West Virginia Forward. (2017). Strategy for economic development and job growth. West Virginia University, the State of West Virginia, and Marshall University. Retrieved from https://westvirginia.gov/files/docs/wvforward/West-Virginia-Forward-Summary-ofFindings.pdf

Williams, J. A. (1984). West Virginia: A History. WW Norton \& Company. 
Zhang, X., Warner, M. E., \& Homsy, G. C. (2017). Environment, equity, and economic development goals: Understanding differences in local economic development strategies. Economic Development Quarterly, 31(3), 196-209. 


\section{CHAPTER 4: ESSAY 3 - LABOR FORCE PARTICIPATION IN WEST VIRGINIA}

\subsection{Introduction/Theoretical Framework}

Nationally, during October 2020 of the pandemic, there were more than 30 million individuals classified as non-employed, which consists both of the unemployed and those out of labor force, which is defined as individuals who were not employed during the Current Population Survey reference week and have "not actively looked for work (or been on temporary layoff) in the last 4 weeks" (Bureau of Labor Statistics [BLS], 2020; Fields, 2020; Kudlyak, 2017). Further, the national labor force participation rate (LFPR) of $61.5 \%$ is a disappointing indicator for a long-term economic recovery (BLS, 2020; Irwin, 2016). The LFPR, according to economists, is a significant labor market measure because it represents the nation's labor resources available for goods and services production (Hipple, 2016).

For decades, the LFPR (the percentage of the civilian non-institutional population 16 years and older who are actively seeking employment or working) has declined in the United States (see Figure 4.1), particularly for prime-age workers (BLS, 2020; Council of Economic Advisers, 2016; Hipple, 2016). From 1948 through 2019, the nation's LFPR averaged 62.88\%, reaching the highest level of $67.30 \%$ during the first four months of 2000 , and the lowest mark, 58.10\%, in December of 1954 (BLS, Federal Reserve Economic Data [FRED], 2019). 
Figure 4.1: U.S. Civilian Labor Force Participation Rate, Seasonally Adjusted

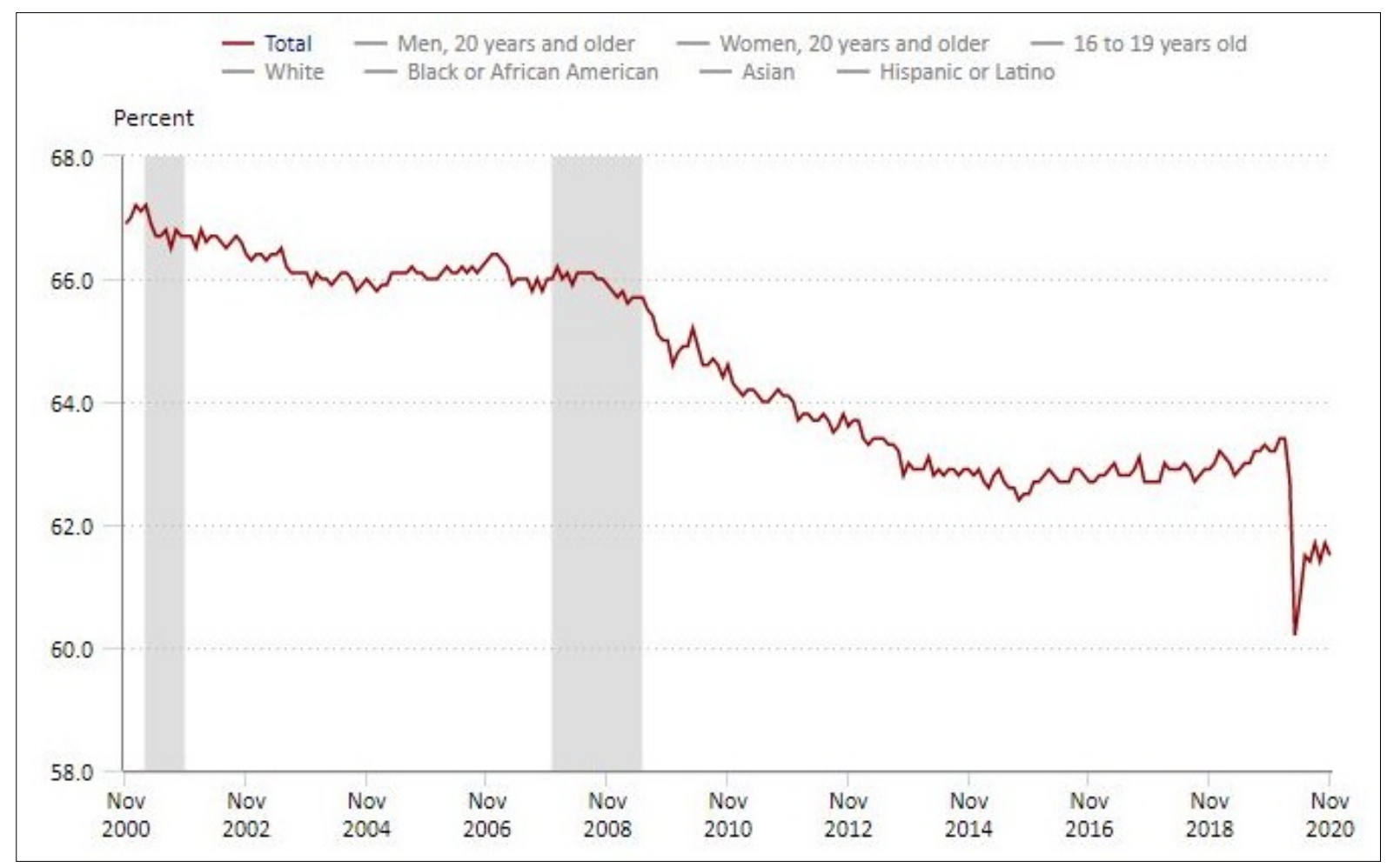

Note: Shaded areas represent recessions, determined by National Bureau of Economic Research (NBER). From Release Tables: Labor Force Participation Rate., U.S. Bureau of Labor Statistics, 2020, Federal Reserve Bank of St. Louis (FRED). Retrieved from https://fred.stlouisfed.org/release/tables?rid=446\&eid=784070\&od=2020-03-01.

During the pandemic, the national LFPR decreased dramatically, moving from $63.4 \%$ in February to $60.2 \%$ in April, rebounding slightly to $61.5 \%$ in November (BLS, 2020). By comparison, West Virginia's LFPR was 53.6\% in November of 2020 (see Figure 4.2), lower than the national rate by 7.9 percentage points (BLS, FRED, 2020). Historically, the state has had the lowest annual LFPR in the nation. Its highest LFPR, 57.1\%, was experienced in March of 2020, just before the pandemic forced the economy to plummet. 
Figure 4.2: U.S. and West Virginia Civilian Labor Force Participation Rate, Seasonally Adjusted

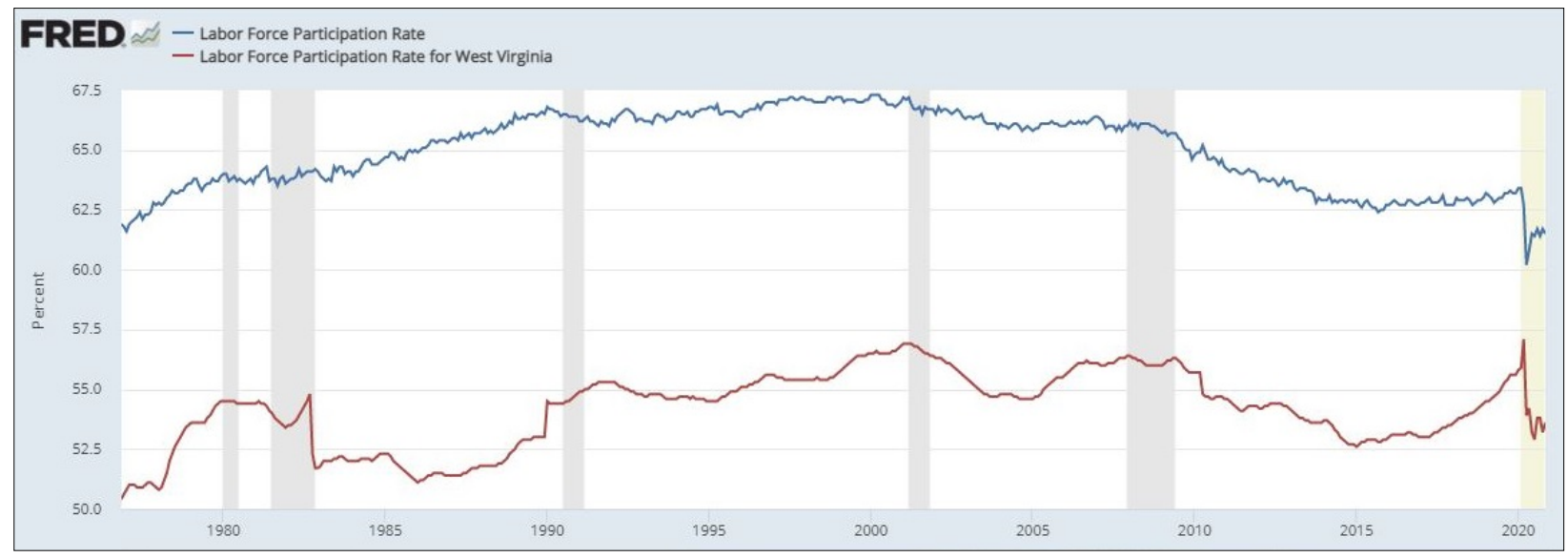

Note: Shaded areas represent recessions, with the most recent end date currently undetermined by NBER. From Release Tables: Labor Force Participation Rate., U.S. Bureau of Labor Statistics, 2020, Federal Reserve Bank of St. Louis (FRED). Retrieved from https://fred.stlouisfed.org/release/tables?rid=446\&eid=784070\&od=2020-03-01.

The second highest LFPR held steady in 2001 at 56.9\% for a four-month period, was followed by a steep descent to $54.7 \%$ by December 2003. The state's lowest recorded LFPR, 50.3\%, was in October 1976 (BLS, FRED, 2019). The previously noted 7.9 percentage point difference of the November LFPR rates of West Virginia and the nation reflects one of the narrowest gaps on record (BLS, FRED, 2020). Prior to the pandemic, the smallest LFPR gap between the nation and West Virginia was in September 2018, with an 8.8 percentage point difference, with the next closest, an 8.9 percentage point gap, occurred only four times: December 2009, August and November 2018, and February 2019 (BLS, FRED, 2019). During the early months of the pandemic, West Virginia's LFPR narrowed to $7.5 \%$ in February; 5.6\% in March; 6.3\% in April; and 6.6\% in May. From June through November 2020, the LFPR gap averaged $8.1 \%$.

Overall, the LFPR gap decrease reflects the $2 \%$ decrease in the nation's LFPR from $63.3 \%$ in 2019 to $61.4 \%$, compared to the same time period in 2020, March through November, 
while the state's LFPR decreased 1\% during these timeframes, from 55\% to 54\%, 2019 and 2020, respectively. Historically, the state's average LFPR has been 54.19\%, with the average gap from the nation's LFPR being 10.82\%, and the largest difference, $14.3 \%$, occurring in May of 1987 (BLS, FRED, 2020).

Serving as a key role in establishing long-term economic sustainability, the LFPR directly impacts total GDP and per capita income (Krause \& Sawhill, 2017). Interlinked with labor force growth is the total GDP growth (Denton \& Spencer, 1997). Prior studies note that the labor force's expansion is one of two key determinants in achieving sustainable economic growth, and for well-being standards to improve, either the number of hours worked must rise or labor productivity must increase (Breitwieser et al., 2018; Panday \& Bovino, 2017). Economists agree that in the long run a strong LFPR is a key component in an economic output per capita and overall standard of living (O’Leary et al., 2015). Long-term economic health is particularly reliant on those individuals who are in the prime age of employment, ages 16 years or to approximately 65, to become active in the workforce (Hansen, 2016). The Congressional Budget Office $(\mathrm{CBO})$ projects that the output growth rate will significantly slow down because of the nation's decreased labor supply (2017). For West Virginia's economic development, the state's weak labor force participation will constrain economic development, even as labor demand increases (Dorsey, 1991).

Over the years, West Virginia's low LFPR has exerted a downward force on the state's economic growth and is considered to be the greatest challenge to the state's long-term economic stability (O'Leary et al., 2015; Weiler, 2001). The state has experienced declines in the LFPR of prime-age workers for more than fifty years. Research also indicates that men in this age bracket are increasingly unconnected to the labor market, and, subsequently, will provide decreased 
economic growth (Force, 2016). Economists are concerned that economic gains will weaken as demand for skilled workers goes unfilled (Irwin, 2016).

Previous studies find that there exists an array of explanations for the decline in labor force participation rates, several of which focus on regional and county-level analysis of market demand and labor supply (Stephens \& Deskins, 2018; Tomaskovic-Devey, 1987; Weiler, 2001). On the demand side, Krause \& Sawhill (2017) note that technological advances and trade imbalances have decreased the demand for less-skilled labor in the manufacturing field, and that technology has made certain low-wage jobs obsolete. Studies regarding the supply side find that low levels of education, physical disabilities and/or health limitations, poor mental health, and increases in premature deaths, identified as deaths of despair, indicate a cumulative history of disadvantages in life, which reduce labor market opportunities (Case \& Deaton, 2017; Council of Economic Advisers, 2016; Olson, 1996; Schilbach et al., 2016). These findings concur with research indicating that approximately half of prime age non-employed men may have a serious health condition, which creates an employment barrier, and that two-thirds of these men take prescription pain medication (Black et al., 2016; Krueger, 2017).

Further, Krause \& Sawhill (2017) find that "on the supply side of the labor market, the problems include not only a lack of skills, but also high reservation wages, poor health, and the availability of disability insurance or other forms of unearned income" (p. 2). LFPR declines stem not only from unskilled prime-age potential workers, but are also concentrated in higherincome households, with the pattern appearing amongst younger workers between the ages of 16 and 24 enrolled in school (Hall, 2016). More young people are enrolled in school, with teenagers experiencing the largest drop in participation (DiCecio et al., 2008). 
Further pressing downward on the LFPR is the existence of an informal sector of the economy, also referred to as a shadow economy or grey labor market, which ranges from $3 \%$ to $40 \%$ of the potential labor force (Nightingale, 2011). These individuals work below the tax and regulatory radar and conduct business in a nonstandard employment arena (Bradley et al., 2001; Nightingale, 2011; O'Leary et al., 2015). The informal market includes millions of workers nationally, the majority of whom, 64\%, are white, with Hispanic workers and African Americans representing $16 \%$ and $12 \%$, respectively (Restrepo-Echavarria \& Arias, 2017). The shadow economy, which extracts labor from the official sector, is estimated to be $9.32 \%$ of GDP in West Virginia, the second largest shadow economy in the nation, followed by Mississippi at $9.54 \%$ (Wiseman, 2013).

A population subset which also pushes the LFPR downward is the discouraged worker, who, as defined by the BLS, is an individual who wants to be employed, but has not looked for work within the previous four weeks prior to the Current Population Survey (CPS) interview. During a period of high unemployment, 1987, Dorsey (1991) examined West Virginia's low LFPR with regard to the Appalachian Culture hypothesis. In his work, Dorsey (1991) noted that the discouraged worker hypothesis may have an impact on the state's LFPR, as would the state's high percentage of retirees and a labor force population with lower educational attainments, as well as the union's influence during this period when the organized labor supported public policies designed to discourage labor supply.

Further, Dorsey's (1991) findings rejected the "hypothesis that depressed labor market conditions are the primary cause of weak participation in West Virginia" (p. 61), and suggest "that cultural differences in the population explain much of the variation in aggregate labor force participation" (p. 62). Moreover, individuals who choose to work in nonmarket productivity 
may be influenced by their preference for more valued leisure activities (Dorsey, 1991). As explained by Altman (2001), "each individual faces a time constraint whereby an individual's total time is allocated between market and nonmarket activities” (p. 202). Krause \& Sawhill (2017) also note that the low LFPR may reflect choices between activities, such as pursuing an education or taking care of family, and that these choices may play a more significant role in a lack of engagement in work.

Research also indicates disabilities and retirement are factors in lowering participation rates as the share of old workers increases and they exit the workforce (Fujita, 2014). Studies find that over half of the decline in LFPR can be explained by demographic patterns (Aaronson et al., 2012). Ranking third in the nation for residents age 65-74 and second nationally for 7584-year-olds, West Virginia has a high rate of retirees with $20.5 \%$ of the population being over age 65 (Census, 2019; Seniorliving.org Team, 2019).

The state also has a high percentage of individuals under age 65 with disabilities (14\%), as well as the highest percentage of veterans ages $18+$, of whom $34 \%$ have a disability (Butterworth et al., 2015; Census, 2019). Further, for 2019, West Virginia has the highest percentage of individuals with the classification of ambulatory disability at $50.8 \%$ (Lauer et al., 2020). Only $28.5 \%$ of West Virginians, 18 - 64 years of age, with disabilities are employed compared to the national rate of $37.5 \%$ of individuals with disabilities obtaining employment (Houtenville \& Boege, 2019).

It should be noted that several studies regarding labor force participation have been conducted using CPS data (Aaronson et al., 2006; Krueger, 2017; Kudlyak \& Lange, 2014), which provides not in labor force respondents the following selections (see Figure 4.3) disabled, ill, in school, taking care of house or family, in retirement, and something elselother (BLS, 
2015), in response to the interviewer's question: “What best describes your situation at this time? For example, are you disabled, ill, in school, taking care of house or family, or something ELSE [sic]?" (BLS, CPS Manual, 2015, p. C4-34). For the selection in retirement, interviewers are directed by the manual that the option is available "in certain initial questions" and that the "questionnaire will route retired persons 50 years old or older who do not want a job, through an abbreviated set of labor force questions" (BLS, CPS Manual, 2015, p. B3-4).

Figure 4.3: CPS Interview Manual, Figure C71, NLFACT, Current Status

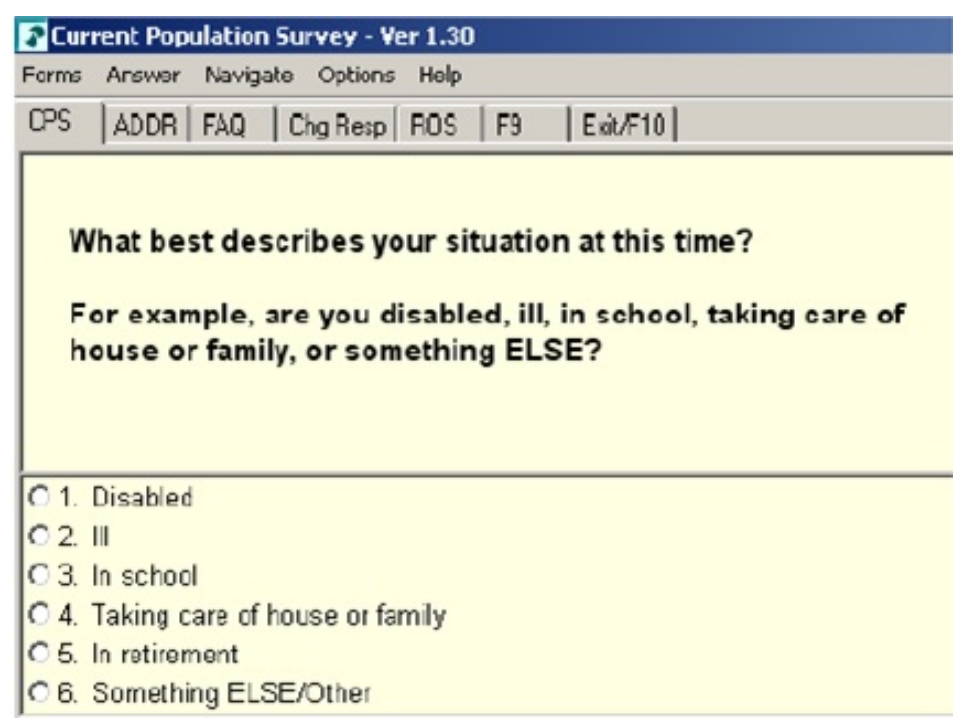

Note. From CPS Interview Manual, Bureau of Labor Statistics, U.S. Department of Labor, CPS Manual (2015). Part B, Chapter 3, Not in labor force concepts. Retrieved from https://www.census.gov/programs-surveys/cps/technicaldocumentation/methodology/interviewer-s-manual.html.

In response to the selection other, the BLS report A-38, Persons not in the labor force by desire and availability for work, age, and sex, indicates respondents who were not actively seeking a job four weeks prior to the survey reported that childcare and transportation were barriers to employment (BLS, 2020). For West Virginians, the lack of childcare and limited 
access to transportation have made gaining and retaining employment more challenging (West Virginia Forward, n.d.). Approximately, 30\% of working age women in West Virginia are single mothers, who have about 7,000 children under age 6 , as well as 26,157 children ages 6-17 (Census, 2019; West Virginia Forward, n.d.).

The state's rural environment, as the majority of its residents live in communities of fewer than 2,500 people (Office of Management and Budget and Census Bureau definitions), results in approximately $64 \%$ of West Virginians living in rural areas (West Virginia State Health Plan, Rural Health. n.d.). Transportation, particularly for rural environments, is considered a significant barrier to employment (Appalachian Regional Commission [ARC], 2013). Further, studies find that the lack of ownership of personal vehicles hampers the state's residents' ability to gain and retain employment. Previous research also indicates that increased access to transportation enhances employability and reduces dependency on government welfare supports (ARC, 2020).

Studies have also found that the labor market landscape may include declining job skills and diminished work experience opportunities, which can result in long-term negative impacts on the employability (Fernandes-Alcantara, 2012; Hipple, 2016). Rural labor markets, which are considered the main variable affecting the upward mobility of low income adults, are starkly different from urban areas, making labor force participation and living-wage earnings difficult to secure, with constrained employment opportunities often limited to temporary, seasonal, or lowpaying hospitality/service jobs (Latimer, 2004; Zimmerman et al., 1999).

Krause \& Sawhill (2017) further note that "even in the presence of strong employer demand for labor," as in the pre-pandemic labor market, "the workforce must come equipped with the education and skills needed for the jobs available" (p. 16). To that end, the dedication 
to workforce development in the United States has been seen as essential to society, "whether in a period of growth or recession" (Pennsylvania Workforce Development Association, 2019). Studies further indicate that core to a successful workforce development program are education and training programs which serve to "bridge the skills gap that occurs through generations of new technological advances" (2019). Since the formation of the New Deal (1933-1938), there have been several major workforce statutes created to address the need for an educated and skilled workforce. The New Deal occurred during the Great Depression, when national employment across was at an all-time low. During this time, the Fair Labor Standards Act and Social Security Act were also passed to protect workers. Under President John F. Kennedy, the Manpower Development and Training Act (1962-1973) followed, providing training to unemployed adults and youth workers. The Manpower Act segued to the Comprehensive Employment and Training Act (1973-1982), with the focus moving to states' responsibility and job creation, as well as training for unemployed adults. The Job Training Partnership Act (19821998) created regional Service Delivery Areas, which have evolved into the Workforce Investment Areas of today (Pennsylvania Workforce Development Association, 2019).

Under President William J. Clinton, the welfare-to-work reform plan, Personal Responsibility \& Work Opportunity Reconciliation Act (1996) and the Workforce Investment Act (1998-2014) were enacted during a period of full employment and designed to be businessled model based on labor market data (Pennsylvania Workforce Development Association, 2019; Watts \& Astone, 1997). The most current iteration, the Workforce Innovation and Opportunity Act (2014-present), was authorized on July 22, 2014 by President Barack Obama to replace the Workforce Investment Act of 1998 (Pennsylvania Workforce Development Association, 2019). 
As the numerous phases of workforce development programs were enacted, researchers and policy-makers became more divided on the issue of quick employment versus high-quality employment, which would pay a living wage and lift welfare recipients off government roles indefinitely (Hasenfeld, 1975), with supporters of the quick employment approach asserting that nearly any employment position would create positive outcomes for individuals, such as obtaining work experience, job skills, and establishing an employment record (Bloom et al., 2003). Alternatively, those in opposition to the quick employment approach, which focuses on job search activities, believe that increasing human capital through job skills training and education would better qualify job seekers for higher quality employment and build pathways to viable careers (Bloom et al., 2003).

Relatedly, the capabilities approach (CA) was developed by welfare economist and Nobel laureate Amartya Sen (1999) and extended by multiple scholars, including Martha Nussbaum (2011). Nussbaum (2011) created a list of ten capabilities deemed as central requirements to living a life with dignity, such as obtaining "an adequate education, including, but by no means limited to, literacy and basic mathematical and scientific training" and "having the right to seek employment on an equal basis with others" (p. 8-9).

Further, in light of the need for individuals to have financial sustainability, this study addresses the issue of quick employment versus gaining long-term human capital and West Virginia's efforts to provide effective workforce development services. Throughout the history of workforce development there has been a significant amount of research examining the underlying causes of non-employment, particularly with regards to West Virginia's low labor force participation rates. Few studies exist that examine the strategies employment agencies in West Virginia currently use to engage unemployed and non-employed individuals. In addition, 
as the state prepares to move forward to a post-pandemic era, there is not a statewide analysis of the strategies the agencies plan to utilize to support the re-employment of the $53.6 \%$ of out of labor force residents (BLS, 2020).

Moreover, this study furthers the understanding of linkages between job placement services agencies in West Virginia and the theoretical framework of human, social, and financial capital theories. Studies of the interrelationship of human, social capital, and financial, with regards to securing employment, find that increases in human capital, such as education, knowledge, skills and training (Aguilera, 2002; Beggs \& Hurlbert, 1997; Burdett \& Mortensen, 1977) combined with the enhancement of social capital, for instance broadening a job seeker's existing network of employment-based connections (Coleman, 1988; Knack \& Keefer, 1997), results in an increase in employment opportunities (Mouw, 2003), and, in turn, serve to build financial capital, being "approximately measured by the family's wealth or income" (Coleman, 1988, p. S109).

There are six main objectives in examining the workforce development agencies serving West Virginia: 1) Assess the workforce development activities conducted by job service agencies, at the regional level and statewide, 2) determine the effectiveness of the workforce development activities and retention strategies, 3) determine if alternative workforce development activities were considered, 4) examine the pre-pandemic and peri-pandemic barriers to employment from the perspective of the job services agencies' staff based on experience, staff case notes and intake interviews conducted by agency staff members, 5) examine the relationship between responding job services agencies and other agencies, statewide, and 6) determine if the agencies' workforce development activities demonstrate increases in human, social, and financial capital. 
Further, based upon a review of literature and theory, the following hypothesis was evaluated regarding the relationship between the range of workforce development activities, quick employment versus training, and the range of job placements across industry sectors.

$\mathrm{H}_{0}$ : There is no association between the range of workforce development activities, quick employment versus training, and the range of job placements across industry sectors.

$\mathrm{H}_{1}$ : There is an association between the range of workforce development activities, quick employment versus training, and the range of job placements across industry sectors.

The remainder of this essay is structured as follows: the second section provides an overview of the relevant literature and the methods/procedures used in this study are explained in section three, with the results presented and discussed in section four. Section five contains the conclusion and limitations to the study, as well as recommendations for further research.

\subsection{Literature Review}

Research regarding the evaluation of employment agencies has addressed mainly two target populations: job training/placement services for individuals with disabilities (Domin et al., 2020; Glover \& Frounfelker, 2013; Unger, 2007) and welfare-to-work studies (Latimer, 1998, 2004; Zimmerman et al., 1999), both of which represent a high percentage of the state's residents, as noted in the introduction. Further, previous researchers have found that employment agency systems tend to serve job seekers who need more one-to-one assistance and job training (McIntire \& Robins, 1999; United States: Department of Labor, Department of Commerce, Department of Education, Department of Health and Human Services, 2014). Moreover, studies find that employment agency clients, such as welfare-to-work clients, tend to progress slower through the system and have lower employment outcomes, particularly if they 
are older than 40 years of age, have several dependents, or have not obtained a high school degree (McIntire \& Robins, 1999).

Although not offering a formal evaluation of employment agencies, McIntire and Robins (1999) selected five one-stop models based on the agencies' successes "in addressing welfare-towork issues, geographic distribution, and urban/rural diversity" (para. 6). The researchers received preliminary data regarding each site's background information, the region's welfare client characteristics, service records, and employment/training outcomes for the sample of 70 to 150 welfare clients. In addition, the investigators utilized the method of focus group interviews with staff and current/previous welfare clients, as well as current employers of welfare clients.

The findings from this previous study, as well as other studies which examine employment agencies that serve ex-offenders and residents older than 65 years of age, indicate that successful job placement and retention goals are enhanced by utilizing an array of best practices, including providing job seekers access to current labor market information regarding job vacancies, skills necessary for in-demand jobs, and employment trends (Dunham et al., 2011; McIntire \& Robins, 1999). Further, these studies found that using a demand-side model for job placement services will benefit individuals who have not traditionally engaged in labor force participation, particularly for individuals with disabilities (Glover \& Frounfelker, 2013; Olson, 1996; Unger, 2007).

Prior studies also indicate that job placement outcomes are enhanced when employment agencies use labor market data is used in conjunction with (1) ensuring service satisfaction of participants and employers, (2) preliminary assessments of skill levels, aptitudes, abilities, and support service needs, (3) assistance filing for unemployment insurance, (4) job training and 
education programs, (5) job search assistance, (6) job placement assistance, (7) and career counseling (Kogan et al., 1997; McIntire \& Robins, 1999; Van Horn, 2015).

As mentioned, West Virginia has a high percentage of individuals with disabilities, as well as low-income individuals, ex-offenders, and residents older than 65 years of age, and previous studies specific to these populations have found that the following approaches increase employment outcomes (Butler et al., 2015; Dunham et al., 2011; Holzer \& Martinson, 2005):

- Provide relatively low caseloads

- Provide financial incentives and supports

- Offer frequent contacts

- Develop trusting relationships with participants

- Support/motivate participants

- Require participants to be job seeking daily, to develop a sense of structure

Based on the Theory of Work Adjustment, which addresses the rewards of employment and job stability (Vandenberg \& Scarpello, 1990), researchers assessed one-stop career center system client satisfaction questionnaires and found that older participants gave lower total client satisfaction scores, while participants with higher levels of education gave higher scores for client satisfaction. Further, participants who were provided a disability program navigator, noted as the best approach for job seekers with a disability, tended to have higher client satisfaction scores, which resonated with participants that spent increased amount of time with the disability program navigator (Noble, 1999). Aguilera (2002) found "that programs that attempt to bring valuable labor market information to individuals and communities lacking employment-related information are likely to be effective in reducing inequality, especially if combined with programs for developing human capital" (p. 853). Furthermore, previous studies indicate that unemployment and the subsequent loss of income negatively impacts social capital (Hörisch \& Obert, 2020; Kawachi et al., 1997; Knack and Keefer, 1997). 
In a previous study regarding hard-to-employ individuals, a research team (Butler et al., 2015), using surveys and administrative records, examined the employment outcomes of approximately 4,000 sample members receiving employment services in New York, Pennsylvania, Rhode Island, Kansas, and Missouri. Although the findings were mixed, the exoffenders and welfare-to-work programs demonstrated increases in employment. The program supports provided to the welfare-to-work clients included "unpaid work experience, job placement, and education services to recipients with health conditions" which resulted in "longer-term gains, increasing employment and reducing the amount of cash assistance received over four years" (Butler et al., 2015, p. 5). The study also observed promising results in programs that combined the use of high-quality childcare to increase parents' employment and earnings. Further, other programs that offered case management services for low-income substance abusers presented no impacts. Overall, the evaluation found that combining employment strategies was "more promising than using either strategy alone, especially for people with disabilities and behavioral health problems" (Butler et al., 2015, p. 67).

Additionally, researchers Haynes et al. (2017) examined the employment agencies in a seven-county region in Minnesota by conducting a community asset mapping and environmental scan. The researchers generated an employment service providers list using the statewide United Way 2-1-1 database and used a survey method to assess the alignment of "workforce development programs and related supportive service assets (service providers) with the people they serve, to expand and identify duplication of these programs and services, and to demonstrate a collaborative workforce system through visual and statistical means" (Haynes et al., 2017, p. vii). 
Figure 4.4: WorkForce West Virginia Map

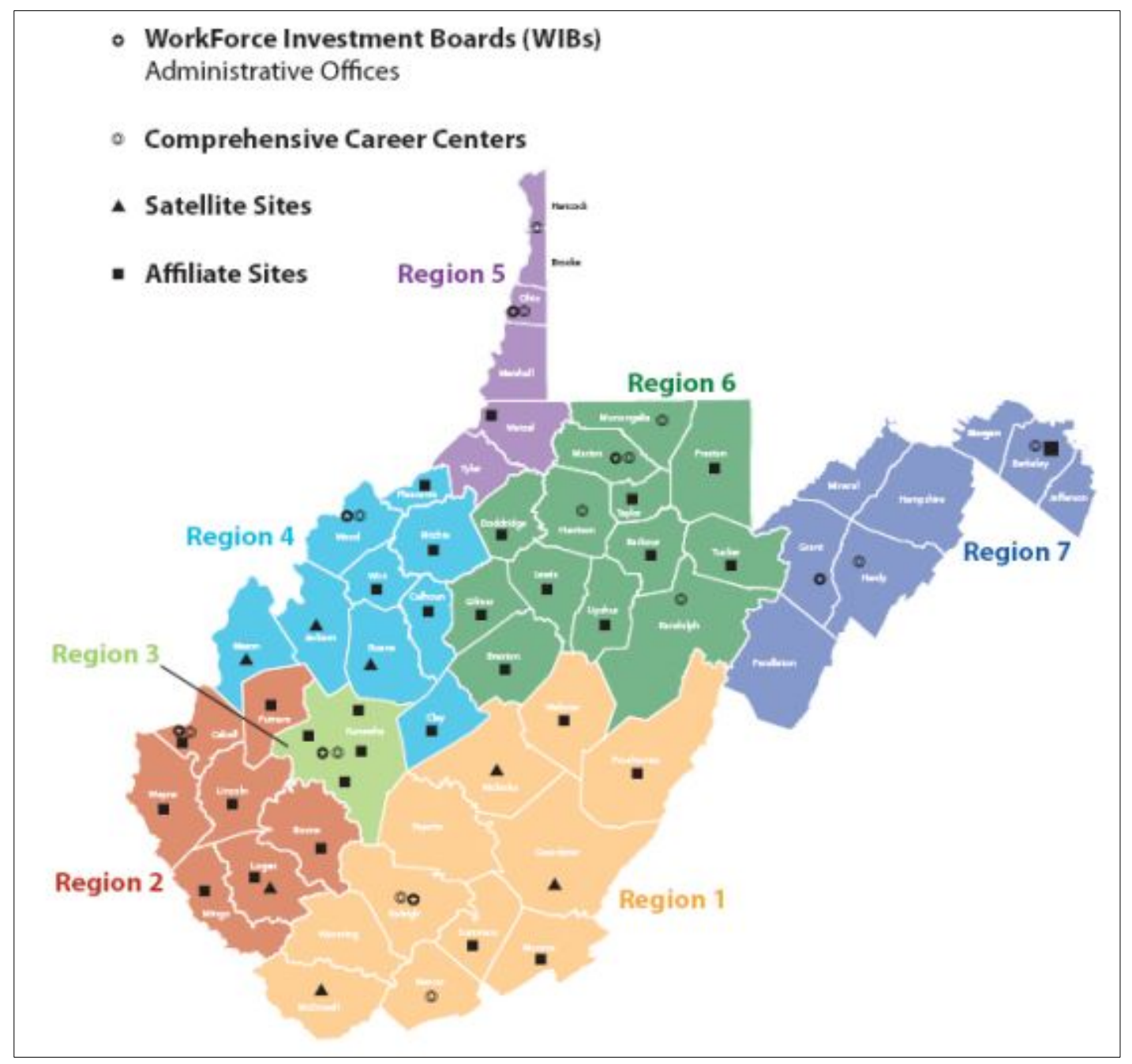

Note. From https://workforcewv.org/images/files/PublicInfo/annual-

reports/WorkForce_Development_Report_2014-2015.pdf by Workforce West Virginia Development System Report for Fiscal Year 2014. 


\subsection{Methods/Procedures}

\section{Research Design/Instrument Development}

\section{Accessible Population}

The target population for this study is comprised of 147 employment agencies that serve West Virginia, including WorkForce West Virginia regional Workforce Investment Boards, as well as educational institutions, nonprofit and profit employment service agencies, as indicated by previous research (Haynes et al., 2017). Further, a coding system with unique individual ID numbers was used in the online survey to maintain the confidentiality of the survey results. Building on the noted prior studies, this research uses themes discussed previously regarding employment training, job placement, and the potential economic well-being of job seekers to determine if West Virginia's employment agencies' efforts align with human, social, and financial capital theories. Further, using the WorkForce West Virginia territories of the seven regional Workforce Investment Boards (see Figure 4.4), this research examines the regional variations in employment training opportunities and projected economic outcomes via job placements across industry sectors.

\section{Instrumentation}

Using a descriptive research design method to summarize the attitudes and characteristics of employment agencies and their respective responding staff members (Ary et al., 2010), this study employed the use of a survey instrument (see Appendix G), which was adapted from previous Workforce Development research findings and surveys (Domin et al., 2020; Haynes et al., 2017; Latimer, 2004; Unger, 2007). The information gathered measures the selection process 
of employment training and job placement activities, as well as the regionally specific barriers to employment. Further, the agencies' perspectives and processes in assisting job seekers were assessed through closed- and open-ended questions, using a five-point Likert scale, in which participants were asked to choose if they: strongly agree, agree, neither agree nor disagree, disagree, or strongly disagree, with a workforce development activity statement. A second fourpoint scale Likert-type question provided information regarding the effectiveness of using industry recognized workforce development activities, with respondents selecting from: not at all, low, medium, high, and not used.

Likert-type data are considered an ordinal measurement scale since the items are not expressed in greater than or less than terms and are analyzed via "the chi-square measure of association, Kendall Tau B, and Kendall Tau C" (Boone \& Boone, 2012, p. 4). Converting the Likert-type statements into Likert scale composite scores by calculating the sum or means, allows the data to be analyzed at the interval measurement scale using Pearson's (r), t-test, ANOVA, or regression procedures (Boone \& Boone, 2012).

For this study, the Likert-type items provided ordinal data, using descriptive statistics to assess mode and median. Additionally, Pearson correlations were used to examine the between the range of workforce development activities, quick employment versus training, and the range of job placements across industry sectors. Further, the demographics data from the questionnaire provided information about the population, including the years of expertise, number of full-time and part-time staff, as well as the professional certification levels of the employment service agencies serving the state. Additional data includes an index of current workforce development activities and strategies to engage long-term non-employed individuals. Also, the instrument 
was submitted to West Virginia University's Institutional Review Board (IRB) for approval and the IRB has acknowledged this study (submitted 1/11/2021, exemption granted 1/15/2021).

\section{Validity and Reliability}

To ensure the instrument and the results are accurate, establishing validity of the instrument is essential, including ensuring that the survey instrument measures what is intended to be measured (Ary et al., 2010). For this study, face and content validity was established by presenting the instrument to a panel of workforce development experts, including West Virginia University faculty in both the Extension Services and the Agricultural and Extension Education program. Further, the instrument cannot be valid without being reliable, which is the "degree of consistency with which it measures whatever it is measuring" (Ary et al., 2010, p. 236). To ensure reliability, a pilot test was conducted with Ohio and Kentucky job services agencies bordering West Virginia. The pilot test was emailed, with an anonymous link to the online survey, and phone call reminders were conducted, as well as emails with attached questionnaires and unique links to the duplicate online survey. Reliability was further established using data from the final survey via a Cronbach's alpha calculation (Robinson et al., 1991). The reliability of survey section regarding Effectiveness of Workforce Supports and Job Retention Services was found to be exemplary at 0.942, and the section addressing Agreement with Agency's Engagement in Workforce Development Activities and Standards was also found to be exemplary at 0.823 (Robinson et al., 1991). The sample error was avoided by using a census of the population. The frame error, which involves developing a complete list of the intended population and surveying only the target population (Ary et al., 2010), was avoided by using a list compiled via United Way of Charleston's 2-1-1 list of community resources, as replicated 
from previous research (Haynes et al., 2017). Additional lists were obtained using information gathered from the websites of the West Virginia Department of Education, Jobs \& Hope West Virginia, West Virginia Family Resource Networks, West Virginia Association of Rehabilitation Facilities, West Virginia Division of Rehabilitation Services, WV Forward, and the Community and Technical College System of West Virginia. The selection error was avoided by checking the identified agencies list for duplications and by contacting potential agencies for organization name changes, such as clarifications in Doing Business As (DBA). Overall, this study avoided a measurement error by ensuring that the instrument utilized was reliable and valid.

\section{Data Collection}

As an efficient means of contacting the target population, the surveys were sent by email using Qualtrics survey links, although traditionally mailed surveys have garnered increased response rates (Ary et al., 2010). Based on Dillman's principles (Dillman et al., 1998, 2000), the instrument design was concise and easily completed. Because the response rate for internet surveys is less than mailed surveys (Ary et al., 2010; Dillman and Bowker, 2001), the online version was offered first, followed by an attached PDF survey available for mailing to increase the response rate. For the pilot test and the primary survey, a personalized cover letter (see Appendix H) was sent as an attachment and included a unique code for access to the online survey. Following the pilot test, pre-notification phone calls were made in advance of the primary survey to encourage participation and to verify current email addresses/contact information, as well as to verify employment services were currently being provided. Agencies that were not currently providing employment services were deleted from the final identified employment agencies. 
Table 4.1: Survey Timeline

\begin{tabular}{|c|c|c|}
\hline Date & Activity & Email Subject Headings \\
\hline $\begin{array}{l}\text { January } \\
14,2021\end{array}$ & $\begin{array}{l}\text { Emailed pilot survey link to Oh } \\
\text { \& KY job services agencies that } \\
\text { border West Virginia }\end{array}$ & WVU Workforce Development Research \\
\hline $\begin{array}{l}\text { February } \\
5-6,2021\end{array}$ & $\begin{array}{l}\text { Emailed WV employment } \\
\text { services agencies survey link }\end{array}$ & WVU Workforce Development Research \\
\hline $\begin{array}{l}\text { February } \\
9-10,2021\end{array}$ & $\begin{array}{l}\text { First reminder emailed, with end } \\
\text { date of Feb } 12^{\text {th }} \text {, with the plan to } \\
\text { continue to accept responses } \\
\text { until March } 5^{\text {th }} \text {, which allows for } \\
\text { Early/Late response comparison. }\end{array}$ & $\begin{array}{l}\text { Re: Reminder - WVU Survey: Mapping } \\
\text { Employment Services Across West } \\
\text { Virginia }\end{array}$ \\
\hline $\begin{array}{l}\text { February } \\
11-12,2021\end{array}$ & $\begin{array}{l}\text { 1. Second email reminder. } \\
\text { 2. Phone call reminders. }\end{array}$ & $\begin{array}{l}\text { Deadline Extended - } 65 \% \text { of WV } \\
\text { Employment Services Under-Reported- } \\
\text { WVU Survey: Mapping Employment } \\
\text { Services Across West Virginia }\end{array}$ \\
\hline $\begin{array}{l}\text { February } \\
16-17,2021\end{array}$ & Third email reminder. & $\begin{array}{l}\text { Deadline Extended - } 65 \% \text { of WV } \\
\text { Employment Services Under-Reported- } \\
\text { WVU Survey: Mapping Employment } \\
\text { Services Across West Virginia }\end{array}$ \\
\hline $\begin{array}{l}\text { February 23, } \\
2021\end{array}$ & $\begin{array}{l}\text { Mailed traditional postcard } \\
\text { reminders (Appendix I). }\end{array}$ & \\
\hline $\begin{array}{l}\text { February } \\
23-25,2021\end{array}$ & $\begin{array}{l}\text { Phone call reminders: updates to } \\
\text { contacts and continued services } \\
\text { re-verifications. }\end{array}$ & \\
\hline $\begin{array}{l}\text { February } \\
24-26,2021\end{array}$ & $\begin{array}{l}\text { Fourth email reminder, with } \\
\text { subject headings customized to } \\
\text { type of organization: } \\
\text { government, education } \\
\text { institution, nonprofit, profit, etc. }\end{array}$ & $\begin{array}{l}\text { Survey Deadline Extended - } 83 \% \text { of the } \\
\text { Employment Services provided by WV's } \\
\text { Career Centers are Currently Under- } \\
\text { Reported. WVU Survey: Mapping } \\
\text { Employment Services Across West } \\
\text { Virginia }\end{array}$ \\
\hline $\begin{array}{l}\text { March 1-2, } \\
2021\end{array}$ & $\begin{array}{l}\text { Fifth emailed reminder to } \\
\text { remaining late respondents, with } \\
\text { the closing date of March } 5 \text { th } \\
\text { announced, combined with } \\
\text { phone reminders. }\end{array}$ & $\begin{array}{l}\text { Survey Closing March 5, 2021, } \\
68 \% \text { of the Employment Services provided } \\
\text { by WV's Career \& Technical Centers are } \\
\text { Currently Under-Reported. WVU Survey: } \\
\text { Mapping Employment Services Across } \\
\text { West Virginia }\end{array}$ \\
\hline $\begin{array}{l}\text { March 3-5, } \\
2021\end{array}$ & $\begin{array}{l}\text { Sixth emailed reminder, final } \\
\text { request, with survey attached } \\
\text { and enclosed return address. } \\
\text { Specified Today for emails sent } \\
\text { on March 5, 2021. }\end{array}$ & $\begin{array}{l}\text { Reminder- Survey Closing Today: } 3 / 5 / 21 \text {, } \\
52 \% \text { of the Employment Services provided } \\
\text { by WV's Career \& Technical Centers are } \\
\text { Currently Under-Reported. WVU Survey: } \\
\text { Mapping Employment Services Across } \\
\text { West Virginia }\end{array}$ \\
\hline
\end{tabular}


The questionnaire link was emailed to the 147 identified employment agencies (see Appendix J). Subsequently, a duplicate questionnaire was emailed as an attachment, with a link enclosed in the email text and a return address to allow individuals the ability to respond by traditional mail. Follow-up calls included verification of contact information and services provided, as well as reiterating the purpose of the survey and encouraging completion of the survey online. Finally, reminder postcards were sent via traditional mail (see Appendix I) and reminders were emailed, resulting in a total of 10 contacts being conducted (see Table 4.1). The overall response rate for the primary survey was $83 \%$. Four questionnaires were submitted blank, which reduced the response rate to $80 \%$, with previous research indicting response rates of 62\% for push-to-web surveys (Dillman, 2011; McMaster et al., 2017; Millar \& Dillman, 2011).

\section{Objective 1: Assess the workforce development activities conducted by job service agencies, at the regional level and statewide.}

The data were obtained using a series of multiple response closed-ended questions regarding current workforce development activities (Q5. What are your agency's current workforce development and job retention programs/activities?), with the coding for the activities as binary: Selected $=1$ and Not Selected $=0$. The coding for the regional level of service activities, as noted previously, was based on the WorkForce West Virginia seven regional Workforce Boards (see Figure 4.4), with the coding of the locations as binary: Selected $=1$ and Not Selected $=0$. To operationalize, the agencies that served counties in more than one WorkForce West Virginia region were coded for each identified region served. For example, the Beckley Veterans Center serves counties in Region 1 and Region 2, and thus was coded for both regions (see Appendix $\mathrm{J}$ for complete list of surveyed employment agencies and areas served). 
Further, if an agency served the entire state, it was coded as providing statewide services. Parent organizations that serve individuals beyond the state's borders were requested to provide information only pertaining to services provided to West Virginians, such as number of clients served and their respective demographics.

\section{Objective 2: Determine the effectiveness of the workforce development activities and retention strategies.}

The data were obtained using a series of Likert-type items (Q7. Please check one effectiveness level for workforce supports and job retention services.), with 16 responses, selecting from the scale: not used $=1 ;$ not at all $=2 ;$ low $=3$; medium $=4$; and high $=5$.

\section{Objective 3: Determine if alternative workforce development activities were considered.}

The data were obtained via an open-ended question, (Q8. Please explain any other workforce supports and job retention services which were considered, and why they were not pursued.), with space available for an open-ended text response.

Objective 4: Examine the pre-pandemic and peri-pandemic barriers to employment from the perspective of the job services agencies' staff based on experience, staff case notes and intake interviews conducted by agency staff members.

The data were obtained using a multiple response question, based on your experience, as well as case notes and intake interviews, to what degree are the barriers listed below impacting your clients' efforts to gain employment? (Q9. Please check the level of significance of employment barriers.), with 17 options, and three possible responses: high, medium, or low. Responses were treated as two separate variables and coded as binary: Selected $=1$ and Not 
Selected $=0$. A text response was also available, as indicated by selection: other, please explain . Additional data were gained regarding a change in barriers, pre- and peri-pandemic, via the questions, (Q10. During the pandemic, have the barriers noted above changed?), and if yes is selected then, (Q11. In what ways have these barriers changed during the pandemic?).

\section{Objective 5: Examine the relationship between responding job services agencies and other agencies, statewide.}

The data were obtained using Likert-type items to determine the respondents attitude toward their respective (Q24) agency's engagement in workforce activities and industry standards. The question had eight items with the codes ranging from 1 (strongly disagree) to 5 (strongly agree). The final item was written in reverse rating order and inverted during coding to ensure scaling remained consistent. Additional data were obtained via an open-ended question, (Q4) Are your organization's workforce development activities influenced by other agencies' strategic or development plans?, and coded as binary: $\mathrm{No}=1$ and $\mathrm{Yes}=2$, with text response requested, please identify the other agencies.

Objective 6: Determine if the agencies' workforce development activities align with human, social, and financial capital theories.

To assess alignment with human capital theory, the data were obtained by requesting responding agencies to identify the number of individuals served and placed during 2019 and 2020, as well as their respective agencies' 2019 and 2020 dropout rates, competitively employed rates, and employed for 90 consecutive days rates (Q12 - Q14), which are indicators for successful completions and improved employment training and skills development outcomes 
(Goolsbee et al., 2019). Further, to ensure workforce development practitioners and clients garner the level of knowledge, skills, and abilities, collectively identified as competencies, needed to perform specific tasks related to employment (McCain et. al, 2004), the agencies' postsecondary development goals for staff and clients were requested (Q19 and Q20). Relatedly, this study assessed the development professional certifications held by staff members: supported employment specialist, job placement specialist or career development facilitator, career adviser/coach, career navigator, career counselor, vocational rehabilitation counselor, certified workforce development professional, no professional certifications and other (Q22).

With regards to the alignment of agencies' efforts with social capital theory, which workforce research indicates is the expansion of an individual's social network links to employment opportunities (Aguilera, 2002; Beggs \& Hurlbert, 1997; Coleman, 1988; Ruhose et al., 2018), through questions that examine program activities, such as the following:

- Strategic or development plans designed to address Diversity, Equity and Inclusion (Q3).

- Efforts to engage non-employed individuals, including long-term unemployed, dislocated workers, low skilled workers, persons with disabilities, youth, women, minorities, veterans and those with barriers to employment (Q5, Q25, and Q26).

Additionally, the social capital data regarding racial and ethnic demographics of individuals served were obtained, as well as target population demographics (Q25 and Q26), which provide insight into the agencies' program design and efforts to engage the long-term nonemployed identified in previous research (Case \& Deaton, 2017). Alignment with financial capital is also examined via the survey questions regarding job placement rates and client goals, which also provide data on employment outcomes. Relatedly, the question (Q6. In what fields of 
employment are your clients placed?) provides data regarding the potential income levels of placed individuals, which focuses on credentials valued by industry in occupations with career pathways leading potentially to earning a living wage (Glasmeier, 2020). In addition, testing the hypothesis of association, Pearson's (r), was calculated using the variables: PerCapita, RangeWFPlacements, TotalNumberCertifications, and RangeWFActivities.

\section{Early and Late Responders}

As determined by the response dates, respondents were divided into two groups, with those responding by the first deadline being classified as early respondents and those responding after the deadline being classified as late respondents, which are comparable to non-respondents (Miller \& Smith, 1983). A t-test was used to compare early and late respondents by the years of experience of the agency's executive director, as well as to the transformed mean Likert scale question regarding the effectiveness of workforce development strategies. Finding no statistically significant differences between the responses of early and late respondents, the findings were generalized to the entire population of the study (Miller \& Smith, 1983).

\section{Data Analysis}

The data were analyzed utilizing the SPSS 27.0 for Windows, with the level of significance was set a priori at $\alpha<.05$ for all statistical tests. Descriptive statistical analyses appropriate for the respective scales of measurement were performed on the data including measures of central tendency (mean, median, and mode) and variability (frequencies or standard deviation). The results were represented as frequencies and percentages as well as means, median and mode in both table and narrative form. 


\subsection{Findings/Results}

To identify the shared characteristics of the employment agencies, some demographic survey questions included the type of organization, number of employees, annual operating budget, and other general information. Further, the respondents $(n=117)$ were asked to classify their organizations as belonging to one of five categories: for-profit, nonprofit, government, faith-based, or educational institution, with the additional option of other available. Fifty-two (44\%) organizations were classified as educational institutions (one respondent indicated other and added in the available text response: for-profit education; another respondent indicated nonprofit, but the website indicated educational institution), 40 (34\%) were coded as nonprofit (one agency selected the option for nonprofit, but it has been coded as a government agency since their website indicates it is a state government agency funded by the federal government), 16 (14\%) were classified as government and included regional respondents from WorkForce West Virginia, West Virginia Division of Rehabilitation Services, and regional US Department Of Veteran Affairs - West Virginia Veterans Centers. Eight (7\%) respondents indicated for-profit and one (1\%) selected faith-based (see Table 4.2). For the respondents $(n=87)$ completing the employment status question, 44 (52\%) identified their positions as executive directors, 27 (31\%) managers, eight $(9 \%)$ support staff, three $(3 \%)$ as instructors or teachers, three $(3 \%)$ directors or principals, and two (2\%) were owners or presidents of the agencies. In addition, the respondents $(n=72)$ were asked how many years of economic development experience their respective agency director had acquired, of which five (7\%) indicated their directors had less than one year of experience and $16(22 \%)$ agencies had directors with 1-5 years of experience, followed by an additional $13(18 \%)$ agencies indicating their executive directors had 6-10 years of experience. 
Further, 17 (24\%) agencies had directors with 11-20 years of experience and 10 (14\%) agencies had directors with 21-30 years of experience, with the remaining 11 (15\%) agencies' directors having 31-40 years of experience (see Table 4.2). On average the agencies' executive directors had approximately 15 years of experience $(\mathrm{M}=14.91, \mathrm{SD}=12.18)$.

Table 4.2: Characteristics of Employment Agencies Providing Services to West Virginia

\begin{tabular}{|c|c|c|c|c|c|c|c|c|}
\hline \multicolumn{3}{|c|}{$\begin{array}{l}\text { Type of Organization } \\
(\mathrm{n}=117)\end{array}$} & \multicolumn{3}{|c|}{$\begin{array}{l}\text { Employment Status } \\
\qquad(\mathrm{n}=87)\end{array}$} & \multicolumn{3}{|c|}{$\begin{array}{c}\text { Executive Directors' Years of } \\
\text { Experience } \\
(\mathrm{n}=72)\end{array}$} \\
\hline Type & $\mathrm{N}$ & $(\%)$ & Title & $\mathrm{N}$ & $(\%)$ & $\begin{array}{l}\text { Length of } \\
\text { Time }\end{array}$ & $\mathrm{N}$ & $(\%)$ \\
\hline $\begin{array}{l}\text { Educational } \\
\text { Institution }\end{array}$ & 52 & (44) & $\begin{array}{l}\text { Executive } \\
\text { Director }\end{array}$ & 44 & (52) & $\begin{array}{l}\text { Less than } 1 \\
\text { year }\end{array}$ & 5 & (7) \\
\hline Nonprofit & 40 & (34) & Manager & 27 & (31) & $1-5$ years & 16 & (22) \\
\hline *Government & 16 & (14) & Support Staff & 8 & (9) & $6-10$ years & 13 & (18) \\
\hline For-profit & 8 & (7) & Instructor & 3 & (3) & $11-20$ years & 17 & (24) \\
\hline \multirow[t]{2}{*}{ Faith-Based } & 1 & (1) & $\begin{array}{l}\text { Director or } \\
\text { Principal }\end{array}$ & 3 & (3) & 21-30 years & 10 & (14) \\
\hline & & & $\begin{array}{l}\text { Owner or } \\
\text { President }\end{array}$ & 2 & (2) & $31-40$ years & 11 & (15) \\
\hline
\end{tabular}

Note. Percentages are computed within columns. *Government agencies represent regional respondents from WorkForce West Virginia, West Virginia Division of Rehabilitation Services, and regional US Department Of Veteran Affairs - West Virginia Veterans Centers.

Respondents were also asked to indicate the agency's staffing levels, which included fulltime employees (FTEs), part-time employees (PTEs), interns (INTs) and volunteers (VOLs). Ranked by staffing capacity of FTEs $(\mathrm{M}=59.26, \mathrm{SD}=86.76)$, the majority, $15(20 \%)$ respondents had 6-15 FTEs, followed by 14 (19\%) respondents indicating their agencies had more than 100 FTEs. Additionally, 11 (15\%) respondents indicated they had 16-30 FTEs, 10 
(13\%) respondents had 41-100 FTEs, nine (12\%) respondents had 31-40 employees, eight (11\%) respondents had 2-5 FTEs, and seven (10\%) respondents had one FTE. Further, for PTEs ranked by percentage of staffing capacity $(M=85.43, \mathrm{SD}=379.97)$, the majority, $18(34 \%)$, of respondents had 1-5 PTEs, followed by $11(20 \%)$ respondents that indicated their agencies had 16-30 PTEs (see Table 4.3).

Table 4.3: Employment Agencies’ Staffing Capacity

\begin{tabular}{|c|c|c|c|c|c|c|c|c|c|c|c|}
\hline $\begin{array}{r}\text { FTE Staf } \\
(\mathrm{n}=74)\end{array}$ & & & $\begin{array}{l}\text { PTE Staff } \\
(\mathrm{n}=53)\end{array}$ & & & $\begin{array}{l}\text { Interns } \\
(n=29)\end{array}$ & & & $\begin{array}{l}\text { Volunteers } \\
(\mathrm{n}=27)\end{array}$ & & \\
\hline $\begin{array}{l}\# \text { of } \\
\text { FTEs }\end{array}$ & $\mathrm{N}$ & $(\%)$ & $\begin{array}{l}\text { \# of } \\
\text { PTEs }\end{array}$ & $\mathrm{N}$ & $(\%)$ & $\begin{array}{c}\# \text { of } \\
\text { Interns }\end{array}$ & $\mathrm{N}$ & $(\%)$ & $\begin{array}{c}\text { \# of } \\
\text { Volunteers }\end{array}$ & $\mathrm{N}$ & $(\%)$ \\
\hline $1 \mathrm{FTE}$ & 7 & (10) & 0 PTEs & 5 & (10) & 0 INTs & 14 & (48) & $0 \mathrm{VOLs}$ & 12 & (44) \\
\hline $\begin{array}{c}2-5 \\
\text { FTEs }\end{array}$ & 8 & (11) & $\begin{array}{c}1-5 \\
\text { PTEs }\end{array}$ & 18 & (34) & $\begin{array}{c}1-5 \\
\text { INTs }\end{array}$ & 13 & (46) & 1-5 VOLs & 8 & (30) \\
\hline $\begin{array}{c}\text { 6-15 } \\
\text { FTEs }\end{array}$ & 15 & $(20)$ & $\begin{array}{l}6-15 \\
\text { PTEs }\end{array}$ & 6 & (11) & $\begin{array}{l}\text { 6-15 } \\
\text { INTs }\end{array}$ & 1 & (3) & $\begin{array}{l}6-30^{+} \\
\text {VOLs }\end{array}$ & 7 & (26) \\
\hline $\begin{array}{l}\text { 16-30 } \\
\text { FTEs }\end{array}$ & 11 & (15) & $\begin{array}{l}16-30 \\
\text { PTEs }\end{array}$ & 11 & (20) & $\begin{array}{c}16-30^{+} \\
\text {INTs }\end{array}$ & 1 & (3) & & & \\
\hline $\begin{array}{l}31-40 \\
\text { FTEs }\end{array}$ & & (12) & $\begin{array}{c}31-40 \\
\text { PTEs }\end{array}$ & 2 & (4) & & & & & & \\
\hline $\begin{array}{l}41-100 \\
\text { FTEs }\end{array}$ & 10 & (13) & $\begin{array}{l}\text { 41-100 } \\
\text { PTEs }\end{array}$ & 7 & (13) & & & & & & \\
\hline $\begin{array}{c}101^{+} \\
\text {FTEs }\end{array}$ & 14 & (19) & $\begin{array}{l}101^{+} \\
\text {PTEs }\end{array}$ & 4 & (8) & & & & & & \\
\hline
\end{tabular}

Note. Percentages are computed within columns.

Additionally, seven (13\%) respondents indicated they had 41-100 PTEs, six (11\%) respondents had 6-15 PTEs, five (10\%) respondents had no PTEs, four (8\%) respondents had 
more than 100 PTEs, and two (4\%) respondents indicated their agencies had 31-40 PTEs (see Table 4.3). Based on the responses, the average agency had approximately 59 full-time and 85 part-time employees. These responses are skewed by the larger organizations reporting having nearly 450 full-time and 450 part-time employees, which results in the two larger numbers of FTEs being between 6-15 employees and $100^{+}$per agency. In addition, $36 \%$ of staffing question respondents $(n=27)$ indicated that they supported their staff capacity with interns and/or volunteers, with five (19\%) agencies indicating their agency operates with the assistance of volunteers and interns, 11 (41\%) respondents indicating they are supported by only volunteers and no interns, and an additional 11 respondents indicating the reverse of support by only interns with no volunteers (see Table 4.3). The majority of responses to the question of interns $(\mathrm{n}=29)$ and volunteers $(\mathrm{n}=27)$ indicates that $14(48 \%)$ of agencies had no interns and $12(44 \%)$ of agencies had no volunteers (see Table 4.3). Per agency, the average number of interns was approximately two $(\mathrm{M}=1.86, \mathrm{SD}=4.73)$, and the average number of volunteers per agency was 36 , with four larger agencies reporting having between $99-450$ volunteers $(\mathrm{M}=36.41, \mathrm{SD}=$ 93.14). The four larger volunteer assisted agencies also indicated their staffing includes $24-50$ FTEs and 8-18 PTEs (see Table 4.3).

The respondents' education levels $(n=89)$ ranged from high school or equivalency to doctoral degrees, with one (1\%) obtaining a high school degree, four (5\%) with some college, one (1\%) completing technical school, one (1\%) with an associate degree, $26(29 \%)$ respondents with bachelor degrees, 48 (54\%) with master degrees, five (6\%) indicating doctoral degrees, and three (3\%) selecting other, noting "2 Masters Degrees, 1 Education Specialist degree," "All but dissertation for doctorate," "20+ years of for profit managerial and business experience," and ED.S. The respondents $(\mathrm{n}=89)$ also indicated their age ranges, with $13(15 \%)$ respondents 
indicating they were 20-35 years old, 15 (17\%) respondents were $36-45$ years old, 22 (25\%) respondents were $46-55$ years old, $32(36 \%)$ respondents were $56-65^{+}$years old, and seven (7\%) respondents preferred not to disclose their ages. The gender of the respondents $(n=89)$ completing the questionnaire include $50(56 \%)$ females and $34(38 \%)$ males, with five $(6 \%)$ respondents not disclosing their gender (see Table 4.4).

Table 4.4: Demographics of Employment Agencies' Respondents

\begin{tabular}{|c|c|c|c|c|c|c|c|c|}
\hline $\begin{array}{l}\text { Education } \\
(\mathrm{n}=89)\end{array}$ & $\mathrm{N}$ & $(\%)$ & $\begin{array}{c}\text { Age } \\
(n=89)\end{array}$ & $\mathrm{N}$ & $(\%)$ & $\begin{array}{l}\text { Gender } \\
(\mathrm{n}=89)\end{array}$ & $\mathrm{N}$ & $(\%)$ \\
\hline $\begin{array}{l}\text { High School or } \\
\text { equivalent }\end{array}$ & 1 & (1) & 20 to 35 & 13 & (15) & Female & 50 & (56) \\
\hline $\begin{array}{l}\text { Some college } \\
\text { but no degree }\end{array}$ & 4 & (5) & 36 to 45 & 15 & (17) & Male & 34 & (38) \\
\hline $\begin{array}{l}\text { Technical } \\
\text { school }\end{array}$ & 1 & (1) & 46 to 55 & 22 & (25) & $\begin{array}{l}\text { Prefer not } \\
\text { to disclose }\end{array}$ & 5 & (6) \\
\hline $\begin{array}{l}\text { College Assoc. } \\
\text { degree (2-yr.) }\end{array}$ & 1 & (1) & 56 to $65^{+}$ & 32 & (36) & & & \\
\hline $\begin{array}{l}\text { College } \\
\text { Bachelor's } \\
\text { degree }\end{array}$ & 26 & (29) & $\begin{array}{l}\text { Prefer not } \\
\text { to } \\
\text { disclose }\end{array}$ & 7 & (7) & & & \\
\hline $\begin{array}{l}\text { Master's } \\
\text { degree }\end{array}$ & 48 & (54) & & & & & & \\
\hline $\begin{array}{l}\text { Doctoral } \\
\text { degree }\end{array}$ & 5 & (6) & & & & & & \\
\hline Other & 3 & (3) & & & & & & \\
\hline
\end{tabular}

Note. Percentages are computed within columns. 
Table 4.5: Regions Served by Employment Agency Types

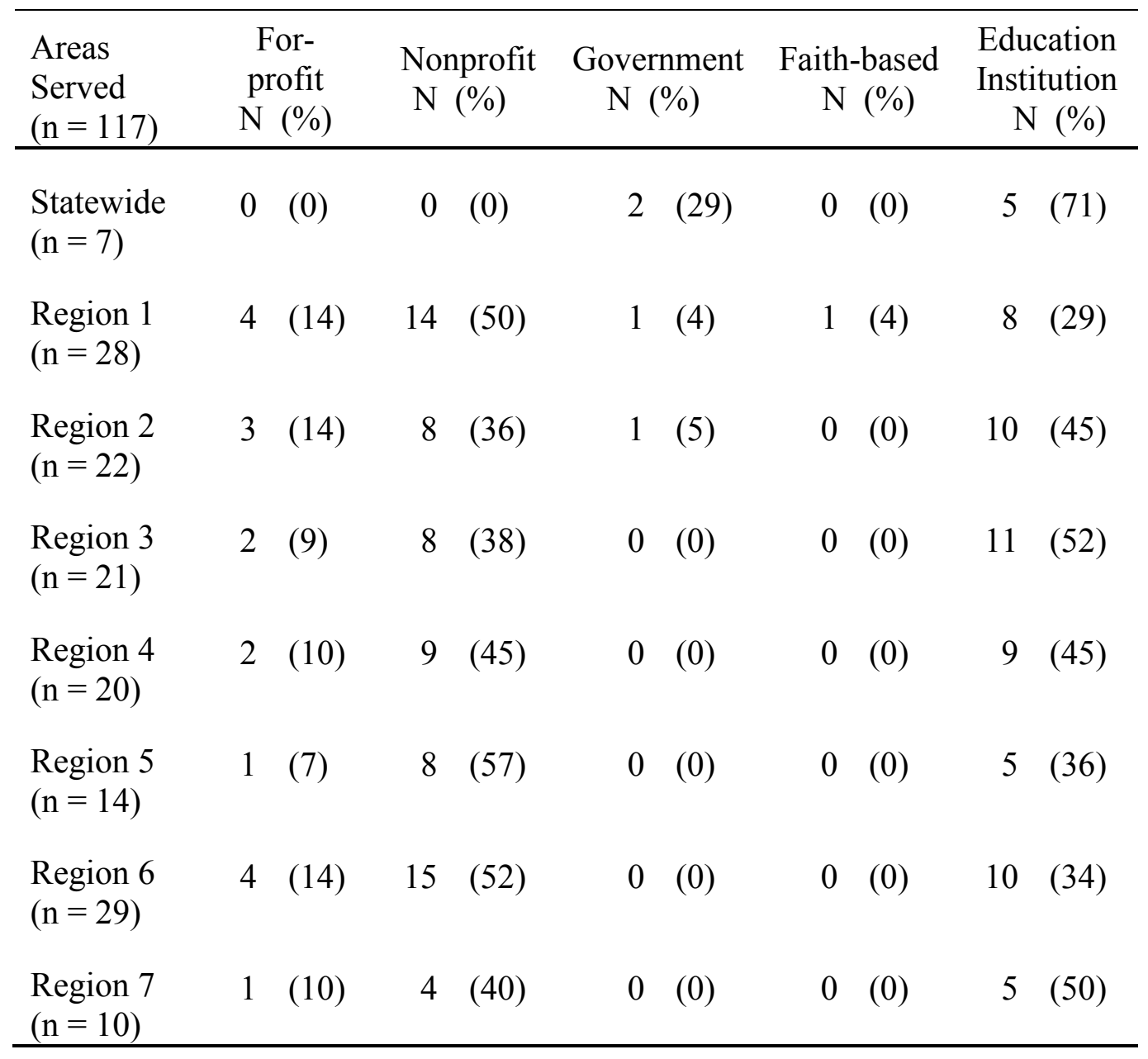

Note. Percentages are computed across rows. Agencies that serve more than one region were counted within their identified multiple regions.

Forty-eight (33\%) of the identified 147 employment agencies surveyed serve multiple counties within WorkForce West Virginia regions (see Appendix J). Further, seven responding employment agencies serve statewide, including two (29\%) government agencies: WorkForce West Virginia and the West Virginia Division of Rehabilitation Services and five (71\%) educational institutions. To assess the range of services offered to West Virginians, the responding agencies $(n=117)$ were asked to identify the counties served by their organizations, 
which allowed for the regional services to be determined (recall that agencies serving multiple regions are counted within each region served, as indicated by the respondent). At the regional level, as related to the five categories of for-profit, nonprofit, government, faith-based, or educational institution, the 28 agencies serving Region 1 include four (14\%) for-profit agencies, $14(50 \%)$ nonprofits, one (4\%) government agency, one (4\%) is a faith-based agency, and eight (29\%) educational institutions, resulting in a total of 28 employment agencies (see Table 4.5). Twenty-two agencies serve Region 2, including three (14\%) for-profits, eight (36\%) nonprofits, one $(5 \%)$ government agencies, and $10(45 \%)$ educational institutions, with no faith-based agencies. Region 3, with 21 agencies serving the area, has two (9\%) for-profits, eight (38\%) nonprofits, no government agencies, no faith-based agencies, and 11 (52\%) educational institutions. Region 4 also has 20 agencies serving the area, including two (10\%) for-profits, nine $(45 \%)$ nonprofits, no government agencies, no faith-based agencies, and nine $(45 \%)$ educational institutions. Served by 14 agencies, Region 5 has one (7\%) for-profit, eight (57\%) nonprofits, no government agencies, no faith-based agencies, and five (36\%) educational institutions. Region 6, with 29 agencies, has the highest number of employment agencies serving a region, with four (14\%) for-profit, 15 (52\%) nonprofits, no government agencies, no faith-based agencies, and 10 (34\%) educational institutions. Region 7, with 10 agencies, has the lowest number of employment agencies, with one (10\%) for-profit, four (40\%) nonprofits, no government agencies, no faith-based agencies, and five (50\%) educational institutions (see Table 4.5).

The responding agencies $(n=22)$ were also asked via an open-ended question to note if any state or local policies or regulations have limited the effectiveness of their organizations, with one (5\%) responding funding limitations, two (9\%) indicating the question was considered 
N/A, six (27\%) indicating none, and six (27\%) indicating COVID-19 related policies, including (a) "We could have qualified for COVID funding, but were restricted/shut out because we were non-profit or we had no employees. We sought out grant money to maintain and keep our doors open, but small, local non-profits were completely forgotten by disaster relief at ALL LEVELS of government assistance;" (b) "The best state of effectiveness I have witnessed in my 40 years of social service was the economic development seen during President Trump administration. More people were working, wages were increasing, all groups were experiencing the lowest unemployment rates in history, millions removed from food stamps and then Covid (sic) hit. I have never seen a social program achieve these accomplishments;" (c) "Transportation issues with Trainees during the pandemic;" (d) "not allowing services during the pandemic or limited in-person interactions;", (e) "Dislocated workers that are underemployed;" and (f) "Last year's extra unemployment limited our job placement abilities."

Further, six (27\%) respondents indicated policies issues included interactions with government agencies, such as (a) "DRS services is prime funder, thus their lack of referrals limits our abilities significantly;" (b) "Federal guidelines for WIOA are too stringent. Working poor are left out;" (c) "Income guidelines for programs are too stringent. Those helping themselves and barely hanging on are not eligible for most services;" (d) "We are limited to the Federal/state regulations and policies;" (e) "Fines that prevent people from getting driver's licenses;" (f) and one respondent simply wrote, WVCAD. Additionally, one (5\%) respondent noted, "We are guided by WVDE CTE. They do not limit our effectiveness but serve to guide us in the appropriate direction. They give us guidelines and consistency in program requirements. 
Table 4.6: Annual Budgets of Employment Agencies by Region

\begin{tabular}{|c|c|c|c|c|c|c|c|}
\hline \multirow{2}{*}{$\begin{array}{l}\begin{array}{l}\text { Areas } \\
\text { Served } \\
(\mathrm{n}=78)\end{array} \\
\begin{array}{l}\text { Statewide } \\
(\mathrm{n}=5)\end{array}\end{array}$} & $\begin{array}{l}\text { Less than } \\
\$ 100,000 \\
\mathrm{~N}(\%)\end{array}$ & $\begin{array}{c}\$ 100,000 \\
\text { to } \\
\$ 499,999 \\
\mathrm{~N}(\%)\end{array}$ & $\begin{array}{c}\$ 500,000 \\
\text { to } \\
\$ 1,999,999 \\
\mathrm{~N}(\%) \\
\end{array}$ & $\begin{array}{c}\$ 2,000,000 \\
\text { to } \\
\$ 4,999,999 \\
\mathrm{~N}(\%) \\
\end{array}$ & $\begin{array}{c}\begin{array}{c}\$ 5^{+} \\
\text {million }\end{array} \\
\mathrm{N}(\%) \\
\end{array}$ & \multicolumn{2}{|c|}{$\begin{array}{l}\text { Prefer not } \\
\text { to respond } \\
\mathrm{N}(\%)\end{array}$} \\
\hline & $\begin{array}{ll}0 & (0)\end{array}$ & $\begin{array}{ll}0 & (0)\end{array}$ & $1 \quad(20)$ & $\begin{array}{ll}0 & (0)\end{array}$ & $2(40)$ & 2 & (40) \\
\hline $\begin{array}{l}\text { Region } 1 \\
(\mathrm{n}=24)\end{array}$ & 3 (13) & $2(8)$ & $\begin{array}{ll}6 & (25)\end{array}$ & $3 \quad(13)$ & $4 \quad(17)$ & 6 & (24) \\
\hline $\begin{array}{l}\text { Region } 2 \\
(\mathrm{n}=20)\end{array}$ & $\begin{array}{ll}0 & (0)\end{array}$ & $4 \quad(20)$ & $2(10)$ & $4 \quad(20)$ & $5 \quad(25)$ & 5 & (25) \\
\hline $\begin{array}{l}\text { Region } 3 \\
(\mathrm{n}=19)\end{array}$ & 2 (11) & $1 \quad(5)$ & $5 \quad(26)$ & 3 (16) & $4 \quad(21)$ & 4 & (21) \\
\hline $\begin{array}{l}\text { Region } 4 \\
(\mathrm{n}=19)\end{array}$ & $\begin{array}{ll}0 & (0)\end{array}$ & 2 (11) & 2 (11) & $6 \quad(31)$ & 3 (16) & 6 & (31) \\
\hline $\begin{array}{l}\text { Region } 5 \\
(\mathrm{n}=12)\end{array}$ & 1 & $1 \quad(8)$ & $2(18)$ & 1 & 1 & 6 & (50) \\
\hline $\begin{array}{l}\text { Region } 6 \\
(\mathrm{n}=26)\end{array}$ & $3 \quad(12)$ & $4 \quad(15)$ & 3 (12) & $5 \quad(19)$ & 3 (12) & 8 & (30) \\
\hline $\begin{array}{l}\text { Region } 7 \\
(\mathrm{n}=10)\end{array}$ & $2 \quad(20)$ & $1 \quad(10)$ & $2(20)$ & $3 \quad(30)$ & $\begin{array}{ll}0 & (0)\end{array}$ & 2 & (20) \\
\hline
\end{tabular}

Note. Percentages are computed across rows, with agencies that serve more than one region being counted within their specific multiple regions.

The responding agencies $(\mathrm{n}=78)$ were also asked to select their relative annual operating budget from options ranging from less than $\$ 100,000$ to $\$ 5^{+}$million, with agencies that serve more than one region being counted within their identified multiple regions (see Table 4.6). Statewide $(n=7)$, two agencies $(40 \%)$ had annual budgets of more than $\$ 5+$ million, two agencies (40\%) preferred not to answer, and one (20\%) agency had an annual budget of $\$ 500,000$ to $\$ 1,999,999$ (see Table 4.6). 
Calculating the percentages within each region based on the following: Region 1 (n = 24), Region $2(n=20)$, Region $3(n=19)$, Region $4(n=19)$, Region $5(n=12)$, Region $6(n=$ 26), and Region $7(n=10)$, the responding agencies with annual budgets less than $\$ 100,000$ were located in five regions, three (13\%) agencies within Region 1, two (11\%) in Region 3, one (8\%) in Region 5, three (12\%) in Region 6, and two (20\%) in Region 7. Agencies with annual budgets between $\$ 100,000$ to $\$ 499,999$ were located in every region, with two (8\%) in Region 1 , four (20\%) in Region 2, one (5\%) in Region 3, two (11\%) in Region 4, one (8\%) in Region 5, four $(15 \%)$ in Region 6, and one (10\%) in Region 7 . For agencies with annual budgets ranging between $\$ 500,000$ to $\$ 1,999,999$, six $(25 \%)$ served Region 1, two (10\%) served Region 2, five (26\%) served Region 3, two (11\%) served Region 4, two (18\%) served Region 5, three (12\%) served Region 6, and two (20\%) served Region 7 (see Table 4.6).

The number of agencies with budgets between $\$ 2,000,000$ to $\$ 4,999,999$ ranged from one to six per region, with three (13\%) in Region 1, four (20\%) in Region 2, three (16\%) in Region 3 , six (31\%) in Region 4, one (8\%) in Region 5, five (19\%) in Region 6, and three (30\%) in Region 7. All regions, except Region 7, had agencies with annual budgets of more than $\$ 5+$ million, with four (17\%) in Region 1, five (25\%) in Region 2, four (21\%) in Region 3, three (16\%) in Region 4, one (8\%) in Region 5, and three (12\%) in Region 6. Preferred not to respond was selected by respondents in every region, with six (24\%) in Region 1, five (25\%) in Region 2 , four (21\%) in Region 3, six (31\%) in Region 4, six (50\%) in Region 5, eight (30\%) in Region 6, and two (20\%) in Region 7 (see Table 4.6).

In addition, responding agencies $(n=84)$ were asked to identify their funding sources from the following options: federal, state, county, other government sources, members, tuition, endowment, fees and/or sales, private donations, and competitive grants, with an open text 
option for other (multiple selections were optional). Ranked by highest to lowest percentage selected, state funding was indicated most often, with $71(85 \%)$ agencies, followed by federal support, with 62 (74\%) agencies. Competitive grants were indicated by 43 (51\%) agencies, followed by 33 (39\%) agencies indicating private donations, with fees and/or sales selected by $28(33 \%)$ agencies, and $25(30 \%)$ agencies indicating county funding was provided. Tuition was selected by $23(27 \%)$ agencies and eight (10\%) agencies selected endowment support, with seven $(8 \%)$ agencies indicating other government sources, and two (2\%) agencies indicating members support (see Table 4.7). In addition, three agencies noted funding streams also included basic support grants, event sponsorships, and fundraisers.

Table 4.7: Employment Agencies’ Funding Sources

\begin{tabular}{lcc}
\hline Sources $(\mathrm{n}=84)$ & $\mathrm{N}$ & $\%$ \\
\hline State & 71 & 85 \\
Federal & 62 & 74 \\
Competitive grants & 43 & 51 \\
Private donations & 33 & 39 \\
Fees and/or sales & 28 & 33 \\
County & 25 & 30 \\
Tuition & 23 & 27 \\
Endowment & 8 & 10 \\
Other government sources & 7 & 8 \\
Members & 2 & 2 \\
\hline
\end{tabular}

Note. Percentages are computed within columns, and the percentage total equates to greater than $100 \%$, as multiple selections were available. 


\section{Objective 1: Assess the workforce development activities conducted by job service agencies, at the regional level and statewide.}

To assess the workforce development activities available to West Virginians, responding agencies $(n=113)$ were asked to identify their services and programs from 37 options, which, following the methods of previous research (Haynes et al., 2017), are organized into four categories:

- Educational services

- Employment services (e.g., on-the-job training (OJT) and/or labor market information)

- Support services (e.g., childcare assistance)

- Services for special populations

With regards the category educational services, the responding agencies $(\mathrm{n}=113)$, include four (57\%) statewide agencies that provide basic academic skills development, four (57\%) agencies provide apprenticeships, and four (57\%) agencies provides digital skills development, with three (43\%) agencies also providing industry recognized certifications. Region $1(n=29)$ has the highest number of agencies providing workforce development activities, followed by Region $2(n=26)$ and Region $6(n=26)$. Regions 3 and 4 have 23 agencies, followed by 15 agencies serving Region 5 and ten agencies serving Region 7. Sixteen (62\%) agencies in Region 6 provide basic academic skills development, with 13 agencies providing the service in Regions 2, 3, and 4 (50\%, 57\%, and 57\%, in sequence) and 11 (38\%) agencies in Region 1, followed by six (60\%) agencies in Region 7 and five (33\%) agencies in Region 5. With 11 (43\%) agencies, Region 6 also has the highest number of agencies providing digital skills development, followed by Regions 1 and 2, with six agencies ( $21 \%$ and $23 \%$, in order). Regions 3 and 4 have five (22\%) agencies providing digital skills 
development, with Region 7 at four (40\%) agencies, and Region 5 having three (20\%) agencies (see Table 4.8).

Table 4.8: Workforce Development Activities, Educational Services

\begin{tabular}{|c|c|c|c|c|c|c|c|c|}
\hline \multirow{2}{*}{$\begin{array}{l}\begin{array}{l}\text { Areas } \\
\text { Served } \\
(\mathrm{n}=113)\end{array} \\
\begin{array}{l}\text { Statewide } \\
(\mathrm{n}=7)\end{array}\end{array}$} & \multicolumn{2}{|c|}{$\begin{array}{c}\text { Basic } \\
\text { Academic } \\
\text { Skills } \\
\text { N (\%) } \\
\end{array}$} & \multicolumn{2}{|c|}{$\begin{array}{c}\text { Digital Skills } \\
\text { Development } \mathrm{N} \\
(\%)\end{array}$} & \multicolumn{2}{|c|}{$\begin{array}{c}\text { Industry } \\
\text { Certifications } \\
\text { N (\%) }\end{array}$} & \multicolumn{2}{|c|}{$\begin{array}{c}\text { Apprenticeships } \\
\text { N (\%) }\end{array}$} \\
\hline & 4 & (57) & 4 & (57) & 3 & (43) & 4 & (57) \\
\hline $\begin{array}{l}\text { Region } 1 \\
(n=29)\end{array}$ & 11 & (38) & 6 & (21) & 3 & (10) & 5 & (17) \\
\hline $\begin{array}{l}\text { Region } 2 \\
(n=26)\end{array}$ & 13 & $(50)$ & 6 & (23) & 9 & (35) & 5 & (19) \\
\hline $\begin{array}{l}\text { Region } 3 \\
(\mathrm{n}=23)\end{array}$ & 13 & $(57)$ & 5 & (22) & 10 & (43) & 3 & (13) \\
\hline $\begin{array}{l}\text { Region } 4 \\
(n=23)\end{array}$ & 13 & $(57)$ & 5 & (22) & 9 & (39) & 2 & (7) \\
\hline $\begin{array}{l}\text { Region } 5 \\
(n=15)\end{array}$ & 5 & (33) & 3 & (20) & 4 & (27) & 1 & (7) \\
\hline $\begin{array}{l}\text { Region } 6 \\
(n=26)\end{array}$ & 16 & $(62)$ & 11 & (43) & 11 & (42) & 5 & (19) \\
\hline $\begin{array}{l}\text { Region } 7 \\
(\mathrm{n}=10)\end{array}$ & 6 & $(60)$ & 4 & $(40)$ & 3 & (30) & 4 & $(40)$ \\
\hline
\end{tabular}

Note. Percentages are computed across rows, with agencies that serve more than one region being counted within their identified multiple regions. The percentage total equates to greater than $100 \%$, as multiple selections were available to respondents.

Further, industry certification training was provided by 11 (42\%) agencies Region 6, with 10 (43\%) agencies in Region 3, and nine agencies in Regions 2 and 4 (35\% and 39\%, respectively), with four (27\%) agencies in Region 5 and three agencies in Regions 1 and 7, (10\% and 30\%, in order). Apprenticeships are more prevalent in Regions 1, 2, and 6, with five agencies $(17 \%, 19 \%$, and 19\%, respectively), followed by four (40\%) in Region 7 and three 
(13\%) agencies in Region 3, with two (7\%) agencies in Region 4 and one (7\%) agency in Region 5 (see Table 4.8).

With regards the category employment services, the responding agencies $[(\mathrm{n}=113$, with Region $1(\mathrm{n}=29)$, Region $2(\mathrm{n}=26)$, Region $3(\mathrm{n}=23)$, Region $4(\mathrm{n}=23)$, Region $5(\mathrm{n}=15)$, Region $6(\mathrm{n}=26)$, and Region $7(\mathrm{n}=10)$ ], include seven statewide agencies, of which six $(86 \%)$ agencies provide job listings, interview skills development, job search skills development, and career counseling, with five (71\%) agencies providing resume preparation assistance, job development and placement, job readiness training, and career and vocational assessments. In addition, three (43\%) statewide agencies provide on-the-job training (OTJ), Individual Employment Plans (IEP), and local labor market jobs/occupations projections, followed by two (29\%) agencies also offering job clubs, with one (14\%) agency providing resume posting \& blasting services (see Table 4.9).

Regionally, the most prevalent employment service ranked by percentage selected is providing job listings to the unemployed or under-employed, a service which is offered by 23 (88\%) agencies in Region 6, followed by 21 agencies in Regions 1 and 2, (72\% and 81\%, in order). In Region 3, 19 (83\%) agencies provide job listings, with 15 (65\%) agencies in Region 4 offering the service, followed by 10 (100\%) in Region 7 and nine (60\%) in Region 5. Resume preparation assistance, the state's second most accessible employment service, is provided by 20 (77\%) agencies in Region 6, followed by 19 agencies (73\% and 83\%, respectively) in Regions 2 and 4, with 18 (78\%) agencies in Region 3 and 17 (59\%) in Region 1. The service is also offered by $12(80 \%)$ agencies Region 5 and eight (80\%) in Region 7 . Additionally, interview skills development, the third most accessible employment services, is provided by 23 (88\%) agencies in Region 6 and 17 agencies in Regions 1, 2, and 3, (59\%,65\%, and 74\%, correspondingly). 
Further, 16 (70\%) agencies in Region 4 provide the services, followed by ten (67\%) in Region 5 and eight (80\%) in Region 7 (see Table 4.9).

The accessibility of job search skills training ranks fourth in the employment services categories, with 21 (81\%) agencies in Region 6 providing the service, followed by 15 agencies in Regions 2 and 3, (58\% and 65\%, respectively). Additionally, 13 (57\%) agencies in Region 4 offer the service, followed by 12 (41\%) agencies in Region 1, and 11 (73\%) in Region 5, with eight (80\%) in Region 7. Ranking fifth is job development and placement, which is provided by 18 (62\%) agencies in Region 1, followed by 17 (65\%) agencies in Region 6, and 14 agencies in Regions 2 and 3, (54\% and 61\%, correspondingly), with 11 (48\%) in Region 4, seven (70\%) in Region 7 and six (40\%) in Region 5. Career counseling, ranking sixth in available employment services, is provided by 14 (54\%) agencies in Region 6, followed by 12 agencies in Regions 2, 3, and $4,(46 \%, 52 \%$, and 52\%, by sequence), and 11 (38\%) agencies in Region 1, with nine (60\%) in Region 5 and five (50\%) in Region 7 (see Table 4.9).

Job readiness training ranks seventh and is provided by 17 (65\%) agencies in Region 6, followed by 13 (45\%) in Region 1 and 12 (46\%) in Region 2, with 10 agencies in Regions 3 and 4, (both at 43\%), eight (80\%) in Region 7, and seven (47\%) in Region 5. Career and vocational assessments follow, with 14 (54\%) agencies in Region 6, followed by 11 (42\%) in Region 2 and ten (34\%) in Region 1. Further, nine (39\%, each) agencies in Regions 3 and 4 provide the service, with eight (53\%) agencies in Region 5 and six (60\%) agencies in Region 7.

Additionally, OTJ training is provided by 15 (58\%) agencies in Region 6, followed by 14 (48\%) agencies in Region 1, with 11 (48\%) in Region 3 and 10 (38\%) in Region 2. Further, nine (39\%) agencies in Region 4 provide OJT services, with seven (70\%) in Region 7 and six (40\%) in Region 5. Local labor market jobs/occupations projections are provided by 15 (58\%) agencies 
in Region 6, followed by 12 (46\%) in Region 2, with 11 in Regions 1, 3 and 4, (38\%, 48\%, and $48 \%$, in order), and six (60\%) in Region 7 and four (27\%) in Region 5. In addition, IEPs are provided by nine (35\%) agencies in Region 6, followed by five (17\%) agencies in Region 1, with four agencies in Regions 3 and 7, (17\% and 40\%, correspondingly), and three agencies each in Regions 2, 4, and 5, (12\%, 13\%, and 20\%, respectively). Resume posting \& blasting services are regionally less accessible, with seven (30\%) agencies in Region 3, followed by six (23\%) agencies in Region 2 and five agencies in Regions 1 and 6, (17\% and 19\%, in order), with four (17\%) in Region 4 and one (10\%) in Region 7. No regional responding agencies provided the service in Region 5. Across the state, job clubs were selected as the least available employment service, with four (15\%) agencies in Region 6, three (12\%) in Region 2, and one agency each in Regions 1,3 , and $4,(3 \%, 4 \%$, and $4 \%$, respectively), with no regional agencies providing the service in Regions 5 and 7 (see Table 4.9).

The responding agencies, $[(\mathrm{n}=113$, with Region $1(\mathrm{n}=29)$, Region $2(\mathrm{n}=26)$, Region 3 $(\mathrm{n}=23)$, Region $4(\mathrm{n}=23)$, Region $5(\mathrm{n}=15)$, Region $6(\mathrm{n}=26)$, and Region $7(\mathrm{n}=10)]$, indicated their agencies provided support services, selecting from a list consisting of financial literacy training, basic necessities, public access to computers, job training and education expense assistance and 90-day case management. Two (29\%) statewide agencies provided the previously listed support services, with three (43\%) statewide agencies providing the additional service of mental health counseling (see Table 4.10).

Regionally, financial literacy is the most accessible support service, which is offered by 12 (46\%) agencies in Region 6, followed by 10 agencies (38\% and 43\%, respectively) in Regions 2 and 3, with nine (31\%) agencies in Region 1, eight (35\%) in Region 4, and five agencies in Regions 5 and 7, (33\% and 50\%, correspondingly). Basic necessities support 
services is the second most available resource, with 12 (41\%) agencies in Region 1, nine (35\%, each) agencies in Regions 2 and 6, and seven (30\%, each) agencies in Regions 3 and 4, with four agencies in Regions 5 and 7, (27\% and 40\%, respectively). Ranking third in accessibility regionally, public access to computers is provided by nine (35\%) agencies in Region 2 and six agencies $(21 \%, 26 \%$, and $26 \%$, in order) in Regions 1,3 , and 4 , with two agencies (13\% and $20 \%$, respectively) in Regions 5 and 7 (see Table 4.10).

Ranking fourth in availability, mental health counseling, is provided by seven (24\%) agencies in Region 1, followed by six (23\%) in Region 6, and five (22\%) agencies in Regions 3 and 4, with four (15\%) agencies in Region 2, and two in Regions 5 and 7, (13\% and 20\%, in sequence). Fifth in accessibility is job training and education expense assistance, which is provided by eight (28\%) agencies in Region 1 and four agencies in Regions 2, 3, and 6, (15\%, $17 \%$, and $15 \%$, respectively), with two agencies ( $9 \%$ and $20 \%$, respectively) in Regions 5 and 7. Ranked the least available support service, 90-day case management is provided by five (17\% and $19 \%$, correspondingly) agencies in Regions 1 and 6 , followed by three $(12 \%$ and $13 \%$, in order) agencies in Regions 2 and 4, and two (9\% and 20\%, respectively) agencies in Regions 3 and 7 (see Table 4.10).

The responding agencies, [ $(n=113$, with Region $1(n=29)$, Region $2(n=26)$, Region 3 $(n=23)$, Region $4(n=23)$, Region $5(n=15)$, Region $6(n=26)$, and Region $7(n=10)]$, indicated that the services for special populations in ranked order of availability are supported employment, job coaching, vocational rehabilitation, WIOA, disability, recovery, displaced worker, veterans, disability center-based employment, ticket to work \& self-sufficiency programs, youth, re-entry, Welfare-to-Work, and federal bonding assistance. Statewide, three (43\%) agencies provide supported employment, job coaching, WIOA, ticket to work \& self- 
sufficiency programs, and re-entry services. In addition, two (29\%) agencies provide vocational rehabilitation, disability, recovery, displaced worker, veterans, disability center-based employment, and federal bonding assistance. Further, one (14\%) statewide agency provides Welfare-to-Work services (see Table 4.11).

At the regional level, supported employment ranks the most available service for special populations, being provided by 17 (65\%) agencies in Region 6, followed by 14 (48\%) agencies in Region 1, with 10 agencies (38\% and 43\%, respectively) in Regions 2 and 3 and nine (39\%) agencies in Region 4. Eight (80\%) agencies provide the service in Region 7 and seven (47\%) in Region 5. Job coaching, utilized in vocational rehabilitation, ranks second in availability and is provided by 16 (62\%) agencies in Region 6, followed by 11 (38\%) agencies in Region 1, with 10 agencies (38\% and 43\%, correspondingly) in Regions 2 and 3, nine (39\%) in Region 4, eight $(80 \%)$ in Region 7, and seven (47\%) in Region 5. Vocational rehabilitation, with availability being ranked third, is provided by 12 (46\%) agencies in Region 6, followed by seven agencies ( $24 \%, 30 \%$, and $30 \%$, in sequence) in Regions 1, 3, and 4, with five agencies (19\% and 33\%, respectively) in Regions 2 and 5 and three (30\%) in Region 7 (see Table 4.11).

Ranking fourth, WIOA is provided by eight agencies (31\%, each) in Regions 2 and 6 , followed by seven (30\%, each) agencies in Regions 3 and 4, with five (17\%) agencies in Region 1, four (27\%) agencies in Region 5, and three (30\%) in Region 7. Veterans programs, ranked fifth, are provided by nine (35\%) agencies in Region 6, eight (31\%) agencies in Region 2, followed by six agencies (26\%, each) in Regions 3 and 4, with four (14\%) in Region 1, two (20\%) in Region 7, and one (7\%) in Region 5. Recovery programs, ranked sixth regionally, is provided by seven (24\%) agencies in Region 1, followed by six (23\%) agencies in Region 2, and five agencies $(22 \%, 22 \%$, and $19 \%$, in order) in Regions 3, 4, and 6, with three (30\%) agencies in 
Region 7 and two (13\%) agencies in Region 5. Disability programs, ranked seventh, are provided by 11 (42\%) agencies in Region 6, followed by six (26\%) agencies in Region 4, five agencies (19\% and 22\%, respectively) in Regions 2 and 3, and four (14\% and 27\%, correspondingly) in Regions 1 and 5, with no responding agencies providing the services in Region 7. Ranked eighth regionally, disability center-based employment services are provided by 11 (42\%) agencies in Region 6, five (19\%) agencies in Region 2, and four agencies (17\%, each) in Regions 3and 4, with three (20\%) in Region 5, and two (20\%) in Region 7 (see Table 4.11).

Ticket to work and self-sufficiency programs, ranked ninth, are provided by seven (27\%) agencies in Region 6, four agencies (14\%, 15\%,17\% and 17\%, respectively) in Regions 1, 2, 3, and 4, with three (30\%) in Region 7 and two (13\%) in Region 5. Matched in percentage of selected ranking order, displaced worker programs are provided by eight (31\%) agencies in Region 6, followed by six (26\%) agencies in Region 4, five (19\%) agencies in Region 2, four agencies in Regions 1 and 2, (14\%, and 17\%, in order), with three (20\%) in Region 5, and two $(20 \%)$ in Region 7. Youth programs, which follows in ranking, are provided by seven (27\%) agencies in Region 6, five agencies (19\% and 50\%, in order) in Regions 2 and 7, four (17\%) agencies in Region 4, and two agencies (7\%, 9\%, 13\%, correspondingly) in Regions 1, 3, and 5 (see Table 4.11). 
Table 4.9: Workforce Development Activities, Employment Services

\begin{tabular}{|c|c|c|c|c|c|c|c|c|c|c|c|c|c|c|c|c|}
\hline \multirow{2}{*}{$\begin{array}{c}\begin{array}{c}\text { Services } \\
(\mathrm{n}=113)\end{array} \\
\text { Job Listings }\end{array}$} & \multicolumn{2}{|c|}{$\begin{array}{c}\text { Statewide } \\
(\mathrm{n}=7) \\
\mathrm{N}(\%)\end{array}$} & \multicolumn{2}{|c|}{$\begin{array}{c}\text { Region } 1 \\
(\mathrm{n}=29) \\
\mathrm{N}(\%)\end{array}$} & \multicolumn{2}{|c|}{$\begin{array}{c}\text { Region } 2 \\
(\mathrm{n}=26) \\
\mathrm{N}(\%)\end{array}$} & \multicolumn{2}{|c|}{$\begin{array}{c}\text { Region } 3 \\
(\mathrm{n}=23) \\
\mathrm{N}(\%)\end{array}$} & \multicolumn{2}{|c|}{$\begin{array}{c}\text { Region } 4 \\
(\mathrm{n}=23) \\
\mathrm{N}(\%)\end{array}$} & \multicolumn{2}{|c|}{$\begin{array}{c}\text { Region } 5 \\
(\mathrm{n}=15) \\
\mathrm{N}(\%)\end{array}$} & \multicolumn{2}{|c|}{$\begin{array}{c}\text { Region } 6 \\
(\mathrm{n}=26) \\
\mathrm{N}(\%)\end{array}$} & \multicolumn{2}{|c|}{$\begin{array}{c}\begin{array}{c}\text { Region } 7 \\
(\mathrm{n}=10) \\
\mathrm{N}(\%)\end{array}\end{array}$} \\
\hline & 6 & (86) & 21 & $(72)$ & 21 & $(81)$ & 19 & (83) & 15 & $(65)$ & 9 & $(60)$ & 23 & (88) & 10 & $(100)$ \\
\hline Resume Prep. & 5 & (71) & 17 & (59) & 19 & (73) & 18 & (78) & 19 & (83) & 12 & (80) & 20 & (77) & 8 & $(80)$ \\
\hline Interview & 6 & (86) & 17 & (59) & 17 & $(65)$ & 17 & (74) & 16 & (70) & 10 & (67) & 23 & (88) & 8 & $(80)$ \\
\hline Job Search & 6 & (86) & 12 & (41) & 15 & $(58)$ & 15 & (65) & 13 & (57) & 11 & (73) & 21 & (81) & 8 & $(80)$ \\
\hline $\begin{array}{l}\text { Job Devel. \& } \\
\text { Placement }\end{array}$ & 5 & (71) & 18 & $(62)$ & 14 & (54) & 14 & (61) & 11 & (48) & 6 & (40) & 17 & (65) & 7 & (70) \\
\hline $\begin{array}{l}\text { Career } \\
\text { Counseling }\end{array}$ & 6 & (86) & 11 & (38) & 12 & $(46)$ & 12 & (52) & 12 & $(52)$ & 9 & (60) & 14 & (54) & 5 & $(50)$ \\
\hline Job Readiness & 5 & (71) & 13 & $(45)$ & 12 & (46) & 10 & (43) & 10 & (43) & 7 & (47) & 17 & (65) & 8 & $(80)$ \\
\hline $\begin{array}{l}\text { Career } \\
\text { Assessments }\end{array}$ & 5 & (71) & 10 & (34) & 11 & $(42)$ & 9 & (39) & 9 & (39) & 8 & (53) & 14 & (54) & 6 & $(60)$ \\
\hline OJT & 3 & (43) & 14 & $(48)$ & 10 & (38) & 11 & (48) & 9 & (39) & 6 & (40) & 15 & (58) & 7 & (70) \\
\hline Labor Market & 3 & (43) & 11 & (38) & 12 & $(46)$ & 11 & $(48)$ & 11 & $(48)$ & 4 & $(27)$ & 15 & (58) & 6 & $(60)$ \\
\hline IEP & 3 & (43) & 5 & (17) & 3 & (12) & 4 & (17) & 3 & (13) & 3 & $(20)$ & 9 & (35) & 4 & $(40)$ \\
\hline Resume Post. & 1 & (14) & 5 & (17) & 6 & (23) & 7 & (30) & 4 & (17) & 0 & $(0)$ & 5 & (19) & 1 & (10) \\
\hline Job Clubs & 2 & (29) & 1 & (3) & 3 & (12) & 1 & (4) & 1 & (4) & 0 & $(0)$ & 4 & (15) & 0 & (0) \\
\hline
\end{tabular}

Note. Percentages are computed within columns for Regions, with agencies that serve more than one region being counted across their identified specific multiple regions. The percentage total equates to greater than $100 \%$, as multiple selections were available to respondents. 
Table 4.10: Workforce Development Activities, Support Services

\begin{tabular}{|c|c|c|c|c|c|c|c|c|}
\hline $\begin{array}{l}\text { Services } \\
(\mathrm{n}=113)\end{array}$ & $\begin{array}{c}\text { Statewide } \\
(\mathrm{n}=7) \\
\mathrm{N}(\%)\end{array}$ & $\begin{array}{c}\text { Region } 1 \\
(\mathrm{n}=29) \\
\mathrm{N}(\%)\end{array}$ & $\begin{array}{c}\text { Region } 2 \\
(\mathrm{n}=26) \\
\mathrm{N}(\%)\end{array}$ & $\begin{array}{c}\text { Region } 3 \\
(\mathrm{n}=23) \\
\mathrm{N}(\%)\end{array}$ & $\begin{array}{c}\text { Region } 4 \\
(\mathrm{n}=23) \\
\mathrm{N}(\%)\end{array}$ & $\begin{array}{c}\text { Region } 5 \\
(\mathrm{n}=15) \\
\mathrm{N}(\%) \\
\end{array}$ & $\begin{array}{c}\text { Region } 6 \\
(\mathrm{n}=26) \\
\mathrm{N}(\%)\end{array}$ & $\begin{array}{c}\text { Region } 7 \\
(\mathrm{n}=10) \\
\mathrm{N}(\%)\end{array}$ \\
\hline $\begin{array}{l}\text { Financial } \\
\text { Literacy }\end{array}$ & 2 (29) & (31) & 10 & (43) & $8 \quad(35)$ & $5 \quad(33)$ & (46) & (50) \\
\hline $\begin{array}{l}\text { Basic } \\
\text { Necessities }\end{array}$ & 2 (29) & $12 \quad(41)$ & $9 \quad(35)$ & $7 \quad(30)$ & $7 \quad(30)$ & $4 \quad(27)$ & $(35)$ & (40) \\
\hline $\begin{array}{l}\text { Public } \\
\text { Access } \\
\text { Computers }\end{array}$ & 2 (29) & $(21)$ & $9 \quad(35)$ & $6 \quad(26)$ & $6 \quad(26)$ & 2 (13) & (23) & (20) \\
\hline $\begin{array}{l}\text { Mental } \\
\text { Health } \\
\text { Counseling }\end{array}$ & (43) & (24) & $4 \quad(15)$ & $5 \quad(22)$ & $5 \quad(22)$ & 2 (13) & (23) & (20) \\
\hline $\begin{array}{l}\text { Job } \\
\text { Training \& } \\
\text { Education } \\
\text { Expense } \\
\text { Assistance }\end{array}$ & 2 (29) & $8 \quad(28)$ & $4 \quad(15)$ & $4 \quad(17)$ & $2 \quad(9)$ & $2 \quad(13)$ & $4 \quad(15)$ & $2(20)$ \\
\hline $\begin{array}{l}\geq 90 \text {-day } \\
\text { case mgmt. }\end{array}$ & $2 \quad(29)$ & $5 \quad(17)$ & $3 \quad(12)$ & 2 (9) & 3 (13) & $1 \quad(7)$ & (19) & $2(20)$ \\
\hline
\end{tabular}

Note. Percentages are computed within columns for Regions, with agencies that serve more than one region being counted across their specific multiple regions.

The percentage total equates to greater than $100 \%$, as multiple selections were available to respondents. 
Table 4.11: Workforce Development Activities, Services for Special Populations

\begin{tabular}{|c|c|c|c|c|c|c|c|c|c|c|c|}
\hline $\begin{array}{l}\text { Services } \\
(\mathrm{n}=113)\end{array}$ & $\begin{array}{c}\text { Statewide } \\
(\mathrm{n}=7) \\
\mathrm{N}(\%) \\
\end{array}$ & $\begin{array}{c}\text { Region } 1 \\
(\mathrm{n}=29) \\
\mathrm{N}(\%)\end{array}$ & $\begin{array}{c}\text { Region } 2 \\
(\mathrm{n}=26) \\
\mathrm{N}(\%)\end{array}$ & & $\begin{array}{l}\text { sion } 3 \\
=23) \\
(\%) \\
\end{array}$ & $\begin{array}{c}\text { Region } 4 \\
(\mathrm{n}=23) \\
\mathrm{N}(\%)\end{array}$ & $\begin{array}{c}\text { Region } 5 \\
(\mathrm{n}=15) \\
\mathrm{N}(\%)\end{array}$ & 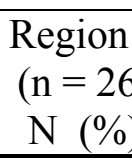 & & & $\begin{array}{l}\text { sion } 7 \\
=10) \\
(\%) \\
\end{array}$ \\
\hline $\begin{array}{l}\text { Supported } \\
\text { Employment }\end{array}$ & $3 \quad(43)$ & $14 \quad(48)$ & (38) & 10 & (43) & (39) & $7 \quad(47)$ & 17 & $(65)$ & 8 & $(80)$ \\
\hline Job Coaching & $3 \quad(43)$ & $11 \quad(38)$ & $(38)$ & 10 & (43) & $9 \quad(39)$ & $7 \quad(47)$ & 16 & (62) & 8 & $(80)$ \\
\hline Voc. Rehab. & $2 \quad(29)$ & $7 \quad(24)$ & $5 \quad(19)$ & 7 & (30) & $7 \quad(30)$ & $5 \quad(33)$ & 12 & (46) & 3 & (30) \\
\hline WIOA & $3 \quad(43)$ & $5 \quad(17)$ & (31) & 7 & (30) & (30) & $4 \quad(27)$ & 8 & (31) & 3 & (30) \\
\hline Veterans & 2 (29) & $4 \quad(14)$ & $(31)$ & 6 & (26) & (26) & $1 \quad(7)$ & 9 & $(35)$ & 2 & (20) \\
\hline Recovery & $2 \quad(29)$ & $7 \quad(24)$ & (23) & 5 & $(22)$ & $5 \quad(22)$ & 2 (13) & 5 & (19) & 3 & (30) \\
\hline Disability & $2 \quad(29)$ & $4 \quad(14)$ & (19) & 5 & (22) & (26) & $4 \quad(27)$ & 11 & (42) & 0 & $(0)$ \\
\hline $\begin{array}{l}\text { Disability } \\
\text { Center-based }\end{array}$ & 2 (29) & $4 \quad(14)$ & (19) & 4 & (17) & $4 \quad(17)$ & $3 \quad(20)$ & 11 & (42) & 2 & (20) \\
\hline $\begin{array}{l}\text { Ticket to } \\
\text { Work }\end{array}$ & $3 \quad(43)$ & $4 \quad(14)$ & $4 \quad(15)$ & 4 & (17) & $4 \quad(17)$ & 2 (13) & 7 & (27) & 3 & $(30)$ \\
\hline $\begin{array}{l}\text { Displaced } \\
\text { Worker }\end{array}$ & 2 (29) & $4 \quad(14)$ & $5 \quad(19)$ & 4 & (17) & $6 \quad(26)$ & $3 \quad(20)$ & 8 & (31) & 2 & $(20)$ \\
\hline Youth & $2 \quad(29)$ & $2 \quad(7)$ & $5 \quad$ (19) & 2 & (9) & $4 \quad(17)$ & $2 \quad(13)$ & 7 & (27) & 5 & $(50)$ \\
\hline Re-entry & $3 \quad(43)$ & $5 \quad(17)$ & $4 \quad(15)$ & 3 & (13) & $4 \quad(17)$ & $3 \quad(20)$ & 8 & (31) & 1 & (10) \\
\hline $\begin{array}{l}\text { Welfare to } \\
\text { Work }\end{array}$ & $1 \quad(14)$ & $4 \quad(14)$ & $3 \quad(12)$ & 2 & (9) & $2(9)$ & $1 \quad(7)$ & 5 & (19) & 2 & (20) \\
\hline Bonding & $2 \quad(29)$ & $0 \quad(0)$ & $1 \quad(4)$ & 1 & (4) & $0 \quad(0)$ & $0 \quad(0)$ & 0 & $(0)$ & 0 & $(0)$ \\
\hline
\end{tabular}

Note. Percentages are computed within columns, with agencies that serve more than one region being counted across their specific multiple regions. The percentage total equates to greater than $100 \%$, as multiple selections were available to respondents. 
Re-entry programs are provided by eight (31\%) agencies in Region 6, followed by five (17\%) agencies in Region 1, and four agencies (15\% and 17\%) in Regions 2 and 4, with three agencies (13\% and 20\%, in sequence) in Regions 3 and 5, and one (10\%) in Region 7 . Welfareto-Work programs follow in ranking, with five (19\%) agencies in Region 6, four (14\%) in Region 1, three (12\%) in Region 2, two (9\%, each) in Regions 3 and 4, followed by two agencies (9\%, 9\%, and 20\%, respectively) in Regions 3, 4, and 7. Lastly, ranked fourteenth, federal bonding assistance is provided by one (4\%) responding agency in Region 2 and at the state level by two (29\%) agencies, as mentioned previously (see Table 4.11$)$. In the available open-text option other, respondents noted their agencies offered Youth Work Experience (ages 18-24), TASC Testing, networking skills development and Life Skills training.

\section{Objective 2: Determine the effectiveness of the workforce development activities and retention strategies.}

Respondents were also asked to rate the effectiveness levels of workforce supports and job retention services, selecting from the scale: not used $=1$; not at all effective $=2 ;$ low $=3$; medium $=4$; and high $=5$, with 16 possible responses (see Table 4.12). Listing responses in order of most effective service to least effective, with respondents, $(\mathrm{n}=98)$, selecting vocational training the most effective, overall. Further, 50 (51\%) respondents selected vocational training as highly effective, with $12(12 \%)$ respondents selecting medium and $12(12 \%)$ respondents selecting low. Eleven (11\%) respondents selected not at all effective and 13 (13\%) respondents selected not used.

Ranked second, technology support/access $(\mathrm{n}=98)$ was considered to be a highly effective by 48 (49\%) respondents, with 24 (25\%) respondents selecting medium, eight (8\%) 
respondents selecting low, eight (8\%) respondents selecting not at all effective, and 10 (10\%) respondents selecting not used. Further, soft skills training $(\mathrm{n}=100)$, ranked third, was identified as highly effective by 44 (44\%) respondents, with 34 (34\%) respondents selecting medium, eight (8\%) respondents selecting low, six (6\%) respondent selecting not at all effective, and eight (8\%) respondents selecting not used. Providing professional certifications training (n =97) was considered to be highly effective by $31(32 \%)$ respondents, with $23(24 \%)$ respondents selecting medium, eight (8\%) respondents selecting low, 18 (19\%) respondents selecting not at all effective, and 17 (18\%) respondents selecting not used (see Table 4.12).

Fifth in ranking, high school equivalency (HSE/GED) training/testing supports $(\mathrm{n}=97)$ was considered to be highly effective by $30(31 \%)$ respondents, with $13(13 \%)$ respondents selecting medium, 11 (11\%) respondents selecting low, 25 (26\%) respondents selecting not at all effective, and $18(19 \%)$ respondents selecting not used. Financial literacy/education $(\mathrm{n}=96)$, ranked sixth, was considered to be highly effective by $22(23 \%)$ respondents, with $16(17 \%)$ respondents selecting medium, 20 (21\%) respondents selecting low, 26 (27\%) respondents selecting not at all effective, and 12 (13\%) respondents selecting not used. In addition, transportation support $(\mathrm{n}=99)$ was considered to be highly effective by $21(21 \%)$ respondents, with $20(20 \%)$ respondents selecting medium, 19 (19\%) respondents selecting low, 26 (26\%) respondents selecting not at all effective, and 13 (13\%) respondents selecting not used. Work related expense assistance $(\mathrm{n}=97)$ was ranked eighth and considered to be highly effective by $18(19 \%)$ respondents, with $18(18 \%)$ respondents selecting medium, $11(11 \%)$ respondents selecting low, 30 (31\%) respondents selecting not at all effective, and 20 (21\%) respondents selecting not used (see Table 4.12). 
Ranked ninth for effectiveness, financial incentives for program completion $(\mathrm{n}=97)$ was considered to be highly effective by 14 (14\%) respondents, with nine (9\%) respondents selecting medium, $16(17 \%)$ respondents selecting low, 36 (36\%) respondents selecting not at all effective, and $22(23 \%)$ respondents selecting not used. Also ranking ninth in effectiveness was addiction/substance abuse services $(\mathrm{n}=95)$, with $14(15 \%)$ respondents considering the service to be highly effective, while $11(12 \%)$ respondents selected medium, $15(16 \%)$ respondents selected low, 34 (36\%) respondents selected not at all effective, and 21 (22\%) respondents selecting not used (see Table 4.12).

Health benefits, such as insurance, access to treatment, or health education $(\mathrm{n}=97)$, was ranked tenth and considered to be highly effective by $13(13 \%)$ respondents, with eight (8\%) respondents selecting medium, 19 (20\%) respondents selecting low, 35 (36\%) respondents selecting not at all effective, and 22 (23\%) respondents selecting not used. Further, assistance completing SNAP, TANF, SSI, or SSDI applications (n=98) was considered to be highly effective by $12(12 \%)$ respondents, with 17 (17\%) respondents selecting medium, 25 (26\%) respondents selecting low, 28 (29\%) respondents selecting not at all effective, and 16 (16\%) respondents selecting not used. Mortgage/Rent deposit or payment assistance $(\mathrm{n}=97)$ was ranked twelfth and considered to be highly effective by $8(8 \%)$ respondents, with nine (9\%) respondents selecting medium, 14 (14\%) respondents selecting low, 40 (41\%) respondents selecting not at all effective, and 27 (26\%) respondents selecting not used (see Table 4.12).

Childcare support $(\mathrm{n}=99)$ was ranked thirteenth and considered to be highly effective by six $(6 \%)$ respondents, with $12(12 \%)$ respondents selecting medium, $10(10 \%)$ respondents selecting low, 43 (43\%) respondents selecting not at all effective, and 28(28\%) respondents selecting not used. Ranked fourteenth out of sixteen options, recovery treatment expense 
assistance $(\mathrm{n}=95)$ was considered to be highly effective by five $(5 \%)$ respondents, with nine (10\%) respondents selecting medium, $10(11 \%)$ respondents selecting low, 42 (44\%) respondents selecting not at all effective, and 29 (31\%) respondents selecting not used. Also ranked at fourteenth, homeless or transitional housing assistance $(\mathrm{n}=97)$ was considered to be highly effective by five (5\%) respondents, with seven (7\%) respondents selecting medium, 22 (23\%) respondents selecting low, 40 (41\%) respondents selecting not at all effective, and 23 (24\%) respondents selecting not used (see Table 4.12).

Overall, the ranking order of workforce development activities and retention strategies not used by employment agencies, by percentage selected, include:

- $29 \%$ Recovery treatment expense assistance $(n=95)$

- $\quad 28 \%$ Childcare support $(\mathrm{n}=99)$

- $26 \%$ Mortgage/Rent deposit or payment assistance $(n=97)$

- $23 \%$ Homeless or Transitional housing $(\mathrm{n}=97)$

- $22 \%$ Financial Incentives for program completion $(n=97)$

- $22 \%$ Health benefits, e.g., insurance, access to treatment, or health education $(n=97)$

- $21 \%$ Addiction/Substance abuse services $(\mathrm{n}=95)$

- $20 \%$ Work related expense assistance $(\mathrm{n}=97)$

- $18 \%$ High school equivalency training/testing supports $(\mathrm{n}=97)$

- $17 \%$ Professional certifications $(\mathrm{n}=97)$

- $16 \%$ SNAP, TANF, SSI, or SSDI application assistance $(\mathrm{n}=98)$

- $13 \%$ Vocational training $(\mathrm{n}=98)$

- $\quad 13 \%$ Transportation support, e.g., bus fare, subsidized gas cards $(\mathrm{n}=99)$

- $12 \%$ Financial literacy/education, e.g., budgeting, credit counseling $(n=96)$

- $10 \%$ Technology support/access for job searches or submit job applications $(\mathrm{n}=98)$

- $\quad 8 \%$ Soft skills training $(\mathrm{n}=100)$ 
Table 4.12: Effectiveness of Workforce Development Activities and Retention Strategies

\begin{tabular}{|c|c|c|c|c|c|c|c|c|c|c|}
\hline \multirow{2}{*}{$\begin{array}{l}\text { Activities } \\
\text { Vocational }(\mathrm{n}=98)\end{array}$} & \multicolumn{2}{|c|}{$\begin{array}{c}\text { Not Used } \\
\text { N }(\%)\end{array}$} & \multicolumn{2}{|c|}{$\begin{array}{c}\text { Not } \\
\text { Effective } \\
\mathrm{N}(\%) \\
\end{array}$} & \multicolumn{2}{|c|}{$\begin{array}{c}\text { Low } \\
\text { N (\%) }\end{array}$} & \multicolumn{2}{|c|}{$\begin{array}{l}\text { Medium } \\
\text { N (\%) }\end{array}$} & \multicolumn{2}{|c|}{$\begin{array}{c}\text { High } \\
\text { N }(\%)\end{array}$} \\
\hline & 13 & (13) & 11 & (11) & 12 & (12) & 12 & (12) & 50 & $(51)$ \\
\hline Tech/Internet $(n=98)$ & 10 & $(10)$ & 8 & (8) & 8 & (8) & 24 & $(25)$ & 48 & (49) \\
\hline Soft skills $(n=100)$ & 8 & (8) & 6 & (6) & 8 & (8) & 34 & (34) & 44 & (44) \\
\hline Certifications $(n=97)$ & 17 & $(18)$ & 18 & (19) & 8 & (8) & 23 & $(24)$ & 31 & (32) \\
\hline HSE/GED $(n=97)$ & 18 & (19) & 25 & (26) & 11 & (11) & 13 & (13) & 30 & $(31)$ \\
\hline $\begin{array}{l}\text { Financial literacy } \\
(\mathrm{n}=96)\end{array}$ & 12 & (13) & 26 & $(27)$ & 20 & $(21)$ & 16 & (17) & 22 & (23) \\
\hline Transp. $(\mathrm{n}=99)$ & 13 & (13) & 26 & (26) & 19 & (19) & 20 & $(20)$ & 21 & (21) \\
\hline $\begin{array}{l}\text { Work related expense } \\
\text { assistance }(n=97)\end{array}$ & 20 & $(21)$ & 30 & $(31)$ & 11 & (11) & 18 & (19) & 18 & (19) \\
\hline Fin. Incentive $(n=97)$ & 22 & (23) & 36 & $(37)$ & 16 & (17) & 9 & (9) & 14 & (14) \\
\hline $\begin{array}{l}\text { Addiction services } \\
(\mathrm{n}=95)\end{array}$ & 21 & $(22)$ & 34 & (36) & 15 & (16) & 11 & (12) & 14 & (15) \\
\hline Health benefits $(n=97)$ & 22 & (23) & 35 & (36) & 19 & (20) & 8 & (8) & 13 & (13) \\
\hline $\begin{array}{l}\text { SNAP, TANF, SSI, or } \\
\text { SSDI application } \\
\text { assistance }(n=98)\end{array}$ & 16 & (16) & 28 & (29) & 25 & $(26)$ & 17 & (17) & 12 & $(12)$ \\
\hline Mortgage/Rent $(\mathrm{n}=97)$ & 26 & $(27)$ & 40 & $(41)$ & 14 & (14) & 9 & (9) & 8 & (8) \\
\hline Childcare $(\mathrm{n}=99)$ & 28 & $(28)$ & 43 & (43) & 10 & $(10)$ & 12 & (12) & 6 & (6) \\
\hline $\begin{array}{l}\text { Recovery treatment } \\
\text { exp. assistance }(n=95)\end{array}$ & 29 & $(31)$ & 42 & (44) & 10 & (11) & 9 & $(10)$ & 5 & (5) \\
\hline Homelessness $(n=97)$ & 23 & (24) & 40 & (41) & 22 & (23) & 7 & (7) & 5 & (5) \\
\hline
\end{tabular}

Note. Percentages are computed across rows, with percentage total equating to greater than $100 \%$, as multiple selections were available to respondents. 
Further, five regions (Region 2, Region 4, Region 5, Region 6, and Region 7) rank technology support/access the most effective activity. Overall, the top three most effective activities are vocational training, technology support/access, and soft skills training. Beyond the top three activities, Region 1 ranks the remaining 13 options in the following order: financial literacy, transportation support, addiction/substance abuse services, professional certifications training, mortgage/rent deposit or payment assistance, high school equivalency (HSE/GED) training/testing supports, financial incentives for program completion, work related expense assistance, SNAP, TANF, SSI, or SSDI application assistance, health benefits, homeless or transitional housing assistance, recovery treatment expense assistance, and childcare support (see Table 4.13).

Region 2 ranks the activities as follows: professional certifications training, high school equivalency (HSE/GED) training/testing supports, financial literacy, transportation support, recovery treatment expense assistance, addiction/substance abuse services, work related expense assistance, financial incentives for program completion, SNAP, TANF, SSI, or SSDI application assistance, mortgage/rent deposit or payment assistance, health benefits, homeless or transitional housing assistance, and childcare support. Region 3 rankings are transportation support, high school equivalency (HSE/GED), professional certifications training, financial literacy, work related expense assistance, addiction/substance abuse services, SNAP, TANF, SSI, or SSDI application assistance, childcare support, financial incentives, mortgage/rent, health benefits, recovery treatment expense assistance, and homeless housing assistance (see Table 4.13).

Additionally, Region 4 rankings are as follows: financial literacy, transportation support, work related expense assistance, high school equivalency (HSE/GED), professional 
certifications training, SNAP, TANF, SSI, or SSDI application assistance, financial incentives, addiction/substance abuse services, childcare support, mortgage/rent, health benefits, recovery treatment expense assistance, and homeless housing assistance. Region 5 ranks the activities in the following order: financial literacy, transportation support, high school equivalency (HSE/GED), professional certifications training, SNAP, TANF, SSI, or SSDI application assistance, work related expense assistance, financial incentives, addiction/substance abuse services, childcare support, mortgage/rent, recovery treatment expense assistance, health benefits, and homeless housing assistance (see Table 4.13).

Region 6 rankings are financial literacy, high school equivalency (HSE/GED), transportation support, work related expense assistance, professional certifications training, financial incentives, SNAP, TANF, SSI, or SSDI application assistance, addiction/substance abuse services, health benefits, childcare support, mortgage/rent, homeless housing assistance, and recovery treatment expense assistance. Also, the rankings for Region 7 do not align with the other regions, as follows: high school equivalency (HSE/GED), financial incentives, work related expense assistance, professional certifications training, SNAP, TANF, SSI, or SSDI application assistance, transportation support, financial literacy, addiction/substance abuse services, health benefits, childcare support, mortgage/rent, homeless housing assistance, and recovery treatment expense assistance. Regionally, with variations in ranking, the least selected five options include: health benefits, childcare support, mortgage/rent, homeless housing assistance, and recovery treatment expense assistance. Further, all regions indicated homeless housing was one of the two least effective activities, often ranked equally with recovery treatment expense assistance (see Table 4.13). 


\section{Objective 3: Determine if alternative workforce development activities were considered.}

In a follow-up open ended question, the agencies were also asked to describe what other activities were considered and to explain why these activities were not pursued. The responses noted alternative activities included offering Driver Learning Permit classes. Further, the respondents indicated that the alternative activities faced barriers such as funding, stating, "Funding is an issue with our organization. We have multiple programs that we would love to implement (GED course prep, interview prep, job fairs, etc.), but funding is a huge issue." Relatedly, another respondent also noted, "There's a work ethic certificate that is available for my TASC (GED) students that is not available for my SPOKES (DHHR) students. I think it's a funding issue."

Objective 4: Examine the pre-pandemic and peri-pandemic barriers to employment from the perspective of the job services agencies' staff based on experience, staff case notes and intake interviews conducted by agency staff members.

To examine employment barriers more fully the respondents were also asked to indicate the degree to which the previously discussed employment barriers impact their clients, based on the respondents' experience, case notes and intake interviews. The respondents were given 17 options, with three possible responses: high, medium, or low (see Table 4.14).

In order of most selected as highest impact, $57(57 \%)$ respondents $(n=100)$ identified transportation limitations as being the most significant barrier to employment, followed by 43 $(45 \%)$ of respondents selecting lack of job skills $(\mathrm{n}=98)$, with $42(43 \%)$ respondents indicating local labor market $(\mathrm{n}=97)$ conditions. Ranked fourth, $37(38 \%)$ respondents noted their clients indicated low-wages could outweigh the additional costs of working, e.g., childcare and transportation $(\mathrm{n}=97)$. In addition, $34(34 \%)$ respondents selected lack of work experience $(\mathrm{n}=$ 
100), with nearly an equal number of respondents, $33(33 \%)$, indicating lack of soft skills $(\mathrm{n}=$ 101). Further, $33(34 \%)$ indicated access to broadband/technology $(\mathrm{n}=97)$ presented a high impact barrier to employment (see Table 4.14).

At mid-range, ranked eighth, 29 (29\%) respondents noted access to childcare $(\mathrm{n}=99)$ presented a high barrier, followed by 28 (28\%) respondents indicating lack of digital literacy skills $(n=99)$ impacted employment. Twenty-five $(26 \%)$ respondents selected family responsibilities $(\mathrm{n}=98)$, with $24(25 \%)$ respondents $(\mathrm{n}=98)$ also indicating clients having criminal records. The five lowest ranked identified barriers, selected as high impact to employment, include $18(18 \%)$ respondents selecting lack of basic literacy $(\mathrm{n}=98), 15(16 \%)$ noting poor health $(\mathrm{n}=97), 10(10 \%)$ respondents indicating unaccommodated disabilities $(\mathrm{n}=$ 98), $10(11 \%)$ respondents identifying housing instability or homelessness $(\mathrm{n}=95)$, and, ranked the lowest of high impact employment barriers, $7(8 \%)$ selected $(n=87)$ high reservation wages (see Table 4.14).

The respondents also selected medium impact barriers to employment from the 17 available options, including $52(52 \%)$ respondents $(\mathrm{n}=101)$ noting lack of soft skills presented a medium impact on employment, compared to the $33 \%$ of respondents that selected lack of soft skills as the sixth highest barrier to employment. Additionally, $49(50 \%)$ respondents indicated the lack of basic literacy skills $(\mathrm{n}=98)$ ranked the second medium impact barrier, followed by $48(48 \%)$ respondents selecting lack of work experience $(n=100)$, and $47(48 \%)$ respondents $(n$ =98) selecting family responsibilities (see Table 4.14). 
Table 4.13: Highly Effective Workforce Development Activities and Retention Strategies

\begin{tabular}{|c|c|c|c|c|c|c|c|c|c|c|c|c|c|c|c|c|}
\hline \multirow{2}{*}{$\begin{array}{l}\text { Ranked by Effectiveness } \\
\text { Vocational }(n=98)\end{array}$} & \multicolumn{2}{|c|}{$\begin{array}{l}\text { Highly Effective } \\
\text { N (\%) }\end{array}$} & \multicolumn{2}{|c|}{$\begin{array}{l}\text { Region } 1 \\
(\mathrm{n}=25) \\
\mathrm{N}(\%) \\
\end{array}$} & \multicolumn{2}{|c|}{$\begin{array}{c}\text { Region } 2 \\
(\mathrm{n}=22) \\
\mathrm{N}(\%)\end{array}$} & \multicolumn{2}{|c|}{$\begin{array}{c}\text { Region } 3 \\
(\mathrm{n}=20) \\
\mathrm{N}(\%) \\
\end{array}$} & \multicolumn{2}{|c|}{$\begin{array}{c}\text { Region } 4 \\
(\mathrm{n}=19) \\
\mathrm{N}(\%) \\
\end{array}$} & \multicolumn{2}{|c|}{$\begin{array}{c}\text { Region } 5 \\
(\mathrm{n}=14) \\
\mathrm{N}(\%) \\
\end{array}$} & \multicolumn{2}{|c|}{$\begin{array}{c}\text { Region } 6 \\
(\mathrm{n}=26) \\
\mathrm{N}(\%) \\
\end{array}$} & \multicolumn{2}{|c|}{$\begin{array}{c}\text { Region } 7 \\
(\mathrm{n}=10) \\
\mathrm{N}(\%)\end{array}$} \\
\hline & 50 & $(51)$ & 13 & $(52)$ & 13 & $(59)$ & 13 & $(65)$ & 10 & (53) & 6 & (43) & 13 & $(50)$ & 6 & (60) \\
\hline Tech/Internet $(n=98)$ & 48 & (49) & 10 & $(40)$ & 14 & (64) & 12 & $(60)$ & 13 & (68) & 10 & (71) & 16 & $(62)$ & 7 & (70) \\
\hline Soft skills $(\mathrm{n}=100)$ & 44 & (44) & 10 & $(40)$ & 13 & (59) & 13 & $(65)$ & 10 & (53) & 9 & (64) & 12 & (46) & 5 & (50) \\
\hline Certifications $(n=97)$ & 31 & $(32)$ & 5 & (20) & 9 & $(41)$ & 5 & (25) & 5 & (26) & 4 & (29) & 5 & (19) & 3 & (30) \\
\hline HSE/GED $(\mathrm{n}=97)$ & 30 & (31) & 4 & (16) & 8 & $(36)$ & 6 & (30) & 5 & $(26)$ & 4 & (29) & 9 & (35) & 5 & $(50)$ \\
\hline Financial literacy $(n=96)$ & 22 & $(23)$ & 9 & $(36)$ & 7 & $(32)$ & 5 & $(25)$ & 7 & $(37)$ & 4 & (29) & 9 & (35) & 1 & (10) \\
\hline Transportation $(\mathrm{n}=99)$ & 21 & $(21)$ & 8 & $(32)$ & 7 & $(32)$ & 7 & $(35)$ & 6 & $(32)$ & 4 & (29) & 6 & (23) & 2 & (20) \\
\hline Work related exp. $(\mathrm{n}=97)$ & 18 & (19) & 3 & (12) & 6 & $(27)$ & 5 & $(25)$ & 6 & $(32)$ & 3 & (21) & 6 & (23) & 3 & (30) \\
\hline Financial Incentives $(\mathrm{n}=97)$ & 14 & (14) & 3 & $(12)$ & 5 & (23) & 2 & (10) & 4 & $(21)$ & 3 & (21) & 5 & (19) & 4 & (40) \\
\hline Addiction services $(\mathrm{n}=95)$ & 14 & $(15)$ & 7 & (28) & 6 & (27) & 3 & (15) & 3 & (16) & 3 & (21) & 4 & $(15)$ & 1 & (10) \\
\hline Health benefits $(n=97)$ & 13 & (13) & 3 & (12) & 3 & (14) & 2 & (10) & 2 & (11) & 0 & $(0)$ & 4 & $(15)$ & 1 & (10) \\
\hline SNAP, etc. assist. $(\mathrm{n}=98)$ & 12 & (12) & 3 & $(12)$ & 5 & (23) & 3 & (15) & 5 & $(26)$ & 4 & (29) & 4 & (15) & 3 & $(30)$ \\
\hline Mortgage/Rent $(\mathrm{n}=97)$ & 8 & (8) & 5 & $(20)$ & 4 & (18) & 2 & $(10)$ & 2 & (11) & 1 & (7) & 2 & (8) & 0 & $(0)$ \\
\hline Childcare Supports $(\mathrm{n}=99)$ & 6 & (6) & 1 & (4) & 1 & (5) & 3 & $(15)$ & 2 & (11) & 2 & (14) & 2 & (8) & 0 & $(0)$ \\
\hline Recovery exp. assist. $(n=95)$ & 5 & $(5)$ & 2 & (4) & 7 & $(32)$ & 1 & (5) & 1 & $(5)$ & 1 & (7) & 0 & $(0)$ & 0 & $(0)$ \\
\hline Homeless housing $(\mathrm{n}=97)$ & 5 & (5) & 3 & (12) & 2 & (9) & 1 & (5) & 1 & (5) & 0 & $(0)$ & 2 & (8) & 0 & $(0)$ \\
\hline
\end{tabular}

Note. Percentages are computed by row for Highly Effective and within columns for Regions, with agencies that serve more than one region being counted across their specific multiple regions. The percentage total equates to greater than $100 \%$, as multiple selections were available to respondents. 
Further, $41(41 \%)$ respondents indicated the lack of digital literacy skills $(\mathrm{n}=99)$ presented a medium impact on employment, ranking this barrier fifth. Also, at nearly the same percentage of respondents that selected low-wages as a high barrier, 38 (39\%) respondents indicated their clients' voiced concerns that low-wages $(\mathrm{n}=97)$ could outweigh the additional costs of working. Additionally, $37(38 \%)$ respondents noted poor health $(\mathrm{n}=97)$ presented a medium impact on employment, followed by 37 (39\%) respondents identifying housing instability or homelessness $(\mathrm{n}=95)$, and $35(35 \%)$ respondents indicating access to childcare $(\mathrm{n}$ =99) presented a medium barrier. Ranked tenth for medium impact on employment, lack of job skills $(\mathrm{n}=98)$ was selected by $34(45 \%)$ respondents, followed by $34(35 \%)$ respondents indicating $(\mathrm{n}=97)$ local labor market conditions (see Table 4.14).

The five remaining medium impacts are as follows: $31(32 \%)$ respondents indicated clients with criminal records $(\mathrm{n}=98)$ face medium barriers to employment, with $30(31 \%)$ indicating access to broadband/technology ( $\mathrm{n}=97)$, and $29(30 \%)$ indicating unaccommodated disabilities $(\mathrm{n}=98)$, as well as $27(27 \%)$ selecting transportation limitations $(\mathrm{n}=100)$, which was ranked fifteenth in medium impact barriers and first in high impact barriers, followed by high reservation wages $(\mathrm{n}=87)$, with $26(30 \%)$ respondents indicating this barrier is the lowest medium barrier to employment, the same position this barrier placed for high impact barriers (see Table 4.14).

Using the same 17 barriers to employment options available, low impact barriers are listed from least selected to most selected, with $16(16 \%)$ respondents noting that lack of soft skills $(\mathrm{n}=101)$ presented a low impact on employment, compared to $33 \%$ of respondents selecting lack of soft skills as the sixth highest barrier to employment and $52(52 \%)$ respondents indicating it was a medium impact barrier. Matched in ranking order as least selected is the 
barrier transportation limitations $(\mathrm{n}=100)$, with $16(16 \%)$ respondents indicating was a low impact barrier, compared to $27(27 \%)$ respondents indicating transportation was a medium impact barrier and an additional 57 (57\%) respondents indicating this was ranked the highest impact barrier to employment (see Table 4.14).

Table 4.14: Barriers to Employment, Ranked by Impact

\begin{tabular}{lllllll}
\hline \multirow{2}{*}{ Type } & \multicolumn{3}{c}{ Low } & \multicolumn{2}{c}{ Medium } & \multicolumn{2}{c}{ High } \\
& N $(\%)$ & N $(\%)$ & N (\%) \\
\hline Transportation limitations $(\mathrm{n}=100)$ & 16 & $(16)$ & 27 & $(27)$ & 57 & $(57)$ \\
Lack of job skills $(\mathrm{n}=98)$ & 21 & $(21)$ & 34 & $(35)$ & 43 & $(44)$ \\
Local labor market, jobs unavailable $(\mathrm{n}=97)$ & 21 & $(22)$ & 34 & $(35)$ & 42 & $(43)$ \\
Low-wages outweigh additional costs of working, & 22 & $(23)$ & 38 & $(39)$ & 37 & $(38)$ \\
e.g., childcare and transportation $(\mathrm{n}=97)$ & 18 & $(18)$ & 48 & $(48)$ & 34 & $(34)$ \\
Lack of work experience $(\mathrm{n}=100)$ & 16 & $(16)$ & 52 & $(52)$ & 33 & $(33)$ \\
Lack of soft skills $(\mathrm{n}=101)$ & 34 & $(35)$ & 30 & $(31)$ & 33 & $(34)$ \\
Access to broadband/technology $(\mathrm{n}=97)$ & 35 & $(35)$ & 35 & $(35)$ & 29 & $(29)$ \\
Access to childcare $(\mathrm{n}=99)$ & 30 & $(30)$ & 41 & $(41)$ & 28 & $(28)$ \\
Lack of digital literacy $(\mathrm{n}=99)$ & 26 & $(27)$ & 47 & $(48)$ & 25 & $(26)$ \\
Family responsibilities $(\mathrm{n}=98)$ & 43 & $(44)$ & 31 & $(32)$ & 24 & $(25)$ \\
Criminal record $(\mathrm{n}=98)$ & 31 & $(32)$ & 49 & $(50)$ & 18 & $(18)$ \\
Lack of basic literacy $(\mathrm{n}=98)$ & 45 & $(46)$ & 37 & $(38)$ & 15 & $(16)$ \\
Poor health $(\mathrm{n}=97)$ & 59 & $(60)$ & 29 & $(30)$ & 10 & $(10)$ \\
Unaccommodated disabilities $(\mathrm{n}=98)$ & 48 & $(51)$ & 37 & $(39)$ & 10 & $(11)$ \\
Housing instability or homelessness $(\mathrm{n}=95)$ & 54 & $(62)$ & 26 & $(30)$ & 7 & $(8)$ \\
High reservation wages $(\mathrm{n}=87)$ & & & & &
\end{tabular}

Note. Percentages are computed across rows. 
Additionally, $18(18 \%)$ respondents indicated lack of work experience $(\mathrm{n}=100)$ was a low impact barrier, followed by lack of job skills $(\mathrm{n}=98)$, which was selected by $21(21 \%)$ respondents. Matched in ranking is local labor market conditions $(n=97)$, with $21(21 \%)$ respondents also noting a low impact influence of labor market on employment, with 22 (23\%) respondents noting their clients had indicated low-wages could outweigh the additional costs of working $(\mathrm{n}=97)$. Further, $26(27 \%)$ respondents selected family responsibilities $(\mathrm{n}=98)$ as a low impact barrier, followed by 30 (30\%) respondents indicating lack of digital literacy skills (n =99) were a low impact barrier, 31 (32\%) respondents selecting a lack of basic literacy skills (n $=98)$ and $34(35 \%)$ indicating access to broadband/technology $(\mathrm{n}=97)$ was a low impact barrier. The same number of respondents, $35(35 \%)$, indicated access to childcare $(\mathrm{n}=99)$ as a medium barrier also selected the barrier as being of low impact, with 29 (29\%) respondents noting the barrier represented a high impact on employment. In addition, 43 (44\%) respondents indicated clients with criminal records $(\mathrm{n}=98)$ faced a low impact barrier to employment, followed by $45(46 \%)$ respondents selecting poor health $(\mathrm{n}=97), 48(51 \%)$ respondents identifying housing instability or homelessness $(\mathrm{n}=95)$, with $54(62 \%)$ respondents indicating high reservation wages $(\mathrm{n}=87)$, and $59(60 \%)$ respondents identifying unaccommodated disabilities $(\mathrm{n}=98)$ as the most selected low impact barrier (see Table 4.14).

Respondents also provided the following comments via the selection of other, please explain, with one respondent noting Work Ethic, followed by another respondent adding, "When so many are on unemployment and stimulus, they don't want to work. Major problem due to this is enabling them to stay home and not work." Additional comments included, (1) Successful TASC Test, (2) substance abuse, and (3) "Low motivation and lack of dedication to complete a program., as well as (4) "Fed Unemp kicker (covid) (sic) makes it better not to work." One 
additional comment involved two themes, "Domestic Violence intimidation, local government does not provide a great level of support for small and local business."

Overall, for the three least selected impactful employment barriers, the order for high impact is unaccommodated disabilities, housing instability or homelessness, and high reservation wages, compared to the medium impact order of unaccommodated disabilities, transportation limitations and high reservation wages. Further, by reversing the order to capture the lowest impact barrier as indicated by the most often selected, the ranking is identified as housing instability or homelessness, high reservation wages, and unaccommodated disabilities (see Table 4.14).

Across all regions, transportation limitations were identified by respondents as having the highest level of impact on employment. The ranking order for the remaining barriers varies by region. For example, the barrier lack of job skills was matched in ranking order with transportation in Region 1 and ranked second in Region 5 and Region 6, while four regions, Region 2, Region 3, Region 4, and Region 7, ranked the barrier third. For Region 1, the complete ranking order is transportation limitations tied with lack of job skills, followed by local labor market and low-wages, with lack of work experience and having a criminal record ranked fourth, lack of soft skills and lack of digital literacy skills concerned equally ranked at fifth, with access to broadband/technology sixth. Family responsibilities and poor health ranked seventh, followed by access to childcare and the lack of basic literacy skills, both ranked eighth. The remaining barriers in order are high reservation wages, unaccommodated disabilities, and housing instability and/or homelessness (see Table 4.15).

Region 2 respondents noted the following order: transportation limitations and lowwages, with lack of job skills and lack of soft skills both ranked at third, followed by local labor 
market at fourth. Lack of work experience is ranked at fourth, as well as three other equally ranked barriers: access to broadband/technology, poor health, and access to childcare, followed by the barrier of having a criminal record being as challenging as family responsibilities. The barriers of the lack of basic literacy skills and the lack of digital literacy skills are ranked seventh and eighth, respectively, followed by housing instability and/or homelessness. The remaining barriers are high reservation wages and unaccommodated disabilities, with the former ranked ninth and the latter ranked tenth (see Table 4.15).

Additionally, the ranking order for Region 3 was transportation limitations, followed by low-wages and local labor market conditions ranking second, with lack of job skills and access to broadband/technology equally indicated at third. Ranked at fourth are lack of soft skills and lack of work experience. The next four barriers are equally ranked at fifth: access to childcare, having a criminal record, family responsibilities and lack of digital literacy skills. Sixth place ranking includes three barriers: poor health, lack of basic literacy skills, and housing instability and/or homelessness. No respondents in the region selected the barriers of high reservation wages and unaccommodated disabilities. In the ranking order for Region 4, two barriers were selected equally as first, transportation limitations and lack of work experience, followed by lowwages in second and for third, three barriers which were considered equally challenging: lack of job skills, access to broadband/technology, and lack of soft skills. Lack of digital literacy skills was ranked fourth, with local labor market and family responsibilities tied for fifth. Access to childcare ranked sixth and having a criminal record ranked seventh, with three barriers ranking eighth: poor health, lack of basic literacy skills, and housing instability and/or homelessness. Ranking ninth was high reservation wages and unaccommodated disabilities (see Table 4.15). 
Table 4.15: Barriers to Employment, Ranked by High Impact, with Regional Responses

\begin{tabular}{|c|c|c|c|c|c|c|c|c|c|c|c|c|c|c|c|c|}
\hline \multirow{2}{*}{$\begin{array}{l}\text { Ranked by Most Selected } \\
\text { Responses } \\
\text { Transportation }(n=100)\end{array}$} & \multicolumn{2}{|c|}{$\begin{array}{c}\text { Overall Totals } \\
\text { High Impact } \\
\text { N (\%) } \\
\end{array}$} & \multicolumn{2}{|c|}{$\begin{array}{c}\text { Region } 1 \\
(\mathrm{n}=29) \\
\mathrm{N}(\%)\end{array}$} & \multicolumn{2}{|c|}{$\begin{array}{c}\begin{array}{c}\text { Region } 2 \\
(\mathrm{n}=23)\end{array} \\
\mathrm{N}(\%)\end{array}$} & \multicolumn{2}{|c|}{$\begin{array}{c}\begin{array}{c}\text { Region } 3 \\
(\mathrm{n}=20)\end{array} \\
\mathrm{N}(\%)\end{array}$} & \multicolumn{2}{|c|}{$\begin{array}{c}\begin{array}{c}\text { Region } 4 \\
(\mathrm{n}=20)\end{array} \\
\mathrm{N}(\%)\end{array}$} & \multicolumn{2}{|c|}{$\begin{array}{c}\begin{array}{c}\text { Region } 5 \\
(\mathrm{n}=13)\end{array} \\
\mathrm{N}(\%)\end{array}$} & \multicolumn{2}{|c|}{$\begin{array}{c}\begin{array}{c}\text { Region } 6 \\
(\mathrm{n}=26)\end{array} \\
\mathrm{N}(\%)\end{array}$} & \multicolumn{2}{|c|}{$\begin{array}{l}\begin{array}{r}\text { Region } 7 \\
(\mathrm{n}=10)\end{array} \\
\mathrm{N}(\%)\end{array}$} \\
\hline & 57 & $(57)$ & 17 & (59) & 15 & $(65)$ & 10 & $(50)$ & 13 & $(65)$ & 12 & $(92)$ & 16 & $(62)$ & 8 & $(80)$ \\
\hline Lack of job skills $(\mathrm{n}=98)$ & 43 & $(44)$ & 17 & $(59)$ & 11 & $(48)$ & 8 & $(40)$ & 11 & $(55)$ & 8 & $(62)$ & 14 & $(54)$ & 6 & $(60)$ \\
\hline Local labor market $(\mathrm{n}=97)$ & 42 & $(43)$ & 15 & $(52)$ & 10 & (43) & 9 & $(45)$ & 8 & $(40)$ & 7 & $(54)$ & 12 & $(46)$ & 5 & $(50)$ \\
\hline Low-wages $(n=97)$ & 37 & $(38)$ & 14 & (48) & 14 & $(61)$ & 9 & $(45)$ & 12 & $(60)$ & 4 & $(31)$ & 12 & $(46)$ & 5 & $(50)$ \\
\hline Lack of work exp. $(n=100)$ & 34 & $(34)$ & 10 & (34) & 8 & $(35)$ & 7 & $(35)$ & 13 & $(65)$ & 8 & $(62)$ & 12 & $(46)$ & 5 & $(50)$ \\
\hline Lack of soft skills $(\mathrm{n}=101)$ & 33 & (33) & 9 & $(31)$ & 11 & $(48)$ & 7 & $(35)$ & 11 & $(55)$ & 7 & $(54)$ & 10 & $(38)$ & 5 & $(50)$ \\
\hline Broadband/technology $(n=97)$ & 33 & (34) & 8 & $(28)$ & 8 & $(35)$ & 8 & $(40)$ & 11 & $(55)$ & 6 & $(46)$ & 14 & $(54)$ & 7 & $(70)$ \\
\hline Access to childcare $(n=99)$ & 29 & $(29)$ & 5 & (17) & 8 & $(35)$ & 5 & $(25)$ & 7 & $(35)$ & 3 & $(23)$ & 10 & $(38)$ & 3 & $(30)$ \\
\hline Lack of digital literacy $(n=99)$ & 28 & $(28)$ & 9 & $(31)$ & 5 & $(22)$ & 5 & $(25)$ & 9 & $(45)$ & 7 & $(54)$ & 12 & $(46)$ & 6 & $(60)$ \\
\hline Family responsibilities $(\mathrm{n}=98)$ & 25 & $(26)$ & 6 & (21) & 7 & $(30)$ & 5 & $(25)$ & 8 & $(40)$ & 4 & $(31)$ & 11 & $(42)$ & 1 & $(10)$ \\
\hline Criminal record $(\mathrm{n}=98)$ & 24 & $(25)$ & 10 & (34) & 7 & $(30)$ & 5 & $(25)$ & 6 & $(30)$ & 2 & $(15)$ & 8 & $(31)$ & 3 & $(30)$ \\
\hline Lack of basic literacy $(n=98)$ & 18 & $(18)$ & 5 & (17) & 6 & (26) & 3 & $(15)$ & 5 & $(25)$ & 4 & $(31)$ & 7 & $(27)$ & 2 & (20) \\
\hline Poor health $(\mathrm{n}=97)$ & 15 & $(16)$ & 6 & (21) & 8 & $(35)$ & 3 & (15) & 5 & $(25)$ & 1 & $(8)$ & 8 & $(31)$ & 1 & $(10)$ \\
\hline Unaccom. disabilities $(\mathrm{n}=98)$ & 10 & $(10)$ & 2 & (7) & 2 & (9) & 0 & $(0)$ & 2 & $(10)$ & 3 & (23) & 5 & (19) & 1 & (10) \\
\hline Homelessness $(\mathrm{n}=95)$ & 10 & (11) & 1 & (3) & 4 & $(17)$ & 3 & $(15)$ & 5 & $(25)$ & 3 & $(23)$ & 6 & $(23)$ & 3 & $(30)$ \\
\hline High reservation wages $(\mathrm{n}=87)$ & 7 & (8) & 3 & (10) & 2 & (9) & 0 & $(0)$ & 2 & (10) & 1 & (8) & 4 & $(15)$ & 2 & (20) \\
\hline
\end{tabular}

Note. Percentages are computed across rows for High Impact and within columns for Regions, with agencies that serve more than one region being counted across their specific multiple regions. The percentage total equates to greater than $100 \%$, as multiple selections were available to respondents. 
Ranking first for Region 5 was transportation limitations, followed by lack of job skills and lack of work experience tied for second. Three barriers were selected equally for third, lack of digital literacy skills, lack of soft skills, and local labor market. Ranked fourth was access to broadband/technology. Three barriers were equally ranked for fifth: low-wages, lack of basic literacy skills, and family responsibilities, followed by three additional barriers ranked at sixth: access to childcare, housing instability and/or homelessness, and unaccommodated disabilities, which places the latter barrier at its highest ranking of any other regions. The final three barriers are ranked seventh, criminal record, and tied for eighth, high reservation wages and poor health (see Table 4.15).

To continue, Region 6 respondents ranked transportation limitations the highest impact barrier on employment, followed by two barriers for second: lack of job skills and access to broadband/technology, with four barriers equally ranked third: lack of work experience, lack of digital literacy skills, local labor market, and low-wages. Ranked fourth was family responsibilities, followed by two barriers ranked fifth: lack of soft skills and access to childcare. Two barriers were ranked sixth, having a criminal record and poor health. The final four barriers in ranked order are a lack of basic literacy skills, housing instability and/or homelessness, unaccommodated disabilities and high reservation wages (see Table 4.15).

Transportation limitations is ranked the highest for Region 7, followed by access to broadband/technology, with two barriers equally ranked for third, lack of job skills and lack of digital literacy skills. Four barriers were equally ranked at fourth: lack of work experience, local labor market, low-wages, and lack of soft skills. Ranked fifth are access to childcare, having a criminal record, and housing instability and/or homelessness. Two barriers were ranked sixth, 
lack of basic literacy skills and high reservation wages, with an additional two barriers ranked seventh, poor health and unaccommodated disabilities (see Table 4.15).

Respondents were also asked if their clients' noted changes in barriers, pre- and peripandemic, with three options available: yes, no, and other, with an open-ended text option (see Table 4.16). In addition, a follow-up question asked for specific information regarding the changes in barriers pre- and peri-pandemic, with $36(37 \%)$ respondents $(n=98)$ noting themes such as increased number of barriers were compounded by government and agency services not being available during the pandemic, with one respondent commenting that the closures "left many people without help, not only with employment but also without access to many agency resources." Shortages in basic necessities served to influence employability, as noted by one respondent in the following, "since the pandemic there has been a higher rate of students not being able to meet their basic needs of food, housing and funds for keeping gas in their vehicles which impacts their jobs." Respondents also indicated job seekers were reluctant to return to work because they were afraid of contracting the virus. For instance, one respondent noted, "Many others are found not to be as motivated because of the day to day uncertainty related to the pandemic. Additionally, respondents indicated the stress of family responsibilities increased, particularly for individuals with children, health issues, or disabilities who had to choose between employment and family, often resulting in the loss of jobs, as illustrated in the following, "the pandemic has magnified many home/work issues, in particular with individuals with Autism Spectrum Disorder. Parents/guardians have experienced and are experiencing difficulties with sitters for children/adults who are in their care." The lack of childcare was a recurring theme, with 12 respondents commenting on the challenges and increased stress of not having childcare available. Further, respondents indicated the closures forced job losses and 
reductions in entry level employment, as well as access to job opportunities. For example, one respondent noted, "Many internship sites that hosted students in the past are unable to accommodate college students who need experience for post-graduate opportunities. Recent graduates are all competing for graduate programs or jobs in a poor market."

From another perspective, respondents also noted the increased unemployment benefits decreased the desire to return to work, with respondents commenting, "government handouts have increased"; "On top of traditional unemployment, the fed unemp (sic) 'relief' is dissuading people from re-entering the work force. Why work when the government is paying you more to stay home?"; "Increase in amount received for unemployment is greater than what a person can make working so the monetary incentive to work is not there. The opposite is occurring, a person is better off financially to continue on unemployment."; "conflict of Government Payments being higher than salaries in the short term; and "collecting unemployment and stimulus, so not accepting work."

One respondent provided an overview into the local economy in the following, "starting wages for competitive placements have increased, particularly in factory and productions positions, alleviating some of the 'opportunity cost' of going to work in reduction in social safety net benefits and increases in costs for child care and transportation," the respondent also added that "transportation, particularly public transportation, remains a difficulty."

With regards to the yes/no question, $37(38 \%)$ respondents $(\mathrm{n}=98)$ indicated there had been changes in the barriers to employment peri-pandemic, with 57 (58\%) respondents selecting no barrier changes had occurred, with four (4\%) respondents selecting other and adding comments. At the statewide agency level, five (71\%) respondents indicated barrier changes had 
occurred during the pandemic and two (29\%) respondents indicated there were no changes (see Table 4.16).

Table 4.16: Changes in Barriers, Pre- and Peri-Pandemic, with Regional Responses

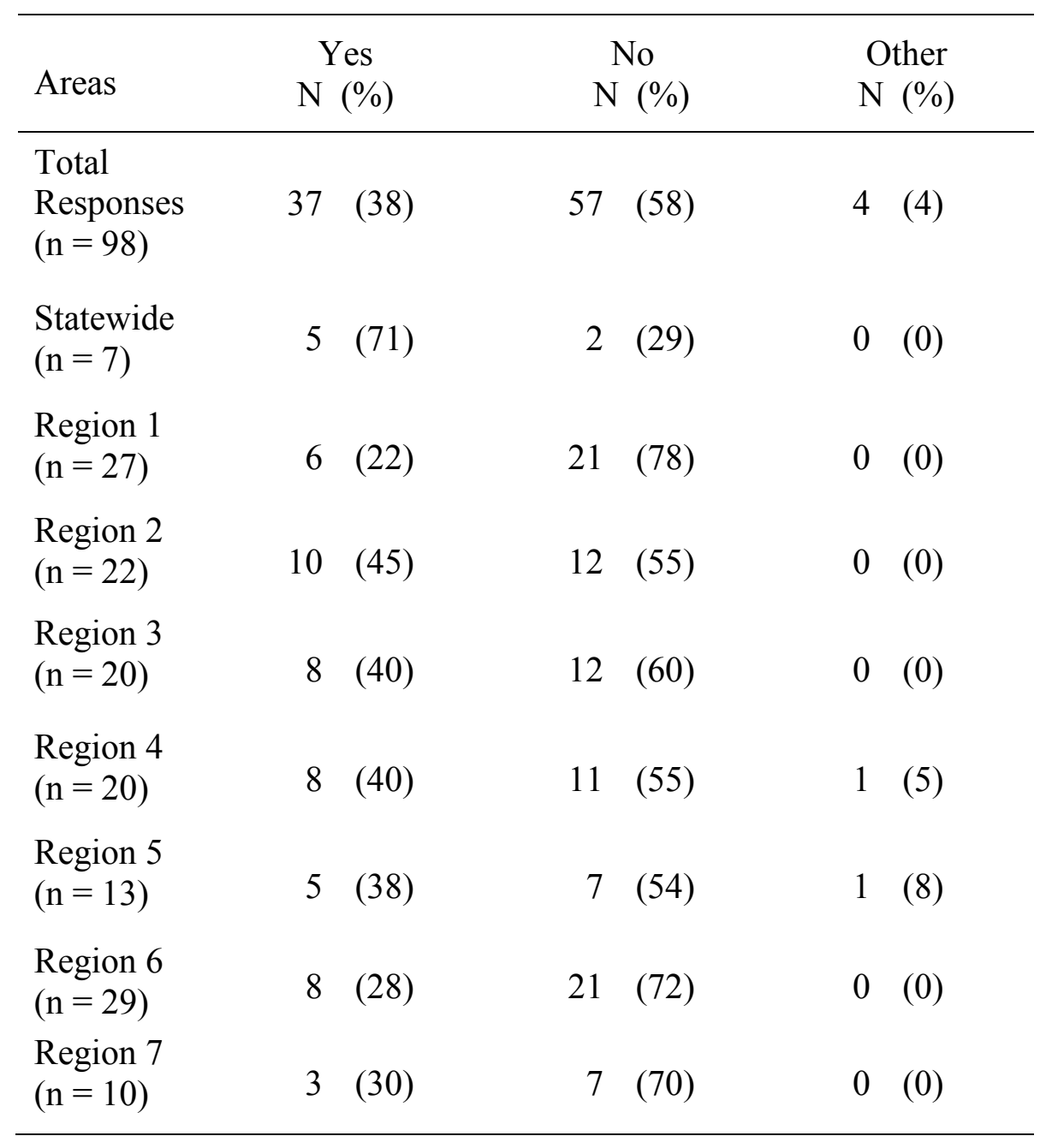

Note. Percentages are computed across rows.

For Region 1, six $(22 \%)$ respondents $(\mathrm{n}=27)$ indicated yes and $21(78 \%)$ respondents selected no. Region 2 respondents $(\mathrm{n}=22)$ were nearly evenly split between whether the pandemic had impacted employment barriers or not, with $10(45 \%)$ respondents indicating yes and an additional 12 (55\%) respondents indicating no. Eight (40\%) Region 3 respondents $(\mathrm{n}=$ 
$20)$ indicated the pandemic had affected employment and $12(60 \%)$ respondents selected $n o$. Resonating with Region 3, eight (40\%) Region 4 respondents $(n=20)$ indicated that in their region the pandemic had affected employment and $11(55 \%)$ respondents selected $n o$, with one (5\%) respondent indicating other (see Table 4.16).

Regarding Region 5 respondents $(\mathrm{n}=13)$, five $(38 \%)$, selected yes, with $7(54 \%)$

respondents indicating no changes in barriers had occurred, and one (8\%) respondent selecting other. In addition, eight $(28 \%)$ respondents $(n=29)$ in Region 6 indicating changes had occurred and $21(21 \%)$ selected $n o$. Three $(30 \%)$ Region 7 respondents $(\mathrm{n}=10)$ indicated that their region had experienced changes in employment barriers during the pandemic and seven (70\%) respondents selected no (see Table 4.16).

\section{Objective 5: Examine the relationship between responding job services agencies and other agencies.}

Respondents were also asked about their interactions with other organizations, including if they had a strategic plan and if yes, during the strategic development stages, was the agency influenced by other agencies' strategic or development plans, using a yes/no format, with a text response requested, please identify the other agencies (see Table 4.17).

Total responses $(n=116)$ indicated that $94(81 \%)$ respondents noted their agencies did have strategic plans, 16 (14\%) indicated their agencies did not have strategic plans, and six (5\%) respondents indicated other. Further, $40(39 \%)$ respondents $(\mathrm{n}=104)$ indicated their agencies were influenced by other agencies and $64(62 \%)$ respondents indicated the agencies were not influenced by other agencies. Additionally, the statewide agencies were split on the question of influence, with three (50\%) respondents indicating their agencies were impacted by the strategic 
plans of other agencies and three (50\%) respondents indicating their agencies had not been influenced (see Table 4.17).

Table 4.17: Influenced by Other Agencies' Strategic or Development Plans

\begin{tabular}{|c|c|c|c|c|c|c|c|c|c|c|}
\hline \multirow[b]{2}{*}{ Areas } & \multicolumn{6}{|c|}{$\begin{array}{l}\text { Does the Agency have a Strategic } \\
\text { Plan? } \\
(n=116)\end{array}$} & \multicolumn{4}{|c|}{$\begin{array}{l}\text { Was the Plan Influenced } \\
\text { by Other Agencies? } \\
(\mathrm{n}=104)\end{array}$} \\
\hline & & $\begin{array}{l}\text { es } \\
(\%)\end{array}$ & & $\begin{array}{l}\text { Jo } \\
(\%)\end{array}$ & & $\begin{array}{l}\text { ther } \\
(\%)\end{array}$ & & $\begin{array}{l}\text { es } \\
(\%)\end{array}$ & & $\begin{array}{l}\text { No } \\
\text { T }(\%)\end{array}$ \\
\hline $\begin{array}{l}\text { Total } \\
\text { Responses }\end{array}$ & 94 & (81) & 16 & (14) & 6 & (5) & 40 & (39) & 64 & (62) \\
\hline $\begin{array}{l}\text { Statewide } \\
(\mathrm{n}=7 \text { and } 6)\end{array}$ & 6 & (86) & 0 & $(0)$ & 1 & (14) & 3 & $(50)$ & 3 & $(50)$ \\
\hline $\begin{array}{l}\text { Region } 1 \\
(n=31)\end{array}$ & 26 & (84) & 4 & (13) & 1 & (3) & 8 & (26) & 23 & (74) \\
\hline $\begin{array}{l}\text { Region } 2 \\
(n=26)\end{array}$ & 22 & (85) & 4 & (15) & 0 & (0) & 11 & (42) & 15 & (58) \\
\hline $\begin{array}{l}\text { Region } 3 \\
(n=23)\end{array}$ & 19 & (83) & 4 & (17) & 0 & $(0)$ & 9 & (39) & 14 & (61) \\
\hline $\begin{array}{l}\text { Region } 4 \\
(n=23)\end{array}$ & 20 & (87) & 3 & (13) & 0 & (0) & 10 & (43) & 13 & (57) \\
\hline $\begin{array}{l}\text { Region } 5 \\
(\mathrm{n}=15)\end{array}$ & 12 & $(80)$ & 2 & (13) & 1 & (7) & 4 & (27) & 11 & (73) \\
\hline $\begin{array}{l}\text { Region } 6 \\
(\mathrm{n}=30 \text { and } 28)\end{array}$ & 25 & (83) & 5 & (17) & 0 & $(0)$ & 14 & $(50)$ & 14 & $(50)$ \\
\hline $\begin{array}{l}\text { Region } 7 \\
(\mathrm{n}=11)\end{array}$ & 7 & (64) & 2 & (18) & 2 & (18) & 6 & $(55)$ & 5 & $(45)$ \\
\hline
\end{tabular}

Note. Percentages are computed across rows.

For Region 1, 26 (84\%) respondents indicated that within their region the crisis had impacted employment and four (13\%) respondents selected no, with one (3\%) selecting other. 
On the issue of influence, eight (26\%) Region 1 respondents indicated their agencies were influenced by other agencies and 23 (74\%) respondents selected no. Compared to Region 2, where $22(85 \%)$ respondents indicated their agencies had strategic plans and four (15\%) agencies did not have strategic plans, with no respondents selecting other. With regards to influence, 11 (42\%) respondents in Region 2 indicated other agencies had collaborated with other agencies during the strategic planning process and 15 (58\%) indicated no relationships influenced the planning process. In addition, $19(83 \%)$ Region 3 respondents indicated their strategic plans existed, while four (17\%) respondents selected no plans were in place. Further, nine (39\%) respondents in the region indicated their agencies were influenced during the planning stage and $14(61 \%)$ indicated no other agencies played a role in the strategic planning process. Twenty $(87 \%)$ Region 4 respondents indicated strategic plans were in place, with three $(13 \%)$ respondents selecting no, followed by $10(43 \%)$ respondents indicating other agencies had been involved in the strategic planning process, and 13 (57\%) respondents indicating no relationships had influence the planning process. In Region 5, 12 (80\%) respondents indicated their agencies had strategic plans and $2(13 \%)$ respondents selected no, with one $(7 \%)$ respondent selecting other. Further, four $(27 \%)$ respondents indicated a relationship with other agencies had impact their strategic plans and $11(73 \%)$ respondents indicated no other agencies held influence over their planning stages.

For Region 6, 25 (83\%) respondents indicated their planning process had been impacted by other agencies and five (17\%) selected no, followed by an even split, 14 (50\%), indicating other agencies influenced the planning process and no agencies played a role in the process. Region 7 respondents, seven (64\%), indicated their agencies had strategic plans and two (2\%) respondents indicated no plans existed, with two (18\%) selecting other. In addition, six (55\%) 
indicated the process had been influence by other agencies, while five (45\%) respondents selected no (see Table 4.17).

In further response to the influence question, (please identify the other agencies), 37 (38\%) respondents listed the following agencies and resources that influenced their strategic and/or development plans: AbilityOne Program, Academic success services, Advisory Council, American's Job Center, Boone County Day report, Boone Memorial Hospital Brighter Futures, Christian Help, College of Education and Human Services, Commission on Accreditation of Rehabilitation Facilities (CARF), Community and Technical College System, Federal Bureau of Prisons, Goodwill Industries International, Telemon, U.S. Department of Labor, Veterans Services, West Virginia Board of Barbers \& Cosmetologists, West Virginia Board of Practical Examiners, West Virginia Department of Education, Adult and Community Education, West Virginia Jobs and Hopes, West Virginia Division of Rehabilitation Services, and Workforce West Virginia.

In addition, the respondents were asked to rate their agreement with statements regarding their respective attitudes toward partnerships, customer service activities and industry standards, selecting from the scale: strongly agree $=1 ;$ agree $=2 ;$ neither agree nor disagree $=$ 3; disagree $=4$; and strongly disagree $=5$ (see Table 4.18). Of the respondents $(\mathrm{n}=81)$, the majority, 36 (44\%), strongly agree that their respective agencies do measure customer satisfaction of both clients and businesses, with an additional 31 (38\%) respondents selecting agree, $11(14 \%)$ respondents selecting neither agree nor disagree, three (3\%) respondent selecting disagree, and no respondents selecting strongly disagree. With regards to the agencies $(\mathrm{n}=84)$ forming strong partnerships with academic institutions, 24 (29\%) respondents selected strongly agree, $40(48 \%)$ respondents selected agree, 15 (18\%) respondents selected neither 
agree nor disagree, five (6\%) respondents selected disagree, and no respondents selected strongly disagree. The respondents also indicated if their agencies had workforce development partnerships $(\mathrm{n}=83)$, with $24(29 \%)$ respondents selecting strongly agree, $39(47 \%)$ respondents selecting agree, 11 (13\%) respondents selecting neither agree nor disagree, nine (11\%) respondent selecting disagree, and no respondents selecting strongly disagree (see Table 4.18).

Regarding the agencies' efforts to follow uniform guidelines and performance standards, $42(50 \%)$ respondents selected strongly agree, 32 (38\%) respondents selected agree, $8(10 \%)$ respondents selected neither agree nor disagree, two (2\%) respondents selected disagree, and no respondents selected strongly disagree. Regarding the agencies' efforts to adopt a proactive approach to job placement $(\mathrm{n}=82), 26(32 \%)$ respondents selected strongly agree, $34(42 \%)$ respondents selected agree, 15 (18\%) respondents selected neither agree nor disagree, six (7\%) respondents selected disagree, and one (1\%) respondents selected strongly disagree. Also, the respondents $(\mathrm{n}=81)$ were asked to address the quality of services they provided to the business community, with 40 (49\%) respondents selecting strongly agree, 19 (24\%) respondents selecting agree, 15 (19\%) respondents selecting neither agree nor disagree, six (7\%) respondents selecting disagree, and one (1\%) respondents selecting strongly disagree. Relatedly, the respondents $(\mathrm{n}=80)$ were asked to identify their agencies' attitude toward conducting on-going focus groups with the local businesses, with 15 (19\%) respondents selecting strongly agree, 24 (30\%) respondents selecting agree, 23 (29\%) respondents selecting neither agree nor disagree, $16(20 \%)$ respondents selecting disagree, and two (3\%) respondents selecting strongly disagree (see Table 4.18). 
Table 4.18: Employment Agencies: Partnerships, Activities, and Industry Standards

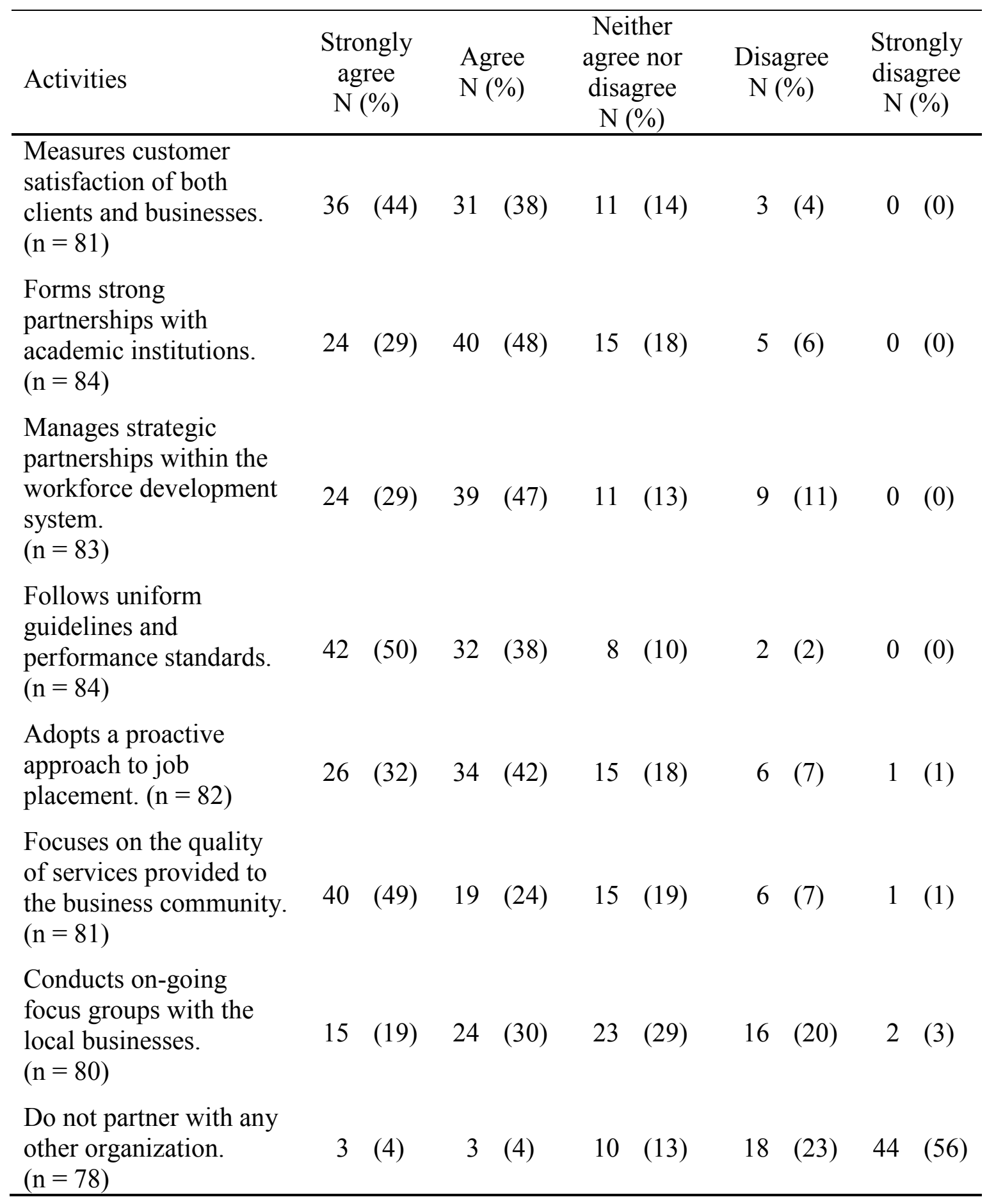

Note. Percentages are computed across rows. 
Additionally, the respondents $(\mathrm{n}=78)$ were asked to confirm that their agencies did not partner with any other organization, with the question inversed during coding to ensure consistency. Three (4\%) respondents selected strongly agree, three (4\%) respondent selected agree, $10(13 \%)$ respondents selected neither agree nor disagree, $18(23 \%)$ respondents selected disagree, and $44(56 \%)$ respondents selected strongly disagree, resulting in $62 \%$ of the population indicating their agencies do partner with other organizations and $6 \%$ indicating their agencies do not form partnerships (see Table 4.18).

\section{Objective 6: Determine if the agencies' workforce development activities align with human, social, and financial capital theories.}

To examine the alignment of the agencies' efforts with the social capital theory, which, as previously noted, is indicated by the enhancement of social network links to viable employment opportunities (Aguilera, 2002; Beggs \& Hurlbert, 1997; Coleman, 1988; Ruhose et al., 2018), the population $(\mathrm{n}=104)$ was asked if their agency's strategic or development plans were designed to address diversity, equity and inclusion (DEI). Eighty-seven respondents (84\%) indicated their agencies had strategic or development plans that were designed to address diversity, equity and inclusion, while nine $(9 \%)$ respondents indicated their respective agencies did not, with eight (8\%) selecting other. The respondents selecting other noted their agencies served everyone, that DEI plans were in the developing stages, and that non-discrimination notices had been posted.

The respondents were also asked to provide their target population demographics, including Race/Ethnicity, to further examine alignment with social capital, while also addressing the agencies' efforts to engage the long-term non-employed, as identified in previous research (Case \& Deaton, 2017). At 70\%, low-income individuals and individuals with disabilities/health 
conditions older adults with the most common populations among the agencies, followed by young adults (69\%), adults (67\%) and unemployed individuals (62\%). Mid-range in populations served were veterans (58\%), older adults (57\%), and high school students (56\%), with the five least common among the target populations being college students (49\%), ex-offenders (48\%), recovery and/or chemically dependent (42\%), homeless people (39\%), and, at $20 \%$, specific ethnic groups (see Table 4.19).

The respondents $(n=49)$ indicated $84 \%$ of their clients are white/Caucasian, compared with the state's population, which is $94 \%$ white/Caucasian, followed by $15 \%$ Black or African American, while the state's Black or African American is 4\%, indicating the agencies clientele are more diverse than the state's overall population. Additionally, the agencies serve a higher percentage of individuals with multiple races (4\%) than the state's respective population ( $2 \%)$, as well as Hispanic/Latino individuals (4\%), which is also (2\%) of the state's population. The least represented races served are Asian (2\%), compared to the state's respective population (1\%), and, at (1\%), Native Hawaiian/Pacific Islanders (see Table 4.20).

Respondents $(\mathrm{n}=106)$ were also asked to indicate the fields of employment in which their clients were placed to determine if employment positions aligned with financial capital development and whether the industry sectors offer career pathways that lead to earning a living wage. The five most common fields of employment placements range in median hourly wages from $\$ 11.43$ to $\$ 16.07$, with the highest percentage of placements being in health care $(66 \%)$, followed by customer service/retail (62\%), food operation (59\%), cleaning and maintenance $(59 \%)$, and factory worker (49\%). The five least common job placement sectors range in median hourly wages from $\$ 9.99$ to $\$ 38.31$, with the following in ranked order: IT sector $(43 \%)$, child 
development (39\%), small business owner (36\%), financial operations (33\%), and, at 33\%, the education sector (see Table 4.21).

Table 4.19: Target Population Demographics, in Ranked Order

\begin{tabular}{lcc}
\hline Category $(\mathrm{n}=89)$ & $\mathrm{N}$ & $(\%)$ \\
\hline Individuals with low incomes & 62 & $(70)$ \\
Individuals with disabilities/health conditions & 62 & $(70)$ \\
Young adults (ages 18-25) & 61 & $(69)$ \\
Adults & 60 & $(67)$ \\
Unemployed individuals & 55 & $(62)$ \\
Veterans & 52 & $(58)$ \\
Older adults (ages 55+) & 51 & $(57)$ \\
High school students & 50 & $(56)$ \\
College students & 44 & $(49)$ \\
Ex-offenders & 43 & $(48)$ \\
Recovery and/or chemically dependent & 37 & $(42)$ \\
Homeless people & 35 & $(39)$ \\
Specific ethnic groups & 18 & $(20)$ \\
\hline
\end{tabular}

Note. Percentages are computed within columns.

Further, respondents that selected other industry sectors of employment provided the following listings of placed employment: aerospace, agriculture/farming, automotive industry, construction, contracting, cosmetology, emergency services, engineering, government, graphic design, HVAC, industrial piece work, law and public safety, management, mechanical, military, 
mining, office administration, physics, pre-veterinary, warehouse, wood working, transportation (CDL), sales, STEM, science general business, seasonal worker, and social services. In addition, one respondent noted that high school graduates who complete "a state approved CTE program typically go on to one of the following: work in career field, go to college or technical school, change career field, military, (and) labor unions."

Table 4.20: Target Population Race/Ethnicity, in Ranked Order

\begin{tabular}{lcc}
\hline Category $(\mathrm{n}=49)$ & $\begin{array}{c}\text { Agency } \\
\text { Served \% }\end{array}$ & Census \% \\
\hline White/Caucasian & 84 & 94 \\
Black or African American & 15 & 4 \\
Multiple races & 4 & 2 \\
Hispanic/Latino & 4 & 2 \\
American Indian and Alaska Native & 2 & 3 \\
Asian & 2 & 1 \\
Native Hawaiian and other Pacific Islanders & 1 & - \\
\hline
\end{tabular}

Note. From United States Decennial Census and American Community Survey (V2019). Retrieved from https://www.census.gov/quickfacts/WV.

Respondents also provided indicators for successful completions and improved employment training and skills development outcomes, which align with human capital theory. The agencies provided the number of individuals served during 2019 and 2020, pre- and peripandemic, as well as their agencies' competitively employed rates (see Table 4.22). Relatedly, respondents were also asked to include their agencies' 2019 and 2020 dropout rates and their competitively employed rate for 90 consecutive days rates (see Table 4.22). 
Table 4.21: Placed in Industry Sectors, Ranked Order

\begin{tabular}{|c|c|c|c|}
\hline Category $(\mathrm{n}=106)$ & $\mathrm{N}$ & $(\%)$ & Median Hourly Wage Estimates \\
\hline $\begin{array}{l}\text { Health Care (nursing, technician, } \\
\text { home health aide, etc.) }\end{array}$ & 70 & (66) & 11.43 \\
\hline $\begin{array}{l}\text { Customer Service/Retail (store } \\
\text { clerk, server, etc.) }\end{array}$ & 66 & (62) & 11.80 \\
\hline Food Operation (cook, etc.) & 63 & (59) & 10.24 \\
\hline $\begin{array}{l}\text { Cleaning and maintenance } \\
\text { (housekeeping, janitorial, etc.) }\end{array}$ & 63 & (59) & 12.19 \\
\hline $\begin{array}{l}\text { Factory Worker (manufacturing, } \\
\text { food production, etc.) }\end{array}$ & 52 & (49) & 16.07 \\
\hline $\begin{array}{l}\text { IT (computer technician, } \\
\text { electronics, etc.) }\end{array}$ & 45 & (43) & 21.39 \\
\hline $\begin{array}{l}\text { Child development (childcare } \\
\text { provider, etc.) }\end{array}$ & 41 & (39) & 9.99 \\
\hline $\begin{array}{l}\text { Small business owner or self- } \\
\text { employed (store, restaurant, beauty } \\
\text { salon, etc.) }\end{array}$ & 38 & (36) & 38.31 \\
\hline $\begin{array}{l}\text { Financial operations (accountant, } \\
\text { teller, etc.) }\end{array}$ & 35 & (33) & 13.60 \\
\hline Education (teacher, etc.) & 35 & (33) & 20.85 \\
\hline
\end{tabular}

Note. From United States Department of Labor (n.d.). Retrieved from https://www.bls.gov/oes/current/oes_wv.htm. Percentages are computed within columns.

During 2019, as indicated by the responding agencies, an estimated 98,206 individuals received employment services, followed in 2020 by an estimated 71,261 served, which reflects a decreased percentage change of $27 \%$. At the statewide agency level, 6,560 individuals received services in 2019 , with a $5 \%$ percentage change increase in 2020 , resulting in 6,863 people being served. Region 1 also experienced an increase in the number served from 2019 to 2020 , with a $2 \%$ percentage change from 13,940 served to 14,257 served. Region 2 had a decrease in number served from 2019 to 2020 , with a $4 \%$ percentage decrease from 26,969 to 25,990, while Region 3 
remained relatively stable from 2019 to 2020 , with 9,539 served pre-pandemic to 9,679 served peri-pandemic. In addition, Region 4 remained relatively stable also, with a $2 \%$ percentage change increase from 9,572 in 2019 to 9,768 in 2020. Region 5 experienced the most extensive decrease, serving 35,214 in 2019 and shifting to 14,367 in 2020, a decreased percentage change of 59\%, with Region 6 undergoing a similar setback having served 29,782 in 2019 and then serving 17,067 in 2020 , resulting in a $43 \%$ percentage change decrease. Region 7 also had a decrease in number served, pre- and peri-pandemic, with 5,014 served in 2019 and 4,288 in 2020, reflecting a 14\% percentage change decrease (see Table 4.22).

For 2019 and 2020, the respondents $(n=30)$ also provided their agencies' competitively employed rate, the unsubsidized placement rate for job seekers, which aligns with increase in financial and social capital. All responding agencies across West Virginia experienced a decreased percentage change from 2019 to 2020 , which ranged from $-26 \%$ to $-5 \%$ (see Table 4.22).

The overall average competitively employed rate of $68 \%$ in 2019 shifted downward in 2020 to $61 \%$, a decreased percentage change of $10 \%$. For the statewide agencies, the shift moved from $73 \%$ gaining employment in 2019 to $69 \%$ in 2020, a decrease in percentage changed of $-5 \%$. For Region 1 , the decrease was slightly more than the statewide agencies, but less than any other region, with the decrease from $61 \%$ getting jobs in 2019 to $57 \%$ of individuals being employed, a percentage change decrease of $-7 \%$, which was followed by Region 4, with a 2019 competitively employed rate of $77 \%$ shifting to a $68 \%$ rate in 2020 , resulting in a $-12 \%$ percentage change. Region 6 had a $72 \%$ rate in 2019 that shifted downward to a $63 \%$ rate in 2020, reflecting a $-13 \%$ percentage change. The downward pull was also felt in Region 3, which 
had a 2019 rate of $69 \%$ and closed 2020 with a $58 \%$ rate, giving the region a $-16 \%$ percentage change (see Table 4.22).

Table 4.22: Estimated Number Served and Competitively Employed Rate

\begin{tabular}{lcccccc}
\hline & \multicolumn{3}{c}{$\begin{array}{c}\text { Number of People of Served } \\
(\mathrm{n}=70)\end{array}$} & \multicolumn{3}{c}{$\begin{array}{c}\text { Competitively Employed Rate } \\
(\mathrm{n}=30)\end{array}$} \\
\hline Areas & 2019 & 2020 & $(\%)$ Changed & 2019 & 2020 & $(\%)$ Changed \\
\hline $\begin{array}{l}\text { Total for } \\
\text { Respondents }\end{array}$ & 98,206 & 71,261 & $(-27)$ & $(68)$ & $(61)$ & $(-10)$ \\
Statewide & 6,560 & 6,863 & $(5)$ & $(73)$ & $(69)$ & $(-5)$ \\
Region 1 & 13,940 & 14,257 & $(2)$ & $(61)$ & $(57)$ & $(-7)$ \\
Region 2 & 26,969 & 25,990 & $(-4)$ & $(69)$ & $(56)$ & $(-19)$ \\
Region 3 & 9,539 & 9,679 & $(1)$ & $(69)$ & $(58)$ & $(-16)$ \\
Region 4 & 9,572 & 9,768 & $(2)$ & $(77)$ & $(68)$ & $(-12)$ \\
Region 5 & 35,214 & 14,367 & $(-59)$ & $(78)$ & $(58)$ & $(-26)$ \\
Region 6 & 29,782 & 17,067 & $(-43)$ & $(72)$ & $(63)$ & $(-13)$ \\
Region 7 & 5,014 & 4,288 & $(-14)$ & $(74)$ & $(59)$ & $(-20)$ \\
\hline
\end{tabular}

Note. Percentages are computed across rows.

Region 2 experienced a 19\% decrease percentage change from 2019 to 2020, moving from a $69 \%$ placement rate to a $56 \%$ rate of individuals securing jobs. Region 7 moved from a $74 \%$ rate in 2019 to a $59 \%$ rate in 2020 , resulting in a downward shift of a -20 percentage change and placing the region second in largest decreases in competitively employed rates, with Region 
5 having the most significant declines in placement levels, moving from a $78 \%$ rate in 2019 to $58 \%$ in 2020 , giving the region a $-26 \%$ percentage change (see Table 4.22 ).

Respondents $(\mathrm{n}=30)$ also provided their agencies' dropout rates for 2019 and 2020, with the overall average of $17 \%$ in 2019 moving to $19 \%$ in 2020 reflecting an increased dropout rate percentage change of $12 \%$. The statewide and Region 6 agencies noted their participants indicated the same outcomes, $17 \%$ in 2019 and $19 \%$ in 2020, resulting a percentage change of $12 \%$ (see Table 4.22).

Region 1 was the only region that indicated the dropout rate remained stable, $6 \%$ in both 2019 and 2020. Region 2 had a dropout rate of $19 \%$ in 2019, which shifted upward to $25 \%$, reflecting a $32 \%$ percentage change, followed by Region 3, which had a rate of $12 \%$ in 2019 and $16 \%$ in 2020 , resulting in a $33 \%$ percentage change. Further, the rate for Region 4 was $17 \%$ for 2019 and $18 \%$ for 2020 , giving a percentage change of $6 \%$, compared to Region 5 , which had $31 \%$ in 2019 and decreased to $30 \%$ in 2020 , the only region to experience a decrease in dropouts pre- and peri-pandemic. Region 7 had a dropout rate of $20 \%$ in 2019 and $22 \%$ in 2020 , producing a percentage change of a $10 \%$ difference (see Table 4.22 ).

For 2019 and 2020, the agencies $(n=30)$ also provided the percentage of individuals who were placed into employment and remained in their jobs for 90 days, which reflects increases in financial and social capital. Across the state, the overall average 90 day employed rate of $77 \%$ in 2019 shifted downward in 2020 to $69 \%$, a decreased percentage change of $10 \%$. Statewide agencies did not provide data for 90 days consecutive rates. Further, Region 1 experienced a shift from $78 \%$ of employees staying in their jobs for 90 days in 2019 to $62 \%$ in 2020 , a percentage change decrease of $-21 \%$, followed by Region 2 with a comparatively minor shift from $79 \%$ in 2019 to $77 \%$ in 2020 , resulting in a $-3 \%$ percentage change. 
Table 4.23: Dropout Rate and Employed 90 Consecutive Days Rate

\begin{tabular}{lcccccc}
\hline & \multicolumn{3}{c}{$\begin{array}{c}\text { Dropout Rate } \\
(\mathrm{n}=30)\end{array}$} & \multicolumn{2}{c}{ Employed $90 \begin{array}{c}\text { Consecutive Days Rate } \\
(\mathrm{n}=32)\end{array}$} \\
\hline Areas & 2019 & 2020 & $\begin{array}{c}(\%) \\
\text { Changed }\end{array}$ & 2019 & 2020 & $\begin{array}{c}(\%) \\
\text { Changed }\end{array}$ \\
\hline $\begin{array}{l}\text { Average for } \\
\text { Respondents }\end{array}$ & $(17)$ & $(19)$ & $(12)$ & $(77)$ & $(69)$ & $(-10)$ \\
Statewide & $(17)$ & $(19)$ & $(12)$ & $(\mathrm{NA})$ & $(\mathrm{NA})$ & $(\mathrm{NA})$ \\
Region 1 & $(6)$ & $(6)$ & $(0)$ & $(78)$ & $(62)$ & $(-21)$ \\
Region 2 & $(19)$ & $(25)$ & $(32)$ & $(79)$ & $(77)$ & $(-3)$ \\
Region 3 & $(12)$ & $(16)$ & $(33)$ & $(86)$ & $(84)$ & $(-2)$ \\
Region 4 & $(17)$ & $(18)$ & $(6)$ & $(79)$ & $(79)$ & $(0)$ \\
Region 5 & $(31)$ & $(30)$ & $(-3)$ & $(72)$ & $(76)$ & $(6)$ \\
Region 6 & $(17)$ & $(19)$ & $(12)$ & $(73)$ & $(73)$ & $(0)$ \\
Region 7 & $(20)$ & $(22)$ & $(10)$ & $(69)$ & $(67)$ & $(3)$ \\
\hline
\end{tabular}

Note. Percentages are computed across rows.

Region 3 also had a small shift from a 2019 rate of $86 \%$ to an $84 \%$ rate in 2020 , giving the region a $-2 \%$ percentage change. Region 4 remained stable with a rate of $79 \%$ in 2019 and 2020, with Region 5 having an increase in employee retention levels, moving from a $72 \%$ rate in 2019 to $76 \%$ in 2020, giving the region a 6\% percentage change. In 2019 and 2020, Region 6 held steady at a $73 \%$ rate, with Region 7 experiencing a 3\% percentage change from a $69 \%$ rate in 2019 to a rate of $67 \%$ in 2020 (see Table 4.22).

As noted previously, research indicates (McCain et. al, 2004) that workforce development practitioners and clients should achieve a level of knowledge, skills, and abilities, 
known as competencies, that are needed to adequately perform the required tasks of employment. To examine the agencies' efforts to ensure staff and clients receive the necessary competencies, the respondents were asked if their agencies held postsecondary advancement goals, as well as the type and number of development professional certifications held by staff members (see Table 4.24).

Table 4.24: Postsecondary Credential Attainment Goals

\begin{tabular}{lcccc}
\hline Category & \multicolumn{2}{c}{ Yes } & \multicolumn{2}{c}{ No } \\
& $\mathrm{N} \mathrm{( \% )}$ & $\mathrm{N} \mathrm{( \% )}$ \\
\hline $\begin{array}{l}\text { Staff, Postsecondary Credential Attainment Goals } \\
(\mathrm{n}=83)\end{array}$ & 21 & $(25)$ & 57 & $(69)$ \\
$\begin{array}{l}\text { Clients/Participants, Postsecondary Credential } \\
\text { Attainment Goals }(\mathrm{n}=84)\end{array}$ & 27 & $(32)$ & $53 \quad(63)$ \\
\hline
\end{tabular}

Note. Percentages are computed across rows.

The respondents $(\mathrm{n}=83)$ indicated that the majority of agencies do not have attainment goals for staff members, with 21 (25\%) of respondents noting their agencies do expect staff to pursue postsecondary opportunities and 57 (69\%) indicating their agencies do not have attainment goals. Further, the respondents $(n=84)$ indicated that most agencies do not have attainment goals for clients, with 27 (32\%) indicating client attainment goals are expected and 53 $(63 \%)$ do not have postsecondary goals for clients (see Table 4.24).

The respondents also provided the number of certifications and types held by staff, which is an additional competency indicator. Most of the respondents $(n=64)$ were nearly evenly split regarding credentialed staff, with 26 (41\%) indicating their staff did not have credentials and 24 $(38 \%)$ indicating their staff members held industry related credentials, with $10(16 \%)$ selecting 
other, while predominantly noting they did not know the status of credentials of their staff members, followed by the respondents $(\mathrm{n}=60)$ noting that $19(32 \%)$ had no professional certifications (see Table 4.25).

Table 4.25: Workforce Development Certifications held by Agencies' Staff

\begin{tabular}{|c|c|c|c|c|c|}
\hline $\begin{array}{l}\text { Certified Staff } \\
\text { Status }(\mathrm{n}=64)\end{array}$ & $\mathrm{N}$ & $(\%)$ & Categories $(\mathrm{n}=60)$ & $\mathrm{N}$ & $(\%)$ \\
\hline No & 26 & (41) & No professional certifications & 19 & (32) \\
\hline Yes & 24 & (38) & Career counselor & 14 & (23) \\
\hline \multirow[t]{8}{*}{ Other } & 10 & (16) & $\begin{array}{l}\text { Job Placement Specialist or Career } \\
\text { Development Facilitator }\end{array}$ & 12 & (20) \\
\hline & & & Career adviser/coach & 8 & (13) \\
\hline & & & Vocational rehabilitation counselor & 8 & (13) \\
\hline & & & Job Skills Coach & 7 & (12) \\
\hline & & & Supported Employment Specialist & 6 & (10) \\
\hline & & & $\begin{array}{l}\text { Certified Workforce Development } \\
\text { Professional (CWDP) }\end{array}$ & 6 & (10) \\
\hline & & & Career navigator & 5 & (8) \\
\hline & & & Other & 12 & (20) \\
\hline
\end{tabular}

Note. Percentages are computed within columns.

Among the identified certifications $(\mathrm{n}=60), 14(23 \%)$ were certified career counselors, 12 (20\%) were certified job placement specialists or career development facilitators, 8 (13\%) were certified career advisers/coaches, 8 (13\%) were certified vocational rehabilitation counselors, 7 (12\%) were certified job skills coaches, 6 (10\%) were certified supported employment specialists, $6(10 \%)$ were Certified Workforce Development Professionals (CWDP), 5 (8\%) were certified career navigators, and $12(20 \%)$ selected other (see Table 4.25). 
The respondents that selected other noted the following: 1) I'm just a staff member; I have no employees. 2) We are just moved into positions with no training and asked to figure it out on our own. 3) We are all teachers. CTE teachers are typically people who have worked in the field and get trained through a grant from WVDE to Marshall University to gain knowledge and college credits in the teaching field. 4) Teachers License 5) no professional certs listed above, 6) Certified Rehabilitation Counselor (CRC), Social Work Licensure, Licensed Practical Counselor (LPC). 7) Various Workforce Development Organization Certifications offered at National Conferences over the past 20 years. 8) certifications are program specific, 9) retired school teacher, Master's in Special Education, Drug abuse counselor retired Master's Criminal Law, etc., 10) No specific career/workforce certifications, but I hold a Doctor in Executive Leadership. 11) customized employment support professional; Certification of Disability Management Specialists (CDMS), and 12) Career \& Technical Education Teaching Certifications (see Table 4.25).

As a follow-up question, respondents were asked what training/support have they received, with the following themes noted: 1) respondent has extensive years of experience, 2) funded programs offer continued training and support, 3) periodic staff and faculty development was provided to meet the expectations of the position held, 4) attended conferences related to the position held and/or agency priorities, 5) continuing education, including online resources, 6) training provided by an affiliated organization, 7) trainings offered by government and nonprofit agencies, 8) grant writing webinars, 9) Human Resources training, 10) mentoring, and 11) none, with some of the respondents adding that the pandemic had made training less available except 
via virtual venues. Several organizations were specifically noted as providing training, including the National Association of Workforce Development Professionals, the Chamber of Commerce, the Society for Human Resource Management, the National Association of Workforce Boards, and the National Association of Job Training Assistance, as well as government agencies such as Workforce West Virginia and the West Virginia Department of Education.

Table 4.26: Correlations

\begin{tabular}{lcccc}
\hline Variable & WP & Certs & $\begin{array}{l}\text { Per Capita } \\
\text { by Region }\end{array}$ & Effect Size \\
\hline Range of Activities/Services ( $\mathrm{n}=105)$ & $.656^{* *}$ & $.465^{* *}$ & .128 & .43 \\
$\begin{array}{l}\text { Range of Workforce Placements (WP) } \\
(\mathrm{n}=105)\end{array}$ & & $.361^{* *}$ & .126 & \\
Range of Professional Certifications (Certs) & & & .092 & \\
\hline
\end{tabular}

Note. ** Correlation is statistically significant at the .01 level (2-tailed).

A Pearson's (r) correlation was conducted to examine the relationships between the range of workforce development activities offered, employment positions secured by participants, professional certifications held by the agencies' staff, and regional per capita incomes. The range of workforce placements was more positively related to the range of workforce development activities and services provided by agencies, $r(103)=.656, p<.001$, than to the range of professional certifications held by the agencies' staff members, $r(69)=.465, p<.001$. A complete list of correlations is presented in Table 4.26. Using Cohen's (1988) conventions, the effect size for workforce activities/services $\left(r^{2}=.43\right)$ indicated that the number of activities and services provided accounted for a moderate portion (43\%) of the variability in job placements. The null hypothesis was rejected, and the alternative hypothesis was accepted; there 
is an association between the range of workforce development activities, quick employment versus training, and the range of job placements across industry sectors.

\subsection{Conclusions/Limitations/Recommendations}

\section{Conclusions}

Aligned with previous research, as noted in the literature review, this study finds that transportation limitations were the most common barrier to employment. Alternatively, the majority of the respondents (58\%) indicated transportation support ranged in effectiveness from low (19\%), to not at all effective or was currently not used (26\% and 13\%, respectively).

It is notable, however, that transportation support (see Table 4.12) was considered to be highly effective by 21 (21\%) respondents, with 20 (20\%) respondents selecting medium. Efforts by government agencies and nonprofits have been used to address transportation barriers, including providing job seekers and program participants access to bus fare passes, subsidized gas cards or reliable vehicles through subsidized programs (e.g., Good News Mountaineer Garage).

Further, the following completes the list of the top five barriers to employment: lack of job skills, local labor market, low wages outweighing the additional costs of working (e.g., childcare and transportation costs), and the lack of work experience. By comparison, agency respondents indicated the top five most effective activities/services provided were vocational training, access to technology and/or internet service, soft skills training, industry-recognized certification training, and high school equivalency assistance. Transportation ranked seventh in effectiveness. The results also found that the majority of agencies did not report changes in the employment barriers faced by job seekers during the pandemic. 
With regards to the strength of the agencies' workforce development networking and collaboration efforts, the results indicated that the majority of agencies $(64 \%)$ do not have partnerships that support their strategic planning processes, while 79\% indicated their agencies do have partnerships that provide support in other areas. Further, the agencies assisted a more ethnically diverse population than the state's population as a whole, while serving target populations of individuals with low incomes, community members with disabilities/health conditions, young adults, adults, and unemployed individuals, as the five most commonly served. Conversely, the five least served populations were college students, ex-offenders, individuals in recovery and/or chemically dependent, homeless people, and specific ethnic groups.

This study also found that the fields of employment in which clients were placed into employment positions did not align with financial capital development nor did the industry sectors offer career pathways that would lead to earning a living wage. The five most common employment positions ranged in median hourly wages from $\$ 11.43$ to $\$ 16.07$. These positions were in the fields of health care, customer service/retail, food operation, cleaning and maintenance, and factory workers. The five least common job placements ranged in median hourly wages from $\$ 9.99$ to $\$ 38.31$, and in the following fields, IT sector, child development, small business owner, financial operations, and the education sector.

Further resonating with previous research, this evaluation found that combining employment strategies was observed to be "more promising than using either strategy alone" (Butler et al., 2015, p. 67). Statistical significance indicated that the range of workforce placements was more positively related to the range of workforce development activities and services provided by agencies than to the range of professional certifications held by the agencies' staff members. Building on this conclusion, with regards to social and human capitals, 
this research found that training opportunities increased human capital, as noted in previous research (Aguilera, 2002; Beggs \& Hurlbert, 1997; Burdett \& Mortensen, 1977). When combined with the enhancement of social capital, for instance enhancing an individual's network of employment opportunities via increased activities and services, job placements in higher wage sectors were increased, as indicated by the increased range of job placement fields.

\section{Limitations of the Study and Recommendations}

This study was limited to the identified 147 agencies that provide employment services to West Virginians. Developing this list of identified agencies depended on several sources, none of which, to my knowledge, had been used collectively to gather data via survey methods. Development of this list resulted in several agencies, such as educational institutions, responding that their role in the state did not include preparing job seekers for careers. For example, one recurrent theme from education institutions can be summarized by the following statement, "I don't believe many of these questions are for the tech center. Need to go through EPIC and reach out to the adult ed (sic) program." A recommendation stemming from this type of response would be to encourage educational institutions to recognize their foundational role in providing job seekers the tools needed to find employment upon graduation. This process may take the form of enhancing their relationships with Workforce West Virginia to provide staff training, employment activities, and services that are available to nonprofit and for-profit agencies.

An additional limitation was the method of identifying employment barriers, which depended wholly on the experience level of respondents, as well as the interpretations of their case notes and intake interviews. Further research could address this gap by directly 
interviewing non-employed or hard-to-employ individuals who were currently not seeking employment. This research examines only those individuals who have interacted with the employment agencies and the respective respondents' perceptions.

The results of this study can also provide policymakers insights into the identified employment barriers and clarification on the need to develop supports designed to address these barriers directly, such as providing enhanced transportation supports via gas cards, bus vouchers or improved bus services. In addition, policies could be developed to offer a broader array of activities and services that would lead to job placements in higher wage sectors, including the IT sector, child development, small business ownership, financial operations, and the education sector. Further, workforce development agencies that serve West Virginia could collectively convene either virtually or in-person periodically to address the shift in expected employment demands as the state moves toward a post-pandemic era. 


\subsection{References}

Aaronson, D., Davis, J., \& Hu, L. (2012). Explaining the decline in the US labor force participation rate. Chicago Fed Letter, (296), 1.

Aaronson, S., Fallick, B., Figura, A., Pingle, J. F., \& Wascher, W. L. (2006). The recent decline in the labor force participation rate and its implications for potential labor supply. Brookings Papers on Economic Activity, 2006(1), 69-154.

Aguilera, M. B. (2002). The impact of social capital on labor force participation: Evidence from the 2000 social capital benchmark survey. Social science quarterly, 83(3), 853-874.

Altman, M. (2001). A behavioral model of labor supply: Casting some light into the black box of income-leisure choice. The Journal of Socio-Economics, 30(3), 199-219.

Appalachian Regional Commission (2020). Access in Appalachia concept and methodologiesfinal report. Washington (DC): Appalachian Regional Commission. Retrieved from https://www.arc.gov/report/transportation-access-in-appalachia/

Ary, D., Jacobs, L. C., \& Sorensen, C. (2010). Introduction to Reserach in Education. Belmont, CA, United States: Wadesworth.

Beggs, J. J., \& Hurlbert, J. S. (1997). The social context of men's and women's job search ties: Membership in voluntary organizations, social resources, and job search outcomes. Sociological Perspectives, 40(4), 601-622.

Black, S., Furman, J., Rackstraw, E., \& Rao, N. (2016). The long-term decline in US prime-age male labour force participation. VoxEU. org.

Boone, H. N., \& Boone, D. A. (2012). Analyzing likert data. Journal of Extension, 50(2), 1-5.

Bradley, D. H., Herzenberg, S. A., \& Wial, H. (2001). An assessment of labor force participation rates and underemployment in Appalachia. Keystone Research Center. 
Breitwieser A., Nunn R., \& Shambaugh. J. (2018). The recent rebound in prime-age labor force participation. Brookings. Retrieved from https://www.brookings.edu/blog/upfront/2018/08/02/the-recent-rebound-in-prime-age-labor-force-participation/

Burdett, K., \& Mortensen, D. T. (1977). Labor supply under uncertainty (No. 297). Discussion Paper.

Bureau of Labor Statistics, U.S. Department of Labor, CPS Manual (2015). Part B, Chapter 3, Not in labor force concepts. Retrieved from https://www.census.gov/programssurveys/cps/technical-documentation/methodology/interviewer-s-manual.html

Bureau of Labor Statistics, U.S. Department of Labor, CPS Manual (2015). Part C, Chapter 4 The labor force interview. Retrieved from https://www2.census.gov/programssurveys/cps/methodology/intman/Part_C_Chapter4.pdf

Bureau of Labor Statistics, U.S. Department of Labor, Civilian labor force participation rate, seasonally adjusted. Retrieved from https://www.bls.gov/charts/employmentsituation/civilian-labor-force-participation-rate.htm

Bureau of Labor Statistics, U.S. Department of Labor, Household data, not seasonally adjusted A-38. Persons not in the labor force by desire and availability for work, age, and sex. Retrieved from https://www.bls.gov/web/empsit/cpseea38.htm

Bureau of Labor Statistics, U.S. Department of Labor, Economy at a glance, West Virginia, labor force data, unemployment. Retrieved from https://www.bls.gov/eag/eag.wv.htm 
Butler, A. D., Alson, J., Bloom, D., Deitch, V., Hill, A., Hsueh, J ., . . Redcross, C. (2015). Enhanced services for the hard-to-employ demonstration and evaluation project: Final results of the hard-to-employ demonstration and evaluation project and selected sites from the employment retention and advancement project. OPRE Report 2012-08, Washington, DC: Office of Planning, Research and Evaluation, Administration for Children and Families, U.S. Department of Health and Human Services.

Butterworth, J., Winsor, J., Smith, F. A., Migliore, A., Domin, D, Ciulla Timmons, J. \& Hall, A.C. (2015). StateData: The national report on employment services and outcomes. Boston, MA: University of Massachusetts Boston, Institute for Community Inclusion.

Case, A., \& Deaton, A. (2017). Mortality and morbidity in the 21 st century. Brookings Papers on Economic Activity, 2017, 397.

Cohen, J. (1988). Statistical power analysis for the behavioral sciences $\left(2^{\text {nd }}\right.$ ed.) Hillsdale, NJ: Lawrence Erlbaum Associates.

Coleman, J. S. (1988). Social capital in the creation of human capital. American Journal of Sociology, 94, S95-S120.

Congressional Budget Office. (2017) The budget and economic outlook: 2017 to 2027. Washington: Congressional Budget Office.

Council of Economic Advisers. (2016). The long-term decline in prime-age male labor force participation. Washington: White House. Retrieved from https://obamawhitehouse. archives.gov/sites/default/files/page/files/20160620_cea_primeage_male_lfp.pdf

DiCecio, R., Engemann, K. M., Owyang, M. T., \& Wheeler, C. H. (2008). Changing trends in the labor force: A survey. Review-Federal Reserve Bank of Saint Louis, 90(1), 47. 
Domin, D., Taylor, A. B., Haines, K. A., Papay, C. K., \& Grigal, M. (2020). "It's not just about a paycheck": perspectives on employment preparation of students with intellectual disability in federally funded higher education programs. Intellectual and Developmental Disabilities, 58(4), 328-347.

Dorsey, S. (1991). The strange case of the missing West Virginia labor force. Growth and Change, 22(3), 49-65.

Dunham, K., Lea, C., Henderson-Frakes, J., \& Harvey, S. (2011). Evaluation of the Newark prisoner re-entry initiative replication project: Interim report. US Department of Labor, Employment and Training Administration.

Federal Reserve Bank of St. Louis (FRED). Release tables: Labor force participation rate. Retrieved from https://fred.stlouisfed.org/release/tables?rid=446\&eid=784070\&od=202003-01

Fernandes-Alcantara, A. L. (2012). Youth and the labor force: Background and trends.

Fields, S. (2020). Unemployment 2020: how many people are unemployed right now? Marketplace, PBS. Retrieved from https://www.marketplace.org/2020/10/12/how-manypeople-are-unemployed-right-now/

Force, P. A. M. L. (2016). The long-term decline in prime-age male labor force participation.

Fujita, S. (2014). On the causes of declines in the labor force participation rate. Research Rap Special Report, Federal Reserve Bank of Philadelphia, 6.

Glasmeier, A. K. (2020). Living Wage Calculator. Massachusetts Institute of Technology. Retrieved from livingwage.mit.edu.

Glover, C. M., \& Frounfelker, R. L. (2013). Competencies of more and less successful employment specialists. Community mental health journal, 49(3), 311-316. 
Goolsbee, A., Hubbard, G., Ganz, A., Burwell, S. M., Kearney, M. S., Porat, R., \& Pritzker, P. (2019). A policy agenda to develop human capital for the modern economy. Aspen Institute Policy Paper. Chicago: University of Chicago.

Hall, Robert \& Nicolas Petrosky-Nadeau. (2016). Changes in labor participation and household income. FRBSF Economic Letter, 2. Retrieved from https://www.frbsf.org/economicresearch/files/el2016-02.pdf

Hansen, Drew. (2016). The low unemployment rate is a momentary calm before the coming economic storm. Retrieved from http:/www.forbes.com/sites/drewhansen/2016/12/04/low-unemployment-calm-beforestorm/.

Hasenfeld, Y. (1975). The role of employment placement services in maintaining poverty. Social Service Review, 49(4), 569-587.

Haynes, M., Grensing, G. C., Hook, A., \& Haedtke, K. (2017). Community asset mapping and environmental scan of workforce services. Bureau of Business and Economic Research Geospatial Analysis Center, University of Minnesota Duluth. Retrieved from https://conservancy.umn.edu/bitstream/handle/11299/203333/BBER\%20Report\%20Com munity\%20Asset $\% 20$ Mapping\%20and\%20Environmental\%20Scan\%20of\%20Workforce $\% 20$ Services.pdf? sequence $=1$

Hipple, S. F. (2016). Labor force participation: What has happened since the peak. Monthly Labor Review, 139, 1.

Holzer, H. J., \& Martinson, K. (2005). Can we improve job retention and advancement among low-income working parents?. Washington, DC: Urban Institute. 
Hörisch, F., \& Obert, P. (2020). Social capital and the impact of the recent economic crisis: Comparing the effects of economic and fiscal policy developments. Social Policy \& Administration, 54(7), 1141-1159.

Houtenville, A. \& Boege, S. (2019). Annual report on people with disabilities in America: 2018. Durham, NH: University of New Hampshire, Institute on Disability.

Irwin, Neil. (2016). The new jobs numbers signal the end of an economic era. Retrieved from http://www.nytimes.com/2016/12/02/upshot/the-new-jobs-numbers-signal-the-end-of-aneconomic-era.html?_r $=0$.

Kawachi, I., Kennedy, B. P., Lochner, K., \& Prothrow-Stith, D. (1997). Social capital, income inequality, and mortality. American Journal of Public Health, 87(9), 1491-1498.

Knack, S., \& Keefer, P. (1997). Does social capital have an economic payoff? A cross-country investigation. Quarterly Journal of Economics, 112(4), 1251-1288.

Kogan, D., Dickinson, K. P., Fedrau, R., Midling, M. J., \& Wolff, K. E. (1997). Creating workforce development systems that work: An evaluation of the initial one-stop implementation experience. Final Report.

Krause, E., \& Sawhill, I. (2017). What we know and don't know about declining labor force participation: a review. Center on Children and Families, Brookings Institution, Washington, $D C$.

Krueger, A. B. (2017). Where have all the workers gone? An inquiry into the decline of the US labor force participation rate. Brookings Papers on Economic Activity, 2017(2), 1.

Kudlyak, M., \& Lange, F. (2014). Measuring heterogeneity in job finding rates among the nonemployed using labor force status histories. IZA DP, (8663). 
Kudlyak, M. (2017). Measuring labor utilization: The non-employment index. FRBSF Economic Letter, 8 .

Latimer, M. (1998). Perceived barriers to labor force participation among welfare recipients in West Virginia. Journal of Rural Social Sciences, 14(1), 4.

Latimer, M. (2004). Between a rock and a hard place — the socioeconomic status of former TANF recipients in West Virginia. Sociological Spectrum, 24(1), 93-123.

Lauer, E.A., Boege, S.L., \& Houtenville, A.J., 2020. Annual disability statistics compendium: 2019. Durham, NH: University of New Hampshire, Institute on Disability.

McCain, M., Gill, P., Wills, J., \& Larson, M. (2004). Knowledge, skills, and abilities of youth service practitioners: The centerpiece of a successful workforce development system. A Background Paper. Institute for Educational Leadership. Retrieved from https://files.eric.ed.gov/fulltext/ED485705.pdf

McIntire, J. L., \& Robins, A. F. (1999). Fixing to change: A best practices assessment of onestop job centers working with welfare recipients. Fiscal Policy Center, University of Washington. Retrieved from https://aspe.hhs.gov/execsum/fixing-change-best-practicesassessment-one-stop-job-centers-working-welfare-recipients

Mouw, T. (2003). Social capital and finding a job: do contacts matter?. American Sociological Review, 868-898.

Nightingale, D. S. (2011). Informal and nonstandard employment in the United States: implications for low-income working families. Urban Institute. Retrieved from http://webarchive.urban.org/url.cfm?ID=412372 
Noble, M. R. (2010). One-stop career centers: An assessment of satisfaction from customers using services of a disability program navigator. (Doctoral dissertation, Capella University). Retrieved from https://www.academia.edu/download/30566146/NobleDissOneStopCareerCentersDec201 $0 . p d f$

Nussbaum, M. C. (2011). Creating capabilities. Harvard University Press.

O’Leary, Sean; Ted Boettner \& Mark Price. (2015). The state of working West Virginia. West Virginia Center on Budget and Policy. Retrieved from https://wvpolicy.org/state-ofworking-west-virginia/

Olson, K. K. (1996). Personal and family challenges to the successful transition from welfare to work. Retrieved from http://webarchive.urban.org/publications/406850.html

Panday S. \& Bovino, B.A. (2017). Declining labor force participation will weigh on U.S. GDP growth--and Fed monetary policy, $S \& P$ Global, Retrieved from https:/www.spglobal.com/our-insights/Declining-Labor-Force-Participation-WillWeigh-on-US-GDP-Growth--And-Fed-Monetary-Policy.html

Restrepo-Echavarria, P. \& Arias, M. A. (2017). What is the informal labor market?. On the Economy.

Ruhose, J., Thomsen, S. L., \& Weilage, I. (2018). The wider benefits of adult learning: Workrelated training and social capital, SOEPpapers on Multidisciplinary Panel Data Research, No. 1004, Deutsches Institut für Wirtschaftsforschung (DIW), Berlin

Schilbach, F., Schofield, H., \& Mullainathan, S. (2016). The psychological lives of the poor. American Economic Review, 106(5), 435-40.

Sen, A. (1999). Commodities and capabilities. OUP Catalogue. 
Seniorliving.org Team. (2019) How old is your state. Retrieved from https://www.seniorliving.org/how-old-your-state/

Stephens, H. M., \& Deskins, J. (2018). Economic distress and labor market participation. American Journal of Agricultural Economics, 100(5), 1336-1356.

Tomaskovic-Devey, D. (1987). Labor markets, industrial structure, and poverty: A theoretical discussion and empirical example. Rural Sociology, 52(1), 56.

Unger, D. (2007). Addressing employer personnel needs and improving employment training, job placement and retention for individuals with disabilities through public-private partnerships. Journal of Vocational Rehabilitation, 26(1), 39-48.

United States. Department of Labor United States. Department of Commerce; United States. Department of Education; United States. Department of Health and Human Services. (2014). What works in job training: a synthesis of the evidence.

U.S. Census Bureau (2019). QuickFacts, West Virginias, 2015-2019 American Community Survey 5-year estimates.

Vandenberg, R. J., \& Scarpello, V. (1990). The matching model: An examination of the processes underlying realistic job previews. Journal of Applied Psychology, 75(1), 60.

Van Horn, C. E. (2015). New labor market realities require new workforce development policies. Employment Research Newsletter, 22(1), 2.

Watts, J., \& Astone, N. M. (1997). The personal responsibility and work opportunity reconciliation act of 1996.

Weiler, S. (2001). Unemployment in regional labor markets: Using structural theories to understand local jobless rates in West Virginia. ILR Review, 54(3), 573-592. 
West Virginia Forward (nd). Understanding the barriers that prevent women from entering or staying in the workforce to improve overall participation. Retrieved from https://wvforward.wvu.edu/wv-forward-work/women-moving-forward/workforcebarriers

West Virginia State Health Plan, Rural Health. nd. Retrieved from https://hca.wv.gov/policyandplanning/Documents/Background\%20Material/shpRurPiper. pdf

Wiseman, T. (2013). US shadow economies: A state-level study. Constitutional Political Economy, 24(4), 310-335.

WorkForce West Virginia (2014). Workforce West Virginia development system report for fiscal year 2014. Retrieved from https://workforcewv.org/images/files/PublicInfo/annualreports/WorkForce_Development_Report_2014-2015.pdf.

Zimmerman, J., Dewees, S., Reinschmiedt, L., \& Hirschl, T. (1999). Rural America and welfare reform: An overview assessment. Rural Policy Research Institute. 


\section{CHAPTER 5: SUMMARY AND CONCLUSIONS}

\section{Summary and Conclusions}

This dissertation examines the impacts of economic development activities, including conservation programs, economic development agency initiatives, and workforce development agencies.

\subsection{Summary Results and Policy Implications}

Chapter 2 analyzes the relationship nonresident landowners have with the conservation programs within West Virginia, specifically the Natural Resources Conservation Service (NRCS) agency, Chapter 3 addresses the issue of economic sustainability, and Chapter 4 examines labor force participation barriers and the employment service agencies that help West Virginians gain employment.

Chapter 2 examines the relationship between nonresident landowners and conservation programs within West Virginia, specifically the Natural Resources Conservation Service (NRCS) agency. Surveys of the absentee landowners indicate the owners' perceived multiple barriers to adoption of NRCS conservation practices, including lack of awareness of conservation services available in the region. Additionally, a logit model was used to quantify factors influencing the adoption of conservation practices by landowners. The results suggest there is a statistically significant negative impact regarding absentee landowners adopting conservation practices. Farm size and land use designation have positive and statistically significant impacts on conservation adoption.

In Chapter 3, based upon a survey of economic development professionals, the findings indicate that over time, West Virginia economic development agencies have invested in higher levels of business supports/incentives, while inversely, these same agencies have provided fewer 
activities in support of environmental, quality of life, and community-based economic development. Moreover, the findings indicate that the main reasons for selecting and implementing specific economic development programs are as follows: 1) concerns about economic sustainability, 2) changes in the local economy, 3) funding sources motivating activities, 4) increased competition, 5) changes in economic development leadership, and 6) changes in political leadership. The survey results further indicate that the five top barriers to development included: 1) inadequate infrastructure, 2) lack of skilled labor, 3) land and/or buildings availability/cost, 4) lack of capital/funding, and 5) declining market due to population loss. Overall, when measured by a balanced approach, strategies focusing on business economic development activities, instead of environmental sustainability and social equity, have resulted in a lower range of economic activities and reduced sustainability.

Chapter 4 examines labor force participation barriers and the employment service agencies that help West Virginians gain employment. This study finds that transportation limitations were the most common barrier to employment, with the following completing the top five barriers to employment: lack of job skills, local labor market, low-wages outweighing the additional costs of working (e.g., childcare and transportation costs), and the lack of work experience. By comparison, agency respondents indicated the top five most effective activities/services provided were vocational training, access to technology and/or internet service, soft skills training, industry-recognized certification training, and high school equivalency assistance, with transportation ranking seventh in effectiveness. The results also found that, during the pandemic, the majority of employment agencies' participants did not experience changes in the employment barriers. 
Methodology similarities of the three studies include using a survey method. While the process of contacts varied across studies, response rates ranged from $42.5 \%$ in Chapter $2,78 \%$ in Chapter 3, and 80\% in Chapter 4. Traditional mailings were used in Chapter 2, mixed traditional and push-to-web in Chapter 3, and finally, push-to-web only in Chapter 4. Similarities also arose between the responses of the economic development agencies and the workforce development agencies (see Tables 3.6 and 4.14), with resonating themes concerning barriers to development, including economic development agencies noting inadequate infrastructure and that lack of skilled labor restricted growth, while workforce development agencies noted barriers to employment included transportation limitations and the lack of job skills. Inversely, economic development agencies indicated one of the least imposing barriers included the high cost of labor, which aligned with the workforce development agencies indicating high reservation wages was one of the lowest impact barriers to job seekers finding employment.

The broad definition for infrastructure includes roads, bridges, railways, tunnels, water/ sewers systems, and electrical or telecommunication grids, as noted in Chapter 3. A narrower definition would capture the job seekers' need for dependable transportation and improved roadways. The two views examined in this research, economic and workforce development, aligned on several key points with regards to development barriers.

\subsection{Limitations and Future Research}

For Chapter 2, study limitations relate primarily to relatively small geographical area used in the analysis. Further, the limited selective sample used in this study does not allow for the results to be generalizable. Commonalities in resistance to adoption of conservation practice may be transferable to other programs facing opposition. 
Limitations in Chapter 3 include the restricted survey population of one Expressway Authority, one Regional Recreation Authority, 11 Regional Planning and Development Councils (RP\&DCs) and 58 Regional Economic Development Authorities (EDAs), which partner with the WV Development Office, an agency of the WV Department of Commerce. The combined number of regional and local EDOs included in this study was 68, as four Economic Development Authorities share directors. The results of this study can provide policymakers insight into the processes EDOs use to determine economic development activities and the relative need for continued opportunities to engage in a balanced sustainable approach, across agencies.

Chapter 4 was limited to the identified 147 agencies that provide employment services to West Virginians. An additional limitation was the method of identifying employment barriers, which depended wholly on the experience level of respondents, as well as the interpretations of their case notes and intake interviews. Future research could address the gap noted in Chapter 4 by directly interviewing non-employed or hard-to-employ individuals who were currently not seeking employment. This research examines only those individuals who have interacted with the employment agencies and the respective respondents' perceptions. The results of this study can also provide policymakers insights into the identified employment barriers and clarification on the need to develop supports designed to address these barriers directly, such as providing enhanced transportation supports via gas cards, bus vouchers or improved bus services. In addition, policies could be developed to offer a broader array of activities and services that would lead to job placements in higher wage sectors, including the IT sector, child development, small business ownership, financial operations, and the education sector. 
APPENDICES 
APPENDIX A

Questionnaire 


\section{NRCS \& WVU: LAND, WATER, AND WILDLIFE CONSERVATION SURVEY}

Introduction This survey refers to the parcel of land bolded in the cover letter that was included with this survey. All responses are voluntary and you may choose to answer or not answer any of the questions asked. All information collected in this survey will be kept strictly confidential. No information about individual responses will be revealed.

For more information about this survey, please contact: Alan Collins, Professor in Resource Economics and Management, West Virginia University, 304-293-5486 or alan.collins@mail.wvu.edu.

Q1. Are you the sole or joint landowner of the parcel described in the cover letter?

Yes $\rightarrow$ If Yes, please complete the remaining survey questions.

No $\rightarrow$ If No, please return the survey and do not complete the remaining survey questions.

Thank you.

Q2. How do you currently manage the parcel of land indicated in the cover letter? (Please check one)

Actively manage yourself.

Limited management by yourself as a sole owner.

Limited management as a joint owner.

Lease out with an active role.

Lease out with a limited role.

Other, please explain 
Q3. Since the year 2000, have any of the following conservation practices been implemented on this parcel? (Please check all that apply)

Land and soil conservation, such as crop rotation, planting cover crops, grazing management, or forestry management.

Water quality protection, such as tree planting, excluding livestock from ponds and streams, or animal waste storage facilities.

Wildlife habitat enhancement, such as creating food plots or cutting timber for wildlife cover.

No conservation practices have been implemented on this parcel.

Don't know due to limited management role.

Other, please explain

Q4. Are there any land, water, or wildlife problems or issues that you have concerns about on this parcel? (Please check one)

No

\section{Don't know}

Yes, please explain

Q5. What is your level of awareness about the U.S. Department of Agriculture agency known as the Natural Resource Conservation Service (NRCS) and its programs that aid landowners in protecting and conserving land, soil, water, and wildlife? (Please check one)

Very aware of the NRCS and have looked into their programs.

Somewhat aware of the NRCS - heard about the agency but not familiar with all of their programs.

Never heard of this agency before.

Other, please explain 
Q6. How did you become aware of the NRCS prior to this survey? (Please check one)

Neighbors, family, or friends informed me.

Contact via a presentation, information booth, or brochure.

Learned about the NRCS from their website.

I was not aware of the NRCS prior to this survey.

Other, please explain

Q7. What are the best information sources for you to find out more about the NRCS? (Please check all that apply)

NRCS website: https://www.nrcs.usda.gov

Brochures and/or information mailed to you.

Periodicals or newspapers

Word of mouth experiences from neighbors, family, or friends.

Learning more at information booths during fairs or festivals.

Presentations at local community meetings (like Rotary, Ruritan, Farm Bureau, etc.).

Other, please explain 
Q8. Are you interested in learning more about the NRCS and its programs?

No

Yes, please provide your contact information below:

Name:

Mailing address, Line 1:

Mailing address, Line 2:

State, Zip Code:

Email Address:

Finally, some questions about you for research purposes.

Q9. What is your year of birth?

Q10. What is your gender? (Please check)

Male

Female

Q11. What is the highest level of education that you have completed or the highest degree you have received?

Less than high school degree

High school graduate (high school diploma or GED)

Some college but no degree

Technical school

College Associate degree (2-year)

College Bachelor's degree or above 
Q12. What is your income status related to this parcel? (Please check one)

I derive all my income from farming and/or forestry.

I am a part-time farmer or forester and depend upon this income.

Farming and/or forestry provides some income, but not much relative to other income sources.

Farming and/or forestry provides me with no income.

Other, please explain

\section{Additional Comments:}

Your comments are appreciated:

This is the end of the survey. Thank you for answering these questions. Your time is very much appreciated. Please return the completed survey in the enclosed envelope. No postage is required. 


\section{APPENDIX B}

Cover Letter 


\title{
WestVirginiaUniversity
}

\section{Davis College of Agriculture, Natural Resources and Design}

February 2018

\author{
Re: Land Parcel Number__, Number of acres:__ (approx.) in __ County as described in deed book _ , on page __, \\ Land Use Code\# \\ Dear;
}

In collaboration with the federal agency Natural Resource Conservation Service (NRCS), we are conducting research at West Virginia University on potential barriers to adoption of conservation practices by landowners in Hampshire and Mineral Counties, WV.

The objective of this survey is to assess the barriers that landowners, particularly owners who do not live on the property, may have regarding implementing conservation practices. Survey results will be used to develop effective outreach strategies designed to engage landowners currently not being served by NRCS. You are receiving this survey because you have been identified an owner of the land parcel listed above in this letter. This information was obtained from the West Virginia Tax Assessor's Office in Charleston WV.

We would very much appreciate your filling out this survey. We have provided two options to complete it: (I) a mail survey enclosed in this letter, or (2) go to the link below for completing an online survey. Either survey will take approximately 5 to 10 minutes to complete. The information that you provide by completing this survey is important to help enhance NRCS conservation services in West Virginia. If you complete the enclosed survey, please return the completed survey in the envelope provided (no postage is required).

Survey link web address:

User Password:

All information gathered in this survey will be kept confidential. You do not have to answer every question and your participation in this survey is completely voluntary. The only data released to the public will be in a form where individual responses cannot be identified. If you have any questions regarding this survey, please contact Alan Collins at 304-293-5486 (alan.collins@mail.wvu.edu) or Gaillynn Bowman, (gmbowman@mix.wvu.edu).

Thank you for your consideration of our request. Sincerely,

Alan R. Collins, Professor

Division of Resource Economics \& Management
Gaillynn Bowman, PhD Student

Human \& Community Development

Enclosure 
APPENDIX C

Reminder Postcard 
West Virginia University

Davis College of Agriculture,

Natural Resources and Design

Alan R. Collins, Professor

Division of Resource Economics \& Management

February, 2018

Several weeks ago, you received a survey about land conservation practices and the Natural Resource Conservation Service. If you have already responded to this survey, thank you very much for your assistance!

If you have not yet responded to this survey, please take a few minutes to do so. Your response would be greatly appreciated!

Survey link web address:

User password located on address mailing label.

If you have any questions regarding this survey, please contact Alan Collins (at 304-293-5486 or alan.collins@mail.wvu.edu). Thank you.

Sincerely,

Alan Collins

West Virginia University 


\section{APPENDIX D}

Instrument 


\section{WVU Economic Development Metrics Survey}

Introduction This survey refers to the local or regional Economic Development Organizations (EDOs) identified in bold on the cover letter included with this survey. All responses are voluntary and you may choose to answer or not answer any of the questions asked. All information collected in this survey will be kept as confidential as possible. No information about individual responses will be revealed.

For more information about this survey, please contact: Gaillynn M. Bowman, PhD Candidate, Human and Community Development, Resource Economics and Management, West Virginia University,gmbowman@mix.wvu.edu.

Q1. Which of the following statements best describes who has responsibility for economic development in your agency's designated area?

(Please check one)

- The local government has primary responsibility for economic development.

- A nonprofit development corporation has primary responsibility for economic development.

- Public-Private Partnerships have primary responsibility for economic development.

$\circ$ Other, please explain

Q2. Are your region's economic growth activities influenced by other agencies' economic development plans or strategic plans?

(Please check one)

- No, if no, please go to Q3

- Yes, Please identify the other agencies 
Q3. What are your agency's current Economic Development activities? (Please check all that apply)

- Business Retention and Expansion

- Brownfields Redevelopment

o Downtown Development

o Economic Development Marketing

- Empowerment Zone/Enterprise Community Initiatives

- Encouraging Entrepreneurship

- Infrastructure development

- Neighborhood Economic Development

- Quality of Life Initiatives

- Real Estate Redevelopment/Site Selection

- Small Business Development

Q4. Why were the current Economic Development activities identified in Q3 selected by your EDO? (Please check all that apply)

- Change in local economy

- Increased competition

- Change in economic development leadership

- Change in political leadership

- Past activities were found to be not successful and trying new development tools

- Past activities were successful, but it was time to try new development tools

- Change in population

- Income inequality

- Concern about economic sustainability

- Funding source motivated the activity

- Other, please explain 


\begin{tabular}{|c|c|c|c|c|c|}
\hline $\begin{array}{l}\text { Q5. Please check one effectiveness level } \\
\text { for each Economic Development tool. }\end{array}$ & $\begin{array}{l}\text { Not } \\
\text { at all }\end{array}$ & Low & Medium & High & $\begin{array}{l}\text { Not } \\
\text { Used }\end{array}$ \\
\hline \multicolumn{6}{|l|}{ Revolving loan fund } \\
\hline \multicolumn{6}{|l|}{ Small business development center } \\
\hline \multicolumn{6}{|l|}{ Microenterprise program } \\
\hline \multicolumn{6}{|l|}{ Matching improvement grants } \\
\hline \multicolumn{6}{|l|}{ Vendor/supplier matching } \\
\hline \multicolumn{6}{|l|}{ Marketing assistance } \\
\hline \multicolumn{6}{|l|}{ Management training } \\
\hline \multicolumn{6}{|l|}{ Export development assistance } \\
\hline \multicolumn{6}{|l|}{ Business clusters/industrial districts } \\
\hline \multicolumn{6}{|l|}{ Technology zones } \\
\hline \multicolumn{6}{|l|}{ Energy efficiency programs } \\
\hline \multicolumn{6}{|l|}{ Business improvement districts } \\
\hline Main street program & & & & & \\
\hline
\end{tabular}


Q6. Please explain any other Economic Development activities which were considered, and why they were not pursued.

Q7. What do you consider to be barriers to planning and implementing Economic Development activities? (Please check either barrier or not a barrier for each potential barrier)

\begin{tabular}{l|l|l} 
Potential Barrier & Barrier & Not a Barrier \\
\hline Land and/or buildings availability/cost & & \\
\hline Inadequate infrastructure & & \\
\hline Lack of skilled labor & & \\
\hline High cost of labor & & \\
\hline Limited number of major employers & & \\
\hline Lack of capital/funding & & \\
\hline Inadequate public transit & & \\
\hline Distance from major markets & \\
\hline Permit process/regulations & \\
\hline Quality of life barriers & \\
\hline Lack of political support & \\
\hline Citizen opposition & & \\
\hline Declining market due to population loss & & \\
\hline $\begin{array}{l}\text { Capacity of local economic development } \\
\text { organizations }\end{array}$ & \\
\hline Other, please explain &
\end{tabular}

Q8. How many full-time development staff members are in your EDO?

Q9. How many individuals in your organization hold Economic Development Certifications? 
Q10. What Economic Development Certifications are held by your staff members? (Please check all that apply)

- Community Development Council: Professional Community and Economic Developer (PCED)

- International Economic Development Council Certified Economic Developers (CEcD)

- Neighborhood Reinvestment Corporation, dba NeighborWorks ${ }^{\circledR}$ America: Community Economic Development Professional Certificate Program

- National Development Council: Economic Development Finance Professional (EDFP) Certification Program ${ }^{\mathrm{TM}}$

- University-based Economic Development Professional Certificate Program (e.g., Ohio University, Penn State).

- No professional certifications

- Other, please explain

\section{Q11. How long has your organization's current Executive Director been in the economic development field? years}

\begin{tabular}{l|l|l|l|l|l|l|}
\cline { 2 - 6 } $\begin{array}{l}\text { Q12. Please check your level of } \\
\text { agreement with each of following } \\
\text { statements listed below. }\end{array}$ & $\begin{array}{c}\text { Strongly } \\
\text { agree }\end{array}$ & Agree & $\begin{array}{c}\text { Neither } \\
\text { agree } \\
\text { nor } \\
\text { disagree }\end{array}$ & Disagree & $\begin{array}{c}\text { Strongly } \\
\text { disagree }\end{array}$ & $\begin{array}{c}\text { Does } \\
\text { Not } \\
\text { Apply }\end{array}$ \\
\hline $\begin{array}{l}\text { Our Economic Development } \\
\text { organization links with agencies that } \\
\text { can provide workforce development } \\
\text { training. }\end{array}$ & & & & & & \\
\hline $\begin{array}{l}\text { Our Economic Development } \\
\text { organization forms strong partnerships } \\
\text { with academic institutions. }\end{array}$ & & & & & & \\
\hline $\begin{array}{l}\text { Our Economic Development } \\
\text { organization follows uniform } \\
\text { guidelines and performance standards. }\end{array}$ & & & & & & \\
\hline $\begin{array}{l}\text { Our Economic Development } \\
\text { organization works closely with county } \\
\text { extension offices in project } \\
\text { development, planning, and community } \\
\text { development. }\end{array}$ & & & & & & \\
\hline $\begin{array}{l}\text { Our Economic Development programs } \\
\text { are conducted in conjunction with } \\
\text { larger strategic plans }\end{array}$ & & & & & & \\
\hline $\begin{array}{l}\text { Our Economic Development } \\
\text { organization does not partner with any } \\
\text { other organization }\end{array}$ & & & & & & \\
\hline
\end{tabular}


Finally, some demographic questions about the person completing this form:

Q13. Please indicate your employment position (Please check one)

- Support staff

○ Development officer

o Other

Q14. Please check your age range? (Please check one)

$\begin{array}{cl}\circ & 20-25 \text { years of age } \\ \circ & 26-30 \text { years of age } \\ \circ & 31-35 \text { years of age } \\ \circ & 36-40 \text { years of age } \\ \circ & 41-45 \text { years of age } \\ \circ & 46-50 \text { years of age } \\ \circ & 51-55 \text { years of age } \\ \circ & 56-60 \text { years of age } \\ \circ & 61-65 \text { years of age } \\ \circ & 66^{+} \text {years of age } \\ \circ & \text { Prefer not to disclose }\end{array}$

Q15. What is your gender? (Please check one)

○ Male

- Female

- Prefer not to disclose

Q16. What is the highest level of education that you have completed or the highest degree you have received? (Please check one)

- Less than high school degree

- High school graduate (high school diploma or GED)

- Some college but no degree

- Technical school

- College Associate degree (2-year)

- College Bachelor's degree

- Master's degree

- Doctoral degree

o Other

\section{Additional Comments:}

Your comments are appreciated:

This concludes our survey. Thank you for answering these questions. Your time is very much appreciated. 
APPENDIX E

Cover Letters (Pilot and Primary Survey)

Emails (Pilot and Primary Survey) 
September 24, 2019

Address

Dear Participant:

This letter is a request for you to take part in a research project being conducted by Gaillynn Bowman, Ph.D. Candidate, Resource Economics \&Management, under the supervision of advisor, Dr. Peter Schaeffer. We are conducting a research study to assess the processes local and regional development organizations undertake in selecting growth activities. The results of this study will be used to prepare a dissertation to partially fulfill the requirements for a Doctorate in Human \& Community Development.

As an economic developer, you are a vital part of the overall well-being of the region. Understandably, your area of responsibility covers several phases of the economic planning process, such as convening stakeholders and implementing policies designed to increase employment, to name a few. Selecting economic growth activities is critical to the financial success of your community. The results will also provide insight for many, including legislatures, community organizations, and investors, as well as enable communities to more effectively manage their economic development. Please take a few moments and share your expertise and opinion with us. We have provided a link for completing the online survey:

\section{Survey link web address:}

Participation in this research study is completely voluntary and all information you provide will be held as confidential as possible. If you decide to participate, the survey should only take about 20 minutes to complete. You may skip any question you are not comfortable answering and you can stop at any time. You must be 18 years of age or older to participate. All data will be reported in the aggregate. You will not be asked any questions that could lead back to your identity as a participant.

The Institutional Review Board (IRB) at West Virginia University has acknowledged this study.

If you have any questions or concerns about completing the questionnaire or about participating in this study, you may contact me at gmbowman@mix.wvu.edu. Your participation in this study is voluntary; you may refuse to participate without penalty. If you withdraw from the study before data collection is completed, your data will be returned to you or destroyed.

\section{Please complete the questionnaire before October 4, 2019.}

Thank you in advance for your assistance with this research effort. We sincerely appreciate you participation.

Sincerely,

\author{
Gaillynn Bowman, Ph.D. Candidate \\ Human \& Community Development

\section{School of Natural Resources Division of Resource Management \\ Phone: 304-293-4832 Fax: 304-293-3752 \\ http://resourcemanagement.wvu.edu \\ PO Box 6108 \\ 2018 Agricultural Sciences Bldg. \\ Morgantown, WV 26506-6108}

Dr. Peter Schaeffer

Division of Resource Economics \& Management
Equal Opportunity/Affirmative Action Institution 
October 10, 2019

Address

Dear Participant:

This letter is a request for you to take part in a research project being conducted by Gaillynn Bowman, Ph.D. Candidate, Resource Economics \& Management, under the supervision of advisor, Dr. Peter Schaeffer. We are conducting a research study to assess the processes local and regional development organizations undertake in selecting growth activities. The results of this study will be used to prepare a dissertation to partially fulfill the requirements for a Doctorate in Human \& Community Development.

As an economic developer in West Virginia, you are a vital part of the overall well-being of our state. Understandably, your area of responsibility covers several phases of the economic planning process, such as convening stakeholders and implementing policies designed to increase employment, to name a few. Selecting economic growth activities is critical to the financial success of your community.

The results will also provide insight for many, including legislatures, community organizations, and investors, as well as enable communities to more effectively manage their economic development. Please take a few moments and share your expertise and opinion with us. We have provided a link for completing the online survey:

\section{Survey link web address:}

Participation in this research study is completely voluntary and all information you provide will be held as confidential as possible. If you decide to participate, the survey should only take about 20 minutes to complete. You may skip any question you are not comfortable answering and you can stop at any time. You must be 18 years of age or older to participate. All data will be reported in the aggregate. You will not be asked any questions that could lead back to your identity as a participant.

The Institutional Review Board (IRB) at West Virginia University has acknowledged this study.

If you have any questions or concerns about completing the questionnaire or about participating in this study, you may contact me at gmbowman@mix.wvu.edu. Your participation in this study is voluntary; you may refuse to participate without penalty. If you withdraw from the study before data collection is completed, your data will be returned to you or destroyed.

\section{Please complete the questionnaire before October 25, 2019.}

Thank you in advance for your assistance with this research effort. We sincerely appreciate you participation.

Sincerely,

Gaillynn Bowman, Ph.D. Candidate Human and Community Development
Peter V. Schaeffer, PhD

Professor of Resource Economics and Management

\section{School of Natural Resources Division of Resource Management \begin{tabular}{l||l} 
Phone: 304-293-4832 & PO Box 6108
\end{tabular} \begin{tabular}{l|l} 
Fax: 304-293-3752 & 2018 Agricultural Sciences Bldg.
\end{tabular} http://resourcemanagement.wvu.edu Morgantown, WV 26506-6108}

Equal Opportunity/Affirmative Action Institution 
(Pilot Test email)

Greetings:

As an Economic Development professional whose agency borders West Virginia, your expertise would provide valuable insights regarding our research project which seeks to assess the processes that local and regional development organizations undertake in selecting growth activities. I have attached a letter which provides more details regarding the project.

Notably, as an economic developer, you are a vital part of the overall well-being of the region. Understandably, your area of responsibility covers several phases of the economic planning process, such as convening stakeholders and implementing policies designed to increase employment, to name a few.

Please take a few moments and share your expertise and opinion with us. The survey should only take about 20 minutes to complete.

We have provided a link for completing the online survey:

Please complete the questionnaire before October 4, 2019.

Participation in this research study is completely voluntary and all information you provide will be held as confidential as possible.

Please note: scroll down during the survey and click $\rightarrow$ to continue.

Thank you in advance for your assistance with this research effort, Gaillynn M. Bowman

\section{Gaillynn Bowman, MA, CGW}

West Virginia University, Davis College of Agriculture, Natural Resources and Design, Ph.D. Candidate

MA English \& MA Journalism, Marshall University Nationally Certified Grant Writer ${ }^{\circledR}$, American Grant Writers' Association, Inc. 
(Primary Survey email)

Greetings:

As an economic developer in West Virginia, you are a vital part of the overall well-being of our state. Indeed, your expertise would provide valuable insights regarding our research project which seeks to assess the processes that local and regional development organizations undertake in selecting growth activities. I have attached a letter which provides more details regarding the project.

Understandably, your area of responsibility covers several phases of the economic planning process, such as convening stakeholders and implementing policies designed to increase employment, to name a few.

Please take a few moments and share your expertise and opinion with us. The survey should only take about 20 minutes to complete.

We have provided a link for completing the online survey:

Survey link web address:

Please complete the questionnaire before October 25, 2019.

Participation in this research study is completely voluntary and all information you provide will be held as confidential as possible.

Please note: scroll down during the survey and click $\rightarrow$ to continue.

Thank you in advance for your assistance with this research effort, Gaillynn M. Bowman

Gaillynn Bowman, MA, CGW

West Virginia University, Davis College of Agriculture, Natural Resources and Design, Ph.D. Candidate

MA English \& MA Journalism, Marshall University

Nationally Certified Grant Writer ${ }^{\circledR}$,

American Grant Writers' Association, Inc. 


\section{APPENDIX F}

Reminder Postcard 
West Virginia University

55018310000

Davis College of Agriculture,

Natural Resources and Design

Gaillynn Bowman, PhD Student

Division of Resource Economics \& Management

October 29, 2019

Last week, you received a survey about Economic Development practices in West Virginia. To date, there are several regions not represented in our data. Your input is highly valued.

Please take a few minutes to complete the survey. Your response would be greatly appreciated!

If you have any questions regarding this survey, please contact Gaillynn Bowman (gmbowman@mix.wvu.edu).

Thank you.

Sincerely,

Gaillynn Bowman,

$\mathrm{PhD}$ Candidate, West Virginia University 


\section{APPENDIX G}

Instrument 


\section{WVU Labor Force Development Survey}

Introduction This survey refers to the Employment Services Agencies identified in bold on the cover letter included with this questionnaire. The purpose of this research is to identify employment services available to support job seekers, including the unemployed and underemployed. With your input, the findings of this study will help to increase labor force participation rates, leverage existing resources, identify gaps in services, enhance services through increased collaboration, and, by demonstrating a unified collaborative workforce development system, invite government, corporate and philanthropic investments.

All responses are voluntary and you may choose to answer or not answer any of the questions asked. All information collected in this survey will be kept as confidential as possible. No information about individual responses will be revealed.

For more information about this survey, please contact: Gaillynn M. Bowman, PhD Candidate, Human and Community Development, Resource Economics and Management, West Virginia University, gmbowman@mix.wvu.edu.

Q1. Which of the following statements best describes your organization's status? (Please check one)
o For-profit
Nonprofit
Government
Faith-based
Educational institution
O Other (please describe)

Q2. Does your organization follow an internal strategic or development plan?

(Please check one)

- Yes, if yes, please go to Q3

- No, if no, please go to Q4

- Other

Q3. Does your organization's strategic or development plan address Diversity, Equity and Inclusion?

(Please check one)

o Yes

- No

o Other

Q4. Are your organization's workforce development activities influenced by other agencies' strategic or development plans?

(Please check one)

No

- Yes, Please identify the other agencies 


\section{Q5. What are your agency's current workforce development and job retention programs/activities? \\ (Please check all that apply)}

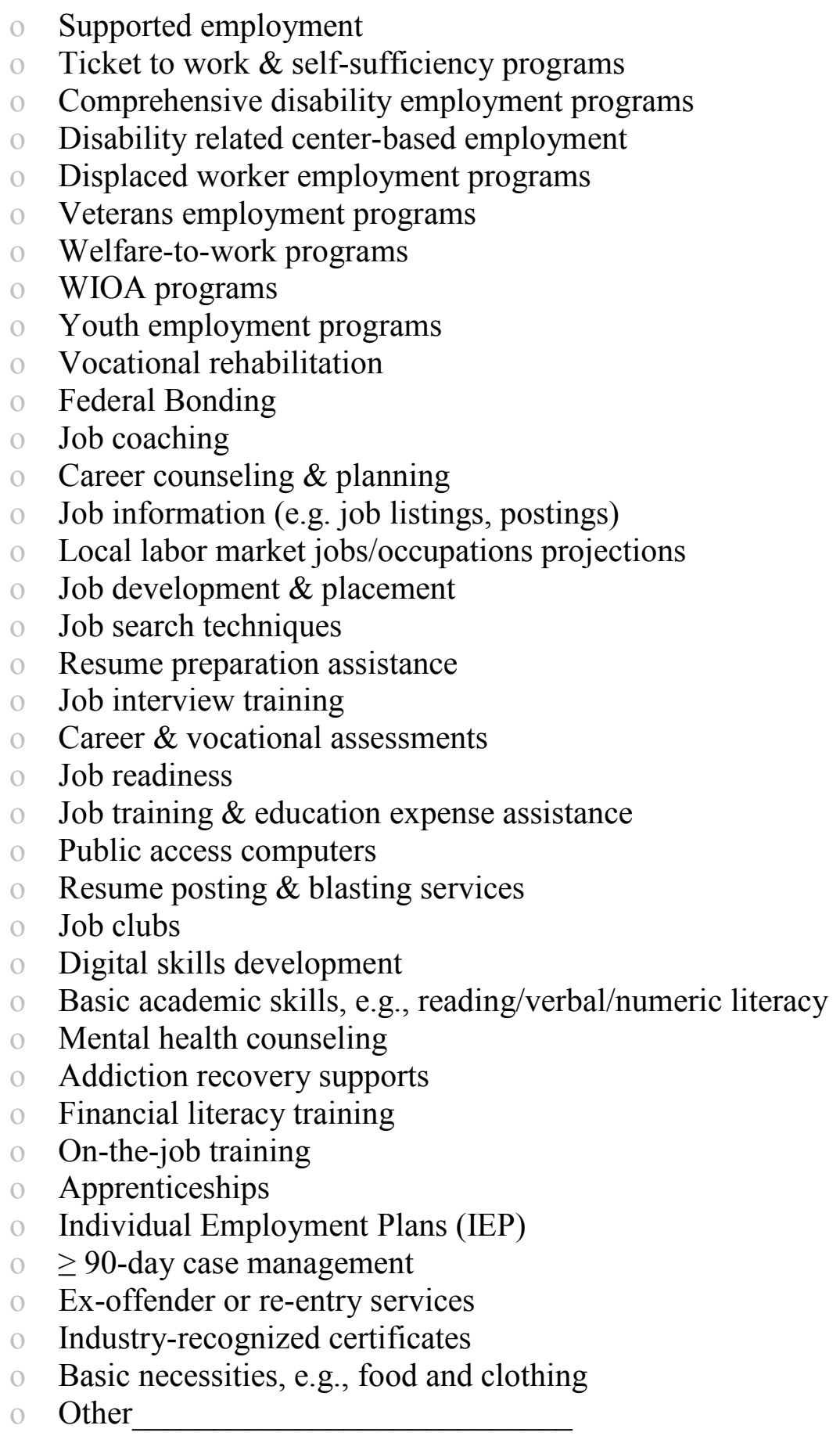


Q6. In what fields of employment are your clients placed? (Please check all that apply)

o Financial operations (accountant, teller, etc.)

Education (teacher, etc.)

Health Care (nursing, technician, CNA, home health aide, etc.)

Customer Service / Retail (store clerk, server, etc.)

Food Operation (cook, etc.)

Factory Worker (manufacturing, food production, etc.)

Cleaning and maintenance (housekeeping, janitorial, etc.)

Child development (childcare provider, etc.)

IT (computer technician, electronics, etc.)

Small business owner or self-employed (store, restaurant, beauty salon, etc.)

Other, please explain

Q7. Please check one effectiveness level for workforce supports and job retention services.

$\begin{gathered}\text { Not Low Medium High } \\ \text { at all }\end{gathered}$
$\begin{gathered}\text { Not } \\ \text { Used }\end{gathered}$

\begin{tabular}{l|l|l|l|l|l}
\hline Childcare support & & & & & \\
\hline $\begin{array}{l}\text { Transportation support, e.g., bus fare, } \\
\text { subsidized gas cards or reliable vehicles } \\
\text { programs (Good News Mountaineer }\end{array}$ & & & & & \\
Garage) & & & & & \\
\hline Financial incentives for program completion & & & & & \\
\hline $\begin{array}{l}\text { Health benefits, e.g., insurance, access to } \\
\text { medical treatment, or health education }\end{array}$ & & & & & \\
\hline $\begin{array}{l}\text { High school equivalency training/testing } \\
\text { supports }\end{array}$ & & & & & \\
\hline Professional certification programming & & & & & \\
\hline Vocational training & & & & & \\
\hline Soft skills training & & & & & \\
\hline $\begin{array}{l}\text { Technology support, e.g., Internet access for } \\
\text { job searches, job application submissions, } \\
\text { or resumes }\end{array}$ & & & & & \\
\hline $\begin{array}{l}\text { Financial education, e.g., budgeting, tax } \\
\text { preparation assistance, asset building or } \\
\text { credit counseling }\end{array}$ & & & & & \\
\hline $\begin{array}{l}\text { Assistance applying for food stamps, } \\
\text { SNAP, TANF, SSI, or SSDI }\end{array}$ & & & & & \\
\hline Substance use treatment expense assistance & & & & & \\
\hline Substance abuse services & & & & \\
\hline $\begin{array}{l}\text { Mortgage/Rent deposit or payment } \\
\text { assistance }\end{array}$ & & & & & \\
\hline Work related expense assistance & & & & & \\
\hline Homeless or Transitional housing & & & & & \\
\hline
\end{tabular}


Q8. Please explain any other workforce supports and job retention services which were considered, and why they were not pursued.

Q9. Based on your experience, as well as case notes and intake interviews, to what degree are the barriers listed below impacting your clients' efforts to gain employment? (Please check the level of significance of employment barriers)

\begin{tabular}{l|l|l|l|} 
Barriers & High & Medium & Low \\
\hline Lack of job skills & & & \\
\hline Local labor market, jobs unavailable & & & \\
\hline Transportation limitations & & & \\
\hline Access to childcare & & & \\
\hline Family responsibilities & & & \\
\hline Criminal record & & & \\
\hline Lack of work experience & & & \\
\hline Lack of soft skills & & & \\
\hline Lack of basic literacy & & & \\
\hline Lack of digital literacy & & & \\
\hline Access to broadband/technology & & & \\
\hline Poor health & & & \\
\hline High reservation wages & & \\
\hline $\begin{array}{l}\text { Low-wages outweigh additional costs } \\
\text { of working, e.g., childcare and } \\
\text { transportation }\end{array}$ & & & \\
\hline Unaccommodated disabilities & & & \\
\hline Housing instability or homelessness & & & \\
\hline Other, please explain & & \\
\hline
\end{tabular}

Q10. During the pandemic, have the barriers noted above changed?

Yes, please go to Q11

No, please go to Q12

Other, please explain

Q11. In what ways have these barriers changed during the pandemic?

Q12. Approximately, how many people were served by your agency-During 2019? During 2020?

Q13. Approximately, what is the agency's competitively employed rate (unsubsidized placement rate) --

During 2019?

During 2020? 
Q14. Approximately, what is the agency's dropout rate--

During 2019?

During 2020?

Q15. Approximately, what is the agency's employed for 90 consecutive days rate-During 2019? During 2020?

Q16. Please list the counties served by your agency:

Q17. Number of employees serving in your agency.
Full-time

Part-time

Interns

Volunteers

Q18. How many years has your organization's current Executive Director been in the Workforce Development field?

Q19. Does your agency have a postsecondary credential attainment goal for staff development?

- Yes

No

o Other

Q20. Does your agency have a postsecondary credential attainment goal for clients?

Yes

No

Other

Q21. How many staff members in your organization hold Workforce Development Certifications? \#

Q22. What Workforce Development Certifications are held by your staff members? (Please check all that apply)

Supported Employment Specialist

Job Placement Specialist or Career Development Facilitator

Career adviser/coach (provides industry information \& advice, while matching client's values, strengths and interests to employment)

Career navigator (provides instruction, career mapping, and one-to-one support)

- Career counselor (provides industry information and advice to locate a job)

- Vocational rehabilitation counselor

- Certified Workforce Development Professional (CWDP)

- Job Skills Coach

- No professional certifications

- Other, please explain 
Q23. During the most recent fiscal year what was your organization's total annual operating budget?

(Please check one)
- Less than $\$ 100,000$
$\$ 100,000$ to $\$ 499,999$
$\$ 500,000$ to $\$ 1,999,999$
$\$ 2,000,000$ to $\$ 4,999,999$
More than $\$ 5$ million
Prefer not to respond

\begin{tabular}{l|l|l|l|l|l|}
\cline { 2 - 5 } $\begin{array}{l}\text { Q24. Please check your level of } \\
\text { agreement with each of following } \\
\text { statements listed below. }\end{array}$ & $\begin{array}{c}\text { Strongly } \\
\text { agree }\end{array}$ & Agree & $\begin{array}{c}\text { Neither } \\
\text { agree } \\
\text { nor } \\
\text { disagree }\end{array}$ & Disagree & $\begin{array}{c}\text { Strongly } \\
\text { disagree }\end{array}$ \\
\hline $\begin{array}{l}\text { Our organization measures customer } \\
\text { satisfaction of both clients and businesses. }\end{array}$ & & & & & \\
\hline $\begin{array}{l}\text { Our organization forms strong } \\
\text { partnerships with academic institutions. }\end{array}$ & & & & & \\
\hline $\begin{array}{l}\text { Our organization manages strategic } \\
\text { partnerships within the workforce } \\
\text { development system. }\end{array}$ & & & & & \\
\hline $\begin{array}{l}\text { Our organization follows uniform } \\
\text { guidelines and performance standards. }\end{array}$ & & & & & \\
\hline $\begin{array}{l}\text { Our organization adopts a proactive } \\
\text { approach to job placement (e.g., providing } \\
\text { awareness training to the business } \\
\text { community, conducting job analysis, etc.). }\end{array}$ & & & & & \\
\hline $\begin{array}{l}\text { Our organization focuses on the quality of } \\
\text { services (e.g., responsiveness, follow- } \\
\text { through, and business knowledge) } \\
\text { provided to the business community to } \\
\text { ensure employer/industry engagement. }\end{array}$ & & & & & \\
\hline $\begin{array}{l}\text { Our organization conducts on-going focus } \\
\text { groups with the local business community } \\
\text { to determine employer needs. }\end{array}$ & & & & & \\
\hline $\begin{array}{l}\text { Our agency does not partner with any } \\
\text { other organizations. }\end{array}$ & & & & & \\
\hline
\end{tabular}


Q25. Which of the following target populations does your organization serve? (Please check all that apply)

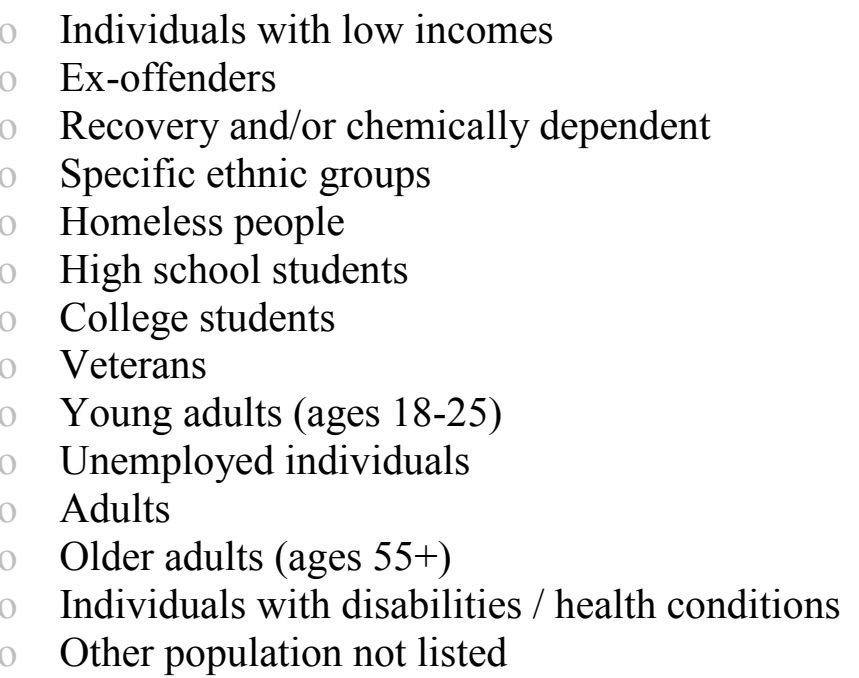

Q26. In the past year, what percentage of the individuals served by your organization were in the following racial and ethnic demographic groups? (Note: total need not sum to 100)

$\%$ White/Caucasian

$\%$ Black or African American

$\%$ American Indian and Alaska Native

$\%$ Asian

$\%$ Native Hawaiian and other Pacific Islanders

$\%$ Multiple races

$\%$ Hispanic/Latino

$\%$ Other race not listed

Q27. What, if any, state or local policies or regulations have limited the effectiveness of your organization?

Q28. From which of the following sources does your organization receive funding? (Please check all that apply)

Federal

State

County

Other government sources

Members

Tuition

Endowment

Fees and/or sales

Private donations

Competitive grants

o Other 
Finally, some demographic questions about the person completing this form:

Q29. Please indicate your employment position (Please check one)

- Support staff

- Executive Director

- Manager

o Other

Q30. Please check your age range? (Please check one)

20-35 years of age

$36-45$ years of age

46-55 years of age

56-65+ years of age

o Prefer not to disclose

Q31. What is your gender? (Please check one)

- Male

- Female

- Prefer not to disclose

Q32. What is the highest level of education that you have completed or the highest degree you have received? (Please check one)

- Less than high school degree

High school diploma or GED

Some college but no degree

Technical school

College Associate degree (2-year)
College Bachelor's degree

Master's degree

Doctoral degree

Other

Q33. What training/support have you received?

Q34. What training/support has been provided by the organization in the past year?

\section{Additional Comments:}

Your comments are appreciated:

This concludes our survey. Thank you for answering these questions.

Your time is very much appreciated. 


\section{APPENDIX H}

Cover Letters (Pilot and Primary Survey)

Introduction Emails (Pilot and Primary Survey) 
January 14, 2021

Dear Pilot Participant:

This letter is a request for you to take part in a research project being conducted by Gaillynn Bowman under the supervision of Dr. Peter Schaeffer. We are conducting a research study to identify employment services available to support West Virginia's job seekers, including the hardto-employ, unemployed and underemployed. This research is being conducted as part of Gaillynn's dissertation to partially fulfill the requirements for a Doctorate in Human \& Community Development.

As a workforce development professional whose agency borders West Virginia, you are a vital part of the overall well-being of our state. With your valuable input, the findings of this study will help to increase labor force participation rates, leverage existing resources, identify gaps in services, enhance services through increased collaboration, and, by demonstrating a unified collaborative workforce development system, invite government, corporate and philanthropic investments.

Please take a few moments and share your expertise and opinion with us. We have provided a link for completing the online survey:

\section{Survey link web address:}

Your participation in this research study is completely voluntary and all information you provide will be held as confidential as possible. If you decide to participate, the survey should only take about 20 minutes to complete. You may skip any question you are not comfortable answering and you can stop at any time. You must be 18 years of age or older to participate. All data will be reported in the aggregate. You will not be asked any questions that could lead back to your identity as a participant. Your participation in this study is voluntary; you may refuse to participate without penalty. If you withdraw from the study before data collection is completed, your data will be returned to you or destroyed.

West Virginia University's Institutional Review Board approval of this project is on file. If you have any questions or concerns about completing the questionnaire or about participating in this study, you may contact me at gmbowman@mix.wvu.edu.

Please complete the questionnaire before January 21, 2021.

Thank you in advance for your assistance with this research effort. We sincerely appreciate you participation.

Sincerely,

Gaillynn Bowman, Ph.D. Candidate

Human and Community Development
Peter V. Schaeffer, PhD

Professor of Resource Economics and Management 
February 5, 2021

Address

Dear Primary Participant:

This letter is a request for you to take part in a research project being conducted by Gaillynn Bowman under the supervision of Dr. Peter Schaeffer. We are conducting a study to identify employment services available to support West Virginia's job seekers, including the hard-toemploy, unemployed and underemployed. This research is being conducted as part of Gaillynn's dissertation to partially fulfill the requirements for a Doctorate in Human \& Community Development.

As a workforce development professional in West Virginia, you are a vital part of the overall wellbeing of our state. With your valuable input, the findings of this study will help to increase labor force participation rates, leverage existing resources, identify gaps in services, enhance services through increased collaboration, and, by demonstrating a unified collaborative workforce development system, invite government, corporate and philanthropic investments.

Please take a few moments and share your expertise and opinion with us. We have provided a link for completing the online survey:

\section{Survey link web address:}

Your participation in this research study is completely voluntary and all information you provide will be held as confidential as possible. If you decide to participate, the survey should only take about 20 minutes to complete. You may skip any question you are not comfortable answering and you can stop at any time. You must be 18 years of age or older to participate. All data will be reported in the aggregate. You will not be asked any questions that could lead back to your identity as a participant. Your participation in this study is voluntary; you may refuse to participate without penalty. If you withdraw from the study before data collection is completed, your data will be returned to you or destroyed.

West Virginia University's Institutional Review Board approval of this project is on file.

If you have any questions or concerns about completing the questionnaire or about participating in this study, you may contact me at gmbowman@mix.wvu.edu.

\section{Please complete the questionnaire before February 12, 2021.}

Thank you in advance for your assistance with this research effort. We sincerely appreciate you participation.

Sincerely,

Gaillynn Bowman, Ph.D. Candidate Human and Community Development
Peter V. Schaeffer, PhD

Professor of Resource Economics and Management 
Greetings Pilot Participant:

As a workforce development professional whose agency borders West Virginia, your response will help to increase labor force participation rates, leverage existing resources, identify gaps in services, and enhance services through increased collaboration.

Please take a few moments and share your expertise and opinion with us. The survey should only take about 20 minutes to complete.

We have provided a link for completing the online survey:

Please complete the questionnaire before January 21, 2021.

Participation in this research study is completely voluntary and all information you provide will be held as confidential as possible.

Please note: scroll forward during the survey and click $\rightarrow$.

Gaillynn Bowman, MA, CGW

West Virginia University, Davis College of Agriculture, Natural Resources and Design, PhD Candidate

MA English \& MA Journalism, Marshall University

Nationally Certified Grant Writer ${ }^{\circledast}$,

American Grant Writers' Association, Inc. 
Greetings Primary Participant:

As a workforce development professional providing services in West Virginia, you are a vital part of the overall well-being of our state. With your valuable input, the findings of this study will help to increase labor force participation rates, leverage existing resources, identify gaps in services, enhance services through increased collaboration, and, by demonstrating a unified collaborative workforce development system, invite government, corporate and philanthropic investments.

Please take a few moments and share your expertise and opinion with us. The survey should only take about 20 minutes to complete.

Please respond to the services provided to West Virginians, thank you.

We have provided a link for completing the online survey:

Survey link web address:

Please complete the questionnaire before February 12, 2021.

Participation in this research study is completely voluntary and all information you provide will be held as confidential as possible. Attached is a cover letter which contains more information regarding this study.

Please note: scroll down during the survey and click $\rightarrow$ to continue.

Thank you in advance for your assistance with this research effort, Gaillynn M. Bowman

Gaillynn Bowman, MA, CGW

West Virginia University, Davis College of Agriculture, Natural Resources and Design, Ph.D. Candidate MA English \& MA Journalism, Marshall University

Nationally Certified Grant Writer ${ }^{\circledR}$

American Grant Writers' Association, Inc.

Goodwill Industries of East Texas, Grant Writer 


\section{APPENDIX I}

Mailed Primary Survey Reminder Postcard 
West Virginia University

Davis College of Agriculture,

Natural Resources and Design

Alan R. Collins, Professor

Division of Resource Economics \& Management

February, 2021

Several weeks ago, you received a survey regarding Mapping Employment Services Across West Virginia. If you have already responded to this survey, thank you very much for your assistance!

If you have not yet responded to this survey, please take a few minutes to do so. Your response would be greatly appreciated!

If you have any questions regarding this survey, please contact Gaillynn Bowman(gmbowman@mix.wvu.edu). Thank you.

Sincerely,

Gaillynn Bowman

West Virginia University, Ph.D. Candidate

Human and Community Development 
APPENDIX J

Surveyed Agencies 


\begin{tabular}{|c|c|c|c|}
\hline $\begin{array}{l}\text { Workforce West Virginia } \\
\text { Regions }\end{array}$ & Employment Services Provided & $\begin{array}{l}\text { Counties } \\
\text { Served } \\
\text { within } \\
\text { Regions }\end{array}$ & $\begin{array}{l}\text { ARC Designation, } \\
2021\end{array}$ \\
\hline \multirow{11}{*}{$\begin{array}{l}\text { Region } 1 \text { Workforce Development } \\
\text { Board }\end{array}$} & \multirow{11}{*}{$\begin{array}{l}\text { Supported employment, vocational rehabilitation, job } \\
\text { coaching, career counseling/planning, local labor market } \\
\text { projections, job development \& placement, job search } \\
\text { techniques, resume preparation assistance, job interview } \\
\text { training, career \& vocational assessments, job readiness, job } \\
\text { training \& education expense assistance, basic academic } \\
\text { skills, addiction recovery supports, on-the-job training, } \\
\text { apprenticeships, Individual Employment Plans (IEP), career } \\
\text { counseling and industry-recognized certifications. }\end{array}$} & Fayette & Distressed \\
\hline & & Greenbrier & $\begin{array}{l}\text { Transitional, with } \\
\text { three distressed areas }\end{array}$ \\
\hline & & McDowell & Distressed \\
\hline & & Mercer & $\begin{array}{l}\text { At-Risk, with six } \\
\text { distressed areas }\end{array}$ \\
\hline & & Monroe & At-Risk \\
\hline & & Nicholas & Distressed \\
\hline & & Pocahontas & At-Risk \\
\hline & & Raleigh & $\begin{array}{l}\text { Transitional, with five } \\
\text { distressed areas }\end{array}$ \\
\hline & & Summers & Distressed \\
\hline & & Webster & Distressed \\
\hline & & Wyoming & Distressed \\
\hline \multirow{7}{*}{$\begin{array}{l}\text { Region } 2 \text { Workforce Investment } \\
\text { Board }\end{array}$} & \multirow{7}{*}{$\begin{array}{l}\text { Supported employment, vocational rehabilitation, federal } \\
\text { bonding, job coaching, career counseling/planning, job } \\
\text { information (e.g. job listings, postings), local labor market } \\
\text { projections, job development \& placement, job search } \\
\text { techniques, resume preparation assistance, job interview } \\
\text { training, career \& vocational assessments, job readiness, job } \\
\text { training \& education expense assistance, public access } \\
\text { computers, resume posting \& blasting services, digital skills } \\
\text { development, basic academic skills, addiction recovery } \\
\text { supports, financial literacy training, on-the-job training, } \\
\text { apprenticeships, Individual Employment Plans (IEP), career } \\
\text { counseling, ex-offender or re-entry services and industry- } \\
\text { recognized certifications. }\end{array}$} & Boone & Distressed \\
\hline & & Cabell & $\begin{array}{l}\text { Transitional, with } 12 \\
\text { distressed areas }\end{array}$ \\
\hline & & Lincoln & Distressed \\
\hline & & Logan & Distressed \\
\hline & & Mingo & Distressed \\
\hline & & Putnam & Transitional \\
\hline & & Wayne & $\begin{array}{l}\text { At-Risk, with four } \\
\text { distressed areas }\end{array}$ \\
\hline
\end{tabular}




\begin{tabular}{|c|c|c|c|}
\hline $\begin{array}{l}\text { Region } 3 \text { Workforce Investment } \\
\text { Board }\end{array}$ & $\begin{array}{l}\text { Supported employment, vocational rehabilitation, federal } \\
\text { bonding, career counseling \& planning, job information (e.g. } \\
\text { job listings, postings), local labor market projections, job } \\
\text { development \& placement, job search techniques, job } \\
\text { interview training, career \& vocational assessments, job } \\
\text { readiness, job training \& education expense assistance, on- } \\
\text { the-job training, apprenticeships, Individual Employment } \\
\text { Plans (IEP), career counseling, basic necessities. }\end{array}$ & Kanawha & $\begin{array}{l}\text { Transitional, with } 10 \\
\text { distressed areas }\end{array}$ \\
\hline \multirow{9}{*}{$\begin{array}{l}\text { Region } 4 \text { Workforce Development } \\
\text { Board }\end{array}$} & \multirow{9}{*}{$\begin{array}{l}\text { Supported employment, vocational rehabilitation, federal } \\
\text { bonding, job coaching, career counseling \& planning, job } \\
\text { information (e.g. job listings, postings), local labor market } \\
\text { projections, job development \& placement, job search } \\
\text { techniques, resume preparation assistance, job interview } \\
\text { training, career \& vocational assessments, job readiness, job } \\
\text { training \& education expense assistance, public access } \\
\text { computers, resume posting \& blasting services, digital skills } \\
\text { development, addiction recovery supports, financial literacy } \\
\text { training, on-the-job training, apprenticeships, Individual } \\
\text { Employment Plans (IEP), ex-offender or re-entry services, } \\
\text { industry-recognized certifications and basic necessities. }\end{array}$} & Calhoun & Distressed \\
\hline & & Clay & Distressed \\
\hline & & Jackson & $\begin{array}{l}\text { Transitional, with one } \\
\text { distressed area }\end{array}$ \\
\hline & & Mason & $\begin{array}{l}\text { At-Risk, with one } \\
\text { distressed area }\end{array}$ \\
\hline & & Pleasants & Transitional \\
\hline & & Ritchie & At-Risk \\
\hline & & Roane & Distressed \\
\hline & & Wirt & Distressed \\
\hline & & Wood & $\begin{array}{l}\text { Transitional, with } \\
\text { seven distressed areas }\end{array}$ \\
\hline \multirow{6}{*}{$\begin{array}{l}\text { Region } 5 \text { Workforce Development } \\
\text { Board }\end{array}$} & \multirow{6}{*}{$\begin{array}{l}\text { Supported employment, vocational rehabilitation, job } \\
\text { coaching, career counseling \& planning, job information (e.g. } \\
\text { job listings, postings), local labor market projections, job } \\
\text { development \& placement, job search techniques, resume } \\
\text { preparation assistance, job interview training, career \& } \\
\text { vocational assessments, job readiness, job training \& } \\
\text { education expense assistance, public access computers, } \\
\text { resume posting \& blasting services, basic academic skills, } \\
\text { addiction recovery supports, financial literacy training, on- } \\
\text { the-job training, apprenticeships, Individual Employment } \\
\text { Plans (IEP), career counseling, ex-offender or re-entry } \\
\text { services and industry-recognized certifications. }\end{array}$} & Brooke & Transitional \\
\hline & & Hancock & $\begin{array}{l}\text { Transitional, with one } \\
\text { distressed area }\end{array}$ \\
\hline & & Marshall & $\begin{array}{l}\text { Transitional, with two } \\
\text { distressed areas }\end{array}$ \\
\hline & & Ohio & $\begin{array}{l}\text { Transitional, with four } \\
\text { distressed areas }\end{array}$ \\
\hline & & Tyler & $\begin{array}{l}\text { Transitional, with one } \\
\text { distressed area }\end{array}$ \\
\hline & & Wetzel & Distressed \\
\hline
\end{tabular}




\begin{tabular}{|c|c|c|c|}
\hline \multirow{13}{*}{$\begin{array}{l}\text { Region } 6 \text { Workforce Development } \\
\text { Board }\end{array}$} & \multirow{13}{*}{$\begin{array}{l}\text { Supported employment, vocational rehabilitation, federal } \\
\text { bonding, job coaching, career counseling \& planning, job } \\
\text { information (e.g. job listings, postings), local labor market } \\
\text { projections, job development \& placement, job search } \\
\text { techniques, resume preparation assistance, job interview } \\
\text { training, career \& vocational assessments, job readiness, job } \\
\text { training \& education expense assistance, public access } \\
\text { computers, resume posting \& blasting services, digital skills } \\
\text { development, addiction recovery supports, financial literacy } \\
\text { training, on-the-job training, apprenticeships, Individual } \\
\text { Employment Plans (IEP), career counseling, ex-offender or } \\
\text { re-entry services, industry-recognized certifications and basic } \\
\text { necessities. }\end{array}$} & Barbour & Distressed \\
\hline & & Braxton & Distressed \\
\hline & & Doddridge & Transitional \\
\hline & & Gilmer & Distressed \\
\hline & & Harrison & $\begin{array}{l}\text { Transitional, with } \\
\text { three distressed areas }\end{array}$ \\
\hline & & Lewis & $\begin{array}{l}\text { At-Risk, with one } \\
\text { distressed area }\end{array}$ \\
\hline & & Marion & $\begin{array}{l}\text { Transitional, with five } \\
\text { distressed areas }\end{array}$ \\
\hline & & Monongalia & $\begin{array}{l}\text { Transitional, with one } \\
\text { distressed area }\end{array}$ \\
\hline & & Preston & Transitional \\
\hline & & Randolph & $\begin{array}{l}\text { At-Risk, with two } \\
\text { distressed areas }\end{array}$ \\
\hline & & Taylor & $\begin{array}{l}\text { Transitional, with one } \\
\text { distressed area }\end{array}$ \\
\hline & & Tucker & At-Risk \\
\hline & & Upshur & At-Risk \\
\hline \multirow{8}{*}{$\begin{array}{l}\text { Region } 7 \text { Workforce Development } \\
\text { Board }\end{array}$} & \multirow{8}{*}{$\begin{array}{l}\text { Supported employment, vocational rehabilitation, federal } \\
\text { bonding, job coaching, career counseling/planning, job } \\
\text { information, local labor market projections, job development \& } \\
\text { placement, job search techniques, resume preparation } \\
\text { assistance, job interview training, career/vocational } \\
\text { assessments, job readiness, job training/education expense } \\
\text { assistance, public access computers, resume services, digital } \\
\text { skills, basic academic skills, mental health counseling, } \\
\text { addiction recovery supports, financial literacy training, on-the- } \\
\text { job training, apprenticeships, Individual Employment Plans } \\
\text { (IEP), career counseling, ex-offender/re-entry services, } \\
\text { industry-recognized certifications and basic necessities. }\end{array}$} & Berkeley & $\begin{array}{l}\text { Transitional, with } \\
\text { three distressed areas }\end{array}$ \\
\hline & & Grant & Transitional \\
\hline & & Hampshire & $\begin{array}{l}\text { Transitional, with two } \\
\text { distressed areas }\end{array}$ \\
\hline & & Hardy & Transitional \\
\hline & & Jefferson & Competitive \\
\hline & & Mineral & Transitional \\
\hline & & Morgan & Transitional \\
\hline & & Pendleton & Transitional \\
\hline
\end{tabular}

Note. From http://lmi.workforcewv.org/Maps/GeographicalAreas.html by Workforce West Virginia. From https://www.arc.gov/county-economic-status-anddistressed-areas-by-state-fy-2021/ by the Appalachian Regional Commission, 2021. Employment Services provided by survey respondents. 


\begin{tabular}{|c|c|c|c|}
\hline Agency Name & $\begin{array}{l}\text { Region \& Counties } \\
\text { Served by Agency }\end{array}$ & Employment Services Provided & Address/Phone \\
\hline Academy of Careers \& Technology & $\begin{array}{l}\text { Region } 1 \\
\text { Raleigh }\end{array}$ & & $\begin{array}{l}390 \text { Stanaford Road } \\
\text { Beckley, WV } 25801 \\
304-256-4615\end{array}$ \\
\hline Adult Education, Brooke County & $\begin{array}{l}\text { Region } 5 \\
\text { Brooke }\end{array}$ & $\begin{array}{l}\text { Supported employment, career counseling \& } \\
\text { planning, job search techniques, resume } \\
\text { preparation assistance, career/vocational } \\
\text { assessments, basic academic skills, e.g., } \\
\text { reading/verbal/numeric literacy, and } \\
\text { financial literacy training. }\end{array}$ & $\begin{array}{l}\text { Follansbee Public } \\
\text { Library } \\
\text { 844 Main Street } \\
\text { Follansbee, WV } 26037 \\
\text { 304-231-6581 }\end{array}$ \\
\hline Adult Learning Center, Berkeley County & $\begin{array}{l}\text { Region } 7 \\
\text { Berkeley }\end{array}$ & $\begin{array}{l}\text { Supported employment, job information (e.g. } \\
\text { job listings, postings), local labor market } \\
\text { jobs/occupations projections, job } \\
\text { development \& placement, job search } \\
\text { techniques, resume preparation assistance, } \\
\text { job interview training, job readiness, and } \\
\text { basic academic skills, e.g., } \\
\text { reading/verbal/numeric literacy. }\end{array}$ & $\begin{array}{l}206 \text { Lutz Ave, } \\
\text { Martinsburg, WV } \\
25404 \\
304-263-3897\end{array}$ \\
\hline Adult Learning Center, Boone County & $\begin{array}{l}\text { Region } 2 \\
\text { Boone }\end{array}$ & $\begin{array}{l}\text { Career counseling \& planning, job } \\
\text { information (e.g. job listings, postings), local } \\
\text { labor market jobs/occupations projections, } \\
\text { job search techniques, resume preparation } \\
\text { assistance, job interview training, career \& } \\
\text { vocational assessments, job readiness, basic } \\
\text { academic skills, e.g., reading/verbal/numeric } \\
\text { literacy and industry-recognized } \\
\text { certifications. }\end{array}$ & $\begin{array}{l}333 \text { 1st Street West, } \\
\text { Madison, WV } 25130 \\
\text { 304-369-4099 }\end{array}$ \\
\hline $\begin{array}{l}\text { Adult Learning Center, Braxton County \& } \\
\text { SPOKES (Strategic Planning in } \\
\text { Occupational Knowledge for Employment \& } \\
\text { Success) }\end{array}$ & $\begin{array}{l}\text { Region } 6 \\
\text { Braxton }\end{array}$ & $\begin{array}{l}\text { Job interview training, job readiness, resume } \\
\text { posting \& blasting services, digital skills } \\
\text { development, basic academic skills, e.g., } \\
\text { reading/verbal/numeric literacy and ex- } \\
\text { offender or re-entry services. }\end{array}$ & $\begin{array}{l}105 \text { Jerry Burton Drive } \\
\text { Sutton, WV } 26601 \\
304-765-5415\end{array}$ \\
\hline Adult Learning Center, Jefferson County & $\begin{array}{l}\text { Region } 7 \\
\text { Jefferson }\end{array}$ & $\begin{array}{l}\text { Career counseling \& planning, job } \\
\text { information, job search techniques, resume } \\
\text { preparation assistance, job interview training, } \\
\text { digital skills development, basic academic } \\
\text { skills, e.g., reading/verbal/numeric literacy } \\
\text { and industry-recognized certifications. }\end{array}$ & $\begin{array}{l}401 \text { S. Fairfax Blvd. } \\
\text { Suite 2, } \\
\text { Ranson, WV } 25438 \\
304-725-3011\end{array}$ \\
\hline
\end{tabular}




\begin{tabular}{|c|c|c|c|}
\hline Agency Name & $\begin{array}{l}\text { Region \& Counties } \\
\text { Served by Agency }\end{array}$ & Employment Services Provided & Address/Phone \\
\hline $\begin{array}{l}\text { Alderson Broaddus University, Career } \\
\text { Services }\end{array}$ & Statewide & & $\begin{array}{l}101 \text { College Hill Drive } \\
\text { Philippi, WV } 26416 \\
304-457-6586\end{array}$ \\
\hline ARC of Harrison County & $\begin{array}{l}\text { Region } 6 \\
\text { Doddridge, Harrison, } \\
\text { Lewis, Marion, Taylor }\end{array}$ & $\begin{array}{l}\text { Community based assessment, direct } \\
\text { placement, extended assessment, extended } \\
\text { supported employment services, job } \\
\text { coaching, life skills, waiver provider, work } \\
\text { adjustment and work skills assessment. }\end{array}$ & $\begin{array}{l}100 \text { North First Street } \\
\text { Clarksburg, WV } 26302 \\
\text { 304-624-3641 }\end{array}$ \\
\hline Beckley Veterans Center & $\begin{array}{ll}\text { Region 1 } & \\
\text { Fayette } & \\
\text { Greenbrier } & \\
\text { Nicholas } & \text { Region 2 } \\
\text { Pocahontas } & \text { Boone } \\
\text { Raleigh } & \\
\text { Summers } & \\
\text { Wyoming } & \end{array}$ & $\begin{array}{l}\text { Veterans employment programs and job } \\
\text { information (e.g. job listings, postings). }\end{array}$ & $\begin{array}{l}201 \text { Grey Flatts Road } \\
\text { Beckley, WV } 25801 \\
304-252-8220 \\
304-255-2121\end{array}$ \\
\hline Ben Franklin Career Center & $\begin{array}{l}\text { Region } 3 \\
\text { Kanawha }\end{array}$ & & $\begin{array}{l}\text { 500 28th Street } \\
\text { Dunbar, WV } 25064 \\
\text { 304-766-0369 ext } 101\end{array}$ \\
\hline Bethany College & Statewide & & $\begin{array}{l}\text { 31 E. Campus Drive } \\
\text { Bethany, WV } 26032 \\
304-829-7150\end{array}$ \\
\hline Bluefield State College & Statewide & Job information (e.g. job listings, postings). & $\begin{array}{l}219 \text { Rock St., } \\
\text { Conley Hall - C314 } \\
\text { Bluefield, WV } 24701 \\
304-327-4540\end{array}$ \\
\hline $\begin{array}{l}\text { Bright Horizons: Sheltered Workshop of } \\
\text { Nicholas County }\end{array}$ & $\begin{array}{l}\text { Region } 1 \\
\text { Fayette } \\
\text { Nicholas } \\
\text { Webster }\end{array}$ & $\begin{array}{l}\text { Supported employment, vocational } \\
\text { rehabilitation, job coaching, job development } \\
\& \text { placement, resume preparation assistance, } \\
\text { career/vocational assessments, job readiness } \\
\text { and on-the-job training. }\end{array}$ & $\begin{array}{l}16810 \text { Webster Road } \\
\text { PO Drawer } 730 \\
\text { Craigsville, WV } 26205 \\
304-742-6202\end{array}$ \\
\hline
\end{tabular}




\begin{tabular}{|c|c|c|c|}
\hline Agency Name & $\begin{array}{l}\text { Region \& Counties } \\
\text { Served by Agency }\end{array}$ & Employment Services Provided & Address/Phone \\
\hline $\begin{array}{l}\text { Buckhannon-Upshur Work Adjustment } \\
\text { Center, Inc. }\end{array}$ & $\begin{array}{l}\text { Region } 6 \\
\text { Barbour } \\
\text { Lewis } \\
\text { Randolph } \\
\text { Upshur }\end{array}$ & $\begin{array}{l}\text { Supported employment, vocational } \\
\text { rehabilitation and Individual Employment } \\
\text { Plans (IEP). }\end{array}$ & $\begin{array}{l}\text { Rt. } 2 \text { Box } 62 \\
\text { Buckhannon, WV } \\
26201 \\
304-472-4678\end{array}$ \\
\hline $\begin{array}{l}\text { Cabell-Huntington Coalition for the } \\
\text { Homeless, Harmony House }\end{array}$ & $\begin{array}{l}\text { Region } 2 \\
\text { Cabell } \\
\text { Wayne }\end{array}$ & $\begin{array}{l}\text { Supported employment, job coaching, job } \\
\text { information (e.g. job listings, postings), job } \\
\text { search techniques, resume preparation } \\
\text { assistance, job interview training, job } \\
\text { readiness, public access computers, addiction } \\
\text { recovery supports, basic necessities, e.g., } \\
\text { food and clothing. }\end{array}$ & $\begin{array}{l}627 \text { 4th Ave } \\
\text { Huntington, WV } 25701 \\
\text { 304-523-2764, ext } 101\end{array}$ \\
\hline $\begin{array}{l}\text { Caperton Center for Applied Technology } \\
\text { Center }\end{array}$ & $\begin{array}{l}\text { Region } 4 \\
\text { Wood }\end{array}$ & & $\begin{array}{l}300 \text { Campus Drive } \\
\text { Parkersburg, } \\
\text { WV 26104 } \\
304-424-8365 \\
\end{array}$ \\
\hline Barbour Career \& Technical Center & $\begin{array}{l}\text { Region } 6 \\
\text { Barbour }\end{array}$ & $\begin{array}{l}\text { Resume preparation assistance, job interview } \\
\text { training, career/vocational assessments, basic } \\
\text { academic skills, e.g., reading/verbal/numeric } \\
\text { literacy, Individual Employment Plans (IEP) } \\
\text { and industry-recognized certifications. }\end{array}$ & $\begin{array}{l}25 \text { Horseshoe Drive } \\
\text { Philippi, WV } 26416 \\
\text { 304-457-4807 }\end{array}$ \\
\hline Boone Career \& Technical Center & $\begin{array}{l}\text { Region } 2 \\
\text { Boone }\end{array}$ & $\begin{array}{l}\text { Job information (e.g. job listings, postings), } \\
\text { local labor market jobs/occupations } \\
\text { projections, resume preparation assistance, } \\
\text { job interview training, career/vocational } \\
\text { assessments, basic academic skills, e.g., } \\
\text { reading/verbal/numeric literacy, on-the-job } \\
\text { training, apprenticeships and industry- } \\
\text { recognized certifications. }\end{array}$ & $\begin{array}{l}3505 \text { Daniel Boone } \\
\text { Pkwy-Suite B } \\
\text { Foster, WV } 25081 \\
\text { 304-369-4585 }\end{array}$ \\
\hline
\end{tabular}




\begin{tabular}{|c|c|c|c|}
\hline Agency Name & $\begin{array}{l}\text { Region \& Counties } \\
\text { Served by Agency }\end{array}$ & Employment Services Provided & Address/Phone \\
\hline Cabell Career \& Technical Center & $\begin{array}{l}\text { Region } 2 \\
\text { Cabell }\end{array}$ & $\begin{array}{l}\text { Vocational rehabilitation, job information } \\
\text { (e.g. job listings, postings), local labor } \\
\text { market jobs/occupations projections, job } \\
\text { search techniques, resume preparation } \\
\text { assistance, career/vocational assessments, } \\
\text { basic academic skills, e.g., } \\
\text { reading/verbal/numeric literacy, on-the-job } \\
\text { training, career counseling and industry- } \\
\text { recognized certifications. }\end{array}$ & $\begin{array}{l}1035 \text { Norway Ave } \\
\text { Huntington, WV } 25705 \\
304-528-5172\end{array}$ \\
\hline McDowell Career \& Technical Center & $\begin{array}{l}\text { Region } 1 \\
\text { McDowell }\end{array}$ & $\begin{array}{l}\text { Career counseling \& planning, job interview } \\
\text { training, career/vocational assessments, job } \\
\text { readiness, job training \& education expense } \\
\text { assistance. }\end{array}$ & $\begin{array}{l}\text { One Stadium Drive } \\
\text { Welch, WV } 24801 \\
\text { 304-436-3488 }\end{array}$ \\
\hline Nicholas Career \& Technical Center & $\begin{array}{l}\text { Region } 1 \\
\text { Nicholas }\end{array}$ & $\begin{array}{l}\text { Career counseling \& planning, local labor } \\
\text { market jobs/occupations projections job } \\
\text { development \& placement, job search } \\
\text { techniques, resume preparation assistance, } \\
\text { job interview training, career/vocational } \\
\text { assessments, job readiness, job training \& } \\
\text { education expense assistance, mental health } \\
\text { counseling, financial literacy training, and } \\
\text { Individual Employment Plans (IEP). }\end{array}$ & $\begin{array}{l}215 \text { Milam Addition Rd } \\
\text { Craigsville, WV } 26205 \\
\text { 304-742-5416 }\end{array}$ \\
\hline Putnam Career \& Technical Center & $\begin{array}{l}\text { Region } 2 \\
\text { Putnam }\end{array}$ & $\begin{array}{l}\text { Supported employment, job coaching, career } \\
\text { counseling \& planning, job information (e.g. } \\
\text { job listings, postings), local labor market } \\
\text { jobs/occupations projections, job search } \\
\text { techniques, resume preparation assistance, } \\
\text { job interview training, career/vocational } \\
\text { assessments, job readiness, job training \& } \\
\text { education expense assistance, resume posting } \\
\text { \& blasting services, and digital skills } \\
\text { development. }\end{array}$ & $\begin{array}{l}\text { P.O. Box } 640300 \\
\text { Roosevelt Blvd. } \\
\text { Eleanor, WV } 25070 \\
304-586-3494\end{array}$ \\
\hline South Branch Career \& Technical Center & $\begin{array}{l}\text { Region } 7 \\
\text { Grant } \\
\text { Hardy } \\
\text { Pendleton }\end{array}$ & & $\begin{array}{l}401 \text { Pierpont Street } \\
\text { Petersburg, WV } 26847 \\
\text { 304-257-1331 }\end{array}$ \\
\hline
\end{tabular}




\begin{tabular}{|c|c|c|c|c|}
\hline Agency Name & \multicolumn{2}{|c|}{$\begin{array}{l}\text { Region \& Counties } \\
\text { Served by Agency }\end{array}$} & \multirow[b]{2}{*}{$\begin{array}{l}\text { Employment Services Provided } \\
\text { Job information (e.g. job listings, postings), } \\
\text { local labor market jobs/occupations } \\
\text { projections, job development \& placement, } \\
\text { job search techniques, resume preparation } \\
\text { assistance, job interview training, career \& } \\
\text { vocational assessments, job readiness, basic } \\
\text { academic skills, e.g., reading/verbal/numeric } \\
\text { literacy, mental health counseling, and } \\
\text { Individual Employment Plans (IEP). }\end{array}$} & \multirow[b]{2}{*}{$\begin{array}{l}\text { Address/Phone } \\
\\
\text { Hcr } 72 \text { Box 200, } 1201 \\
\text { Bear Hole Road } \\
\text { Pineville, WV 24874 } \\
\text { 304-732-8050 }\end{array}$} \\
\hline Wyoming Career \& Technical Center & $\begin{array}{l}\text { Region } 1 \\
\text { Wyoming }\end{array}$ & & & \\
\hline \multirow{2}{*}{ Calhoun-Gilmer Career Center } & $\begin{array}{l}\text { Region } 4 \\
\text { Calhoun }\end{array}$ & & & \multirow{2}{*}{$\begin{array}{l}5260 \text { East } \\
\text { Little Kanawha Hwy } \\
\text { Grantsville, WV } 26147 \\
\text { 304-354-6151 }\end{array}$} \\
\hline & $\begin{array}{l}\text { Region } 6 \\
\text { Gilmer }\end{array}$ & & & \\
\hline Mason Career Center & $\begin{array}{l}\text { Region } 4 \\
\text { Mason }\end{array}$ & & $\begin{array}{l}\text { Job information (e.g. job listings, postings), } \\
\text { job development \& placement, job search } \\
\text { techniques, resume preparation assistance, } \\
\text { job interview training, career/vocational } \\
\text { assessments, basic academic skills, e.g., } \\
\text { reading/verbal/numeric literacy, and career } \\
\text { counseling. }\end{array}$ & $\begin{array}{l}281 \text { Scenic Drive } \\
\text { Point Pleasant, } \\
\text { WV 25550 } \\
304-675-3039\end{array}$ \\
\hline Hampshire Career Training Center & \multicolumn{2}{|l|}{$\begin{array}{l}\text { Region } 7 \\
\text { Hampshire }\end{array}$} & & $\begin{array}{l}\text { Hc } 63 \text { Box } 1970 \\
\text { Romney, WV } 26757 \\
304-822-3979\end{array}$ \\
\hline Carver Career Center & $\begin{array}{l}\text { Region } 1 \\
\text { Fayette } \\
\text { Raleigh } \\
\text { Region } 2 \\
\text { Boone } \\
\text { Lincoln } \\
\text { Logan } \\
\text { Mingo }\end{array}$ & $\begin{array}{l}\text { Region } 3 \\
\text { Kanawha } \\
\text { Region } 4 \\
\text { Clay } \\
\text { Jackson }\end{array}$ & $\begin{array}{l}\text { Job information (e.g. job listings, postings), } \\
\text { local labor market jobs/occupations } \\
\text { projections, and resume preparation } \\
\text { assistance. }\end{array}$ & $\begin{array}{l}\text { 4799 Midland Drive } \\
\text { Charleston, WV } 25306 \\
\text { 304-348-1965 }\end{array}$ \\
\hline
\end{tabular}




\begin{tabular}{|c|c|c|c|c|}
\hline Agency Name & \multicolumn{2}{|c|}{$\begin{array}{l}\text { Region \& Counties } \\
\text { Served by Agency }\end{array}$} & \multirow[b]{2}{*}{$\begin{array}{l}\text { Employment Services Provided } \\
\text { Supported employment, vocational } \\
\text { rehabilitation, job coaching, career } \\
\text { counseling \& planning, job information (e.g. } \\
\text { job listings, postings), local labor market } \\
\text { jobs/occupations projections, job } \\
\text { development \& placement, job search } \\
\text { techniques, resume preparation assistance, } \\
\text { job interview training, career/vocational } \\
\text { assessments, job readiness, job training \& } \\
\text { education expense assistance, public access } \\
\text { computers, resume posting \& blasting } \\
\text { services, job clubs, digital skills } \\
\text { development, basic academic skills, e.g., } \\
\text { reading/verbal/numeric literacy, addiction } \\
\text { recovery supports, financial literacy training, } \\
\text { on-the-job training, apprenticeships, } \\
\text { Individual Employment Plans (IEP), career } \\
\text { counseling, and basic necessities. }\end{array}$} & Address/Phone \\
\hline Catholic Charities West Virginia & $\begin{array}{l}\text { Region } 2 \\
\text { Boone } \\
\text { Cabell } \\
\text { Lincoln } \\
\text { Logan } \\
\text { Mingo } \\
\text { Putnam } \\
\text { Wayne } \\
\text { Region } 3 \\
\text { Kanawha } \\
\text { Region } 6 \\
\text { Braxton }\end{array}$ & $\begin{array}{l}\text { Region } 4 \\
\text { Calhoun } \\
\text { Clay } \\
\text { Jackson } \\
\text { Mason } \\
\text { Roane } \\
\text { Wirt } \\
\text { Wood }\end{array}$ & & $\begin{array}{l}2000 \text { Main St. } \\
\text { Wheeling, WV } 26003 \\
\text { 304-905-9860 Ext } 2021\end{array}$ \\
\hline $\begin{array}{l}\text { Center for Excellence in Disabilities at West } \\
\text { Virginia University, Work Incentive } \\
\text { Planning and Assistance }\end{array}$ & Statewide & & $\begin{array}{l}\text { Supported employment, local labor market } \\
\text { jobs/occupations projections, job } \\
\text { development \& placement, resume } \\
\text { preparation assistance, job interview training, } \\
\text { job readiness, resume posting \& blasting } \\
\text { services, mental health counseling, addiction } \\
\text { recovery supports, financial literacy training, } \\
\text { Individual Employment Plans (IEP), career } \\
\text { counseling, and basic necessities. }\end{array}$ & $\begin{array}{l}4510 \text { Penn. Ave. } \\
\text { Charleston, WV } 25302 \\
304-720-3200 \\
304-293-2914\end{array}$ \\
\hline Charleston Job Corps Center & $\begin{array}{l}\text { Region } 3 \\
\text { Kanawha }\end{array}$ & & $\begin{array}{l}\text { Supported employment, vocational } \\
\text { rehabilitation, job information, local labor } \\
\text { market jobs/occupations projections, job } \\
\text { development/placement, job search } \\
\text { techniques, resume preparation assistance, } \\
\text { job interview training, career/vocational } \\
\text { assessments, job readiness, basic academic, } \\
\text { mental health counseling, financial literacy } \\
\text { training, on-the-job training, and } \\
\text { apprenticeships. }\end{array}$ & $\begin{array}{l}1000 \text { Curtis Price Way } \\
\text { Charleston, WV } 25311 \\
\text { 304-925-3200 }\end{array}$ \\
\hline
\end{tabular}




\begin{tabular}{|c|c|c|c|}
\hline Agency Name & $\begin{array}{l}\text { Region \& Counties } \\
\text { Served by Agency }\end{array}$ & Employment Services Provided & Address/Phone \\
\hline $\begin{array}{l}\text { Children's Home Society of West Virginia, } \\
\text { Transitional Living Program }\end{array}$ & Statewide & $\begin{array}{l}\text { Job information (e.g. job listings, postings) } \\
\text { and on-the-job training. }\end{array}$ & $\begin{array}{l}1422 \text { Kanawha } \\
\text { Boulevard, East } \\
\text { P.O. Box } 2942 \\
\text { Charleston, WV } 25330 \\
\text { 304-400-8148 }\end{array}$ \\
\hline Christian Help, Jobs for Life & $\begin{array}{l}\text { Region } 5 \\
\text { Tyler } \\
\text { Wetzel } \\
\text { Region } 6 \\
\text { Marion } \\
\text { Monongalia } \\
\text { Preston } \\
\text { Taylor }\end{array}$ & $\begin{array}{l}\text { Career counseling \& planning, job } \\
\text { information (e.g. job listings, postings), job } \\
\text { search techniques, resume preparation } \\
\text { assistance, job interview training, career \& } \\
\text { vocational assessments, job readiness, job } \\
\text { training \& education expense assistance, } \\
\text { public access computers, financial literacy } \\
\text { training, Individual Employment Plans (IEP), } \\
\text { career counseling, ex-offender or re-entry } \\
\text { services and basic necessities. }\end{array}$ & $\begin{array}{l}219 \text { Walnut Street } \\
\text { Morgantown, WV } \\
26505 \\
304-296-0221\end{array}$ \\
\hline Clay County Services Unlimited, Inc. & $\begin{array}{l}\text { Region } 1 \\
\text { Fayette } \\
\text { Region } 3 \\
\text { Kanawha } \\
\text { Region } 4 \\
\text { Calhoun } \\
\text { Clay } \\
\text { Roane } \\
\text { Region } 6 \\
\text { Braxton }\end{array}$ & $\begin{array}{l}\text { Supported employment, vocational } \\
\text { rehabilitation, job development \& placement, } \\
\text { resume preparation assistance, basic } \\
\text { academic skills and on-the-job training. }\end{array}$ & $\begin{array}{l}13072 \text { Clay Highway } \\
\text { Lizmores, WV } 25125 \\
\text { 304-587-7852 }\end{array}$ \\
\hline $\begin{array}{l}\text { Coalfield Community Action Partnership, } \\
\text { Inc. }\end{array}$ & $\begin{array}{l}\text { Region } 1 \\
\text { McDowell } \\
\text { Region } 2 \\
\text { Mingo }\end{array}$ & $\begin{array}{l}\text { Supported employment, job information (e.g. } \\
\text { job listings, postings) and addiction recovery } \\
\text { supports. }\end{array}$ & $\begin{array}{l}\text { P.O. Box } 1406 \\
\text { Williamson, WV } 25661 \\
\text { 304-235-1701 }\end{array}$ \\
\hline
\end{tabular}




\begin{tabular}{|c|c|c|c|}
\hline Agency Name & $\begin{array}{l}\text { Region \& Counties } \\
\text { Served by Agency }\end{array}$ & Employment Services Provided & Address/Phone \\
\hline Blue Ridge Community \& Technical College & $\begin{array}{l}\text { Region } 7 \\
\text { Berkeley } \\
\text { Jefferson } \\
\text { Morgan }\end{array}$ & $\begin{array}{l}\text { Supported employment, job coaching, career } \\
\text { counseling \& planning, job information (e.g. } \\
\text { job listings, postings), local labor market } \\
\text { jobs/occupations projections, job } \\
\text { development \& placement, job search } \\
\text { techniques, resume preparation assistance, } \\
\text { job interview training, career \& vocational } \\
\text { assessments, job readiness, job training \& } \\
\text { education expense assistance, basic academic } \\
\text { skills, e.g., reading/verbal/numeric literacy, } \\
\text { mental health counseling, addiction recovery } \\
\text { supports, financial literacy training, on-the- } \\
\text { job training, apprenticeships, career } \\
\text { counseling, industry-recognized certificates } \\
\text { and basic necessities. }\end{array}$ & $\begin{array}{l}13650 \text { Apple Harvest } \\
\text { Drive } \\
\text { Martinsburg, WV } \\
25403 \\
304-260-4380 \text { ext. } 335\end{array}$ \\
\hline $\begin{array}{l}\text { BridgeValley Community \& Technical } \\
\text { College }\end{array}$ & $\begin{array}{l}\text { Region } 1 \\
\text { Fayette } \\
\text { Region } 2 \\
\text { Putnam } \\
\text { Region } 3 \\
\text { Kanawha }\end{array}$ & $\begin{array}{l}\text { Supported employment, career counseling \& } \\
\text { planning, job information (e.g. job listings, } \\
\text { postings), job development \& placement, job } \\
\text { search techniques, resume preparation } \\
\text { assistance, job interview training, resume } \\
\text { posting \& blasting services, mental health } \\
\text { counseling, addiction recovery supports, } \\
\text { financial literacy training, apprenticeships } \\
\text { and career counseling. }\end{array}$ & $\begin{array}{l}2001 \text { Union Carbide } \\
\text { Drive } \\
\text { South Charleston, WV } \\
25303 \\
304-205-6792\end{array}$ \\
\hline Pierpont Community \& Technical College & $\begin{array}{l}\text { Region } 4 \\
\text { Calhoun } \\
\text { Region } 6 \\
\text { Barbour, Braxton, } \\
\text { Doddridge, Gilmer, } \\
\text { Harrison, Lewis, Marion } \\
\text { Monongalia, Preston } \\
\text { Randolph, Taylor, Upshur }\end{array}$ & $\begin{array}{l}\text { Local labor market jobs/occupations } \\
\text { projections and mental health counseling. }\end{array}$ & $\begin{array}{l}1000 \text { Mississippi Street } \\
\text { Morgantown, WV } \\
26501 \\
304-534-7102\end{array}$ \\
\hline
\end{tabular}




\begin{tabular}{|c|c|c|c|c|}
\hline Agency Name & \multicolumn{2}{|c|}{$\begin{array}{l}\text { Region \& Counties } \\
\text { Served by Agency }\end{array}$} & \multirow[t]{2}{*}{ Employment Services Provided } & Address/Phone \\
\hline Southern Community \& Technical College & $\begin{array}{l}\text { Region } 1 \\
\text { McDowell } \\
\text { Wyoming }\end{array}$ & $\begin{array}{l}\text { Region } 2 \\
\text { Boone } \\
\text { Lincoln } \\
\text { Logan } \\
\text { Mingo }\end{array}$ & & $\begin{array}{l}2900 \text { Dempsey Branch } \\
\text { Road } \\
\text { Mount Gay, WV } 25637 \\
\text { 304-792-7098 }\end{array}$ \\
\hline $\begin{array}{l}\text { Community Access, Inc. (CAI); Vocational } \\
\text { Services, Inc. }\end{array}$ & & & Vocational rehabilitation and job coaching. & $\begin{array}{l}\text { P.O. Box } 8885 \\
\text { S. Charleston, WV } \\
25303 \\
304-766-2413\end{array}$ \\
\hline $\begin{array}{l}\text { Community Action of South Eastern West } \\
\text { Virginia }\end{array}$ & $\begin{array}{l}\text { Region } 1 \\
\text { Mercer } \\
\text { Monroe } \\
\text { Summers }\end{array}$ & & $\begin{array}{l}\text { Job information, resume preparation } \\
\text { assistance, job interview training, job } \\
\text { training/education expense assistance, public } \\
\text { access computers, addiction recovery } \\
\text { supports, on-the-job training and basic } \\
\text { necessities. }\end{array}$ & $\begin{array}{l}355 \text { Bluefield Avenue } \\
\text { Bluefield, WV } 24701 \\
\text { 304-324-0450 }\end{array}$ \\
\hline Community Resources, Inc., Parkersburg & $\begin{array}{l}\text { Region } 4 \\
\text { Calhoun } \\
\text { Jackson } \\
\text { Pleasants } \\
\text { Ritchie } \\
\text { Roane, Wirt, } \\
\text { Wood }\end{array}$ & $\begin{array}{l}\text { Region } 5 \\
\text { Tyler } \\
\text { Wetzel } \\
\text { Region } 6 \\
\text { Doddridge } \\
\text { Gilmer }\end{array}$ & $\begin{array}{l}\text { Job search techniques, resume preparation } \\
\text { assistance, job interview training, addiction } \\
\text { recovery supports and financial literacy } \\
\text { training. }\end{array}$ & $\begin{array}{l}1037 \text { Market Street } \\
\text { Parkersburg, WV } 26101 \\
304-485-5525\end{array}$ \\
\hline Community Services, Inc. & $\begin{array}{l}\text { Region } 2 \\
\text { Putnam }\end{array}$ & $\begin{array}{l}\text { Region } 3 \\
\text { Kanawha }\end{array}$ & $\begin{array}{l}\text { Community based assessment, direct } \\
\text { placement, extended assessment, extended } \\
\text { supported employment services, job } \\
\text { coaching, life skills, work adjustment and } \\
\text { work skills assessment. }\end{array}$ & $\begin{array}{l}1400 \text { Ohio Avenue } \\
\text { Dunbar, WV } 25064 \\
\text { 304-205-7978 }\end{array}$ \\
\hline Concord University & \multicolumn{2}{|c|}{$\begin{array}{l}\text { Region 1 } \\
\text { Fayette, Greenbrier, } \\
\text { McDowell, Mercer, } \\
\text { Monroe, Nicholas, } \\
\text { Pocahontas, Raleigh, } \\
\text { Summers, Webster } \\
\text { Region } 2 \\
\text { Boone, Lincoln, Logan } \\
\text { Mingo }\end{array}$} & $\begin{array}{l}\text { Career counseling \& planning, job } \\
\text { information, local labor market projections, } \\
\text { job development \& placement, job search } \\
\text { techniques, resume preparation assistance, } \\
\text { job interview training, job readiness, basic } \\
\text { academic skills, mental health counseling, } \\
\text { financial literacy training, career counseling } \\
\text { and basic necessities. }\end{array}$ & $\begin{array}{l}\text { Vermillion Street } \\
\text { P.O. Box } 1000 \\
\text { Athens, WV } 24712 \\
\text { 304-384-6292 }\end{array}$ \\
\hline
\end{tabular}




\begin{tabular}{|c|c|c|c|}
\hline Agency Name & $\begin{array}{l}\text { Region \& Counties } \\
\text { Served by Agency }\end{array}$ & Employment Services Provided & Address/Phone \\
\hline Council of the Southern Mountains & $\begin{array}{l}\text { Region } 1 \\
\text { McDowell, Mercer, } \\
\text { Monroe, Raleigh, } \\
\text { Summers, Wyoming }\end{array}$ & $\begin{array}{l}\text { Job information (e.g. job listings, postings), } \\
\text { apprenticeships and basic necessities, e.g., } \\
\text { food and clothing. }\end{array}$ & $\begin{array}{l}148 \text { McDowell Street } \\
\text { Welch, WV } 24801 \\
304-436-6800\end{array}$ \\
\hline D.S. Supported Employment & & $\begin{array}{l}\text { Supported employment, vocational } \\
\text { rehabilitation, job coaching, job information } \\
\text { (e.g. job listings, postings), local labor } \\
\text { market jobs/occupations projections, job } \\
\text { development \& placement, job search } \\
\text { techniques, resume preparation assistance, } \\
\text { job interview training, career/vocational } \\
\text { assessments, job readiness, job training \& } \\
\text { education expense assistance and public } \\
\text { access computers. }\end{array}$ & $\begin{array}{l}\text { P.O. Box } 322 \\
\text { Petersburg, WV } 26847 \\
\text { 304-851-0383 }\end{array}$ \\
\hline Davis \& Elkins College & $\begin{array}{l}\text { Region } 6 \\
\text { Randolph }\end{array}$ & $\begin{array}{l}\text { Supported employment, job coaching, job } \\
\text { information (e.g. job listings, postings), local } \\
\text { labor market jobs/occupations projections, } \\
\text { job search techniques, resume preparation } \\
\text { assistance, job interview training, } \\
\text { career/vocational assessments, job readiness, } \\
\text { job training \& education expense assistance, } \\
\text { job clubs, basic academic skills, e.g., } \\
\text { reading/verbal/numeric literacy, mental } \\
\text { health counseling, addiction recovery } \\
\text { supports, financial literacy training, on-the- } \\
\text { job training, apprenticeships, Individual } \\
\text { Employment Plans (IEP), career counseling, } \\
\text { and industry-recognized certifications. }\end{array}$ & $\begin{array}{l}100 \text { Campus Drive } \\
\text { Elkins, WV } 26241 \\
304-637-1316\end{array}$ \\
\hline Developmental Center \& Workshop, Inc. & $\begin{array}{l}\text { Region } 7 \\
\text { Berkeley, Grant, } \\
\text { Hampshire, Hardy, } \\
\text { Jefferson, Mineral, } \\
\text { Morgan }\end{array}$ & Supported employment and job coaching. & $\begin{array}{l}50 \text { Clary Street } \\
\text { Keyser, WV } 26726 \\
\text { 304-788-3046 }\end{array}$ \\
\hline
\end{tabular}




\begin{tabular}{|c|c|c|c|c|}
\hline Agency Name & \multicolumn{2}{|c|}{$\begin{array}{l}\text { Region \& Counties } \\
\text { Served by Agency }\end{array}$} & Employment Services Provided & Address/Phone \\
\hline Eastern Action & \multicolumn{2}{|c|}{$\begin{array}{l}\text { Region } 7 \\
\text { Berkeley, Grant, } \\
\text { Hampshire, Hardy, } \\
\text { Jefferson, Mineral, } \\
\text { Morgan, Pendleton }\end{array}$} & $\begin{array}{l}\text { Career counseling/planning and job } \\
\text { readiness. }\end{array}$ & $\begin{array}{l}228 \text { Clay Street } \\
\text { Moorefield, WV } 26836 \\
\text { 304-538-7711 }\end{array}$ \\
\hline $\begin{array}{l}\text { Eastern West Virginia Community \& } \\
\text { Technical College }\end{array}$ & \multicolumn{2}{|c|}{$\begin{array}{l}\text { Region } 6 \\
\text { Tucker } \\
\text { Region } 7 \\
\text { Grant, Hampshire, } \\
\text { Hardy, Mineral, } \\
\text { Pendleton }\end{array}$} & $\begin{array}{l}\text { Supported employment, job information (e.g. } \\
\text { job listings, postings), local labor market } \\
\text { jobs/occupations projections, } \\
\text { career/vocational assessments and on-the-job } \\
\text { training. }\end{array}$ & $\begin{array}{l}316 \text { Eastern Drive } \\
\text { Moorefield, WV } 26836 \\
\text { 304-434-8000 }\end{array}$ \\
\hline EnAct Community Action & $\begin{array}{l}\text { Region } 1 \\
\text { Fayette } \\
\text { Region } 2 \\
\text { Boone } \\
\text { Putnam }\end{array}$ & $\begin{array}{l}\text { Region } 3 \\
\text { Kanawha } \\
\text { Region } 4 \\
\text { Clay }\end{array}$ & $\begin{array}{l}\text { Job development \& placement, resume } \\
\text { preparation assistance, job interview training, } \\
\text { job training \& education expense assistance, } \\
\text { public access computers, resume posting \& } \\
\text { blasting services, addiction recovery } \\
\text { supports, financial literacy training, and } \\
\text { basic necessities, e.g., food and clothing. }\end{array}$ & $\begin{array}{l}\text { Schoenbaum FEC } \\
17015 \text { th Avenue } \\
\text { Charleston, WV } 25387 \\
304-414-4475\end{array}$ \\
\hline $\begin{array}{l}\text { Express Employment Professionals, } \\
\text { Charleston }\end{array}$ & \multicolumn{2}{|l|}{$\begin{array}{l}\text { Region } 3 \\
\text { Kanawha }\end{array}$} & & $\begin{array}{l}47 \text { RHL Blvd } \\
\text { Charleston, WV } 25309 \\
\text { 304-746-8888 }\end{array}$ \\
\hline $\begin{array}{l}\text { Express Employment Professionals, } \\
\text { Huntington }\end{array}$ & \multicolumn{2}{|l|}{$\begin{array}{l}\text { Region } 2 \\
\text { Cabell } \\
\text { Wayne } \\
\text { Region } 4 \\
\text { Mason }\end{array}$} & $\begin{array}{l}\text { Supported employment, job coaching, job } \\
\text { information (e.g. job listings, postings), local } \\
\text { labor market jobs/occupations projections, } \\
\text { job development \& placement, career \& } \\
\text { vocational assessments, resume posting \& } \\
\text { blasting services, basic academic skills, e.g., } \\
\text { reading/verbal/numeric literacy, on-the-job } \\
\text { training, ex-offender or re-entry services and } \\
\text { basic necessities, e.g., food and clothing. }\end{array}$ & $\begin{array}{l}3677 \text { US Route } 60 \text { E \#5 } \\
\text { Barboursville, WV } \\
25504 \\
304-733-5627\end{array}$ \\
\hline
\end{tabular}




\begin{tabular}{|c|c|c|c|}
\hline Agency Name & $\begin{array}{l}\text { Region \& Counties } \\
\text { Served by Agency }\end{array}$ & Employment Services Provided & Address/Phone \\
\hline $\begin{array}{l}\text { Extended Learning \& Technical Center, } \\
\text { Mingo County }\end{array}$ & $\begin{array}{l}\text { Region } 2 \\
\text { Mingo }\end{array}$ & & $\begin{array}{l}\text { Route } 2 \text { Box } 52 \text { A } \\
\text { Delbarton, WV } 25670 \\
\text { 304-475-3347 }\end{array}$ \\
\hline Fairmont State University & Statewide & $\begin{array}{l}\text { Career counseling \& planning, job } \\
\text { information (e.g. job listings, postings), job } \\
\text { search techniques, resume preparation } \\
\text { assistance, job interview training, career \& } \\
\text { vocational assessments, mental health } \\
\text { counseling, apprenticeships, Individual } \\
\text { Employment Plans (IEP), Career counseling } \\
\text { and basic necessities. }\end{array}$ & $\begin{array}{l}1201 \text { Locust Ave } \\
\text { Fairmont, WV } 26554 \\
\text { 304-367-4892 }\end{array}$ \\
\hline Fayette Institute of Technology & $\begin{array}{l}\text { Region } 1 \\
\text { Fayette } \\
\text { Nicholas } \\
\text { Raleigh } \\
\text { Webster }\end{array}$ & $\begin{array}{l}\text { Job information (e.g. job listings, postings), } \\
\text { job development \& placement, job interview } \\
\text { training, career \& vocational assessments, } \\
\text { job readiness and basic academic skills. }\end{array}$ & $\begin{array}{l}300 \text { West Oyler Avenue } \\
\text { Oak Hill, WV } 25901 \\
\text { 304-469-2911 }\end{array}$ \\
\hline Fred W. Eberle Technical Center & $\begin{array}{l}\text { Region } 6 \\
\text { Barbour } \\
\text { Lewis } \\
\text { Upshur }\end{array}$ & & $\begin{array}{l}208 \text { Morton Avenue } \\
\text { Buckhannon, WV } \\
26201 \\
304-472-1259\end{array}$ \\
\hline Garnet Career Center & $\begin{array}{l}\text { Region } 2 \\
\text { Boone } \\
\text { Cabell } \\
\text { Lincoln } \\
\text { Logan } \\
\text { Putnam } \\
\text { Region } 3 \\
\text { Kanawha }\end{array}$ & Job information (e.g. job listings, postings). & $\begin{array}{l}422 \text { Dickinson Street } \\
\text { Charleston, WV } 25301 \\
\text { 304-348-6195 }\end{array}$ \\
\hline
\end{tabular}




\begin{tabular}{|c|c|c|c|c|}
\hline Agency Name & \multicolumn{2}{|c|}{$\begin{array}{l}\text { Region \& Counties } \\
\text { Served by Agency }\end{array}$} & Employment Services Provided & Address/Phone \\
\hline Gateway Industries, Inc. & $\begin{array}{l}\text { Region } 1 \\
\text { Greenbrier } \\
\text { Monroe } \\
\text { Pocahontas } \\
\text { Region } 3 \\
\text { Kanawha }\end{array}$ & & $\begin{array}{l}\text { Supported employment, vocational } \\
\text { rehabilitation, job coaching, career } \\
\text { counseling/planning, job information, local } \\
\text { labor market projections, job development \& } \\
\text { placement, job search techniques, resume } \\
\text { assistance, job interview training, job } \\
\text { readiness, job training/education expense } \\
\text { assistance, resume services, digital skills, } \\
\text { basic academic skills, addiction recovery } \\
\text { supports, financial literacy training, on-the- } \\
\text { job training, Individual Employment Plans } \\
\text { (IEP), career counseling, ex-offender/re- } \\
\text { entry services and basic necessities. }\end{array}$ & $\begin{array}{l}787 \text { Edgar Avenue } \\
\text { Ronceverte, WV } 24970 \\
304-645-3165\end{array}$ \\
\hline Glenville State College & Statewide & & & $\begin{array}{l}200 \text { High Street } \\
\text { Glenville, WV } 26351 \\
304-462-6059\end{array}$ \\
\hline Goodwill Industries of Greater Cleveland & $\begin{array}{l}\text { Region } 5 \\
\text { Brooke } \\
\text { Hancock }\end{array}$ & & $\begin{array}{l}\text { Vocational rehabilitation, job coaching, } \\
\text { career counseling \& planning, local labor } \\
\text { projections, job development \& placement, } \\
\text { job search techniques, resume preparation } \\
\text { assistance, job interview training, career \& } \\
\text { vocational assessments, job readiness, digital } \\
\text { skills development, on-the-job training, } \\
\text { Individual Employment Plans (IEP) and } \\
\text { basic necessities. }\end{array}$ & $\begin{array}{l}408 \text { Ninth Street, SW } \\
\text { Canton, OH } 44707 \\
330-445-1000\end{array}$ \\
\hline Goodwill Industries of Kanawha Valley, Inc. & $\begin{array}{l}\text { Region } 1 \\
\text { Fayette } \\
\text { Greenbrier } \\
\text { McDowell } \\
\text { Mercer } \\
\text { Monroe } \\
\text { Nicholas } \\
\text { Pocahontas } \\
\text { Raleigh } \\
\text { Summers } \\
\text { Webster } \\
\text { Wyoming }\end{array}$ & $\begin{array}{l}\text { Region 2 } \\
\text { Boone } \\
\text { Logan } \\
\text { Putnam } \\
\text { Region 3 } \\
\text { Kanawha } \\
\text { Region } 4 \\
\text { Clay } \\
\text { Jackson } \\
\text { Roane } \\
\text { Region 6 } \\
\text { Braxton }\end{array}$ & $\begin{array}{l}\text { Community based assessment, direct } \\
\text { placement, extended assessment, extended } \\
\text { supported employment, job coaching, life } \\
\text { skills, work adjustment and work skills } \\
\text { assessment. }\end{array}$ & $\begin{array}{l}209 \text { Virginia St West } \\
\text { Charleston, WV } 25302 \\
\text { 304-346-0811 }\end{array}$ \\
\hline
\end{tabular}




\begin{tabular}{|c|c|c|c|}
\hline Agency Name & $\begin{array}{l}\text { Region \& Counties } \\
\text { Served by Agency } \\
\end{array}$ & Employment Services Provided & Address/Phone \\
\hline Goodwill Industries of KYOWVA Area, Inc. & $\begin{array}{l}\text { Region } 2 \\
\text { Cabell } \\
\text { Lincoln } \\
\text { Mingo } \\
\text { Region } 4 \\
\text { Mason }\end{array}$ & $\begin{array}{l}\text { Supported employment, vocational } \\
\text { rehabilitation, federal bonding, job coaching, } \\
\text { career counseling \& planning, job } \\
\text { information, job development \& placement, } \\
\text { job search techniques, resume preparation } \\
\text { assistance, job interview training, } \\
\text { career/vocational assessments, job readiness, } \\
\text { public access computers, job clubs and } \\
\text { digital skills development. }\end{array}$ & $\begin{array}{l}1102 \text { Memorial Blvd } \\
\text { Huntington, WV } 25701 \\
304-525-7034\end{array}$ \\
\hline Goodwill of Industries, Horizon Goodwill & $\begin{array}{l}\text { Region } 7 \\
\text { Berkeley } \\
\text { Grant } \\
\text { Hampshire } \\
\text { Hardy } \\
\text { Jefferson } \\
\text { Mineral } \\
\text { Morgan } \\
\end{array}$ & $\begin{array}{l}\text { Supported employment, job coaching, job } \\
\text { information, job development \& placement, } \\
\text { job search techniques, resume preparation } \\
\text { assistance, job interview training, career \& } \\
\text { vocational assessments, job readiness, public } \\
\text { access computers and digital skills } \\
\text { development. }\end{array}$ & $\begin{array}{l}100 \text { Eagle School Road } \\
\text { Martinsburg, WV } \\
25401 \\
304-267-3177\end{array}$ \\
\hline $\begin{array}{l}\text { Goodwill of North Central West Virginia, an } \\
\text { affiliate of Goodwill of Southwestern } \\
\text { Pennsylvania }\end{array}$ & $\begin{array}{l}\text { Region } 6 \\
\text { Barbour } \\
\text { Harrison } \\
\text { Lewis } \\
\text { Marion } \\
\text { Monongalia } \\
\text { Preston } \\
\text { Randolph } \\
\text { Taylor } \\
\text { Upshur }\end{array}$ & $\begin{array}{l}\text { Supported employment, vocational } \\
\text { rehabilitation, job coaching, career } \\
\text { counseling \& planning, job information, job } \\
\text { development/placement, job search } \\
\text { techniques, resume preparation assistance, } \\
\text { job interview training, career \& vocational } \\
\text { assessments, job readiness, digital skills } \\
\text { development, basic academic skills, on-the- } \\
\text { job training, Individual Employment Plans } \\
\text { (IEP), career counseling, ex-offender or re- } \\
\text { entry services and basic necessities. }\end{array}$ & $\begin{array}{l}\text { 1954 Hunters Way } \\
\text { Michael A. Oliverio } \\
\text { Building } \\
\text { Morgantown, WV } \\
26505 \\
888-449-6298\end{array}$ \\
\hline Green Acres Regional Center, Inc. & $\begin{array}{l}\text { Region } 2 \\
\text { Cabell } \\
\text { Lincoln } \\
\text { Wayne } \\
\text { Region } 4 \\
\text { Mason }\end{array}$ & Job development \& placement. & $\begin{array}{l}7830 \text { Ohio River Road } \\
\text { Lesage, WV } 25537 \\
304-762-2522\end{array}$ \\
\hline
\end{tabular}




\begin{tabular}{|c|c|c|c|c|}
\hline Agency Name & \multicolumn{2}{|c|}{$\begin{array}{l}\text { Region \& Counties } \\
\text { Served by Agency }\end{array}$} & Employment Services Provided & Address/Phone \\
\hline $\begin{array}{l}\text { Hampshire County Special Services Center, } \\
\text { Inc. }\end{array}$ & \multicolumn{2}{|c|}{$\begin{array}{l}\text { Region } 7 \\
\text { Grant } \\
\text { Hampshire } \\
\text { Hardy } \\
\text { Mineral }\end{array}$} & $\begin{array}{l}\text { Supported employment, vocational } \\
\text { rehabilitation, job coaching, job information, } \\
\text { career/vocational assessments, job readiness, } \\
\text { basic academic skills, on-the-job training and } \\
\text { basic necessities. }\end{array}$ & $\begin{array}{l}9 \text { Industrial Boulevard } \\
\text { Romney, WV } 26757 \\
\text { 304-822-3818 }\end{array}$ \\
\hline Hancock Co. Sheltered Workshop, Inc. & \multicolumn{2}{|l|}{$\begin{array}{l}\text { Region } 5 \\
\text { Brooke } \\
\text { Hancock }\end{array}$} & $\begin{array}{l}\text { Community based assessment, direct } \\
\text { placement, extended assessment, extended } \\
\text { supported employment services, job } \\
\text { coaching, life skills, waiver provider, work } \\
\text { adjustment and work skills assessment. }\end{array}$ & $\begin{array}{l}1100 \text { Pennsylvania } \\
\text { Avenue } \\
\text { Weirton, WV } 26062 \\
304-748-2370\end{array}$ \\
\hline Hopewell Community Services LLC & \multicolumn{2}{|l|}{$\begin{array}{l}\text { Region } 1 \\
\text { Fayette } \\
\text { Raleigh } \\
\text { Region } 2 \\
\text { Boone } \\
\text { Cabell } \\
\text { Lincoln } \\
\text { Putnam } \\
\end{array}$} & $\begin{array}{l}\text { Supported employment and job search } \\
\text { techniques. }\end{array}$ & $\begin{array}{l}418 \text { New Goff Mtn. RD } \\
\text { STE } 201 \\
\text { Cross Lanes, WV } \\
25313 \\
304-755-9411\end{array}$ \\
\hline \multirow{4}{*}{$\begin{array}{l}\text { Human Resources Development Foundation, } \\
\text { Morgantown }\end{array}$} & \multicolumn{2}{|c|}{$\begin{array}{l}\text { Region } 2 \\
\text { Cabell, Lincoln, Putnam, } \\
\text { Wayne }\end{array}$} & \multirow{4}{*}{$\begin{array}{l}\text { Job coaching, job information, job } \\
\text { development \& placement, job search } \\
\text { techniques, resume preparation assistance, } \\
\text { job interview training, job readiness, } \\
\text { addiction recovery supports, financial } \\
\text { literacy training, on-the-job training, } \\
\text { apprenticeships, Individual Employment } \\
\text { Plans (IEP) and industry-recognized } \\
\text { certifications. }\end{array}$} & \multirow{4}{*}{$\begin{array}{l}1644 \text { Mileground } \\
\text { Morgantown, WV } \\
26505 \\
304-296-8223\end{array}$} \\
\hline & \multicolumn{2}{|c|}{$\begin{array}{l}\text { Region } 3 \text { Kanawha } \\
\text { Region } 4 \\
\text { Clay, Jackson, Ritchie, } \\
\text { Wood }\end{array}$} & & \\
\hline & \multicolumn{2}{|c|}{$\begin{array}{l}\text { Region } 6 \\
\text { Barbour, Braxton, } \\
\text { Doddridge, Gilmer, } \\
\text { Harrison, Lewis, Marion, } \\
\text { Monongalia, Preston, } \\
\text { Randolph, Taylor, Tucker, } \\
\text { Upshur }\end{array}$} & & \\
\hline & \multicolumn{2}{|c|}{$\begin{array}{l}\text { Region } 7 \\
\text { Grant, Mineral, Pendleton }\end{array}$} & & \\
\hline
\end{tabular}




\begin{tabular}{|c|c|c|c|}
\hline Agency Name & $\begin{array}{l}\text { Region \& Counties } \\
\text { Served by Agency }\end{array}$ & Employment Services Provided & Address/Phone \\
\hline Jackson County Developmental Center, Inc. & $\begin{array}{l}\text { Region } 4 \\
\text { Calhoun, Jackson, Mason, } \\
\text { Ritchie, Roane, Wirt, } \\
\text { Wood } \\
\text { Region } 5 \\
\text { Tyler }\end{array}$ & $\begin{array}{l}\text { Supported employment, vocational } \\
\text { rehabilitation and job coaching. }\end{array}$ & $\begin{array}{l}270 \text { Jack Burlingame } \\
\text { Drive } \\
\text { Millwood, WV } 25262 \\
\text { 304-273-9311 }\end{array}$ \\
\hline James Rumsey Technical Institute & $\begin{array}{l}\text { Region } 7 \\
\text { Berkeley, Jefferson, } \\
\text { Morgan }\end{array}$ & $\begin{array}{l}\text { Vocational rehabilitation, job coaching, } \\
\text { career counseling \& planning, job } \\
\text { information (e.g. job listings, postings), local } \\
\text { labor market projections, job development \& } \\
\text { placement, job search techniques, resume } \\
\text { preparation assistance, job interview training, } \\
\text { career/vocational assessments, job readiness, } \\
\text { job training \& education expense assistance, } \\
\text { digital skills development, basic academic } \\
\text { skills, financial literacy training, on-the-job } \\
\text { training, apprenticeships, Individual } \\
\text { Employment Plans (IEP), career counseling } \\
\text { and industry-recognized certifications. }\end{array}$ & $\begin{array}{l}3274 \text { Hedgesville Road } \\
\text { Martinsburg, WV } \\
25403 \\
304-754-7925\end{array}$ \\
\hline Job Squad, Bridgeport & $\begin{array}{l}\text { Region } 2 \\
\text { Putnam } \\
\text { Region } 3 \\
\text { Kanawha } \\
\text { Region } 6 \\
\text { Harrison, Marion, } \\
\text { Monongalia }\end{array}$ & $\begin{array}{l}\text { Supported employment, vocational } \\
\text { rehabilitation, job coaching, career } \\
\text { counseling \& planning, job information (e.g. } \\
\text { job listings, postings), job development \& } \\
\text { placement, job search techniques, resume } \\
\text { preparation assistance, job interview training, } \\
\text { career \& vocational assessments, job } \\
\text { readiness, digital skills development, basic } \\
\text { academic skills, financial literacy training, } \\
\text { on-the-job training and career counseling. }\end{array}$ & $\begin{array}{l}102 \text { 2nd Street } \\
\text { Bridgeport, WV } 26330 \\
\text { 304-848-0850 }\end{array}$ \\
\hline
\end{tabular}




\begin{tabular}{|c|c|c|c|}
\hline Agency Name & $\begin{array}{l}\text { Region \& Counties } \\
\text { Served by Agency }\end{array}$ & Employment Services Provided & Address/Phone \\
\hline John D. Rockefeller Career Center & $\begin{array}{l}\text { Region } 5 \\
\text { Hancock }\end{array}$ & $\begin{array}{l}\text { Job coaching, career counseling \& planning, } \\
\text { job information, job search techniques, } \\
\text { resume preparation assistance, job interview } \\
\text { training, career/vocational assessments, job } \\
\text { readiness, job training/education expense } \\
\text { assistance, digital skills development, basic } \\
\text { academic skills, career counseling and } \\
\text { industry-recognized certifications. }\end{array}$ & $\begin{array}{l}95 \text { Rockyside Road } \\
\text { New Cumberland, WV } \\
26047 \\
304-564-3337\end{array}$ \\
\hline \multirow{6}{*}{$\begin{array}{l}\text { Kanawha Institute For Social Research and } \\
\text { Action, Inc. (KISRA) }\end{array}$} & $\begin{array}{l}\text { Region } 1 \\
\text { Mercer, Raleigh }\end{array}$ & \multirow{6}{*}{$\begin{array}{l}\text { Supported employment, job coaching, career } \\
\text { counseling \& planning, job information (e.g. } \\
\text { job listings, postings), local labor market } \\
\text { jobs/occupations projections, job } \\
\text { development \& placement, job search } \\
\text { techniques, resume preparation assistance, } \\
\text { job interview training, job readiness, public } \\
\text { access computers, mental health counseling, } \\
\text { addiction recovery supports, financial } \\
\text { literacy training, on-the-job training, ex- } \\
\text { offender or re-entry services and basic } \\
\text { necessities. }\end{array}$} & \multirow{6}{*}{$\begin{array}{l}11624 \text { Winfield Road } \\
\text { Winfield, WV } 25213 \\
\text { 304-768-8924 }\end{array}$} \\
\hline & $\begin{array}{l}\text { Region } 2 \\
\text { Cabell, Putnam }\end{array}$ & & \\
\hline & $\begin{array}{l}\text { Region } 3 \\
\text { Kanawha }\end{array}$ & & \\
\hline & $\begin{array}{l}\text { Region } 4 \\
\text { Pleasants, Ritchie, Wood }\end{array}$ & & \\
\hline & $\begin{array}{l}\text { Region } 6 \\
\text { Doddridge }\end{array}$ & & \\
\hline & $\begin{array}{l}\text { Region } 7 \\
\text { Grant }\end{array}$ & & \\
\hline $\begin{array}{l}\text { Lawrence County WIOA Office/KY Career } \\
\text { Center, Northeast Kentucky Community } \\
\text { Action Agency }\end{array}$ & $\begin{array}{l}\text { Region } 2 \\
\text { Wayne }\end{array}$ & $\begin{array}{l}\text { Supported employment, vocational } \\
\text { rehabilitation, job coaching, career } \\
\text { counseling/planning, job information, local } \\
\text { labor market projections, job } \\
\text { development/placement, job search } \\
\text { techniques, resume preparation assistance, } \\
\text { job interview training, career/vocational } \\
\text { assessments, job readiness, job } \\
\text { training/education expense assistance, public } \\
\text { access computers, job clubs, basic academic } \\
\text { skills, addiction recovery supports, financial } \\
\text { literacy training, on-the-job training, } \\
\text { apprenticeships, Individual Employment } \\
\text { Plans (IEP), career counseling, ex-offender } \\
\text { or re-entry services, industry-recognized } \\
\text { certificates and basic necessities. }\end{array}$ & $\begin{array}{l}180 \text { Bulldog Ln, } \\
\text { Louisa, KY } 41230 \\
606-638-4067\end{array}$ \\
\hline
\end{tabular}




\begin{tabular}{|c|c|c|c|}
\hline Agency Name & $\begin{array}{l}\text { Region \& Counties } \\
\text { Served by Agency }\end{array}$ & Employment Services Provided & Address/Phone \\
\hline Lillian James Learning Center, Inc. & $\begin{array}{l}\text { Region } 1 \\
\text { Fayette, Raleigh, } \\
\text { Summers }\end{array}$ & $\begin{array}{l}\text { Community based assessment, direct } \\
\text { placement, job coaching, life skills, } \\
\text { supported employment, work adjustment and } \\
\text { work skills assessment. }\end{array}$ & $\begin{array}{l}\text { PO Box } 698 \\
\text { Crab Orchard, WV } \\
25827 \\
304-253-8913\end{array}$ \\
\hline Man Power Group-Charleston & $\begin{array}{l}\text { Region } 1 \\
\text { Fayette } \\
\text { Raleigh } \\
\text { Region } 2 \\
\text { Boone, Cabell, Lincoln, } \\
\text { Logan, Mingo, Putnam } \\
\text { Region } 3 \\
\text { Kanawha } \\
\text { Region } 4 \\
\text { Calhoun, Clay, Jackson, } \\
\text { Mason, Ritchie, Roane } \\
\text { Region } 6 \\
\text { Barbour, Braxton, Gilmer, } \\
\text { Harrison, Lewis, Marion, } \\
\text { Monongalia, Taylor }\end{array}$ & $\begin{array}{l}\text { Supported employment, job coaching, career } \\
\text { counseling \& planning, job information (e.g. } \\
\text { job listings, postings), local labor market } \\
\text { jobs/occupations projections, job } \\
\text { development \& placement, job search } \\
\text { techniques, resume preparation assistance, } \\
\text { job interview training, career \& vocational } \\
\text { assessments, public access computers, } \\
\text { resume posting \& blasting services, digital } \\
\text { skills development, basic academic skills, } \\
\text { on-the-job training, career counseling, ex- } \\
\text { offender or re-entry services and industry- } \\
\text { recognized certifications. }\end{array}$ & $\begin{array}{l}503 \text { Pennsylvania Ave } \\
\text { Charleston, WV } 25302 \\
\text { 304-346-9617 }\end{array}$ \\
\hline $\begin{array}{l}\text { Marshall University, Career } \\
\text { Services/Education }\end{array}$ & Statewide & $\begin{array}{l}\text { Job coaching, career counseling \& planning, } \\
\text { job information (e.g. job listings, postings), } \\
\text { job search techniques, resume preparation } \\
\text { assistance, job interview training, career \& } \\
\text { vocational assessments, job readiness, public } \\
\text { access computers, resume posting \& blasting } \\
\text { services, mental health counseling, addiction } \\
\text { recovery supports, career counseling and ex- } \\
\text { offender or re-entry services. }\end{array}$ & $\begin{array}{l}\text { One John Marshall } \\
\text { Drive } \\
\text { Huntington, WV } 25755 \\
304-696-2248\end{array}$ \\
\hline Mercer County Opportunity Industries, Inc. & $\begin{array}{l}\text { Region } 1 \\
\text { Mercer }\end{array}$ & $\begin{array}{l}\text { Supported employment, job coaching, job } \\
\text { information (e.g. job listings, postings), job } \\
\text { development \& placement, resume } \\
\text { preparation assistance, job interview training, } \\
\text { career/vocational assessments, job readiness } \\
\text { and on-the-job training. }\end{array}$ & $\begin{array}{l}238 \text { Career Path } \\
\text { Princeton, WV } 24739 \\
304-425-3810\end{array}$ \\
\hline
\end{tabular}




\begin{tabular}{|c|c|c|c|}
\hline Agency Name & $\begin{array}{l}\text { Region \& Counties } \\
\text { Served by Agency }\end{array}$ & Employment Services Provided & Address/Phone \\
\hline Mid-Ohio Valley Technical Institute & $\begin{array}{l}\text { Region } 4 \\
\text { Pleasants }\end{array}$ & & $\begin{array}{l}2134 \text { N. Pleasants Hwy } \\
\text { St. Marys, WV } 26170 \\
304-684-2464\end{array}$ \\
\hline Mountaineer Challenge Academy & Statewide & $\begin{array}{l}\text { Supported employment, job information, } \\
\text { local labor market projections, job } \\
\text { development \& placement, job search } \\
\text { techniques, resume preparation assistance, } \\
\text { job interview training, career/vocational } \\
\text { assessments, job readiness, basic academic } \\
\text { skills, financial literacy training, on-the-job } \\
\text { training, apprenticeships and career } \\
\text { counseling. }\end{array}$ & $\begin{array}{l}1001 \text { Army Rd - Camp } \\
\text { Dawson } \\
\text { Kingwood, WV } 26537 \\
\text { 304-329-2118 }\end{array}$ \\
\hline $\begin{array}{l}\text { MountWest Community \& Technical } \\
\text { College }\end{array}$ & $\begin{array}{l}\text { Region } 2 \\
\text { Cabell, Logan, Putnam, } \\
\text { Wayne } \\
\text { Region } 3 \\
\text { Kanawha } \\
\text { Region } 4 \\
\text { Pleasants }\end{array}$ & $\begin{array}{l}\text { Career counseling \& planning, job } \\
\text { information, job search techniques, resume } \\
\text { preparation assistance, job interview training, } \\
\text { career/vocational assessments, job readiness, } \\
\text { public access computers, resume posting \& } \\
\text { blasting services, basic academic skills, } \\
\text { mental health counseling, financial literacy } \\
\text { training, career counseling, industry- } \\
\text { recognized certificates and basic necessities. }\end{array}$ & $\begin{array}{l}\text { One Mountwest Way } \\
\text { Huntington, WV } 25701 \\
\text { 304-710-3366 }\end{array}$ \\
\hline Mt State Centers for Independent Living & $\begin{array}{l}\text { Region } 1 \\
\text { Raleigh } \\
\text { Region } 2 \\
\text { Cabell, Wayne }\end{array}$ & $\begin{array}{l}\text { Community based assessment, direct } \\
\text { placement, extended assessment, extended } \\
\text { supported employment, job coaching, life } \\
\text { skills, work adjustment and work skills } \\
\text { assessment. }\end{array}$ & $\begin{array}{l}821 \text { Fourth Avenue } \\
\text { Huntington, WV } 25701 \\
304-525-3324\end{array}$ \\
\hline New Directions & $\begin{array}{l}\text { Region } 1 \\
\text { Pocahontas } \\
\text { Region } 6 \\
\text { Barbour, Randolph, } \\
\text { Tucker, Upshur } \\
\text { Region } 7 \\
\text { Grant, Hampshire, Hardy, } \\
\text { Mineral, Pendleton }\end{array}$ & $\begin{array}{l}\text { Supported employment, vocational } \\
\text { rehabilitation, job coaching, career } \\
\text { counseling/planning, job information, local } \\
\text { labor market projections, job development \& } \\
\text { placement, job search techniques, resume } \\
\text { preparation assistance, job interview training, } \\
\text { career/vocational assessments, job readiness, } \\
\text { resume services, digital skills development, } \\
\text { basic academic skills, financial literacy } \\
\text { training, on-the-job training, apprenticeships, } \\
\text { Individual Employment Plans (IEP), career } \\
\text { counseling and basic necessities. }\end{array}$ & $\begin{array}{l}470 \text { Slabtown Road } \\
\text { P.O. Box } 225 \\
\text { Whitmer, WV } 26296 \\
\text { 304-940-9339 }\end{array}$ \\
\hline
\end{tabular}




\begin{tabular}{|c|c|c|c|}
\hline Agency Name & $\begin{array}{l}\text { Region \& Counties } \\
\text { Served by Agency }\end{array}$ & Employment Services Provided & Address/Phone \\
\hline New Hope Residential Services, Inc. & $\begin{array}{l}\text { Region } 1 \\
\text { Fayette } \\
\text { Nicholas } \\
\text { Raleigh }\end{array}$ & $\begin{array}{l}\text { Job information (e.g. job listings, postings), } \\
\text { job training \& education expense assistance } \\
\text { and on-the-job training. }\end{array}$ & $\begin{array}{l}\text { P.O. Box } 366 \\
\text { Summersville, WV } \\
26651 \\
540-815-0988\end{array}$ \\
\hline New River Community \& Technical College & $\begin{array}{l}\text { Region } 1 \\
\text { Fayette, Greenbrier, } \\
\text { Mercer, Monroe, } \\
\text { Nicholas, Pocahontas, } \\
\text { Raleigh, Summers, } \\
\text { Webster }\end{array}$ & $\begin{array}{l}\text { Career counseling \& planning, resume } \\
\text { preparation assistance, job interview training, } \\
\text { mental health counseling and career } \\
\text { counseling. }\end{array}$ & $\begin{array}{l}280 \text { University Drive } \\
\text { Beaver, WV } 25813 \\
\text { 304-929-5027 }\end{array}$ \\
\hline $\begin{array}{l}\text { North Central West Virginia Community } \\
\text { Action Association, Inc. (NCWVCAA) }\end{array}$ & $\begin{array}{l}\text { Region } 1 \\
\text { Greenbrier } \\
\text { Pocahontas } \\
\text { Region } 6 \\
\text { Barbour, Marion, } \\
\text { Monongalia, Preston } \\
\text { Randolph, Taylor, Tucker }\end{array}$ & Ex-offender or re-entry services. & $\begin{array}{l}1304 \text { Goose Run Road } \\
\text { Fairmont, WV } 26554 \\
\text { 304-363-2170 }\end{array}$ \\
\hline $\begin{array}{l}\text { Northern West Virginia Center for } \\
\text { Independent Living (NWVCIL) }\end{array}$ & $\begin{array}{l}\text { Region } 6 \\
\text { Barbour, Braxton, } \\
\text { Doddridge, Gilmer, } \\
\text { Harrison, Lewis, Marion, } \\
\text { Monongalia, Preston, } \\
\text { Randolph, Taylor, Tucker, } \\
\text { Upshur }\end{array}$ & $\begin{array}{l}\text { Job information, job search techniques, } \\
\text { resume preparation assistance, job interview } \\
\text { training, basic academic skills, mental health } \\
\text { counseling and basic necessities. }\end{array}$ & $\begin{array}{l}\text { 601-3 East Brockway } \\
\text { Ave. } \\
\text { Suite A\&B } \\
\text { Morgantown, WV } \\
26501 \\
304-296-6091\end{array}$ \\
\hline Open Doors, Inc. & $\begin{array}{l}\text { Region } 1 \\
\text { Greenbrier, Monroe, } \\
\text { Nicholas, Pocahontas, } \\
\text { Webster }\end{array}$ & $\begin{array}{l}\text { Supported employment, job coaching, job } \\
\text { development \& placement, job search } \\
\text { techniques, resume preparation assistance, } \\
\text { job interview training, career \& vocational } \\
\text { assessments and job readiness. }\end{array}$ & $\begin{array}{l}1108 \text { Washington St. } \\
\text { East } \\
\text { Lewisburg, WV } 24901 \\
304-645-2130\end{array}$ \\
\hline PACE Enterprises, Inc. & $\begin{array}{l}\text { Region } 3 \\
\text { Kanawha } \\
\text { Region } 6 \\
\text { Marion } \\
\text { Monongalia } \\
\text { Taylor }\end{array}$ & $\begin{array}{l}\text { Supported employment, vocational } \\
\text { rehabilitation, job coaching, job information, } \\
\text { local labor market projections, job } \\
\text { development/placement, job search } \\
\text { techniques, job interview training, job } \\
\text { readiness, financial literacy training and on- } \\
\text { the-job training. }\end{array}$ & $\begin{array}{l}\text { 889 Mylan Park Lane } \\
\text { P.O. Box 4241 } \\
\text { Morgantown, WV } \\
26501 \\
\text { 304-983-7223 }\end{array}$ \\
\hline
\end{tabular}




\begin{tabular}{|c|c|c|c|}
\hline Agency Name & $\begin{array}{l}\text { Region \& Counties } \\
\text { Served by Agency }\end{array}$ & Employment Services Provided & Address/Phone \\
\hline Potomac Highland Guild & $\begin{array}{l}\text { Region } 7 \\
\text { Grant, Hampshire, Hardy, } \\
\text { Mineral, Pendleton }\end{array}$ & & $\begin{array}{l}7 \text { Mountain View St. } \\
\text { Petersburg, WV } 26847 \\
\text { 304-788-2241 }\end{array}$ \\
\hline Preston County Workshop & $\begin{array}{l}\text { Region } 6 \\
\text { Monongalia } \\
\text { Preston }\end{array}$ & $\begin{array}{l}\text { Supported employment, vocational } \\
\text { rehabilitation, job information, job } \\
\text { development/placement, job interview } \\
\text { training and on-the-job training. }\end{array}$ & $\begin{array}{l}\text { 650 Jennmar Road } \\
\text { Reedsville, WV } 26547 \\
\text { 304-864-6446 }\end{array}$ \\
\hline PRIDE Community Services & $\begin{array}{l}\text { Region } 1 \\
\text { McDowell } \\
\text { Wyoming } \\
\text { Region } 2 \\
\text { Boone } \\
\text { Lincoln } \\
\text { Logan } \\
\text { Mingo }\end{array}$ & $\begin{array}{l}\text { Job development/placement, job training \& } \\
\text { education expense assistance, public access } \\
\text { computers, financial literacy training, on-the- } \\
\text { job training, apprenticeships and basic } \\
\text { necessities. }\end{array}$ & $\begin{array}{l}\text { P.O. Box } 1346 \\
\text { Logan, WV } 25601 \\
\text { 304-752-6868 }\end{array}$ \\
\hline Ralph R. Willis Career \& Technical Center & $\begin{array}{l}\text { Region } 2 \\
\text { Logan }\end{array}$ & & $\begin{array}{l}\text { Box } 1747 \\
\text { Logan, WV } 25601 \\
304-752-4687\end{array}$ \\
\hline Randolph Co. Sheltered Workshop, Inc. & $\begin{array}{l}\text { Region } 1 \\
\text { Pocahontas } \\
\text { Region } 6 \\
\text { Barbour, Randolph } \\
\text { Tucker } \\
\end{array}$ & $\begin{array}{l}\text { Supported employment, vocational } \\
\text { rehabilitation, job coaching, job development } \\
\& \text { placement and job readiness. }\end{array}$ & $\begin{array}{l}890 \text { Industrial Park } \\
\text { Road } \\
\text { Elkins, WV } 26241 \\
\text { 304-636-1638 }\end{array}$ \\
\hline Rem, Inc. & Statewide & $\begin{array}{l}\text { Supported employment, vocational } \\
\text { rehabilitation, job coaching, job information, } \\
\text { job development \& placement, career \& } \\
\text { vocational assessments, basic academic skills } \\
\text { and basic necessities. }\end{array}$ & $\begin{array}{l}713 \text { South Oakwood } \\
\text { Avenue } \\
\text { Beckley, WV } 25801 \\
304-254-8420\end{array}$ \\
\hline Roane-Jackson Technical Center & $\begin{array}{l}\text { Region } 3 \\
\text { Kanawha } \\
\text { Region } 4 \\
\text { Calhoun, Jackson, Mason, } \\
\text { Roane, Wirt, Wood } \\
\text { Region } 6 \\
\text { Gilmer }\end{array}$ & $\begin{array}{l}\text { Vocational rehabilitation, job information, } \\
\text { local labor market projections, resume } \\
\text { preparation assistance, job interview training, } \\
\text { public access computers, basic academic } \\
\text { skills and industry-recognized certifications. }\end{array}$ & $\begin{array}{l}9450 \text { Spencer Rd. } \\
\text { LeRoy, WV } 25252 \\
304-372-7335\end{array}$ \\
\hline
\end{tabular}




\begin{tabular}{|c|c|c|c|}
\hline Agency Name & $\begin{array}{l}\text { Region \& Counties } \\
\text { Served by Agency }\end{array}$ & Employment Services Provided & Address/Phone \\
\hline Russell Nesbitt Services, Inc. & $\begin{array}{l}\text { Region } 5 \\
\text { Ohio }\end{array}$ & $\begin{array}{l}\text { Supported employment, vocational } \\
\text { rehabilitation, job coaching, job information, } \\
\text { job development \& placement, basic } \\
\text { academic skills and on-the-job training. }\end{array}$ & $\begin{array}{l}\text { 431 Fulton Street } \\
\text { Wheeling, WV } 26003 \\
304-232-0233\end{array}$ \\
\hline $\begin{array}{l}\text { Salem International University, Career } \\
\text { Services }\end{array}$ & Statewide & & $\begin{array}{l}223 \text { W Main St } \\
\text { Salem, WV } 26426 \\
304-326-1482\end{array}$ \\
\hline Shepherd University Career Center & Statewide & & $\begin{array}{l}301 \text { N King St. } \\
\text { Shepherdstown, WV } \\
25443 \\
304-876-5814 \\
\end{array}$ \\
\hline Solutions Positive Behavior Strategies, LLC & $\begin{array}{l}\text { Region } 1 \text { Fayette } \\
\text { Region } 2 \\
\text { Boone, Cabell, Lincoln } \\
\text { Logan, Putnam } \\
\text { Region } 3 \text { Kanawha } \\
\text { Region } 4 \\
\text { Clay, Jackson, Mason } \\
\text { Region } 6 \\
\text { Braxton, Harrison, Lewis, } \\
\text { Taylor }\end{array}$ & & $\begin{array}{l}325 \text { 6th Ave } \\
\text { South Charleston, WV } \\
25303 \\
304-720-3383\end{array}$ \\
\hline Southern Highlands CMHC & $\begin{array}{l}\text { Region } 1 \\
\text { McDowell, Mercer, } \\
\text { Wyoming }\end{array}$ & $\begin{array}{l}\text { Supported employment, job information, job } \\
\text { training/education expense assistance, basic } \\
\text { academic skills, mental health counseling, } \\
\text { addiction recovery supports and on-the-job } \\
\text { training. }\end{array}$ & $\begin{array}{l}20012 \text { th St Extension } \\
\text { Princeton, WV } 24740 \\
\text { 304-425-9541 }\end{array}$ \\
\hline $\begin{array}{l}\text { Southwestern Community Action Council, } \\
\text { Inc. }\end{array}$ & $\begin{array}{l}\text { Region } 2 \\
\text { Cabell, Lincoln, Logan, } \\
\text { Mingo, Putnam, Wayne } \\
\text { Region } 3 \text { Kanawha } \\
\text { Region } 4 \\
\text { Mason, Ritchie, Wirt, } \\
\text { Wood } \\
\text { Region } 6 \\
\text { Barbour, Braxton, } \\
\text { Randolph, Tucker } \\
\end{array}$ & $\begin{array}{l}\text { Supported employment, job coaching, career } \\
\text { counseling \& planning, job information, } \\
\text { local labor market projections, job } \\
\text { development/placement, job interview } \\
\text { training, job readiness, digital skills } \\
\text { development, basic academic skills, on-the- } \\
\text { job training, Individual Employment Plans } \\
\text { (IEP), career counseling, industry-recognized } \\
\text { certificates and basic necessities. }\end{array}$ & $\begin{array}{l}540 \text { Fifth Avenue } \\
\text { Huntington, WV } 25701 \\
\text { 304-525-5151 }\end{array}$ \\
\hline
\end{tabular}




\begin{tabular}{|c|c|c|c|}
\hline Agency Name & $\begin{array}{l}\text { Region \& Counties } \\
\text { Served by Agency }\end{array}$ & Employment Services Provided & Address/Phone \\
\hline $\begin{array}{l}\text { SPOKES (Strategic Planning in } \\
\text { Occupational Knowledge for Employment } \\
\text { and Success) Barbour County }\end{array}$ & $\begin{array}{l}\text { Region } 6 \\
\text { Barbour, Taylor }\end{array}$ & $\begin{array}{l}\text { Job information, local labor market } \\
\text { projections, job search techniques, resume } \\
\text { preparation assistance, job interview training, } \\
\text { career/vocational assessments, job readiness, } \\
\text { digital skills development, basic academic } \\
\text { skills, financial literacy training and } \\
\text { industry-recognized certifications. }\end{array}$ & $\begin{array}{l}\text { Tygart Valley } \\
\text { Conservation District } \\
16360 \text { Barbour County } \\
\text { Highway } \\
\text { Philippi, WV } 26416 \\
\text { 304-457-3007 }\end{array}$ \\
\hline Starlight Behavioral Health & $\begin{array}{l}\text { Region } 2 \\
\text { Cabell, Lincoln, Putnam, } \\
\text { Wayne } \\
\text { Region } 3 \text { Kanawha } \\
\text { Region } 4 \text { Mason } \\
\end{array}$ & $\begin{array}{l}\text { Community based assessment, direct } \\
\text { placement, extended assessment, extended } \\
\text { supported employment, job coaching and } \\
\text { work skills assessment. }\end{array}$ & $\begin{array}{l}5317 \text { Cherry Lawn } \\
\text { Road } \\
\text { Huntington, WV } 25705 \\
\text { 304-302-2078 }\end{array}$ \\
\hline SW Resources & $\begin{array}{l}\text { Region } 4 \\
\text { Jackson, Pleasants, } \\
\text { Ritchie, Wood } \\
\text { Region } 6 \\
\text { Doddridge }\end{array}$ & $\begin{array}{l}\text { Supported employment, vocational } \\
\text { rehabilitation, job coaching, career } \\
\text { counseling/planning, job information, local } \\
\text { labor market projections, job } \\
\text { development/placement, job search } \\
\text { techniques, resume preparation assistance, } \\
\text { job interview training, career/vocational } \\
\text { assessments, job readiness, digital skills, } \\
\text { basic academic skills, mental health } \\
\text { counseling, addiction recovery supports, } \\
\text { financial literacy training, on-the-job } \\
\text { training, career counseling, ex-offender or } \\
\text { re-entry services, industry-recognized } \\
\text { certificates and basic necessities. }\end{array}$ & $\begin{array}{l}\text { 1007 Mary Street } \\
\text { Parkersburg, WV } 26101 \\
\text { 304-428-6344 }\end{array}$ \\
\hline $\begin{array}{l}\text { Technical Center, Adult \& Community } \\
\text { Education Center \& SPOKES, Marion } \\
\text { County }\end{array}$ & $\begin{array}{l}\text { Region } 6 \\
\text { Marion }\end{array}$ & $\begin{array}{l}\text { Job information, job development/placement, } \\
\text { job search techniques, resume preparation } \\
\text { assistance, job interview training, career \& } \\
\text { vocational assessments, basic academic } \\
\text { skills, Individual Employment Plans (IEP) } \\
\text { and industry-recognized certifications. }\end{array}$ & $\begin{array}{l}2 \text { North Marion Drive } \\
\text { Farmington, WV } 26571 \\
\text { 304-986-3590 }\end{array}$ \\
\hline Mineral Technical Center & $\begin{array}{l}\text { Region } 7 \\
\text { Mineral }\end{array}$ & & $\begin{array}{l}981 \text { Harley O'Staggers } \\
\text { Keyser, WV } 26726 \\
304-788-4240\end{array}$ \\
\hline
\end{tabular}




\begin{tabular}{|c|c|c|c|}
\hline Agency Name & $\begin{array}{l}\text { Region \& Counties } \\
\text { Served by Agency }\end{array}$ & Employment Services Provided & Address/Phone \\
\hline Monroe Technical Center & $\begin{array}{l}\text { Region } 1 \\
\text { Monroe }\end{array}$ & & $\begin{array}{l}\text { 74 James Monroe Drive } \\
\text { Lindside, WV } 24951 \\
\text { 304-753-9971 }\end{array}$ \\
\hline Randolph Technical Center & $\begin{array}{l}\text { Region } 6 \\
\text { Randolph }\end{array}$ & $\begin{array}{l}\text { Supported employment, vocational } \\
\text { rehabilitation, job information, local labor } \\
\text { market projections, job } \\
\text { development/placement, job search } \\
\text { techniques, resume preparation assistance, } \\
\text { job interview training, career/vocational } \\
\text { assessments, job readiness, basic academic } \\
\text { skills, financial literacy training, on-the-job } \\
\text { training, apprenticeships, career counseling } \\
\text { and industry-recognized certifications. }\end{array}$ & $\begin{array}{l}200 \text { Kennedy Drive } \\
\text { Elkins, WV } 26241 \\
\text { 304-636-9195 }\end{array}$ \\
\hline Wood Technical Center & $\begin{array}{l}\text { Region } 4 \\
\text { Wood }\end{array}$ & $\begin{array}{l}\text { Career counseling \& planning, resume } \\
\text { preparation assistance, job interview training, } \\
\text { career/vocational assessments, job readiness } \\
\text { and basic academic skills. }\end{array}$ & $\begin{array}{l}1515 \text { Blizzard Drive } \\
\text { Parkersburg, WV } 26101 \\
\text { 304-420-9501 }\end{array}$ \\
\hline Mercer Technical Education Center & $\begin{array}{l}\text { Region } 1 \\
\text { Mercer }\end{array}$ & & $\begin{array}{l}1397 \text { Stafford Drive } \\
\text { Princeton, WV } 24740 \\
304-425-9551\end{array}$ \\
\hline Monongalia Technical Education Center & $\begin{array}{l}\text { Region } 6 \\
\text { Monongalia }\end{array}$ & $\begin{array}{l}\text { Job coaching, career counseling/planning, } \\
\text { job information, job development/placement, } \\
\text { job search techniques, resume preparation } \\
\text { assistance, job interview training, career \& } \\
\text { vocational assessments, job readiness, job } \\
\text { training \& education expense assistance, } \\
\text { resume posting \& blasting services, job } \\
\text { clubs, digital skills development, basic } \\
\text { academic skills, mental health counseling, } \\
\text { on-the-job training, apprenticeships, } \\
\text { Individual Employment Plans (IEP), career } \\
\text { counseling, industry-recognized } \\
\text { certifications and basic necessities. }\end{array}$ & $\begin{array}{l}2213 \text { Mountaineer } \\
\text { Highway } \\
\text { New Martinsville, WV } \\
26155 \\
\text { 304-455-2441 }\end{array}$ \\
\hline Telamon Corporation & $\begin{array}{l}\text { Region } 7 \\
\text { Berkeley, Hardy, } \\
\text { Jefferson, Morgan }\end{array}$ & Employment Training and Services. & $\begin{array}{l}67 \text { Aikens Center } \\
\text { Martinsburg, WV } \\
25404 \\
304-263-0916\end{array}$ \\
\hline
\end{tabular}




\begin{tabular}{|c|c|c|c|}
\hline Agency Name & $\begin{array}{l}\text { Region \& Counties } \\
\text { Served by Agency }\end{array}$ & Employment Services Provided & Address/Phone \\
\hline The Disability Action Center, Inc. & $\begin{array}{l}\text { Region } 6 \\
\text { Barbour, Harrison, } \\
\text { Marion, Monongalia, } \\
\text { Taylor }\end{array}$ & $\begin{array}{l}\text { Community based assessment, direct } \\
\text { placement, extended assessment, extended } \\
\text { supported employment services, job } \\
\text { coaching, life skills and work skills } \\
\text { assessment. }\end{array}$ & $\begin{array}{l}102 \text { Benoni Ave } \\
\text { Fairmont, WV } 26554 \\
\text { 304-366-3213 }\end{array}$ \\
\hline \multirow[b]{3}{*}{ The Op Shop, Inc. } & $\begin{array}{l}\text { Region } 4 \\
\text { Calhoun }\end{array}$ & \multirow{3}{*}{$\begin{array}{l}\text { Job coaching, life skills, work adjustment } \\
\text { and work skills assessment. }\end{array}$} & \multirow{3}{*}{$\begin{array}{l}316 \text { Columbia Street } \\
\text { Fairmont, WV } 26554 \\
\text { 304-366-5737 }\end{array}$} \\
\hline & $\begin{array}{l}\text { Region } 5 \\
\text { Hancock }\end{array}$ & & \\
\hline & $\begin{array}{l}\text { Region } 6 \\
\text { Barbour, Doddridge } \\
\text { Harrison, Marion, } \\
\text { Monongalia, Taylor }\end{array}$ & & \\
\hline The Seeing Hand Assoc., Inc. & $\begin{array}{l}\text { Region } 5 \\
\text { Brooke, Hancock, Ohio, } \\
\text { Tyler, Wetzel }\end{array}$ & $\begin{array}{l}\text { Supported employment, vocational } \\
\text { rehabilitation, resume preparation assistance, } \\
\text { career/vocational assessments, job readiness } \\
\text { and on-the-job training. }\end{array}$ & $\begin{array}{l}750 \text { Main Street } \\
\text { Wheeling, WV } 26003 \\
\text { 304-232-4810 }\end{array}$ \\
\hline \multirow{5}{*}{ United Talent Staffing Services, Charleston } & Region 2 & \multirow{5}{*}{$\begin{array}{l}\text { Job information, job development \& } \\
\text { placement, job search techniques, resume } \\
\text { preparation assistance and job interview } \\
\text { training. }\end{array}$} & \multirow{5}{*}{$\begin{array}{l}500 \text { Leon Sullivan Way } \\
\text { Charleston, WV } 25301 \\
\text { 304-556-1190 }\end{array}$} \\
\hline & $\begin{array}{l}\text { Region } 3 \\
\text { Kanawha }\end{array}$ & & \\
\hline & $\begin{array}{l}\text { Region } 4 \\
\text { Clay, Jackson, Ritchie, } \\
\text { Roane, Wirt, Wood }\end{array}$ & & \\
\hline & $\begin{array}{l}\text { Region } 5 \\
\text { Marshall, Tyler } \\
\text { Wetzel }\end{array}$ & & \\
\hline & $\begin{array}{l}\text { Region } 6 \\
\text { Braxton, Doddridge, } \\
\text { Harrison, Lewis, Marion, } \\
\text { Monongalia, Preston, } \\
\text { Taylor }\end{array}$ & & \\
\hline
\end{tabular}




\begin{tabular}{|c|c|c|c|}
\hline Agency Name & $\begin{array}{l}\text { Region \& Counties } \\
\text { Served by Agency }\end{array}$ & Employment Services Provided & Address/Phone \\
\hline United Technical Center & $\begin{array}{l}\text { Region } 6 \\
\text { Doddridge, Harrison, } \\
\text { Taylor }\end{array}$ & & $\begin{array}{l}251 \text { Marietta Street } \\
\text { Clarksburg, WV } 26301 \\
\text { 304-326-7580 }\end{array}$ \\
\hline University of Charleston, Career Center & $\begin{array}{l}\text { Region } 3 \\
\text { Kanawha }\end{array}$ & $\begin{array}{l}\text { Job coaching, career counseling \& planning, } \\
\text { job information, job development \& } \\
\text { placement, job search techniques, resume } \\
\text { preparation assistance, job interview training, } \\
\text { career/vocational assessments, job readiness, } \\
\text { job training \& education expense assistance, } \\
\text { resume posting \& blasting services, basic } \\
\text { academic skills, mental health counseling, } \\
\text { financial literacy training, on-the-job } \\
\text { training, career counseling, industry- } \\
\text { recognized certifications and basic } \\
\text { necessities. }\end{array}$ & $\begin{array}{l}2300 \text { MacCorkle Ave } \\
\text { SE } \\
\text { Charleston, WV } 25304 \\
\text { 304-357-4977 }\end{array}$ \\
\hline Valley College, Martinsburg & $\begin{array}{l}\text { Region } 7 \\
\text { Berkeley }\end{array}$ & $\begin{array}{l}\text { Career counseling \& planning and } \\
\text { career/vocational assessments. }\end{array}$ & $\begin{array}{l}287 \text { Aikens Center } \\
\text { Martinsburg, WV } \\
25404 \\
304-451-3172\end{array}$ \\
\hline West Liberty University, Career Services & Statewide & $\begin{array}{l}\text { Career counseling/planning, job information, } \\
\text { job search techniques, resume preparation } \\
\text { assistance, job interview training and career } \\
\text { counseling. }\end{array}$ & $\begin{array}{l}208 \text { University Dr. } \\
\text { West Liberty, WV } \\
26074 \\
304-336-8274\end{array}$ \\
\hline $\begin{array}{l}\text { West Virginia Division of Rehabilitation } \\
\text { Services, Charleston District } 1 \text { and Branch } \\
\text { Office }\end{array}$ & $\begin{array}{l}\text { Region } 2 \\
\text { Boone, Putnam } \\
\text { Region } 3 \\
\text { Kanawha } \\
\text { Region } 4 \\
\text { Calhoun, Clay, Jackson, } \\
\text { Mason, Roane }\end{array}$ & $\begin{array}{l}\text { Supported employment, comprehensive } \\
\text { disability employment programs, disability } \\
\text { related center-based employment, vocational } \\
\text { rehabilitation, job coaching, career } \\
\text { counseling \& planning, job information, job } \\
\text { development/placement, job search } \\
\text { techniques, resume preparation assistance, } \\
\text { job interview training, career/vocational } \\
\text { assessments, job readiness, job training \& } \\
\text { education expense assistance, job clubs, on- } \\
\text { the-job training, Individual Employment } \\
\text { Plans (IEP) and career counseling. }\end{array}$ & $\begin{array}{l}4701 \text { MacCorkle Ave., } \\
\text { SE } \\
\text { Charleston, WV } 25304 \\
\text { 304-356-2371 }\end{array}$ \\
\hline
\end{tabular}




\begin{tabular}{|c|c|c|c|}
\hline Agency Name & $\begin{array}{l}\text { Region \& Counties } \\
\text { Served by Agency }\end{array}$ & Employment Services Provided & Address/Phone \\
\hline $\begin{array}{l}\text { West Virginia Division of Rehabilitation } \\
\text { Services, Clarksburg District } 2 \text { and Branch } \\
\text { Office }\end{array}$ & $\begin{array}{l}\text { Region } 6 \\
\text { Barbour, Braxton, Gilmer, } \\
\text { Harrison, Lewis, Marion, } \\
\text { Monongalia, Preston, } \\
\text { Randolph, Taylor, Tucker, } \\
\text { Upshur }\end{array}$ & $\begin{array}{l}\text { Supported employment, vocational } \\
\text { rehabilitation, job coaching, career } \\
\text { counseling/planning, job information, local } \\
\text { labor market projections, job development \& } \\
\text { placement, job search techniques, job } \\
\text { interview training, career/vocational } \\
\text { assessments, job readiness, job training \& } \\
\text { education expense assistance, public access } \\
\text { computers, job clubs, basic academic skills, } \\
\text { on-the-job training, apprenticeships, career } \\
\text { counseling and ex-offender or re-entry } \\
\text { services. }\end{array}$ & $\begin{array}{l}153 \text { West Main Street, } \\
\text { Suite F } \\
\text { Clarksburg, WV } 2630 \\
304-625-6044\end{array}$ \\
\hline $\begin{array}{l}\text { West Virginia Division of Rehabilitation } \\
\text { Services, Wheeling District } 3 \text { and Branch } \\
\text { Office }\end{array}$ & $\begin{array}{l}\text { Region } 4 \\
\text { Pleasants, Ritchie, Wirt, } \\
\text { Wood } \\
\text { Region } 5 \\
\text { Brooke, Hancock, } \\
\text { Marshall, Ohio, Tyler, } \\
\text { Wetzel } \\
\text { Region } 6 \\
\text { Doddridge }\end{array}$ & $\begin{array}{l}\text { Supported employment, vocational } \\
\text { rehabilitation, job coaching, career } \\
\text { counseling/planning, job information, local } \\
\text { labor market projections, job development \& } \\
\text { placement, job search techniques, resume } \\
\text { preparation assistance, job interview training, } \\
\text { career/vocational assessments, job readiness, } \\
\text { job training/education expense assistance, } \\
\text { job clubs, mental health counseling, } \\
\text { addiction recovery supports, on-the-job } \\
\text { training, apprenticeships, Individual } \\
\text { Employment Plans (IEP), career counseling } \\
\text { and ex-offender or re-entry services. }\end{array}$ & $\begin{array}{l}\text { 1324 Chapline Street, } \\
\text { Suite 200 } \\
\text { Wheeling, WV } 26003 \\
304-238-1092\end{array}$ \\
\hline $\begin{array}{l}\text { West Virginia Division of Rehabilitation } \\
\text { Services, Beckley District } 4 \text { and Branch } \\
\text { Office }\end{array}$ & $\begin{array}{l}\text { Region } 1 \\
\text { Fayette, Greenbrier, } \\
\text { Mercer, Monroe, } \\
\text { Nicholas, Pocahontas, } \\
\text { Raleigh, Summers and } \\
\text { Webster }\end{array}$ & $\begin{array}{l}\text { Supported employment, vocational } \\
\text { rehabilitation, job coaching, career } \\
\text { counseling/planning, job information, local } \\
\text { labor market projections, job development \& } \\
\text { placement, job search techniques, resume } \\
\text { preparation assistance, job interview training, } \\
\text { career/vocational assessments, job readiness, } \\
\text { job training/education expense assistance, } \\
\text { job clubs, basic academic skills, mental } \\
\text { health counseling, addiction recovery } \\
\text { supports, on-the-job training, } \\
\text { apprenticeships, Individual Employment } \\
\text { Plans (IEP) and career counseling. }\end{array}$ & $\begin{array}{l}800 \text { New River Town } \\
\text { Center } \\
\text { Beckley, WV } 25801 \\
304-256-6900\end{array}$ \\
\hline
\end{tabular}




\begin{tabular}{|c|c|c|c|}
\hline Agency Name & $\begin{array}{l}\text { Region \& Counties } \\
\text { Served by Agency }\end{array}$ & Employment Services Provided & Address/Phone \\
\hline $\begin{array}{l}\text { West Virginia Division of Rehabilitation } \\
\text { Services, Huntington District } 5 \text { and Branch } \\
\text { Office }\end{array}$ & $\begin{array}{l}\text { Region } 1 \\
\text { McDowell, Wyoming } \\
\text { Region } 2 \\
\text { Cabell, Lincoln, Logan, } \\
\text { Mingo, Wayne }\end{array}$ & $\begin{array}{l}\text { Vocational rehabilitation, career counseling } \\
\& \text { planning, job information, local labor } \\
\text { market projections, job development \& } \\
\text { placement, job search techniques, resume } \\
\text { preparation assistance, job interview training, } \\
\text { career/vocational assessments, job training \& } \\
\text { education expense assistance, job clubs, on- } \\
\text { the-job training, Individual Employment } \\
\text { Plans (IEP) and career counseling. }\end{array}$ & $\begin{array}{l}2699 \text { Park Ave., Suite } \\
200 \\
\text { Huntington, WV } 25704 \\
304-528-5585\end{array}$ \\
\hline $\begin{array}{l}\text { West Virginia Division of Rehabilitation } \\
\text { Services, Martinsburg District } 6 \text { and Branch } \\
\text { Office }\end{array}$ & $\begin{array}{l}\text { Region } 7 \\
\text { Berkeley, Grant, } \\
\text { Hampshire, Hardy, } \\
\text { Jefferson, Mineral, } \\
\text { Morgan, Pendleton }\end{array}$ & $\begin{array}{l}\text { Supported employment, vocational } \\
\text { rehabilitation, federal bonding, job coaching, } \\
\text { career counseling/planning, job information, } \\
\text { local labor market projections, job } \\
\text { development/placement, job search } \\
\text { techniques, resume preparation assistance, } \\
\text { job interview training, career \& vocational } \\
\text { assessments, job readiness, job clubs, basic } \\
\text { academic skills, mental health counseling, } \\
\text { on-the-job training, apprenticeships, } \\
\text { Individual Employment Plans (IEP), career } \\
\text { counseling and ex-offender or re-entry } \\
\text { services. }\end{array}$ & $\begin{array}{l}489 \text { Mid Atlantic } \\
\text { Parkway, Suite } 2 \\
\text { Martinsburg, WV } \\
25404 \\
304-267-0009\end{array}$ \\
\hline $\begin{array}{l}\text { West Virginia Family Support \& Rehab } \\
\text { Services }\end{array}$ & $\begin{array}{l}\text { Region } 4 \\
\text { Jackson, Wirt, Wood } \\
\text { Region } 3 \\
\text { Kanawha }\end{array}$ & $\begin{array}{l}\text { Community based assessment, direct } \\
\text { placement, extended assessment, extended } \\
\text { supported employment services, job } \\
\text { coaching, life skills, work adjustment and } \\
\text { work skills assessment. }\end{array}$ & $\begin{array}{l}214 \text { Eighth Street } \\
\text { Parkersburg, WV } 26101 \\
\text { 304-424-3457 }\end{array}$ \\
\hline West Virginia Junior College & Statewide & $\begin{array}{l}\text { Career counseling \& planning, job } \\
\text { information, job development \& placement, } \\
\text { job search techniques, resume preparation } \\
\text { assistance, job interview training, job } \\
\text { readiness and career counseling. }\end{array}$ & $\begin{array}{l}148 \text { Willey St. } \\
\text { Morgantown, WV } \\
26505 \\
304-296-8282\end{array}$ \\
\hline West Virginia Northern Community College & $\begin{array}{l}\text { Region } 5 \\
\text { Brooke, Hancock, } \\
\text { Marshall, Ohio, Wetzel }\end{array}$ & $\begin{array}{l}\text { Job information, job development \& } \\
\text { placement, job search techniques, resume } \\
\text { preparation assistance, job interview training, } \\
\text { career counseling and industry-recognized } \\
\text { certifications. }\end{array}$ & $\begin{array}{l}\text { 107B B\&O Building } \\
\text { Wheeling, WV } 26003 \\
\text { 304-214-8817 }\end{array}$ \\
\hline
\end{tabular}




\begin{tabular}{|c|c|c|c|}
\hline Agency Name & $\begin{array}{l}\text { Region \& Counties } \\
\text { Served by Agency }\end{array}$ & Employment Services Provided & Address/Phone \\
\hline West Virginia State University & Statewide & & $\begin{array}{l}108 \text { Wallace Hall } \\
\text { Institute, WV } 25112 \\
304-766-3236\end{array}$ \\
\hline $\begin{array}{l}\text { West Virginia University, Career Services } \\
\text { Center }\end{array}$ & Statewide & $\begin{array}{l}\text { Job coaching, career counseling \& planning, } \\
\text { job information, job development \& } \\
\text { placement, job search techniques, resume } \\
\text { preparation assistance, job interview training, } \\
\text { career/vocational assessments, job readiness, } \\
\text { resume posting/blasting services, basic } \\
\text { academic skills, apprenticeships, Individual } \\
\text { Employment Plans (IEP) and career } \\
\text { counseling. }\end{array}$ & $\begin{array}{l}133 \text { Mountainlair } \\
\text { Building } \\
\text { Morgantown, WV } \\
26506 \\
304-293-2221\end{array}$ \\
\hline West Virginia Wesleyan College & Statewide & $\begin{array}{l}\text { Career counseling/planning, job information, } \\
\text { job development/placement, job search } \\
\text { techniques, resume preparation assistance, } \\
\text { job interview training, job readiness, job } \\
\text { clubs, digital skills development, basic } \\
\text { academic skills, mental health counseling } \\
\text { and career counseling. }\end{array}$ & $\begin{array}{l}59 \text { College Ave. } \\
\text { Buckhannon, WV } \\
26201 \\
304-473-8607\end{array}$ \\
\hline Wetzel County Technical Education Center & $\begin{array}{l}\text { Region } 5 \\
\text { Wetzel }\end{array}$ & $\begin{array}{l}\text { Comprehensive disability employment } \\
\text { programs and job information (e.g. job } \\
\text { listings, postings). }\end{array}$ & $\begin{array}{l}2213 \text { Mountaineer Hwy } \\
\text { New Martinsville, WV } \\
26155 \\
304-455-2441\end{array}$ \\
\hline WISE Women's Resource Center & $\begin{array}{l}\text { Region } 1 \\
\text { McDowell, Mercer, } \\
\text { Raleigh, Summers }\end{array}$ & $\begin{array}{l}\text { Job information, job search techniques, } \\
\text { resume preparation assistance, job interview } \\
\text { training, digital skills development, basic } \\
\text { academic skills, addiction recovery supports, } \\
\text { on-the-job training, ex-offender or re-entry } \\
\text { services and basic necessities. }\end{array}$ & $\begin{array}{l}\text { 511 Commerce Street } \\
\text { Bluefield, WV } 24701 \\
\text { 304-324-5809 }\end{array}$ \\
\hline
\end{tabular}




\begin{tabular}{|c|c|c|c|}
\hline Agency Name & $\begin{array}{l}\text { Region \& Counties } \\
\text { Served by Agency }\end{array}$ & Employment Services Provided & Address/Phone \\
\hline WVU Parkersburg, Career Services & $\begin{array}{l}\text { Region } 2 \\
\text { Putnam } \\
\text { Region } 3 \\
\text { Kanawha } \\
\text { Region } 4 \\
\text { Calhoun, Jackson, } \\
\text { Ritchie, Roane, Wirt, } \\
\text { Wood } \\
\text { Region } 5 \\
\text { Marshall, Ohio, Tyler } \\
\text { Region } 6 \\
\text { Braxton, Doddridge, } \\
\text { Gilmer, Harrison, Marion, } \\
\text { Monongalia }\end{array}$ & $\begin{array}{l}\text { Supported employment, job coaching, career } \\
\text { counseling/planning, job information, local } \\
\text { labor market projections, job search } \\
\text { techniques, resume preparation assistance, } \\
\text { job interview training, career/vocational } \\
\text { assessments, basic academic skills, mental } \\
\text { health counseling, financial literacy training, } \\
\text { on-the-job training, apprenticeships, career } \\
\text { counseling, industry-recognized certificates } \\
\text { and basic necessities. }\end{array}$ & $\begin{array}{l}300 \text { Campus Drive } \\
\text { Parkersburg, WV } 26104 \\
304-424-8395\end{array}$ \\
\hline $\begin{array}{l}\text { Zanesville Welfare Organization \& Goodwill } \\
\text { Industries, Inc. }\end{array}$ & $\begin{array}{l}\text { Region } 4 \\
\text { Calhoun, Pleasants, } \\
\text { Ritchie, Wirt } \\
\text { Region } 5 \\
\text { Marshall, Ohio, Tyler, } \\
\text { Wetzel } \\
\text { Region } 6 \\
\text { Doddridge, Gilmer }\end{array}$ & $\begin{array}{l}\text { Supported employment, vocational } \\
\text { rehabilitation, job coaching, career } \\
\text { counseling/planning, job information, job } \\
\text { development/placement, job search } \\
\text { techniques, resume preparation assistance, } \\
\text { job interview training, career/vocational } \\
\text { assessments, job readiness, digital skills } \\
\text { development, on-the-job training, Individual } \\
\text { Employment Plans (IEP), career counseling } \\
\text { and ex-offender or re-entry services. }\end{array}$ & $\begin{array}{l}319 \text { Lafayette Dr. } \\
\text { Moundsville, WV } \\
26041 \\
304-905-1241\end{array}$ \\
\hline
\end{tabular}

Note. Following previous research methods (Haynes et al., 2017) for Appendix J, non-respondents agencies' support services and areas served were supplemented from respective agency websites and the 2018 West Virginia Division of Rehabilitation Services' Vendor Directory. 